\title{
Molecular imaging in the combined modality treatment of lung cancer
}

Citation for published version (APA):

van Loon, J. G. M. (2010). Molecular imaging in the combined modality treatment of lung cancer. [Doctoral Thesis, Maastricht University]. Datawyse / Universitaire Pers Maastricht.

https://doi.org/10.26481/dis.20101022jl

Document status and date:

Published: 01/01/2010

DOI:

10.26481/dis.20101022jl

Document Version:

Publisher's PDF, also known as Version of record

\section{Please check the document version of this publication:}

- A submitted manuscript is the version of the article upon submission and before peer-review. There can be important differences between the submitted version and the official published version of record.

People interested in the research are advised to contact the author for the final version of the publication, or visit the DOI to the publisher's website.

- The final author version and the galley proof are versions of the publication after peer review.

- The final published version features the final layout of the paper including the volume, issue and page numbers.

Link to publication

\footnotetext{
General rights rights.

- You may freely distribute the URL identifying the publication in the public portal. please follow below link for the End User Agreement:

www.umlib.nl/taverne-license

Take down policy

If you believe that this document breaches copyright please contact us at:

repository@maastrichtuniversity.nl

providing details and we will investigate your claim.
}

Copyright and moral rights for the publications made accessible in the public portal are retained by the authors and/or other copyright owners and it is a condition of accessing publications that users recognise and abide by the legal requirements associated with these

- Users may download and print one copy of any publication from the public portal for the purpose of private study or research.

- You may not further distribute the material or use it for any profit-making activity or commercial gain

If the publication is distributed under the terms of Article $25 \mathrm{fa}$ of the Dutch Copyright Act, indicated by the "Taverne" license above, 


\section{Molecular imaging in the combined modality treatment of lung cancer}




\section{Cover}

"Highlighted lung" | www.sciepro.com

\section{Production}

Printing: Datawyse | Universitaire Pers Maastricht

ISBN: $\quad$ 978-90-5278-973-6

CC J. van Loon, Maastricht 2010

The work presented in this thesis was supported by the CTMM Airforce project, the Dutch Cancer Society and Siemens Nederland NV. 


\title{
Molecular imaging in the combined modality treatment of lung cancer
}

\author{
PROEFSCHRIFT \\ ter verkrijging van de graad van doctor aan de Universiteit Maastricht, \\ op gezag van de Rector Magnificus, Prof. mr. G.P.M.F. Mols, \\ volgens het besluit van het College van Decanen, \\ in het openbaar te verdedigen \\ op vrijdag 22 oktober 2010 om 12.00 uur
}

door

Judith Gertruda Mechtilda van Loon

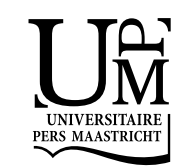




\section{Promotores}

Prof. dr. D. De Ruysscher

Prof. dr. Ph. Lambin

\section{Copromotor}

Dr. L. Boersma

\section{Beoordelingscommissie}

Prof. dr. E.F.M. Wouters (voorzitter)

Dr. B. Brans

Prof. dr. Y. Lievens (UZ Leuven)

Prof. dr. J.P.A.M. van Meerbeeck (UZ Gent) 
Part I FDG-PET-CT based target volume definition to optimize radiotherapy for locally advanced lung cancer

Chapter 2 Microscopic disease extension in 3D for Non Small Cell

Lung Cancer: development of a prediction model using pathology validated PET and CT features

Chapter $3{ }^{18}$ FDG-PET based radiation planning of mediastinal lymph nodes in limited disease small cell lung cancer changes radiotherapy fields: a planning study

Chapter 4 Selective nodal irradiation on basis of ${ }^{18}$ FDG-PET scans in limited disease small cell lung cancer: a prospective study

Part II The value of FDG-PET-CT in the follow-up of locally advanced NSCLC patients

Chapter 5 Follow-up with ${ }^{18}$ FDG-PET-CT after radical radiotherapy with or without chemotherapy allows the detection of potentially curable progressive disease in non-small cell lung cancer patients: a prospective study

Chapter $6 \quad{ }^{18}$ FDG-PET-CT in the follow-up of non-small cell lung cancer patients after radical radiotherapy with or without chemotherapy: an economic evaluation

Part III Development of novel PET tracers for the non invasive imaging of specific tumour characteristics

Chapter 7 PET imaging of hypoxia using $\left[{ }^{18} \mathrm{~F}\right] \mathrm{HX} 4$ : a phase I trial

Chapter 8 PET imaging of Cetuximab-Zirconium-89 uptake: a phase I trial

\section{Part IV Discussion}

Chapter 9 Therapeutic implications of molecular imaging with PET in the combined modality treatment of lung cancer 
Chapter 11 Summary

Appendices Dankwoord

Publications and grants 


\section{CHAPTER 1}

General introduction and outline 
CHAPTER 1 


\subsection{Epidemiology}

Each year, more than 3 million cancer cases are diagnosed in Europe, with over 1.5 million patients dying from this disease. The major cause of cancer death is lung carcinoma, accounting for almost $20 \%$ of all deaths due to cancer in $2008^{1}$. It is the third common malignancy in Europe, after colorectal and breast cancer, accounting for more than $12 \%$ of all new cancer cases.

In the Netherlands, the age-standardised incidence of lung carcinoma is decreasing in men, but still increasing in women. These trends largely reflect the changes in the prevalence of smoking, which is the major cause of this disease ${ }^{2}$. Since 2006 , more than 10,000 patients a year are diagnosed with lung carcinoma. Given the ageing of the population, lung cancer will remain an important health problem. The prognosis of the disease is poor, with a 1 year overall survival of $40 \%$ and a 5 year overall survival of only $14 \%^{3}$.

Lung cancer is broadly divided in two main categories on basis of its histology: nonsmall cell lung cancer (NSCLC), accounting for $80-85 \%$ of cases, and small cell lung cancer (SCLC), accounting for $15-20 \%$ of cases. Approximately $40 \%$ of NSCLC and more than $70 \%$ of SCLC patients have distant metastases at initial presentation ${ }^{4}$. Most of these patients are treated with palliative systemic treatment, together with analgesics and palliative radiotherapy to relieve symptoms. The remaining patients present with disease confined to the thorax. Those patients are generally offered curative intent therapy.

\section{Non-small cell lung cancer (NSCLC)}

NSCLC is divided in four different stages on basis of the anatomical extent of disease, which is classified according to the TNM classification. The TNM classification is used to define the extent of disease with respect to the primary tumour (T), involvement of regional lymph nodes $(N)$ and the presence of distant metastases $(M)$. Recently, the $7^{\text {th }}$ edition of the TNM classification system has been introduced ${ }^{5}$. With respect to NSCLC, this edition includes some changes in the T and M descriptors, as well as in the assigned stages on basis of the TNM $^{6}$.

The assigned stage is prognostic for survival, and it forms the basis for selection of the most appropriate treatment regimen (Figure 1.1). Of all patients with NSCLC, only $25 \%$ is diagnosed with stage I \& II disease, which is considered as resectable. Early stage patients who are medically inoperable are commonly treated with radiotherapy. In particular, stereotactic radiotherapy has become an attractive treatment modality for this patient category, with a 3 year local control rate of more than $90 \%$ and a 3 year overall survival of $60 \%{ }^{7}$. Thirty-five percent of patients have locally 
advanced (stage III) disease, for whom surgery is mostly not an option ${ }^{4}$. For these patients, the current standard treatment consists of radiotherapy in combination with chemotherapy.

\begin{tabular}{|c|c|c|c|c|}
\hline $\mathrm{T}$ & $\mathrm{N}$ & M & Stage & First choice treatment ${ }^{*}$ \\
\hline 1 & 0 & 0 & IA & \multirow{2}{*}{ Surgery } \\
\hline $2 a$ & 0 & 0 & IB & \\
\hline 1 & 1 & 0 & IIA & \multirow{5}{*}{$\begin{array}{l}\text { Surgery + } \\
\text { chemotherapy }\end{array}$} \\
\hline $2 a$ & 1 & 0 & IIA & \\
\hline $2 b$ & 0 & 0 & IIA & \\
\hline $2 b$ & 1 & 0 & IIB & \\
\hline 3 & 0 & 0 & IIB & \\
\hline 1 & 2 & 0 & IIIA & \\
\hline 2 & 2 & 0 & IIIA & \\
\hline 3 & 1 or 2 & 0 & IIIA & \multirow{2}{*}{$\begin{array}{l}\text { Concurrent } \\
\text { chemoradiotherapy }\end{array}$} \\
\hline 4 & 0 or 1 & 0 & IIIA & \\
\hline any & 3 & 0 & IIIB & \\
\hline 4 & 2 or 3 & 0 & IIIB & \\
\hline any & any & 1 & IV & Chemotherapy** \\
\hline
\end{tabular}

Figure 1.1 TNM staging ( $7^{\text {th }}$ edition) for NSCLC and treatment of choice per assigned stage

* According to the American College of Chest Physicians (ACCP) guidelines

** In selected patients with oligometastasis: chemotherapy, high dose radiotherapy, surgery

\section{Small cell lung cancer (SCLC)}

$\mathrm{SCLC}$ is characterized by a rapid growth rate and early dissemination to lymph nodes and distant organs. SCLC patients are classically divided into limited and extensive stage disease ${ }^{8,9}$. Recently, however, the use of the TNM staging system has been recommended for SCLC as well ${ }^{10,11}$. Approximately $25 \%$ of SCLC patients present with stage I-III disease ${ }^{4}$. Even in this patient group without distant metastases, surgery is rarely an option because of the advanced stage of locoregional disease. Furthermore, its benefit in the rare stage I patient is controversial ${ }^{12,13}$. Therefore, combined chemo-radiotherapy is the first choice treatment for patients with stage IIII SCLC. 


\subsection{Imaging modalities for patient selection and evaluation of treatment}

Traditionally, anatomical imaging modalities are applied for the diagnosis and staging, as well as in the follow-up of lung cancer patients. These modalities are based on contrast differences between normal and cancerous tissue. More recently, molecular imaging techniques have been developed, which allow the visualization of molecular processes inside tumour and normal tissues in a non-invasive manner.

\section{Anatomical imaging}

Chest X-ray and computed tomography (CT) are the most widely used anatomical imaging modalities in lung cancer. A chest X-ray is useful as a first-line tool to assess the indication for further imaging. The chest CT scan allows cross-sectional imaging of the body through rotational x-ray imaging. Modern CT scanners have a resolution down to less than $1 \mathrm{~mm}$. For lung cancer, it is the imaging modality that provides best anatomic detail. It has a high sensitivity for the detection of the primary tumour, enabling its exact localization. The contrast between adjacent tissues can be further improved by the administration of intravenous contrast agents.

While CT is the most accurate imaging modality with respect to anatomical information in lung cancer, its limited potential to distinguish between vital tumour and non-malignant tissue prevents the use in certain areas of the TNM classification. Anatomic imaging modalities are compromised in their ability to define the exact tumour border in certain circumstances, such as in patients with atelectasis or tumours near the thoracic wall ${ }^{14}$. Furthermore, the accuracy to differentiate between malignant and benign lymph nodes is lower, with a sensitivity and specificity of CT for identifying mediastinal lymph node involvement of $51 \%$ and $85 \%$, respectively ${ }^{15}$. Finally, the assessment of changes early during or after treatment with conventional chest X-ray and CT is limited by their poor discriminating capacity between residual tumour and treatment induced changes ${ }^{16,17}$.

With respect to these issues, molecular imaging with positron emission tomography (PET), providing information on specific biochemical pathways, has additional value.

\section{Molecular imaging with positron emission tomography (PET)}

The principle of PET lies in the detection of positrons emitted by a radioactive tracer. In this way, three dimensional images can be obtained which show the distribution of the tracer throughout the body. Different radiopharmaceuticals have been evaluated for the imaging of malignant tumours, of which ${ }^{18} \mathrm{~F}$-fluorode- 
oxyglucose (FDG) is by far most commonly used. Like glucose, FDG is transported into the cell and subsequently phosphorylated by hexokinase. The fluorine atom of FDG, however, prevents it further metabolization, and hereby, FDG is metabolically trapped inside the cell. FDG-PET scanning utilizes the difference in accumulation of FDG between normal and cancerous tissues, based on an enhanced glucose metabolism in cancer cells owing to increased expression of the glucose transporter enzyme Glut-1. In this way, tumours can be imaged as focal accumulations of FDG. This makes FDG-PET scanning a sensitive method for the detection and visualization of tumour bearing areas, as well as for monitoring response to treatment.

The added value of FDG-PET in the staging of locally advanced lung cancer is beyond doubt, as it results in stage migration for up to $30 \%$ of stage III NSCLC and $6-33 \%$ of limited disease (LD) SCLC patients, which are diagnosed with distant metastases ${ }^{18-}$ 30. This upstaging withholds toxic radical therapy in these patients who will not benefit from it. FDG-PET is more accurate than CT with respect to mediastinal lymph node staging as well, with a sensitivity and specificity of $74 \%$ and $85 \%$, respectively ${ }^{15}$. At present, performing an FDG-PET scan is recommended as a routine clinical staging tool for assumed stage IB-IIIB NSCLC ${ }^{15}$.

There are certain limitations, however, to the use of FDG as a cancer imaging agent. One important limitation is the increased uptake in non-malignant areas with enhanced glucose metabolism, such as inflammatory regions ${ }^{31}$. These limitations have driven the search for tracers other than FDG that specifically visualize certain molecular characteristics. These include proliferation markers, such as ${ }^{11} \mathrm{C}$-methionine, ${ }^{11} \mathrm{C}$-choline and ${ }^{18} \mathrm{~F}$-fluorothymidine and markers of hypoxia, of which ${ }^{18} \mathrm{~F}$-FMISO is most commonly applied. Furthermore, tracers are being developed that visualize the expression of specific receptors at the surface of tumour cells.

Thus, molecular imaging with PET shows many advantages over anatomical imaging alone in the combined modality treatment of lung cancer. Especially the use of integrated PET-CT, combining anatomical information with functional information of the PET scan has great clinical potential.

\subsection{Combined modality treatment for inoperable lung cancer}

Radiotherapy (RT) in combination with chemotherapy is the treatment of choice for the approximately $35 \%$ of NSCLC patients presenting with locally advanced (stage III) disease, for whom surgery is mostly not an option ${ }^{4}$. It is also the first choice treatment for the approximately $25 \%$ of SCLC patients presenting with stage I-III disease. 
Chemotherapy can be given either before the start of RT (sequential chemoradiotherapy) or simultaneously with RT (concurrent chemo-radiotherapy). In NSCLC, concurrent treatment demonstrated superior outcome compared to sequential chemo-radiation with a 3 year survival of $24 \%$ with concurrent treatment, vs. approximately $18 \%$ with sequential therapy ${ }^{32}$. The same holds true for SCLC, in which a clear benefit of concurrent over sequential chemo-radiotherapy has been demonstrated $^{33}$.

\subsection{Purpose and outline of the thesis}

Although the survival of locally advanced NSCLC and stage I-III SCLC has significantly improved with combined chemo-radiotherapy, the majority of patients still show disease progression shortly after the completion of treatment. About one third of patients experience local tumour progression as their first site of relapse ${ }^{34-38}$. Furthermore, these combined treatment strategies are associated with higher toxicity rates than treatment with RT alone. Theoretically, locoregional tumour control could be improved by increasing the radiotherapy dose or intensification of the chemotherapy regimen. Because dose limiting toxicity already occurs with the presently applied combined treatment schedules, this is not straightforward, as further intensifying therapy would result in unacceptable toxicity.

Recently, more conformal radiotherapy techniques such as stereotactic body RT (SBRT), intensity modulated RT (IMRT) or proton therapy have been introduced, as well as targeted systemic agents, which increasingly allow for specific antitumour therapy. This provides opportunities to improve locoregional control without enhancing toxicity. The introduction of these techniques, however, emphasizes the need for imaging techniques enabling accurate definition of the presence and extent of tumour.

Another approach to optimize the treatment benefit in each individual patient can be found in strategies directed at an early adaptation of therapy dependent on the treatment response. Finally, the outcome after completion of curative treatment could potentially be improved by an early detection of local progression, increasing the opportunity to be offered salvage therapy. In view of the limited ability of anatomical imaging techniques to discriminate between active tumour and posttreatment changes, molecular imaging could play an important role in this respect.

The aim of this thesis is to assess the potential of molecular imaging with PET to optimize the combined modality treatment of lung cancer. 
In regard to this aim the following aspects are addressed:

- FDG-PET-CT based target volume definition to optimize radiotherapy for locally advanced lung cancer

- The value of FDG-PET-CT in the follow-up of locally advanced NSCLC patients

- Development of novel PET tracers for the non invasive imaging of specific tumour characteristics

\section{Part I: FDG-PET-CT based target volume definition to optimize radiotherapy for locally advanced lung cancer}

No imaging technique allows a direct evaluation of the presence and extent of microscopic disease extension around the tumour visible on PET and CT. Therefore, in RT planning, a margin of tissue surrounding the macroscopic tumour (Gross tumour volume, GTV) is added in all patients to ensure that the area with potential microscopic spread is covered by the radiation field ${ }^{39}$. The resulting volume is defined as the clinical target volume (CTV).

Microscopic disease spread, however, does not occur in all patients with NSCLC ${ }^{40}$, ${ }^{41}$. Hence, the ability to predict the presence of microscopic spread on the basis of pre-treatment PET or CT imaging could lead to tumour tailored margins, resulting in an optimal sparing of normal tissue in individual patients. In chapter 2, risk factors for the presence of microscopic disease spread were identified on pre-treatment PET-CT.

Traditionally, both in NSCLC and SCLC, prophylactic irradiation of clinically uninvolved mediastinal lymph nodes was performed. This resulted in large treatment volumes. Routine elective nodal irradiation is no longer recommended in NSCLC ${ }^{42}$, ${ }^{43}$, as both PET- and CT-based selective irradiation of involved lymph nodes have proven its safety ${ }^{44-47}$. The safety of selective nodal irradiation (SNI) in NSCLC, however, cannot straightforwardly be extrapolated to SCLC. This is illustrated by a study showing an unacceptable amount of $11 \%$ of isolated nodal failures outside of the treatment volume in SCLC with CT-based SNI in SCLC ${ }^{48}$. As FDG-PET scanning is more accurate than $\mathrm{CT}$ in the primary staging of $\mathrm{SCLC}^{29,49-51}$, we hypothesized that PET based SNI would improve the coverage of involved lymph nodes compared to CT-based $\mathrm{SNI}^{29,49-51}$. Chapter 3 describes the results of a planning study in which the influence of selective irradiation of FDG-PET positive mediastinal nodes on radiation fields and normal tissue exposure in limited disease (LD) SCLC was investigated. A prospective study was subsequently performed to evaluate the safety of PET-based SNI in LD-SCLC, of which the results are reported in chapter 4. 


\section{Part II: The value of FDG-PET-CT in the follow-up of locally advanced NSCLC patients}

Theoretically, early detection of progressive disease after curative intent therapy, at a time that radical retreatment is still an option, could improve survival. In NSCLC however, there are at present no convincing data supporting that early detection of progression with chest X-ray or CT scan results in survival benefit ${ }^{16,52-54}$. A major restriction of both modalities is the poor discriminating capacity between residual or recurrent tumour and post-treatment changes ${ }^{16,17}$. As repeated imaging is often needed to confirm progression, this delay could lead to missing the chance for salvage treatment. In this respect, FDG-PET scanning could have additional value, as PET is more accurate than CT in the distinction of tumour from post-radiotherapy effects ${ }^{55-57}$, and is known to be prognostic for outcome ${ }^{58-62}$. In chapter 5, we evaluated whether a PET-CT 3 months after therapy can detect potentially curable progression in NSCLC patients treated with curative intent with (chemo-)radiation. Chapter 6 describes the results of an economic evaluation assessing the costeffectiveness of a PET-CT based follow-up strategy.

\section{Part III: Development of novel PET tracers for the non invasive imaging of specific tumour characteristics}

Recent advances in molecular biology have revealed a number of biological characteristics of cancer cells that offer potential targets for imaging. Some of these characteristics, such as hypoxia, cell density and proliferation, are associated with tumour aggressiveness and response to anticancer treatment. These characteristics are known to be heterogeneous across the tumour ${ }^{63-65}$. Non-invasive imaging of those characteristics could have great clinical importance, as it would allow patient selection for targeted antitumour therapy as well as the identification of relatively treatment resistant areas within the tumour.

In part III of this thesis, two phase I trials are presented evaluating novel PET tracers. In chapter 7 the results of a phase I trial evaluating $\left[{ }^{18} \mathrm{~F}\right] \mathrm{HX} 4$, a novel marker of hypoxia, are reported. In chapter 8 , the safety of Zirconium- $89\left({ }^{89} \mathrm{Zr}\right)$ labelled cetuximab was evaluated. Cetuximab is a monoclonal antibody against the epidermal growth factor receptor (EGFR), a receptor which expression has been correlated with tumour aggressiveness and treatment resistance ${ }^{66}$.

\section{Part IV:Discussion}

In part IV, the role of PET in the combined modality therapy of lung cancer is discussed. A review of the available literature regarding this subject is provided in chapter 9 . In chapter 10 , the major results of this thesis are described in the context of the currently existing evidence, and perspectives for future research are highlighted. 


\subsection{References}

1. Ferlay J, Parkin DM, Steliarova-Foucher E. Estimates of cancer incidence and mortality in Europe in 2008. Eur J Cancer;46:765-81.

2. Bray $\mathrm{FI}$, Weiderpass $\mathrm{E}$. Lung cancer mortality trends in 36 European countries: secular trends and birth cohort patterns by sex and region 1970-2007. Int J Cancer;126:1454-66.

3. www.ikcnet.nl. 2010. (Accessed February 26, 2010, at www.ikcnet.nl.)

4. de Jong WK, Schaapveld M, Blaauwgeers JL, Groen HJ. Pulmonary tumours in the Netherlands: focus on temporal trends in histology and stage and on rare tumours. Thorax 2008;63:1096-102.

5. Sobin L, Gospodarowicz M, Wittekind C. TNM classification of malignant tumours, 7th edition. 7 ed: Wiley-Blackwell; 2009.

6. Goldstraw P, Crowley J, Chansky K, et al. The IASLC Lung Cancer Staging Project: proposals for the revision of the TNM stage groupings in the forthcoming (seventh) edition of the TNM Classification of malignant tumours. J Thorac Oncol 2007;2:706-14.

7. Baumann $\mathrm{P}$, Nyman J, Hoyer $\mathrm{M}$, et al. Outcome in a prospective phase II trial of medically inoperable stage I non-small-cell lung cancer patients treated with stereotactic body radiotherapy. J Clin Oncol 2009;27:3290-6.

8. Zelen M. Keynote address on biostatistics and data retrieval. Cancer Chemother Rep 3 1973;4:31-42.

9. Micke $P$, Faldum A, Metz $T$, et al. Staging small cell lung cancer: Veterans Administration Lung Study Group versus International Association for the Study of Lung Cancer--what limits limited disease? Lung Cancer 2002;37:271-6.

10. Shepherd FA, Crowley J, Van Houtte P, et al. The International Association for the Study of Lung Cancer lung cancer staging project: proposals regarding the clinical staging of small cell lung cancer in the forthcoming (seventh) edition of the tumor, node, metastasis classification for lung cancer. J Thorac Oncol 2007;2:1067-77.

11. Vallieres E, Shepherd FA, Crowley J, et al. The IASLC Lung Cancer Staging Project: proposals regarding the relevance of TNM in the pathologic staging of small cell lung cancer in the forthcoming (seventh) edition of the TNM classification for lung cancer. J Thorac Oncol 2009;4:1049-59.

12. Koletsis EN, Prokakis C, Karanikolas M, Apostolakis E, Dougenis D. Current role of surgery in small cell lung carcinoma. J Cardiothorac Surg 2009;4:30.

13. Hann CL, Rudin CM. Management of small-cell lung cancer: incremental changes but hope for the future. Oncology (Williston Park) 2008;22:1486-92.

14. Van de Steene J, Linthout N, de Mey J, et al. Definition of gross tumor volume in lung cancer: interobserver variability. Radiother Oncol 2002;62:37-49.

15. Silvestri GA, Gould MK, Margolis ML, et al. Noninvasive staging of non-small cell lung cancer: ACCP evidenced-based clinical practice guidelines (2nd edition). Chest 2007;132:178S-201S.

16. Korst RJ, Gold HT, Kent MS, Port JL, Lee PC, Altorki NK. Surveillance computed tomography after complete resection for non-small cell lung cancer: results and costs. J Thorac Cardiovasc Surg 2005;129:652-60.

17. Korst RJ, Kansler AL, Port JL, Lee PC, Altorki NK. Accuracy of surveillance computed tomography in detecting recurrent or new primary lung cancer in patients with completely resected lung cancer. Ann Thorac Surg 2006;82:1009-15; discussion 15.

18. Hoekstra CJ, Stroobants SG, Hoekstra OS, et al. The value of [18F]fluoro-2-deoxy-D-glucose positron emission tomography in the selection of patients with stage IIIA-N2 non-small cell lung cancer for combined modality treatment. Lung Cancer 2003;39:151-7.

19. Mac Manus MP, Hicks RJ, Ball DL, et al. F-18 fluorodeoxyglucose positron emission tomography staging in radical radiotherapy candidates with nonsmall cell lung carcinoma: powerful correlation with survival and high impact on treatment. Cancer 2001;92:886-95.

20. MacManus MP, Hicks RJ, Matthews JP, et al. High rate of detection of unsuspected distant metastases by pet in apparent stage III non-small-cell lung cancer: implications for radical radiation therapy. Int J Radiat Oncol Biol Phys 2001;50:287-93. 
21. Hicks RJ, Kalff V, MacManus MP, et al. (18)F-FDG PET provides high-impact and powerful prognostic stratification in staging newly diagnosed non-small cell lung cancer. J Nucl Med 2001;42:1596-604.

22. Mac Manus MP, Wong K, Hicks RJ, Matthews JP, Wirth A, Ball DL. Early mortality after radical radiotherapy for non-small-cell lung cancer: comparison of PET-staged and conventionally staged cohorts treated at a large tertiary referral center. Int J Radiat Oncol Biol Phys 2002;52:351-61.

23. Fischer B, Lassen $U$, Mortensen J, et al. Preoperative staging of lung cancer with combined PET-CT. N Engl J Med 2009;361:32-9.

24. Maziak DE, Darling GE, Inculet RI, et al. Positron emission tomography in staging early lung cancer: a randomized trial. Ann Intern Med 2009;151:221-8, W-48.

25. Azad A, Chionh F, Scott AM, et al. High Impact of (18)F-FDG-PET on Management and Prognostic Stratification of Newly Diagnosed Small Cell Lung Cancer. Mol Imaging Biol 2009.

26. Blum R, MacManus MP, Rischin D, Michael M, Ball D, Hicks RJ. Impact of positron emission tomography on the management of patients with small-cell lung cancer: preliminary experience. Am J Clin Oncol 2004;27:164-71.

27. Brink I, Schumacher T, Mix M, et al. Impact of [18F]FDG-PET on the primary staging of small-cell lung cancer. Eur J Nucl Med Mol Imaging 2004;31:1614-20.

28. Chin R, Jr., McCain TW, Miller AA, et al. Whole body FDG-PET for the evaluation and staging of small cell lung cancer: a preliminary study. Lung Cancer 2002;37:1-6.

29. Kamel EM, Zwahlen D, Wyss MT, Stumpe KD, von Schulthess GK, Steinert HC. Whole-body (18)F-FDG PET improves the management of patients with small cell lung cancer. J Nucl Med 2003;44:1911-7.

30. Schumacher T, Brink I, Mix M, et al. FDG-PET imaging for the staging and follow-up of small cell lung cancer. Eur J Nucl Med 2001;28:483-8.

31. Strauss LG. Fluorine-18 deoxyglucose and false-positive results: a major problem in the diagnostics of oncological patients. Eur J Nucl Med 1996;23:1409-15.

32. Auperin A, Le Pechoux C, Rolland E, et al. Meta-Analysis of Concomitant Versus Sequential Radiochemotherapy in Locally Advanced Non-Small-Cell Lung Cancer. J Clin Oncol. 2010 in press

33. Takada M, Fukuoka M, Kawahara M, et al. Phase III study of concurrent versus sequential thoracic radiotherapy in combination with cisplatin and etoposide for limited-stage small-cell lung cancer: results of the Japan Clinical Oncology Group Study 9104. J Clin Oncol 2002;20:3054-60.

34. Ataman OU, Barrett A, Filleron T, Kramar A. Optimization of follow-up timing from study of patterns of first failure after primary treatment. An example from patients with NSCLC: a study of the REACT working group of ESTRO. Radiother Oncol 2006;78:95-100.

35. Fournel $P$, Robinet $G$, Thomas $P$, et al. Randomized phase III trial of sequential chemoradiotherapy compared with concurrent chemoradiotherapy in locally advanced non-small-cell lung cancer: Groupe Lyon-Saint-Etienne d'Oncologie Thoracique-Groupe Francais de Pneumo-Cancerologie NPC 95-01 Study. J Clin Oncol 2005;23:5910-7.

36. Furuse K, Fukuoka M, Kawahara M, et al. Phase III study of concurrent versus sequential thoracic radiotherapy in combination with mitomycin, vindesine, and cisplatin in unresectable stage III nonsmall-cell lung cancer. J Clin Oncol 1999;17:2692-9.

37. Mac Manus MP, Hicks RJ, Matthews JP, Wirth A, Rischin D, Ball DL. Metabolic (FDG-PET) response after radical radiotherapy/chemoradiotherapy for non-small cell lung cancer correlates with patterns of failure. Lung Cancer 2005;49:95-108.

38. Zatloukal $\mathrm{P}$, Petruzelka L, Zemanova $\mathrm{M}$, et al. Concurrent versus sequential chemoradiotherapy with cisplatin and vinorelbine in locally advanced non-small cell lung cancer: a randomized study. Lung Cancer 2004;46:87-98.

39. ICoRUa. International Commission on Radiation Units and Measurements. ICRU Report 62: Prescribing, recording, and reporting photon beam therapy (Supplement to ICRU Report 50). Bethesda; 1999.

40. Giraud $\mathrm{P}$, Antoine M, Larrouy A, et al. Evaluation of microscopic tumor extension in non-small-cell lung cancer for three-dimensional conformal radiotherapy planning. Int J Radiat Oncol Biol Phys 2000;48:1015-24. 
41. Stroom J, Blaauwgeers $H$, van Baardwijk A, et al. Feasibility of pathology-correlated lung imaging for accurate target definition of lung tumors. Int J Radiat Oncol Biol Phys 2007;69:267-75.

42. Belderbos JS, Kepka L, Spring Kong FM, Martel MK, Videtic GM, Jeremic B. Report from the International Atomic Energy Agency (IAEA) consultants' meeting on elective nodal irradiation in lung cancer: non-small-Cell lung cancer (NSCLC). Int J Radiat Oncol Biol Phys 2008;72:335-42.

43. Senan S, De Ruysscher D, Giraud P, Mirimanoff R, Budach V. Literature-based recommendations for treatment planning and execution in high-dose radiotherapy for lung cancer. Radiother Oncol 2004;71:139-46.

44. Belderbos JS, Heemsbergen WD, De Jaeger K, Baas P, Lebesque JV. Final results of a Phase I/II dose escalation trial in non-small-cell lung cancer using three-dimensional conformal radiotherapy. Int J Radiat Oncol Biol Phys 2006;66:126-34.

45. De Ruysscher D, Wanders S, van Haren E, et al. Selective mediastinal node irradiation based on FDGPET scan data in patients with non-small-cell lung cancer: a prospective clinical study. Int J Radiat Oncol Biol Phys 2005;62:988-94.

46. Senan S, Burgers S, Samson MJ, et al. Can elective nodal irradiation be omitted in stage III non-smallcell lung cancer? Analysis of recurrences in a phase II study of induction chemotherapy and involvedfield radiotherapy. Int J Radiat Oncol Biol Phys 2002;54:999-1006.

47. Sulman EP, Komaki R, Klopp AH, Cox JD, Chang JY. Exclusion of elective nodal irradiation is associated with minimal elective nodal failure in non-small cell lung cancer. Radiat Oncol 2009;4:5.

48. De Ruysscher D, Bremer RH, Koppe F, et al. Omission of elective node irradiation on basis of CT-scans in patients with limited disease small cell lung cancer: a phase II trial. Radiother Oncol 2006;80:30712.

49. Fischer BM, Mortensen J, Langer SW, et al. A prospective study of PET/CT in initial staging of smallcell lung cancer: comparison with $\mathrm{CT}$, bone scintigraphy and bone marrow analysis. Ann Oncol 2007; 18:338-45.

50. Niho S, Fujii H, Murakami K, et al. Detection of unsuspected distant metastases and/or regional nodes by FDG-PET in LD-SCLC scan in apparent limited-disease small-cell lung cancer. Lung Cancer 2007; 57:328-33.

51. Shen YY, Shiau YC, Wang JJ, Ho ST, Kao CH. Whole-body 18F-2-deoxyglucose positron emission tomography in primary staging small cell lung cancer. Anticancer Res 2002;22:1257-64.

52. Benamore R, Shepherd FA, Leighl N, et al. Does intensive follow-up alter outcome in patients with advanced lung cancer? J Thorac Oncol 2007;2:273-81.

53. Edelman MJ, Schuetz J. Follow-up of local (stage I and stage II) non-small-cell lung cancer after surgical resection. Curr Treat Options Oncol 2002;3:67-73.

54. Walsh GL, O'Connor M, Willis KM, et al. Is follow-up of lung cancer patients after resection medically indicated and cost-effective? Ann Thorac Surg 1995;60:1563-70; discussion 70-2.

55. Duhaylongsod FG, Lowe VJ, Patz EF, Jr., Vaughn AL, Coleman RE, Wolfe WG. Detection of primary and recurrent lung cancer by means of F-18 fluorodeoxyglucose positron emission tomography (FDG PET). J Thorac Cardiovasc Surg 1995;110:130-9; discussion 9-40.

56. Mac Manus MP, Hicks RJ, Matthews JP, et al. Positron emission tomography is superior to computed tomography scanning for response-assessment after radical radiotherapy or chemoradiotherapy in patients with non-small-cell lung cancer. J Clin Oncol 2003;21:1285-92.

57. Patz EF, Jr., Connolly J, Herndon J. Prognostic value of thoracic FDG PET imaging after treatment for non-small cell lung cancer. AJR Am J Roentgenol 2000;174:769-74.

58. Ahuja V, Coleman RE, Herndon J, Patz EF, Jr. The prognostic significance of fluorodeoxyglucose positron emission tomography imaging for patients with nonsmall cell lung carcinoma. Cancer 1998;83:918-24. 
59. Berghmans T, Dusart M, Paesmans $M$, et al. Primary tumor standardized uptake value (SUVmax) measured on fluorodeoxyglucose positron emission tomography (FDG-PET) is of prognostic value for survival in non-small cell lung cancer (NSCLC): a systematic review and meta-analysis (MA) by the European Lung Cancer Working Party for the IASLC Lung Cancer Staging Project. J Thorac Oncol 2008;3:6-12.

60. Downey RJ, Akhurst T, Gonen M, et al. Preoperative F-18 fluorodeoxyglucose-positron emission tomography maximal standardized uptake value predicts survival after lung cancer resection. J Clin Oncol 2004;22:3255-60.

61. Kased N, Erasmus JJ, Komaki R, Cox JD. Prognostic value of posttreatment [18F] fluorodeoxyglucose uptake of primary non-small cell lung carcinoma treated with radiation therapy with or without chemotherapy: a brief review. J Thorac Oncol 2008;3:534-8.

62. van Baardwijk A, Dooms C, van Suylen RJ, et al. The maximum uptake of (18)F-deoxyglucose on positron emission tomography scan correlates with survival, hypoxia inducible factor-1alpha and GLUT-1 in non-small cell lung cancer. Eur J Cancer 2007;43:1392-8.

63. Cooper RA, Carrington BM, Loncaster JA, et al. Tumour oxygenation levels correlate with dynamic contrast-enhanced magnetic resonance imaging parameters in carcinoma of the cervix. Radiother Oncol 2000;57:53-9.

64. Foo SS, Abbott DF, Lawrentschuk N, Scott AM. Functional imaging of intratumoral hypoxia. Mol Imaging Biol 2004;6:291-305.

65. Zhao S, Kuge Y, Mochizuki T, et al. Biologic correlates of intratumoral heterogeneity in $18 \mathrm{~F}-$ FDG distribution with regional expression of glucose transporters and hexokinase-II in experimental tumor. J Nucl Med 2005;46:675-82.

66. Eriksen JG, Steiniche T, Overgaard J. The influence of epidermal growth factor receptor and tumor differentiation on the response to accelerated radiotherapy of squamous cell carcinomas of the head and neck in the randomized DAHANCA 6 and 7 study. Radiother Oncol 2005;74:93-100. 



\section{Part}

FDG-PET-CT based target volume definition to optimize radiotherapy for locally advanced lung cancer 



\section{CHAPTER 2 \\ Microscopic disease extension in 3D for Non Small Cell Lung Cancer: development of a prediction model using pathology validated PET and CT features}

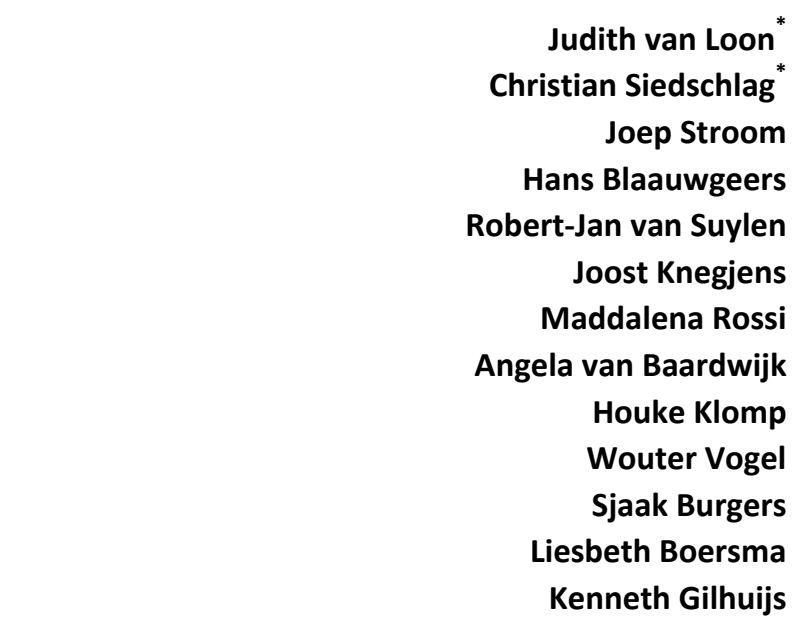

* Both authors contributed equally to this manuscript

Submitted 


\section{Abstract}

\section{Background and purpose}

One major uncertainty in radiotherapy planning of non-small cell lung cancer (NSCLC) concerns the definition of the clinical target volume (CTV), meant to cover potential microscopic disease extension (MDE) around the macroscopically visible tumour. The primary aim of this study was to establish pre-treatment risk factors for the presence of MDE. The secondary aim was to establish the impact of these factors on the accuracy of PET and CT to assess the total tumour-bearing region at pathology $\left(\mathrm{CTV}_{\text {path }}\right)$.

\section{Methods and materials}

34 NSCLC patients, who underwent CT and PET prior to lobectomy, were included. Specimens were examined microscopically for MDE. The gross tumour volume (GTV) on CT and PET was compared with the GTV and the CTV at pathology, taking tissue deformations into account. Using multivariate logistic regression, image based risk factors for the presence of MDE were identified and a prediction model was developed based on these factors.

\section{Results}

MDE was found in 17 of the 34 patients (50\%). MDE did not exceed $26 \mathrm{~mm}$ in $90 \%$ of patients. In multivariate analysis, two parameters (mean CT tumour density and $\mathrm{GTV}_{\mathrm{CT}}$ ) were significantly associated with MDE. The AUC of the 2 parameter prediction model was 0.86. 13 tumours (38\%, 95\% Cl: 24-55\%) were identified as low risk for MDE, being potential candidates for reduced intensity therapy around the GTV. In the low risk group, the effective diameter of the GTV the $\mathrm{CTV}_{\text {path }}$. In the high risk group, GTV $\mathrm{V}_{\mathrm{CT} / \mathrm{PET}}$ underestimated the CTV $\mathrm{V}_{\text {path }}$ with on average 19.2 and $26.7 \mathrm{~mm}$, respectively.

\section{Conclusions}

CT features have potential to predict the presence of MDE. Tumours identified as low risk of MDE show lower rates of disease around the GTV than high risk tumours. Both CT and PET accurately visualize the $\mathrm{CTV}_{\text {path }}$ in low risk tumours, but underestimate it in high risk tumours. 


\subsection{Introduction}

Radiotherapy (RT) with or without chemotherapy is the current standard treatment in locally advanced (stage III) and inoperable stage I/II non-small cell lung cancer (NSCLC). Even with concurrent chemoradiotherapy, about one third of patients experience local failure as their first site of relapse ${ }^{1-3}$. Improving locoregional tumour control by increasing the radiation dose is not straightforward, because dose limiting toxicity occurs, such as lung damage and severe esophagitis ${ }^{4,5}$. Technical improvements in radiotherapy, like respiration-correlated (RC) imaging, stereotactic body RT (SBRT), intensity modulated RT (IMRT) and the use of ${ }^{18}$ Fluoro-DeoxyGlucose (FDG)-PET scans in RT planning have facilitated radiation dose escalation with acceptable side effects ${ }^{6-9}$. These techniques allow a more precise targeting of RT. As a result, accurate target definition becomes increasingly important. PET and CT imaging allow definition of the location and extent of the macroscopic tumour with growing accuracy ${ }^{10,11}$. However, large inter- and intraobserver variation exists in the delineation of the Gross Tumour Volume (GTV) ${ }^{12}$. Even more uncertainty exists in the definition of the clinical target volume (CTV), which should include the GTV with a margin of surrounding tissue covering potential microscopic spread ${ }^{13}$. Current imaging techniques do not allow direct evaluation of the presence and extent of microscopic disease extension (MDE) around the tumour as seen on PET and CT. Hence, only population statistics on MDE are available, based on correlation of imaging with pathology. These studies report an average MDE from $1.5 \mathrm{~mm}$ to 8 $\mathrm{mm}^{14-17}$, with more extensive MDE in adenocarcinoma than in squamous cell carcinoma ${ }^{15}$. Considering tissue deformations between in-vivo imaging and ex-vivo pathology, it is likely, however, that these ranges are underestimated. When tissue deformations are not taken into account, underestimation of the extent of MDE may occur up to a factor $2^{18,19}$.

MDE, however, does not occur in all patients ${ }^{15,18}$. The ability to predict the presence of MDE on the basis of pre-treatment imaging could lead to tumour tailored CTV margins, resulting in an optimal sparing of normal tissue in individual patients.

The aim of the current study was two-fold: first, to establish pre-treatment risk factors for the presence of MDE at pathology. Secondly, to establish the impact of these factors on the accuracy of PET and CT to assess the total tumour-bearing region at pathology ("CTV path") in three dimensions. 


\subsection{Methods and Materials}

\section{Patients}

Patients were included in the following participating hospitals: the Netherlands Cancer Institute (Amsterdam, the Netherlands, central approval from the medical ethical board), the Onze Lieve Vrouwe Gasthuis (Amsterdam, the Netherlands) and the Maastricht University Medical Centre (Maastricht, the Netherlands). All patients gave written informed consent.

\section{Preoperative imaging and tumour delineation}

All patients underwent a chest CT and ${ }^{18}$ FDG-PET scan within 8 weeks prior to surgery. The CT slice-thickness ranged from 1 to $5 \mathrm{~mm}$, depending on whether the scan was made in the diagnostic process or for study purposes. The PET scan was performed during free-breathing with a voxel size of $5 \mathrm{~mm}$, using attenuation correction based on low dose CT. On the CT scans, the lung lobes and the gross tumour volume (GTV) were delineated using lung window level settings ( $W=1600, L=600)$ by an experienced RT technician (MR) in consensus with a dedicated lung radiation oncologist (JK/JB). On the PET scans, the GTV was delineated automatically using a $42 \%$ threshold of the maximum standardized uptake value $\left(S U V_{\max }\right)$ as described elsewhere ${ }^{20,21}$. PET scanners were calibrated between participating institutes using a dedicated phantom ${ }^{22,23}$.

\section{Pathology processing}

A fixed protocol was used among participating centres to process the resected lung lobes $^{18}$. In short, the lobe was inflated with $10 \%$ formaldehyde injected through the bronchial opening. After a minimum of 24 hours the specimen was sectioned into $0,5 \mathrm{~cm}$ slices in a region of $2 \mathrm{~cm}$ around the tumour, and of $1 \mathrm{~cm}$ thickness throughout the rest of the lobe. Sectioning was performed perpendicular to the longest axis of the lobe, which, in approximation, was parallel to the cranio-caudal axis of the patient. Hence, the orientation of the specimen slices was as close as practically possible to the orientation of the CT slices. A digital photograph was taken of each separate slice. Subsequently, microscopic thin sections covering the tumour and a 2 $\mathrm{cm}$ margin in three dimensions around the tumour were obtained.

\section{Assessment of GTV and microscopic disease extension at pathology}

All samples were microscopically analyzed by one observer (JVL) in consensus with an experienced lung pathologist (RvS). Both the gross tumour based on pathology 
$\left(G V_{\text {path }}\right)$ and microscopic disease extension were delineated in each microscopic section. MDE was defined by the presence of microscopic tumour deposits beyond the GTV $\mathrm{Vath}_{\text {p. Thus, the GTV }}$ path did not include MDE.

The microscopic samples were scanned and loaded into image processing software (GNU Image Manipulation Program (GIMP), version 2.0). The volume of the GTV $\mathrm{V}_{\text {path }}$ was calculated by multiplying the area of the index tumour in each microscopic slide with the thickness of the corresponding slice. The effective tumour diameter of this volume was computed as follows:

$d=2\left(\frac{3 V}{4 \pi}\right)^{1 / 3}$, where $V$ denotes the GTV $V_{\text {path. }}$.

In addition to the $\mathrm{GTV}_{\text {path, }}$ the presence of MDE was recorded for each patient. When MDE was found, its shortest distance to the GTV path was measured in 3-D. These distances were corrected for residual deformations between the in-vivo scans and the ex-vivo specimen using a previously described method ${ }^{19}$. Briefly, the deformations around the GTV at pathology are modelled by an ellipse, where the deformation factor varies between 0.7 and 3.1, depending on the angle relative to the direction of gravity during sectioning. All locations of MDE were corrected for deformation using the ellipse parameters for each separate lobe. Subsequently, a cumulative histogram of the maximum distances between MDE and the GTV $\left(\mathrm{MDE}_{\max }\right)$ was obtained.

\section{Analysis of risk factors for microscopic disease extension and development of a prediction model}

Image, tumour and patient characteristics were evaluated for their potential association with the presence of MDE (Table 2.1).

\begin{tabular}{|c|c|}
\hline Variable & Description \\
\hline $\mathrm{GTV}_{\mathrm{CT}}$ & The gross tumour volume as delineated on the CT scan \\
\hline $\mathrm{CT}_{\text {mean }}$ & $\begin{array}{l}\text { The mean signal (in water units) observed in the delineated GTV on the } \\
\text { CT scan }\end{array}$ \\
\hline \multirow[t]{4}{*}{ CT Circularity } & The circularity of the delineated $\mathrm{GTV}_{\mathrm{CT}}$, defined as \\
\hline & Volume of $G T V_{C T}$ within sphere of effective diameter \\
\hline & Volume of $G T V_{C T}$ \\
\hline & Here, the effective diameter is given by $2 \cdot \sqrt[3]{\frac{3 \cdot G T V_{C T}}{4 \pi}}$ \\
\hline $\mathrm{SUV}_{\max }$ & The maximum standardized uptake value as measured on the PET scan \\
\hline GTV $_{\text {PET }}$ & $\begin{array}{l}\text { The gross tumour volume on the PET scan (calculated using a } 42 \% \\
\text { threshold of the maximum SUV). }\end{array}$ \\
\hline Tumour type & The histology of the tumour (adeno or non-adeno carcinoma) \\
\hline Age & The age of the patient at surgery \\
\hline
\end{tabular}


The effective diameter of the GTV on CT and PET, the mean CT density of the GTV and the circularity of the $\mathrm{GTV}_{\mathrm{CT}}$ were automatically calculated using an adaptation of previously employed methods ${ }^{24}$.

All statistical analyses were performed using SPSS version 15.0. The variables were tested for their association with the presence of MDE using the independent samples T-test for scale variables and the Chi-square test for nominal variables. Multivariate binary logistic regression was subsequently applied in combination with backward feature selection ( $p$-to-entry 0.05 and p-to-remove of 0.1 ). The performance of the resulting prediction model was quantified using receiver operating characteristic (ROC) analysis. Based on the output of the model, the patients were categorized into a group at low risk of presence of MDE and a group at high risk.

\section{Comparison of the GTV at PET and CT with the GTV and CTV at pathology}

The effective diameter of the GTV at CT and PET was first compared to that of the $\mathrm{GTV}_{\text {path }}$ (i.e., not including MDE). Secondly, the effective diameters of the GTV $\mathrm{V}_{C T}$ and $\mathrm{GTV}_{\mathrm{PET}}$ were compared to that of the total tumour-bearing tissue at pathology $\left(\mathrm{CTV}_{\text {path }}\right)$. The latter was defined as the sum of the effective diameter of $\mathrm{GTV}_{\text {path }}$ and two times the maximum MDE (to convert radius to diameter). Thereafter, the accuracy of $\mathrm{PET}$ and $\mathrm{CT}$ to assess the $\mathrm{CTV}_{\text {path }}$ was established separately in the group of patients with $\mathrm{MDE}(\mathrm{MDE}+)$ and without $\mathrm{MDE}$ (MDE-). The latter analysis was performed twice; once based on the presence of MDE at pathology, and once based on its presence according to the prediction model.

\subsection{Results}

\section{Patient and tumour characteristics}

From September 2006 to December 2008, 34 NSCLC patients (19 male and 15 female) scheduled for a lobectomy were included. The average age at surgery was 60.6 years (range: $42-80$ years). PET and CT imaging were performed at a median of 19 days (range: 1-55 days) before surgery. The surgical specimen consisted of the left upper lobe $(n=11)$, left lower lobe $(n=5)$, right upper lobe $(n=13)$, right middle lobe $(n=2)$ and right lower lobe $(n=3)$. Tumour histology was adenocarcinoma in $53 \%(n=18)$, squamous cell in $18 \%(n=6)$, large cell in $12 \%(n=4)$, mixed adenosquamous in $9 \%(n=3)$, bronchioloalveolar in $3 \%(n=1)$ and NSCLC, not otherwise specified in $6 \%(n=2)$. 


\section{Assessment of GTV and microscopic disease extension at pathology}

1311 microscopic sections (median: 38 per patient, range: 17-103) were analyzed. MDE outside of the $\mathrm{GTV}_{\text {path }}$ was found in 17 of the $34(50 \%, 95 \% \mathrm{Cl}: 34-66 \%)$ patients. The cumulative distribution of $\mathrm{MDE}_{\max }$, both with and without deformation correction, is shown in Figure 2.1. Without deformation correction, a CTV margin of $14 \mathrm{~mm}$ would be needed to cover MDE in $90 \%$ of the patients. With deformation correction the margin to cover MDE in $90 \%$ of the patients increased to $26 \mathrm{~mm}$. The distribution of microscopic tumour deposits was found to be isotropic in the transverse plane: MDE medial of the $\mathrm{GTV}_{\text {path }}$ was seen in $26 \%$, lateral in $29 \%$, dorsal in $23 \%$ and ventral in $22 \%$. With the current sampling method, no MDE was found in the cranial and caudal direction. No association was found between the location of the tumour in the lobe and the presence of microscopic tumour deposits. Furthermore, there was no correlation between the time interval between imaging and surgery and the extent of overestimation/underestimation with CT and PET.

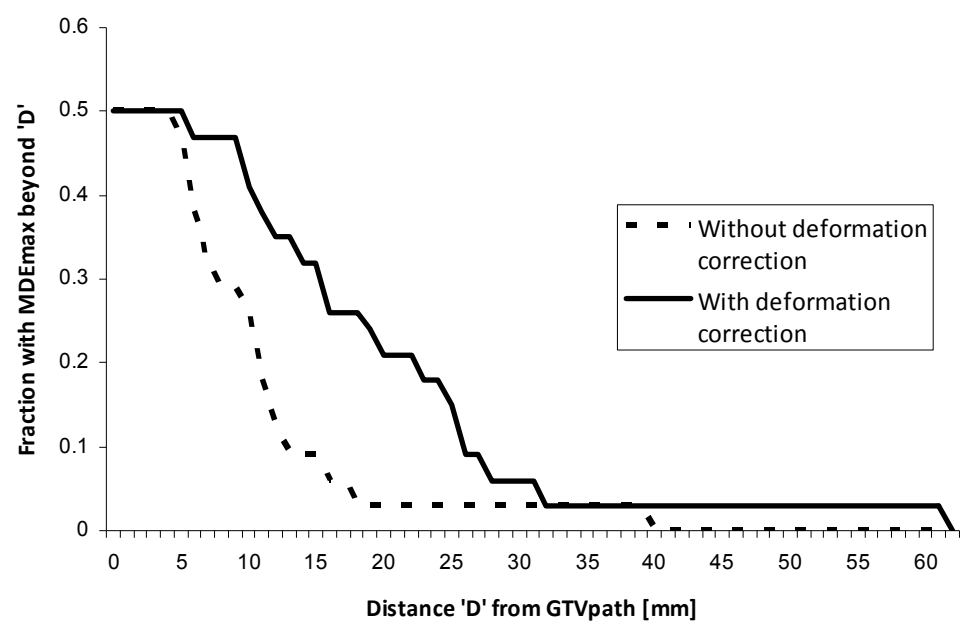

Figure 2.1 Cumulative distribution of the distance of maximum microscopic disease extension (MDE ${ }_{\max }$ ) to the border of the $\mathrm{GTV}_{\text {path }}$

\section{Prediction of microscopic disease extension}

The distribution of the potential predictive variables in the subgroups with and without MDE is shown in Table 2.2. Two features (CT mean and GTV $\mathrm{PET}_{\text {) }}$ ) showed significant differences. Multivariate analysis yielded $\mathrm{CT}_{\text {mean }}$ and $\mathrm{GTV}_{\mathrm{CT}}$ as significant factors in the logistic regression model (Table 2.2). The area under the ROC curve of this two-parameter prediction model was $0.86(95 \% \mathrm{Cl}: 0.73-0.98, \mathrm{p}=0.001)$ (Figure 2.2). 


\begin{tabular}{|c|c|c|c|c|}
\hline & MDE absent & MDE present & UVA & MVA \\
\hline & Mean $\pm S D$ & Mean $\pm S D$ & $p$-value & $p$-value \\
\hline $\mathrm{GTV}_{\mathrm{CT}}\left(\mathrm{cm}^{3}\right)$ & $22.9 \pm 11.4$ & $61 \pm 21.1$ & 0.14 & 0.03 \\
\hline $\mathrm{CT}_{\text {mean }}{ }^{*}$ & $787 \pm 22.8$ & $860 \pm 24.1$ & 0.04 & 0.03 \\
\hline CT Circularity & $0.78 \pm 0.02$ & $0.71 \pm 0.03$ & 0.10 & ns \\
\hline$S_{\text {SUax }}$ & $9.7 \pm 4.9$ & $11.7 \pm 1.4$ & 0.28 & ns \\
\hline $\operatorname{GTV}_{\mathrm{PET}}\left(\mathrm{cm}^{3}\right)$ & $9.8 \pm 3.1$ & $24.6 \pm 5.7$ & 0.04 & ns \\
\hline Tumour type & $58 \%$ & $35 \%$ & 0.18 & ns \\
\hline Age (years) & $58.4 \pm 11.4$ & $62.6 \pm 11.4$ & 0.29 & ns \\
\hline
\end{tabular}

SD: standard deviation; UVA: Univariate analysis; MVA: Multivariate logistic regression analysis; Ns: not significant

UVA: $p$-values $\leq 0,05$ indicate a statistically significant difference of the predictor variables between the subgroups

MVA: $p$-values $\leq 0,05$ indicate statistically significant factors resulting from backward logistic regression $*$ in water units

**percentage with adenocarcinoma

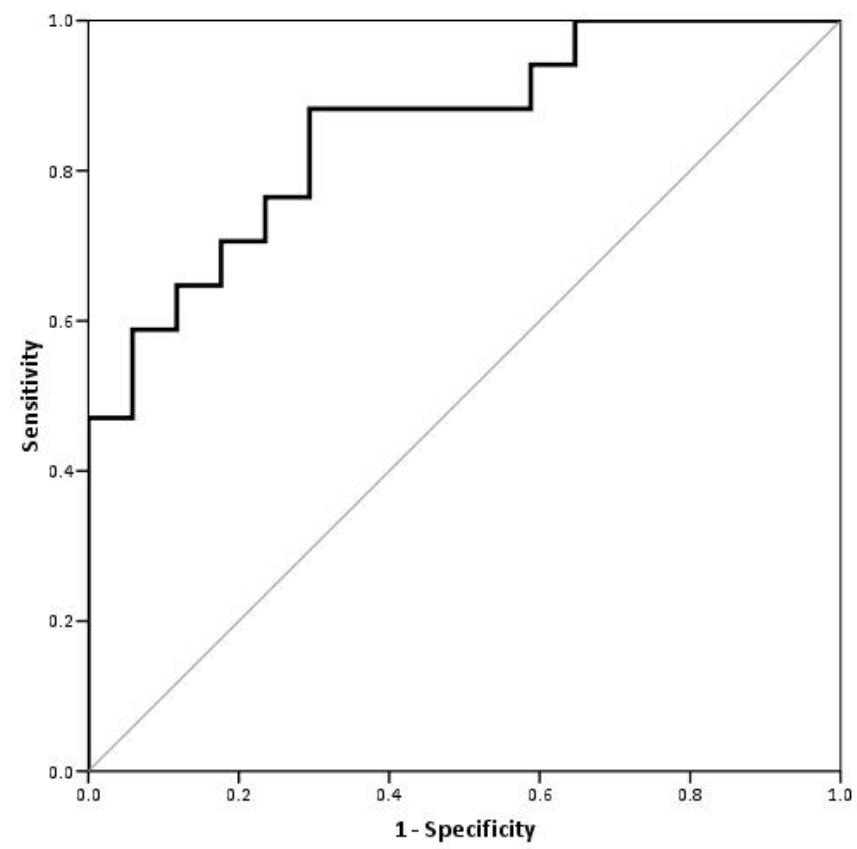

Figure 2.2 Receiver operating characteristic (ROC) curve of the two parameter prediction model Multivariate regression analysis results in $\mathrm{CT}$ mean and $\mathrm{GTV}_{\mathrm{CT}}$ as significant parameters in the prediction model. Area under the curve: 0.86

A cut-off value in the model was chosen corresponding to a sensitivity of $90 \%$ and a specificity of $64 \%$. This operating point corresponds to a probability threshold for MDE of $30 \%$. At this operating point, $13 / 34$ patients (38\%, $95 \% \mathrm{Cl}: 24-55 \%)$ were 
assigned to the low-risk group for MDE. The cumulative distribution of the maximum distances to the GTV border for these two groups is shown in Figure 2.3.

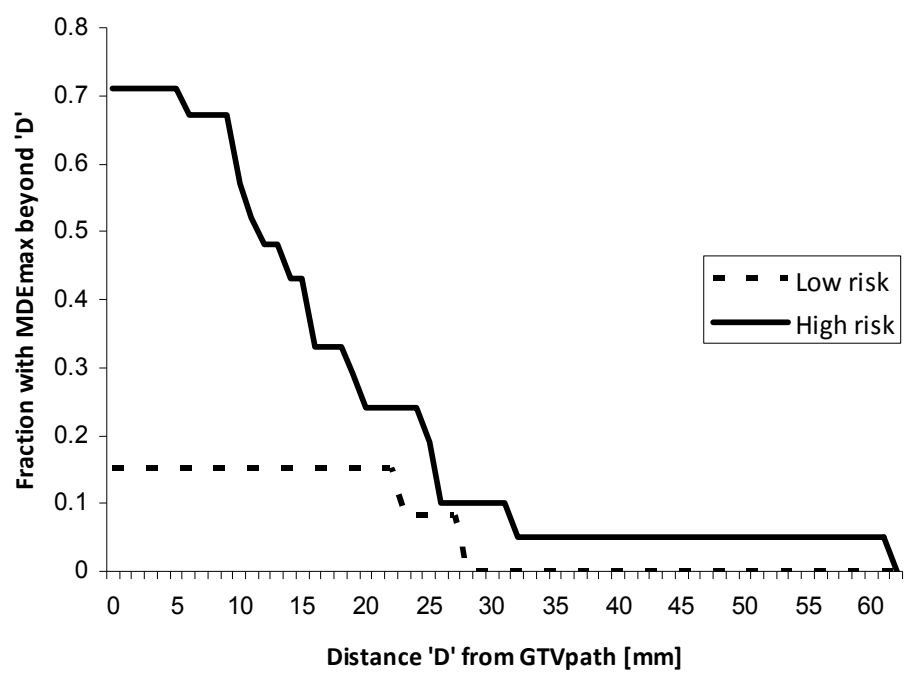

Figure 2.3 Cumulative distribution of the maximum distance of microscopic disease extension $\left(\mathrm{MDE}_{\max }\right)$ to the border of the $\mathrm{GTV}_{\text {path }}$ according to the risk of MDE

$\mathrm{MDE}_{\max }$ per patient in the group at low risk of $\mathrm{MDE}(\mathrm{N}=13)$ and the group at high risk of $\mathrm{MDE}(\mathrm{N}=21)$, as predicted by the linear regression model

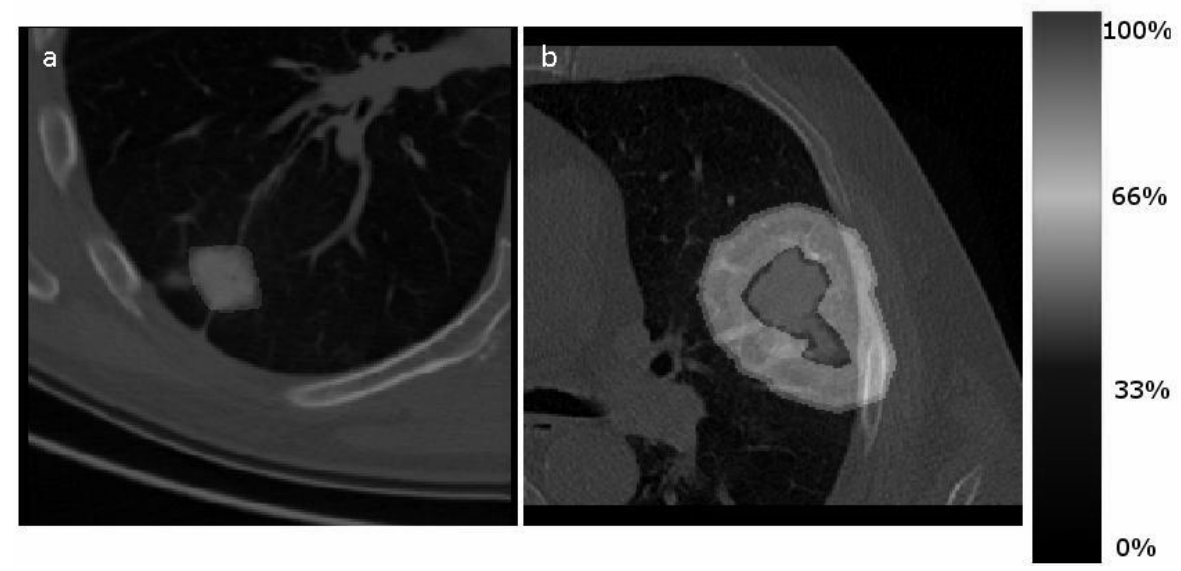

Figure 2.4 Illustration of the difference in overall disease load around the GTV at imaging between patients at low and at high risk of microscopic disease extension (MDE)

The difference in overall disease load between high and low risk patients is shown for the GTV $\mathrm{CT}_{\mathrm{CT}}$ only to provide anatomical information. Colour represents the fraction of patients in whom disease extension was found at various distances from the $\mathrm{GTV}_{\mathrm{CT}}$. Only regions inside the lung are relevant

A. Illustration in $\mathrm{CT}$ scan of a patient at low risk of MDE

B. Illustration in CT scan of a patient at high risk of MDE 
Of the 17 patients with actual presence of MDE, two were at low risk for MDE, according to the model, corresponding to a sensitivity of $88 \%$. Of the 17 patients without actual MDE, 6 were at high risk of MDE, corresponding to a specificity of $65 \%$.

The overall disease load, reflected in the total tumour bearing tissue at pathology, around the GTV $\mathrm{GT}_{\mathrm{CT}}$ and $\mathrm{GTV}_{\mathrm{PET}}$ was larger in the subgroup of patients at high risk for MDE compared to the subgroup at low risk. This difference in overall disease load between patients at low and high risk of MDE is graphically illustrated in Figure 2.4. Especially differences in prevalence of microscopic tumour deposits close to the GTV at imaging were evident.

\section{Comparison of the GTV at PET and CT with the GTV and CTV at pathology}

The mean GTV $V_{\text {path }}$ was $17.5 \mathrm{~cm}^{3}$ (range: $0.5 \mathrm{~cm}^{3}-81.9 \mathrm{~cm}^{3}$ ). Overall, the effective diameter of the GTV $_{C T}$ overestimated that of the $\mathrm{GTV}_{\text {path }}$ by $6.6 \mathrm{~mm}(\mathrm{p}<0.001)$. The effective diameter of the $\mathrm{GTV}_{\mathrm{PET}}$ was $0.4 \mathrm{~mm}$ larger than that of the $\mathrm{GTV}_{\text {path }}$, which was not statistically significant $(p=0.63)$ (Figure 2.5$)$. Conversely, the effective diameter of the CTV path (deformations included) was underestimated by CT with 13.4 $\mathrm{mm}$ on average, while the PET showed an even larger underestimation of $20.1 \mathrm{~mm}$. Both underestimations were significant $(p=0.008$ and $p=0.0003$, respectively) (Figure 2.6).

Stratified according to MDE at pathology, the CTV $\mathrm{Cath}_{\text {was }}$ wanderestimated more on $C T$ and on PET in the MDE+ subgroup than in the MDE- group (Table 2.3A). The underestimation on $C T$ and PET was significant in the MDE+ group $(p<0.001)$, but not in the MDE- group. Stratification according to the risk of MDE according to the logistic model, demonstrated comparable results (Table 2.3B); both CT and PET underestimated the $\mathrm{CTV}_{\text {path }}$ in the subgroup at high risk for MDE ( $p=0.009$ and $\mathrm{p}=0.001$ for $\mathrm{CT}$ and $\mathrm{PET}$, respectively), but the underestimations were not significant in the subgroup at low risk. 


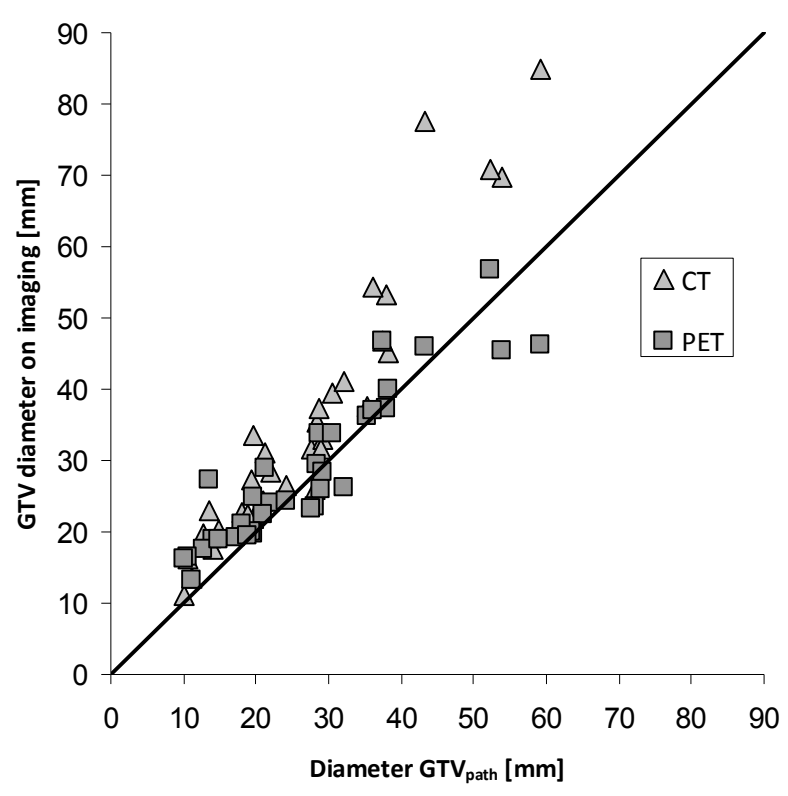

Figure 2.5 Comparison of the effective diameter of the GTV $\mathrm{CT}_{\mathrm{CT}}$ and the GTV $\mathrm{PET}_{\mathrm{PT}}$ with that of the $\mathrm{GTV}_{\text {path }}$ Correlation coefficients: GTV $\mathrm{CT}_{\mathrm{T}}-\mathrm{GTV}_{\text {path }}: 0.95$; GTV $\mathrm{PET}_{\mathrm{PE}}-\mathrm{GTV}_{\text {path }}: 0.91$

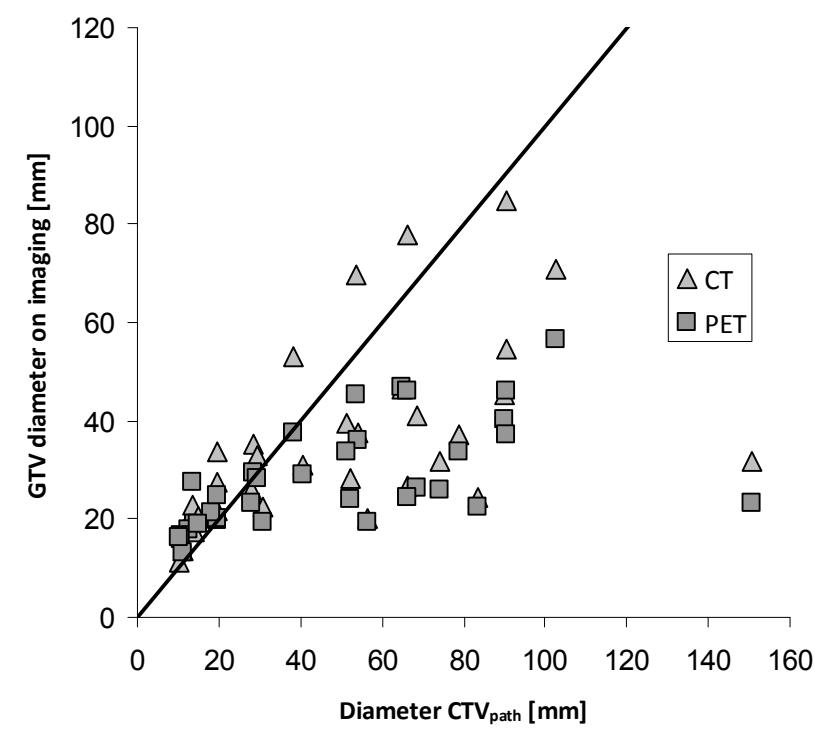

Figure 2.6 Comparison of the effective diameter of the $\mathrm{GTV}_{\mathrm{CT}}$ and the $\mathrm{GTV}_{\mathrm{PET}}$ with that of the $\mathrm{CTV}_{\text {path }}$ Correlation coefficients: $\mathrm{GTV}_{\mathrm{CT}}-\mathrm{GTV}_{\text {path }}: 0.55$; $\mathrm{GTV}_{\mathrm{PET}}-\mathrm{GTV}_{\text {path }}: 0.55$ 


\begin{tabular}{|c|c|c|c|c|c|}
\hline \multicolumn{6}{|c|}{ A) Comparison according to the presence of MDE found at pathology } \\
\hline $\mathrm{CT}^{*}$ & $\begin{array}{c}\text { Mean } \pm \text { SD } \\
(\mathrm{mm})\end{array}$ & p-value & $\mathrm{PET}^{* *}$ & $\begin{array}{c}\text { Mean } \pm \text { SD } \\
(\mathrm{mm})\end{array}$ & p-value \\
\hline Overall & $-13.4 \pm 27.9$ & 0.008 & Overall & $-20.1 \pm 29.0$ & 0.0003 \\
\hline $\mathrm{MDE}+$ & $-30.6 \pm 28.8$ & 0.0005 & $\mathrm{MDE}+$ & $-39.9 \pm 27.5$ & 0.00002 \\
\hline MDE- & $3.7 \pm 39.5$ & 0.229 & MDE- & $-0.3 \pm 11.7$ & 0.92 \\
\hline \multicolumn{6}{|c|}{ B) Comparison according to the risk of MDE according to the prediction model } \\
\hline $\mathrm{CT}^{*}$ & $\begin{array}{c}\text { Mean } \pm \text { SD } \\
(\mathrm{mm})\end{array}$ & $p$-value & $\mathrm{PET}^{* *}$ & $\begin{array}{c}\text { Mean } \pm \text { SD } \\
(\mathrm{mm})\end{array}$ & $p$-value \\
\hline $\mathrm{MDE}+$ & $-19.2 \pm 30.6$ & 0.009 & $\mathrm{MDE}+$ & $-26.7 \pm 31.1$ & 0.001 \\
\hline MDE- & $-4.1 \pm 20.6$ & 0.482 & MDE- & $-9.4 \pm 22.3$ & 0.154 \\
\hline
\end{tabular}

\subsection{Discussion}

To ensure that all tumour bearing tissue is covered by the radiotherapy fields, an accurate knowledge of both the gross tumour volume (GTV) and the microscopic extension of tumour beyond the visible border on imaging (the margin to be included in the clinical target volume (CTV)) is essential. Accurate distinction between the location of macroscopic tumour and microscopic disease is of value as tumour control probability calculations suggest that the dose required to eradicate microscopic disease (thus, the dose in the CTV margin) is lower than the dose for macroscopic tumour ${ }^{25,26}$.

In the current study, MDE was found in $50 \%$ (95\% Cl: $34-66 \%)$ of patients. Mean tumour density on $\mathrm{CT}\left(\mathrm{CT}_{\text {mean }}\right)$ and tumour volume on $\mathrm{CT}\left(\mathrm{GTV}_{\mathrm{CT}}\right)$ were found to be significant factors at multivariate analysis associated with the presence of MDE. The prediction model on basis of those two parameters had an area under the curve of 0.86. This model may be used to identify patients with higher overall incidence of disease at all distances around the GTV visible on imaging. These findings are encouraging as they could ultimately allow to adapt dose painting across the CTV margin according to subgroups of patients ${ }^{27}$, thus optimizing local control while limiting toxicity in patients who are at low risk of microscopic disease extension. Therefore, validation of the prediction model in a larger patient population is strongly encouraged.

MDE showed an isotropic distribution around the GTV $\mathrm{V}_{\text {path. }}$ This finding suggests that uniform CTV margins may be appropriate. It also supports the use of our CTV path definition, being the GTV with a circumferential margin equal to the maximum ob- 
served MDE. In this study, no MDE was found in cranial and caudal directions. This finding is most probably due to the incomplete histological sampling in these directions compared to the other directions. All pulmonary tissue ventrodorsal and mediolateral of the tumour was available for microscopic examination. In the craniocaudal directions, histological information was only available from slices taken at 5 $\mathrm{mm}$ distance from each other. In this way, microscopic tumour deposits present in between two slices will have been missed.

\section{Literature comparison}

The current study shows that the GTV delineated on the PET scan using a fixed threshold $\left(42 \%\right.$ of SUV $\left._{\max }{ }^{20,21}\right)$ is better correlated with the $\mathrm{GTV}_{\text {path }}$ than the manually delineated $\mathrm{GTV}_{\text {ст. }}$. The latter overestimated the diameter of the $\mathrm{GTV}_{\text {path }}$ with 6.6 $\mathrm{mm}$ on average. Few reports of other groups are available comparing both PET and CT with pathology: With respect to $\mathrm{CT}$, Grills et al. found an overestimation of the GTV $_{\text {path }}$ by CT of $5.8 \mathrm{~mm}^{16}$, which is comparable to our study. Others, however, found a close approximation ${ }^{15,17,29}$. Yu et al. reported a benefit of PET based delineation over CT mainly in patients with atelectasis ${ }^{28}$. As the resolution of both imaging techniques is not sufficient to visualize microscopic disease, it may not be surprising that both the PET- and CT-based GTV underestimated disease extension when MDE is taken into account. In this study, we show however, that the overestimation of the GTV at CT and PET does not make up for the lack of coverage of microscopic disease. In patients without MDE, all tumour bearing tissue was covered by the CT- and PET-based GTV.

The margin of $26 \mathrm{~mm}$ found to cover MDE in $90 \%$ of patients is much larger than what is expected on basis of the literature. The extent of MDE found previously in studies correlating imaging with findings at pathology range from 0 to $12 \mathrm{~mm}^{14-16 \text {, }}$ 30. It would appear, however, that the microscopic examination of the pathology specimen in the present study was more extensive than the methods applied in previous investigations. Secondly, deformation of the lung tissue between in-vivo and ex-vivo was not taken into account in these studies. Grills et al. concluded that a $9 \mathrm{~mm}$ CTV margin added to the CT-based GTV should cover MDE in $90 \%$ of cases. Taking into account that CT tends to overestimate the GTV $\mathrm{Vath}_{\text {by }} 7 \mathrm{~mm}$ on average, our results suggest that a CTV margin of $16 \mathrm{~mm}$ may still be required to cover $90 \%$ of MDE.

Nonetheless, the application of large CTV margins would inevitably lead to a considerable increase in normal tissue exposure. Tumour control probability models, however, indicate that only $70-80 \%$ of the prescription dose to control the macroscopic tumour may be needed to eradicate microscopic disease ${ }^{25,26}$. This suggests that MDE outside the macroscopic tumour would be largely covered by the beam penumbra of conventional RT fields. New RT technologies, however, are associated 
with altered penumbra characteristics. Grills et al. investigated to what extent MDE would be covered with the use of SBRT ${ }^{16}$. Depending on the technique used, $\leq 6-8.5$ $\mathrm{mm}$ of MDE would be automatically covered by the $80 \%$ isodose line (dose considered by the authors to be adequate to control microscopic disease). This confirms that with the use of more conformal techniques, inadequate CTV margins increase the risk of underdosage to tumour-bearing tissue. Our results suggest that this risk is higher in patients stratified to the MDE-positive group by the prediction model than in patients stratified to the MDE-negative group.

\section{Prediction model}

Although the prediction model has a relatively high sensitivity, the specificity is lower (67\%), indicating that only 2 out of 3 patients without MDE are correctly identified as low risk patients. Nonetheless, the model shows distinct differences in disease load around the GTV $\mathrm{FET}_{\mathrm{P}}$ and $\mathrm{GTV}_{\mathrm{CT}}$ between the two groups, indicating that pre-treatment imaging features have the potential to discriminate between the presence and absence of microscopic extension. Validation of the prediction model in an independent patient cohort is required in order to become a valuable tool in clinical practice.

An explanation as to why higher CT density in the tumour is associated with a larger risk for microscopic disease extension is still pending. Theoretically, higher CT density could be caused by a higher tumour cell density, a higher fraction of necrosis and/or a lower fraction of stroma, but these hypotheses are currently unproven and subject of further research. Although MDE was present more frequently in squamous cell carcinoma than in adenocarcinoma $(p=0.18)$, the histological subtype was not significantly associated with MDE in univariate and multivariate analysis. $\mathrm{GTV}_{\mathrm{PET}}$ did not retain significance in multivariate analysis, likely due to its correlation with $\mathrm{GTV}_{\mathrm{CT}}$.

\section{Study limitations}

The methods used in the current study for the correlation of imaging with pathology have some limitations. Firstly, during PET scanning, no system was used to account for respiratory movements of the tumour. Therefore, the exact anatomical localization of the tumour is subject to some uncertainty. The role of PET as a predictor for the presence of MDE may have been underestimated for this reason. New technology, such as 4D-PET-CT scanners may further increase the accuracy of the correlation of the imaging characteristics with pathology. A second limitation is that potential differences in shape of the GTV at imaging and at pathology have not been taken into account. A third limitation originates from the inaccuracy at pathology to accurately achieve uniform slice thickness of $5 \mathrm{~mm}$. It is theoretically possible that 
thinner slicing at pathology would result in a higher detection rate of microscopic tumour deposits, but this was technically not feasible.

\subsection{Conclusion}

Multivariate analysis of tumour, patient and PET and CT characteristics shows that CT characteristics of NSCLC have the potential to predict the presence of microscopic disease extension (MDE) around the GTV at pathology. Patients at low risk of MDE show smaller rates of disease at all distances around the GTV than patients at high risk. Both CT and PET accurately visualize the $C \mathrm{VV}_{\text {path }}$ in patients at low risk of $\mathrm{MDE}$, but significantly underestimate the $\mathrm{CTV}_{\text {path }}$ in high risk patients.

\section{Acknowledgements}

We would like to thank J. Belderbos, W. Koops and H. Bartelink for their clinical contribution and L. van Garsse and G. Geskes for their help with patient inclusion. This project was supported by a grant of the Dutch Cancer Society (Project UM 2006-3514). 


\subsection{References}

1. Fournel $\mathrm{P}$, Robinet $\mathrm{G}$, Thomas $\mathrm{P}$, et al. Randomized phase III trial of sequential chemoradiotherapy compared with concurrent chemoradiotherapy in locally advanced non-small-cell lung cancer: Groupe Lyon-Saint-Etienne d'Oncologie Thoracique-Groupe Francais de Pneumo-Cancerologie NPC 95-01 Study. J Clin Oncol 2005;23:5910-7.

2. Furuse K, Fukuoka M, Kawahara M, et al. Phase III study of concurrent versus sequential thoracic radiotherapy in combination with mitomycin, vindesine, and cisplatin in unresectable stage III nonsmall-cell lung cancer. J Clin Oncol 1999;17:2692-9.

3. Zatloukal P, Petruzelka L, Zemanova $M$, et al. Concurrent versus sequential chemoradiotherapy with cisplatin and vinorelbine in locally advanced non-small cell lung cancer: a randomized study. Lung Cancer 2004;46:87-98.

4. Belderbos J, Heemsbergen W, Hoogeman M, Pengel K, Rossi M, Lebesque J. Acute esophageal toxicity in non-small cell lung cancer patients after high dose conformal radiotherapy. Radiother Oncol 2005;75:157-64.

5. Rowell NP, O'Rourke N P. Concurrent chemoradiotherapy in non-small cell lung cancer. Cochrane Database Syst Rev 2004:CD002140.

6. Belderbos JS, Heemsbergen WD, De Jaeger K, Baas P, Lebesque JV. Final results of a Phase I/II dose escalation trial in non-small-cell lung cancer using three-dimensional conformal radiotherapy. Int J Radiat Oncol Biol Phys 2006;66:126-34.

7. Grills IS, Yan D, Martinez AA, Vicini FA, Wong JW, Kestin LL. Potential for reduced toxicity and dose escalation in the treatment of inoperable non-small-cell lung cancer: a comparison of intensitymodulated radiation therapy (IMRT), 3D conformal radiation, and elective nodal irradiation. Int J Radiat Oncol Biol Phys 2003;57:875-90.

8. van Der Wel A, Nijsten S, Hochstenbag M, et al. Increased therapeutic ratio by 18FDG-PET CT planning in patients with clinical CT stage N2-N3M0 non-small-cell lung cancer: a modeling study. Int J Radiat Oncol Biol Phys 2005;61:649-55.

9. Wulf J, Haedinger U, Oppitz U, Thiele W, Mueller G, Flentje M. Stereotactic radiotherapy for primary lung cancer and pulmonary metastases: a noninvasive treatment approach in medically inoperable patients. Int J Radiat Oncol Biol Phys 2004;60:186-96.

10. Greco C, Rosenzweig K, Cascini GL, Tamburrini O. Current status of PET/CT for tumour volume definition in radiotherapy treatment planning for non-small cell lung cancer (NSCLC). Lung Cancer 2007; 57:125-34.

11. Senan S, De Ruysscher D, Giraud P, Mirimanoff R, Budach V. Literature-based recommendations for treatment planning and execution in high-dose radiotherapy for lung cancer. Radiother Oncol 2004;71:139-46.

12. Steenbakkers RJ, Duppen JC, Fitton I, et al. Observer variation in target volume delineation of lung cancer related to radiation oncologist-computer interaction: a 'Big Brother' evaluation. Radiother Oncol 2005;77:182-90.

13. ICoRUa. International Commission on Radiation Units and Measurements. ICRU Report 62: Prescribing, recording, and reporting photon beam therapy (Supplement to ICRU Report 50). Bethesda; 1999.

14. Chan R, He Y, Haque A, Zwischenberger J. Computed tomographic-pathologic correlation of gross tumor volume and clinical target volume in non-small cell lung cancer: a pilot experience. Arch Pathol Lab Med 2001;125:1469-72.

15. Giraud $P$, Antoine $M$, Larrouy $A$, et al. Evaluation of microscopic tumor extension in non-small-cell lung cancer for three-dimensional conformal radiotherapy planning. Int J Radiat Oncol Biol Phys 2000;48:1015-24.

16. Grills IS, Fitch DL, Goldstein NS, et al. Clinicopathologic analysis of microscopic extension in lung adenocarcinoma: defining clinical target volume for radiotherapy. Int J Radiat Oncol Biol Phys 2007;69:334-41. 
17. Li WL, Yu JM, Liu GH, Zhong WX, Li WW, Zhang BJ. [A comparative study on radiology and pathology target volume in non-small-cell lung cancer]. Zhonghua Zhong Liu Za Zhi 2003;25:566-8.

18. Stroom J, Blaauwgeers $H$, van Baardwijk $A$, et al. Feasibility of pathology-correlated lung imaging for accurate target definition of lung tumors. Int J Radiat Oncol Biol Phys 2007;69:267-75.

19. Siedschlag C, van Loon J, van Baardwijk A, et al. Analysis of the relative deformation of lung lobes before and after surgery in patients with NSCLC. Phys Med Biol 2009;54:5483-92.

20. Black QC, Grills IS, Kestin LL, et al. Defining a radiotherapy target with positron emission tomography. Int J Radiat Oncol Biol Phys 2004;60:1272-82.

21. Erdi YE, Mawlawi O, Larson SM, et al. Segmentation of lung lesion volume by adaptive positron emission tomography image thresholding. Cancer 1997;80:2505-9.

22. Boellaard R, Oyen WJ, Hoekstra CJ, et al. The Netherlands protocol for standardisation and quantification of FDG whole body PET studies in multi-centre trials. Eur J Nucl Med Mol Imaging 2008;35:2320-33.

23. Ollers $M$, Bosmans $G$, van Baardwijk $A$, et al. The integration of PET-CT scans from different hospitals into radiotherapy treatment planning. Radiother Oncol 2008;87:142-6.

24. Gilhuijs KG, Giger ML, Bick U. Computerized analysis of breast lesions in three dimensions using dynamic magnetic-resonance imaging. Med Phys 1998;25:1647-54.

25. Goitein M, Schultheiss TE. Strategies for treating possible tumor extension: some theoretical considerations. Int J Radiat Oncol Biol Phys 1985;11:1519-28.

26. Webb S, Nahum AE. A model for calculating tumour control probability in radiotherapy including the effects of inhomogeneous distributions of dose and clonogenic cell density. Phys Med Biol 1993;38:653-66.

27. Ling CC, Humm J, Larson S, et al. Towards multidimensional radiotherapy (MD-CRT): biological imaging and biological conformality. Int J Radiat Oncol Biol Phys 2000;47:551-60.

28. Yu HM, Liu YF, Hou M, Liu J, Li XN, Yu JM. Evaluation of gross tumor size using CT, (18)F-FDG PET, integrated (18)F-FDG PET/CT and pathological analysis in non-small cell lung cancer. Eur J Radiol 2008.

29. van Baardwijk A, Bosmans G, Boersma L, et al. PET-CT-based auto-contouring in non-small-cell lung cancer correlates with pathology and reduces interobserver variability in the delineation of the primary tumor and involved nodal volumes. Int J Radiat Oncol Biol Phys 2007;68:771-8.

30. Goldstein NS, Ferkowicz M, Kestin L, Chmielewski GW, Welsh RJ. Wedge resection margin distances and residual adenocarcinoma in lobectomy specimens. Am J Clin Pathol 2003;120:720-4. 

CHAPTER 3

${ }^{18}$ FDG-PET based radiation planning of mediastinal lymph nodes in limited disease small cell lung cancer changes radiotherapy fields: a planning study

Judith van Loon Claudia Offermann

Geert Bosmans

Rinus Wanders

André Dekker Jacques Borger Michel Öllers Anne-Marie Dingemans Angela van Baardwijk Jaap Teule Gabriel Snoep Monique Hochstenbag Ruud Houben Philippe Lambin Dirk De Ruysscher 


\section{Abstract}

\section{Background and purpose}

To investigate the influence of selective irradiation of ${ }^{18}$ FDG-PET positive mediastinal nodes on radiation fields and normal tissue exposure in limited disease small cell lung cancer (LD-SCLC).

\section{Methods and materials}

Twenty-one patients with LD-SCLC, of whom both CT and PET images were available, were studied. For each patient, two three-dimensional conformal treatment plans were made with selective irradiation of involved lymph nodes, based on CT and on PET, respectively. Changes in treatment plans as well as dosimetric factors associated with lung and esophageal toxicity were analyzed and compared.

\section{Results}

FDG-PET information changed the treatment field in 5 patients (24\%). In 3 patients this was due to a decrease and in 2 patients to an increase in the number of involved nodal areas. However, there were no significant differences in gross tumour volume (GTV), lung, and esophageal parameters between CT- and PET-based plans.

\section{Conclusions}

Incorporating FDG-PET information in radiotherapy planning for patients with LDSCLC changed the treatment plan in $24 \%$ of patients compared to CT. Both increases and decreases of the GTV were observed, theoretically leading to the avoidance of geographical miss or a decrease of radiation exposure of normal tissues, respectively. Based on these findings, a phase II trial, evaluating PET-scan based selective nodal irradiation, is ongoing in our department. 


\subsection{Introduction}

Small cell lung cancer (SCLC) is a tumour with a poor prognosis, with only one-third of patients presenting with limited-disease (LD-SCLC) ${ }^{1,2}$. In LD-SCLC, long-term survival has improved with chemo-radiation and this is, therefore, currently the first choice treatment. This is at the expense, however, of severe reversible esophagitis and lung damage ${ }^{3-6}$. Moreover, over $30 \%$ of patients still fail locally with this treatment ${ }^{7}$. Therefore, in the subgroup of patients with limited disease, strategies to reduce toxicity and increase local tumour control would be of great clinical value. $A$ straightforward strategy to reduce toxicity is to diminish the radiation fields, which could be done by omitting routine elective nodal irradiation. In case of non-small cell lung cancer (NSCLC) elective nodal irradiation is no longer recommended ${ }^{8}$. In NSCLC, radiation fields could be safely reduced by selective nodal irradiation, based on $\mathrm{CT}$, and even further based on FDG-PET $\left({ }^{18} \mathrm{~F}\right.$-fluorodeoxyglucose-Positron Emission Tomography) scans ${ }^{9-12}$. Treating only FDG-positive mediastinal areas decreased radiation exposure of the lungs and the esophagus sufficiently as to allow for radiation dose-escalation in NSCLC ${ }^{13,14}$. However, contrary to NSCLC, in a phase II study in LD-SCLC, we observed isolated nodal failures outside of the clinical target volume (CTV) in $11 \%$ of cases with selective nodal irradiation, based on $\mathrm{CT}^{15}$. This finding illustrates that the positive results obtained for selective mediastinal node irradiation in NSCLC cannot straightforwardly imply the same results in SCLC patients. To our knowledge, no clinical data are available on PET-based selective mediastinal irradiation in SCLC.

The available literature suggests that FDG-PET scan has diagnostic value in SCLC ${ }^{16-22}$.

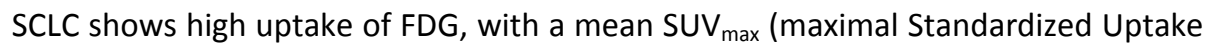
Value) for primary and mediastinal nodal lesions similar to that seen in NSCLC ${ }^{16}$. In the largest reported series of 120 patients with SCLC, FDG-PET resulted in a stage migration for 14 patients, upstaging 10 patients to extensive disease and downstaging 3 patients ${ }^{20}$. In a retrospective analysis of 46 patients with SCLC, Pandit et al. described a $100 \%$ sensitivity of PET for detection of disease, based on pathologic correlation ${ }^{21}$. It has been suggested that an FDG-PET scan can identify metastases to regional lymph nodes in $15-25 \%$ of patients whose mediastinal CT scan was negative ${ }^{16,22}$. It is therefore likely that, as in NSCLC, the use of FDG-PET scans will improve the coverage of the mediastinal lymph node areas in LD-SCLC, hence resulting in less geographical miss and improved local tumour control.

As FDG-PET scans may thus be more accurate than CT to stage the mediastinum, we investigated the possible role of FDG-PET scanning in the radiotherapy planning of patients with LD-SCLC. We hypothesized that (1) there would be changes in the radiotherapy fields using FDG-PET scanning compared to $\mathrm{CT}$, theoretically resulting 
in less geographical miss and (2) there would be differences in the radiation exposure of dose limiting normal tissues such as lungs, esophagus and spinal cord, when radiation treatment planning is performed based on FDG-PET compared to CT. We compared the radiation treatment planning of involved mediastinal lymph node areas based on FDG-PET and on CT for 21 consecutive patients with LD-SCLC. Radiotherapy was planned to the standard total radiation dose of $45 \mathrm{~Gy}$ delivered in 30 fractions in 3 weeks (1.5 Gy BID) either based on FDG-PET or on CT scan. DVH (dose volume histogram) parameters of the lung, the esophagus, the heart and the spinal cord were compared.

\subsection{Methods and Materials}

\section{Patients}

Patients diagnosed with LD-SCLC and referred for radical radiotherapy to MAASTRO clinic between January 1, 2004 and October 1, 2006 were reviewed retrospectively. Twenty-one patients, of whom either both a pre-treatment FDG-PET and a contrastenhanced CT scan, or a combined FDG-PET-CT scan (with contrast-enhancement) was available, were eligible for this planning study.

\section{Staging}

All patients underwent bronchoscopy with biopsy, standard haematological and biochemical workup, CT of the thorax and upper abdomen, including liver and adrenal glands, and a whole body FDG-PET scan. CT or MRI of the brain was performed as part of the routine workup for all patients.

\section{Imaging with CT and PET}

For CT-based planning, a contrast-enhanced CT scan of the thorax performed for radiotherapy planning was used. For PET-based planning, a combined PET-CT scan was performed either in the diagnostic process alone or both in the diagnostic process and for radiotherapy simulation. In both cases, the PET-CT scan was made in radiotherapy position. Patients had to be fasting for at least 6 hours before the examination. The injected total activity of FDG was calculated based on the weight of the patient: (weight* $4+20$ ) MBq. After a rest period of 60 minutes (time needed for uptake of FDG) PET and CT images were acquired. A CT-scan of the whole thorax was performed with intravenous contrast. 
The CT-findings were interpreted by an experienced chest radiologist. Lymph nodes were considered to be pathological on CT when their axial diameter exceeded $1 \mathrm{~cm}$. FDG-PET scans were visually interpreted by an experienced PET scan specialist.

The involved lymph node stations were recorded according to the Mountain and Dresler classification scheme ${ }^{23}$, both on the basis of the CT and FDG-PET scan, by the diagnostic radiologist and the nuclear medicine specialist, respectively.

\section{Radiation treatment planning and dosimetry}

Radiotherapy planning was performed with a XiO (Computerized Medical Systems (CMS) Inc.) treatment planning system, using inhomogeneity corrections based on a convolution algorithm. For all patients, a Gross Tumour Volume (GTV) and a Planning Target Volume (PTV) were defined based on CT data and PET data, respectively, for the CT- and PET-CT based plans. This was carried out in two separate sessions by the same person (JVL), in order to avoid intra-observer variability. For the primary tumour, the GTV was delineated based on CT only using the lung window settings ( $W=1700, L=-300)$. We deliberately avoided contouring on the basis of ill-defined areas on PET scan. Instead, the sharp boundaries of the CT scan images were used. These procedures aimed at minimizing the problems of tumour size determination on PET scans in general and of a moving part of the body in particular, as no respiratory gating was used. For delineation of the lymph nodes on CT, mediastinal window setting $(W=600, L=40)$ was used. The involved anatomical region as described by the radiologist or nuclear medicine specialist in the original diagnostic report (i.e. before the start of chemotherapy) was delineated ${ }^{24}$. With respect to the pathological lymph nodes on PET, the involved zones were delineated based on the anatomical information of the CT scan. In this way, the whole pathological anatomical region of the mediastinum (e.g. area 7) was taken as GTV for that lymph node station. No SUV-threshold was used, as a visual scale has been shown to be at least as accurate as the use of a SUV-threshold to distinguish benign from malignant nodes ${ }^{25,26}$. CT and PET images were automatically registered based on Mutual Information and were subsequently fused using Focal (CMS Inc.). If the PET scan was negative in the mediastinum and the CT scan positive, the mediastinum was considered not to harbour cancer cells, and was hence not included in the PETCT based GTV. The margin from the GTV to the CTV (Clinical Target Volume) was 5 $\mathrm{mm}$, and from the CTV to the PTV also $5 \mathrm{~mm}$, both for CT- and for PET- based treatment planning. No assessments of tumour movement, for example by slow CT scans, were performed. No elective nodal irradiation was planned.

Contouring of the lung was done automatically by the treatment planning system. For the calculation of the $V_{\text {lung20 }}$ (Percentage of lung receiving more than $20 \mathrm{~Gy}$ ), we followed the published guidelines namely: the volume of both lungs reduced by the PTV was used, whereas for the mean lung dose (MLD), the volume of both lungs 
minus the GTV was considered ${ }^{8}$. The esophagus was delineated from just below the larynx to the gastro-esophageal junction. Neither the GTV nor the PTV was subtracted from this volume ${ }^{8}$. The spinal cord was drawn throughout the whole CT scan and was considered to be at the inner margin of the bony spinal canal.

The heart was contoured from its caudal part at the apex until its cranial level at the beginning of the large vessels. The latter were not included in the contour of the heart. The pericardium was a part of the contour of the heart.

A 3-dimensional conformal treatment plan was calculated on the CT-based PTV and the PET-CT-based PTV for all patients, with a prescribed dose of $45 \mathrm{~Gy}$ in 30 fractions delivered in 3 weeks (1.5 Gy BID) to the PTV, according to ICRU 50 guidelines ${ }^{27}$. Dosimetric values were calculated on the basis of DVH's and dose distributions on each axial CT plane both for CT and PET-CT based planning.

For the tumour and pathological lymph nodes, factors analyzed were GTV and PTV volume. Because no consistent DVH parameters are known to predict early and late esophageal toxicity, the $V_{\text {eso30 }}$, the $V_{\text {eso35 }}$, the $V_{\text {eso40 }}$, the $V_{\text {eso45 }}$, the $V_{\text {eso50 }}$, the maximal esophageal dose $\left(D_{\max }\right)$ and the mean esophageal dose (MED) were analyzed ${ }^{8,}$ ${ }^{28,29}$. For the lung, the $\mathrm{V}_{\text {lung } 20}$ and the MLD were analyzed as predictors for radiation pneumonitis ${ }^{8}$. The maximal dose to the spinal cord was recorded, although it was not expected that in either the CT-based or in the PET-CT based plan the tolerance of the spinal cord ( $50 \mathrm{~Gy}$ ) would be exceeded. The mean dose to the heart ( $D_{\text {heart- }}$ mean $)$, as well as the maximal dose $\left(D_{\text {heartmax }}\right)$, the $V_{\text {heart } 30}$, the $V_{\text {heart 35, }}$, the $V_{\text {heart } 40 \text {, the }}$ $V_{\text {heart } 45}$, and the $V_{\text {heart }} 50$ was recorded.

\section{Ethics}

As this was a retrospective planning/modelling study, patients were diagnosed and treated previously according to standard guidelines in our institute. No approval of the Ethical Committee was required.

\section{Statistics}

On the basis of literature at the start of the project, we hypothesized that introducing PET in radiotherapy planning would change the treatment fields in $25 \%$ of the patients ${ }^{16}$. In order to detect this change with a $95 \%$ confidence interval of $5-45 \%$, at least 19 patients should be included in this study ${ }^{30}$.

Results are either expressed as mean \pm standard deviation (SD) or as a proportion with $95 \%$ confidence intervals $(95 \% \mathrm{Cl})$. Statistical differences between paired parameters from CT versus PET-CT based plans were evaluated with the Wilcoxon signed rank test. Differences were considered to be significant when the two-tailed p-value was less than 0.05 . 


\subsection{Results}

\section{Patient characteristics and FDG-PET and CT correlations}

All 21 patients had LD-SCLC, as defined by PET-CT for the detection of distant metastasis. Two patients had stage N0, while 14 patients had the same nodal areas involved on both PET and CT. Five patients had mediastinal nodal involvement on both PET and CT, but in different nodal areas (Table 3.1).

\begin{tabular}{|c|c|c|c|c|}
\hline \multirow[t]{3}{*}{ Pt. No. } & No. of involved & Primary tumour & \multicolumn{2}{|c|}{ Involved lymph node station } \\
\hline & & & PET-scan & $C T$-scan \\
\hline & $P E T<C T$ & & & \\
\hline 2 & & Right upper lobe & $2 \mathrm{~L}, 3 \mathrm{~L}, 4 \mathrm{~L}, 2 \mathrm{R}, 3 \mathrm{R}, 4 \mathrm{R}$ & $\begin{array}{c}2 \mathrm{~L}, 3 \mathrm{~L}, 4 \mathrm{~L}, 2 \mathrm{R}, 3 \mathrm{R}, 4 \mathrm{R} \\
10 \mathrm{R}, 5,7\end{array}$ \\
\hline 12 & & Left hilus & $4 \mathrm{~L}, 10 \mathrm{~L}, 5,7$ & $4 \mathrm{~L}, 10 \mathrm{~L}, 4 \mathrm{R}, 5,7$ \\
\hline \multirow[t]{2}{*}{17} & & Left hilus & $10 \mathrm{~L}, 7$ & $4 \mathrm{~L}, 10 \mathrm{~L}, 7$ \\
\hline & $P E T>C T$ & & & \\
\hline 6 & & Right upper lobe & $2 \mathrm{R}, 4 \mathrm{R}, 10 \mathrm{R}, 5,7$ & $2 \mathrm{R}, 4 \mathrm{R}, 10 \mathrm{R}, 7$ \\
\hline \multirow[t]{2}{*}{7} & & Left upper lobe & $2 \mathrm{~L}, 4 \mathrm{~L}, 10 \mathrm{~L}, 5,7$ & $2 \mathrm{~L}, 4 \mathrm{~L}, 10 \mathrm{~L}, 5$ \\
\hline & $P E T=C T$ & & & \\
\hline 1 & & Right upper lobe & $4 \mathrm{~L}, 2 \mathrm{R}, 4 \mathrm{R}, 10 \mathrm{R}, 7$ & $4 \mathrm{~L}, 2 \mathrm{R}, 4 \mathrm{R}, 10 \mathrm{R}, 7$ \\
\hline 3 & & Left lower lobe & None & None \\
\hline 4 & & Left upper lobe & $2 \mathrm{~L}, 4 \mathrm{~L}, 5,6$ & $2 \mathrm{~L}, 4 \mathrm{~L}, 5,6$ \\
\hline 5 & & Right upper lobe & $4 \mathrm{R}, 10 \mathrm{R}, 7$ & $4 \mathrm{R}, 10 \mathrm{R}, 7$ \\
\hline 8 & & Right hilus & $4 \mathrm{R}, 10 \mathrm{R}$ & $4 \mathrm{R}, 10 \mathrm{R}$ \\
\hline 9 & & Left upper lobe & None & None \\
\hline 10 & & Unknown & $4 \mathrm{~L}, 1 \mathrm{R}, 2 \mathrm{R}, 4 \mathrm{R}, 3,7$ & $4 \mathrm{~L}, 1 \mathrm{R}, 2 \mathrm{R}, 4 \mathrm{R}, 3,7$ \\
\hline 11 & & Right upper lobe & $4 \mathrm{~L}, 2 \mathrm{R}, 4 \mathrm{R}, 10 \mathrm{R}, 3,7$ & $4 \mathrm{~L}, 2 \mathrm{R}, 4 \mathrm{R}, 10 \mathrm{R}, 3,7$ \\
\hline 13 & & Lingula & 6 & 6 \\
\hline 14 & & Unknown & $2 \mathrm{R}, 4 \mathrm{R}, 10 \mathrm{R}, 5,7$ & $2 \mathrm{R}, 4 \mathrm{R}, 10 \mathrm{R}, 5,7$ \\
\hline 15 & & Right upper lobe & $4 \mathrm{R}, 10 \mathrm{R}, 7$ & $4 \mathrm{R}, 10 \mathrm{R}, 7$ \\
\hline 16 & & Right upper lobe & $10 R$ & $10 R$ \\
\hline 18 & & Left hilus & $4 \mathrm{~L}, 10 \mathrm{~L}, 5,6,7,8$ & $4 \mathrm{~L}, 10 \mathrm{~L}, 5,6,7,8$ \\
\hline 19 & & Right upper lobe & $2 \mathrm{~L}, 4 \mathrm{~L}, 7$ & $2 \mathrm{~L}, 4 \mathrm{~L}, 7$ \\
\hline 20 & & Left lower lobe & $10 \mathrm{~L}, 10 \mathrm{R}, 5,6,7$ & $10 \mathrm{~L}, 10 \mathrm{R}, 5,6,7$ \\
\hline 21 & & Left hilus & $2 \mathrm{~L}, 4 \mathrm{~L}, 10 \mathrm{~L}, 2 \mathrm{R}, 5,6,7$ & $2 \mathrm{~L}, 4 \mathrm{~L}, 10 \mathrm{~L}, 2 \mathrm{R}, 5,6,7$ \\
\hline
\end{tabular}

In three patients (14\%), there were less nodal stations involved on PET compared to $\mathrm{CT}$ : in the first patient, PET showed no involvement of the CT-involved stations 5, 7 and 10 ; in the second and third patient, there was no involvement of station $4 R$ 
(Figure 3.1) and $4 \mathrm{~L}$, respectively. In two patients (10\%), PET identified nodal stations that were negative on $\mathrm{CT}$ : station 5 and 7 , respectively.

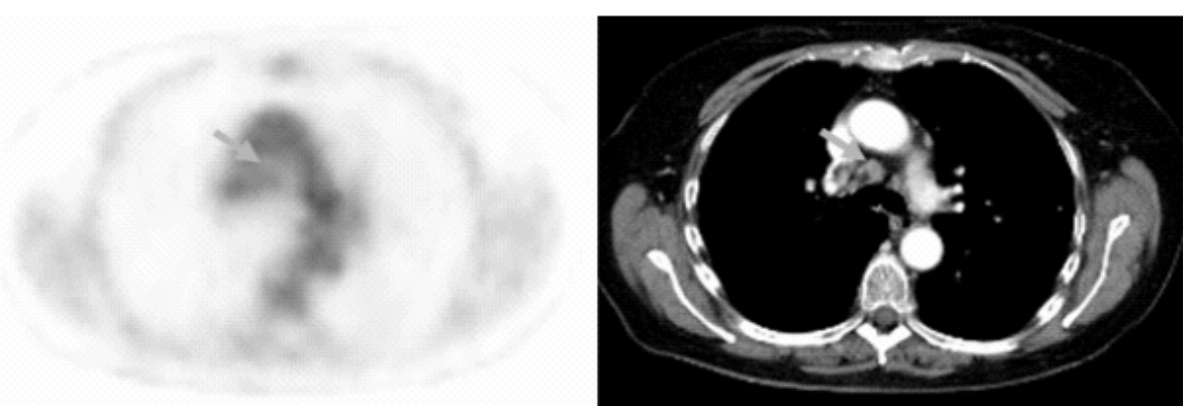

Figure 3.1 Image of a patient with different nodal involvement on CT and PET (patient 12) Station $4 \mathrm{R}$ is positive on $\mathrm{CT}$ and negative on PET

\section{Radiotherapy (RT) plans}

In 5 of 21 patients $(24 \%, 95 \% \mathrm{Cl}: 5-40 \%)$, there was a change in RT plans with the incorporation of the PET-data. For two patients (10\%), the radiation fields based on PET were larger than based on CT, while in $3 / 21$ (14\%) patients the CT-based radiation fields were larger.

\section{Nodal GTV}

Taken all 21 patients together, the nodal GTV was $57.9 \pm 67.0 \mathrm{~cm}^{3}$ on CT and $56.8 \pm$ $66.5 \mathrm{~cm}^{3}$ on PET $(p=0.92)$. For the three patients with a nodal GTV on PET that was smaller than on CT (Table 3.1), the nodal GTV was $81.0 \pm 50.9 \mathrm{~cm}^{3}$ on CT and $61.5 \pm$ $29.0 \mathrm{~cm}^{3}$ on PET. Two patients had a nodal GTV on PET that was larger than on CT. Their nodal GTV was $72.5 \pm 71.4 \mathrm{~cm}^{3}$ on CT and $81.0 \pm 76.4 \mathrm{~cm}^{3}$ on PET.

\section{Normal tissue radiation exposure}

An overview of the radiation exposure of normal tissues comparing CT- and PETbased plans is shown in Table 3.2. Incorporating the PET information in the radiation planning did not lead to a statistically significant change in any of the dosimetric factors analyzed.

For the three patients in whom the nodal GTV decreased with PET, the MED decreased from $25.0 \pm 8.5$ to $21.0 \pm 5.7 \mathrm{~Gy}$ and $D_{\max }$ from $46.2 \pm 0.2$ to $45.5 \pm 0.7 \mathrm{~Gy}$. The $\mathrm{V}_{20}$ decreased from $25.5 \pm 4.9 \%$ to $22.0 \pm 7.1 \%$; the MLD decreased from $13.2 \pm$ 2.5 to $11.6 \pm 3.3 \mathrm{~Gy}$. For the two patients in whom the nodal GTV was larger on PET, the MED increased from $23.0 \pm 5.7$ to $24.5 \pm 3.5 \mathrm{~Gy}$; $D_{\max }$ remained the same with a 
dose of $46.5 \pm 0.7 \mathrm{~Gy}$. The $\mathrm{V}_{20}$ increased from $16.0 \pm 2.8 \%$ to $20.0 \pm 1.4 \%$; the MLD increased from $9.9 \pm 1.6$ to $11.7 \pm 1.3 \mathrm{~Gy}$.

\begin{tabular}{|c|c|c|c|c|}
\hline Normal tissue & & $\begin{array}{c}\text { CT-based plan } \\
\text { ( } \pm \text { SD) }\end{array}$ & $\begin{array}{l}\text { PET-based plan } \\
\quad( \pm S D)\end{array}$ & p-value \\
\hline \multirow[t]{2}{*}{ Esophagus } & MED (Gy) & $24.4( \pm 8.6)$ & $24.1( \pm 8.5)$ & 0.50 \\
\hline & $D_{\max }(G y)$ & $45.8( \pm 2.9)$ & $45.7( \pm 2.9)$ & 0.32 \\
\hline \multirow[t]{2}{*}{ Lung } & $\mathrm{V}_{20}(\%)$ & $25.6( \pm 12.4)$ & $25.6( \pm 12.3)$ & 1.00 \\
\hline & MLD (Gy) & $13.7( \pm 5.6)$ & $13.7( \pm 5.6)$ & 0.89 \\
\hline \multirow[t]{2}{*}{ Heart } & $D_{\text {mean }}(G y)$ & $12.2( \pm 9.7)$ & $12.2( \pm 9.7)$ & 0.79 \\
\hline & $V_{30}(\%)$ & $19.7( \pm 19.1)$ & $19.5( \pm 19.2)$ & 0.46 \\
\hline Spinal cord & $D_{\max }(G y)$ & $41.0( \pm 5.1)$ & $40.9( \pm 5.1)$ & 0.27 \\
\hline
\end{tabular}

SD: standard deviation; PET: positron emission tomography; CT: computed tomography; MED: mean esophageal dose; $D_{\max }$ : maximal (esophageal, respective heart) dose; MLD: mean lung dose.; $D_{\text {mean }}$ : mean (heart) dose

\subsection{Discussion}

The treatment of choice for patients with LD-SCLC consists of concurrent chemoradiotherapy ${ }^{31}$, which is at the expense of dose-limiting toxicity, primarily of the esophagus and lung ${ }^{6,7}$. Moreover, there is still a considerable amount of local tumour failure ${ }^{7}$.

An obvious way of reducing radiation fields and hence toxicity is by omitting elective nodal irradiation of clinically uninvolved nodal stations. This selective nodal irradiation has been shown to be effective in NSCLC based on CT, and even further, based on FDG-PET, with an acceptable amount of isolated nodal failures ${ }^{9,11}$. In LD-SCLC however, we observed $11 \%$ of isolated nodal failures when only irradiating mediastinal nodal stations that were positive on $\mathrm{CT}^{15}$. Because literature suggests that like in NSCLC, FDG-PET has a greater accuracy than CT for staging mediastinal nodal areas in SCLC as well ${ }^{16-20}$, we hypothesized that there would be less geographical misses by using PET for radiation treatment planning. Furthermore, the differences in the nodal PTV could also change the radiation exposure of normal tissues. Therefore, we retrospectively planned the radiation treatment for 21 consecutive patients with LD-SCLC using CT with and without PET information.

The incorporation of FDG-PET data into RT planning led to a change in the radiation fields in $24 \%$ of patients. This is in line with previous studies on FDG-PET in the staging of SCLC ${ }^{16,32}$, showing a difference in positive nodal areas between PET and CT in $25 \%$ and $21 \%$ of patients, respectively. In the present study, both increases $(2 / 21)$ and decreases $(3 / 21)$ in radiation fields were observed. Assuming that like in NSCLC, 
PET is more accurate than CT in identifying pathologic lymph nodes in SCLC ${ }^{16-20}$, the increase in radiation fields on the basis of PET could theoretically lead to the avoidance of geographical misses. In $10 \%$ of patients, PET-based radiotherapy planning increased the radiation fields. In those patients, irradiation based on CT could theoretically result in a geographic miss. This percentage is about the same as the amount of geographical misses we found with selective nodal irradiation based on CT only $(11 \%)^{15}$. Theoretically, the decrease of the GTV in some patients could lead to a decreased radiation exposure of lung and esophagus and hence less toxicity ${ }^{28,}$ 33. However, taken all patients together, no significant changes in the GTV or in the radiation exposure of the normal organs (esophagus, lungs, heart and spinal cord) were observed. This is in contrast to the incorporation of FDG-PET in radiotherapy planning of NSCLC, where generally reductions of the radiation fields were observed 11-14.

The present study has some limitations. First, no pathologic verification of the lymph nodes was obtained. However, as FDG-PET scans are likely to be more accurate than $\mathrm{CT}$ to detect mediastinal nodal involvement in $\mathrm{SCLC}^{16,20-22}$, we believe that our results support the need to investigate in clinical studies the role of FDG-PET scans in radiotherapy planning of LD-SCLC. Second, no system was used to take into account respiratory movements. We therefore cannot rule out the possibility that the exact anatomical localisation of the mediastinal lymph nodes may have been blurred. However, motion artefacts are less of a problem in the mediastinum compared to the primary lung tumour ${ }^{34}$. In any case, new technology, such as combined 4D-PET-CT scanners may further increase the usefulness of integrating PET scan data into PET-CT simulation ${ }^{35,36}$. Third, the fact that different individuals were involved in the identification of nodal stations could theoretically introduce interobserver variability. Regarding PET however, it has been published that in NSCLC a good interobserver agreement was found with respect to staging mediastinal lymph node stations ${ }^{37}$. For contrast-enhanced $\mathrm{CT}$, a good intra- and interobserver agreement to detect enlarged mediastinal lymph nodes in patients with lung cancer was described ${ }^{38}$. Therefore, as only contrast-enhanced CT images were used, we believe to have minimized possible interobserver variability.

The largest potential benefit of incorporating FDG-PET scans in radiotherapy planning of LD-SCLC may be the reduction of isolated nodal failures compared to CTbased planning ${ }^{15}$. Therefore, a phase II trial, evaluating PET-scan based selective nodal irradiation in LD-SCLC, in which a larger amount of patients will be included, is ongoing in our department. 


\subsection{References}

1. Bunn PA, Jr., Carney DN. Overview of chemotherapy for small cell lung cancer. Semin Oncol 1997;24:S7-69-S7-74.

2. Ihde DC. Small cell lung cancer. State-of-the-art therapy 1994. Chest 1995;107:243S-8S.

3. De Ruysscher D, Pijls-Johannesma M, Bentzen SM, et al. Time between the first day of chemotherapy and the last day of chest radiation is the most important predictor of survival in limited-disease small-cell lung cancer. J Clin Oncol 2006;24:1057-63.

4. De Ruysscher D, Pijls-Johannesma M, Vansteenkiste J, Kester A, Rutten I, Lambin P. Systematic review and meta-analysis of randomised, controlled trials of the timing of chest radiotherapy in patients with limited-stage, small-cell lung cancer. Ann Oncol 2006;17:543-52.

5. Pijls-Johannesma MC, De Ruysscher D, Lambin P, Rutten I, Vansteenkiste JF. Early versus late chest radiotherapy for limited stage small cell lung cancer. Cochrane Database Syst Rev 2005:CD004700.

6. Choi NC, Herndon JE, 2nd, Rosenman J, et al. Phase I study to determine the maximum-tolerated dose of radiation in standard daily and hyperfractionated-accelerated twice-daily radiation schedules with concurrent chemotherapy for limited-stage small-cell lung cancer. J Clin Oncol 1998;16:352836.

7. Turrisi AT, 3rd, Kim K, Blum R, et al. Twice-daily compared with once-daily thoracic radiotherapy in limited small-cell lung cancer treated concurrently with cisplatin and etoposide. N Engl J Med 1999;340:265-71.

8. Senan S, De Ruysscher D, Giraud P, Mirimanoff R, Budach V. Literature-based recommendations for treatment planning and execution in high-dose radiotherapy for lung cancer. Radiother Oncol 2004;71:139-46.

9. Senan S, Burgers S, Samson MJ, et al. Can elective nodal irradiation be omitted in stage III non-smallcell lung cancer? Analysis of recurrences in a phase II study of induction chemotherapy and involvedfield radiotherapy. Int J Radiat Oncol Biol Phys 2002;54:999-1006.

10. Vanuytsel L, Vansteenkiste JF, Stroobants SG, et al. The impact of (18)F-fluoro-2-deoxy-D-glucose positron emission tomography (FDG-PET) lymph node staging on the radiation treatment volumes in patients with non-small cell lung cancer. Radiother Oncol 2000;55:317-24.

11. De Ruysscher D, Wanders S, van Haren E, et al. Selective mediastinal node irradiation based on FDGPET scan data in patients with non-small-cell lung cancer: a prospective clinical study. Int J Radiat Oncol Biol Phys 2005;62:988-94.

12. Belderbos JS, Heemsbergen WD, De Jaeger K, Baas $P$, Lebesque JV. Final results of a Phase $I / I I$ dose escalation trial in non-small-cell lung cancer using three-dimensional conformal radiotherapy. Int J Radiat Oncol Biol Phys 2006;66:126-34.

13. De Ruysscher D, Wanders $S$, Minken A, et al. Effects of radiotherapy planning with a dedicated combined PET-CT-simulator of patients with non-small cell lung cancer on dose limiting normal tissues and radiation dose-escalation: a planning study. Radiother Oncol 2005;77:5-10.

14. van Der Wel A, Nijsten S, Hochstenbag M, et al. Increased therapeutic ratio by 18FDG-PET CT planning in patients with clinical CT stage N2-N3M0 non-small-cell lung cancer: a modeling study. Int J Radiat Oncol Biol Phys 2005;61:649-55.

15. De Ruysscher D, Bremer RH, Koppe F, et al. Omission of elective node irradiation on basis of CT-scans in patients with limited disease small cell lung cancer: a phase II trial. Radiother Oncol 2006;80:30712.

16. Bradley JD, Dehdashti F, Mintun MA, Govindan R, Trinkaus K, Siegel BA. Positron emission tomography in limited-stage small-cell lung cancer: a prospective study. J Clin Oncol 2004;22:3248-54.

17. Chin R, Jr., McCain TW, Miller AA, et al. Whole body FDG-PET for the evaluation and staging of small cell lung cancer: a preliminary study. Lung Cancer 2002;37:1-6.

18. Shen YY, Shiau YC, Wang JJ, Ho ST, Kao CH. Whole-body 18F-2-deoxyglucose positron emission tomography in primary staging small cell lung cancer. Anticancer Res 2002;22:1257-64. 
19. Fischer BM, Mortensen J, Langer SW, et al. A prospective study of PET/CT in initial staging of smallcell lung cancer: comparison with $\mathrm{CT}$, bone scintigraphy and bone marrow analysis. Ann Oncol 2007;18:338-45.

20. Brink I, Schumacher T, Mix M, et al. Impact of [18F]FDG-PET on the primary staging of small-cell lung cancer. Eur J Nucl Med Mol Imaging 2004;31:1614-20.

21. Pandit N, Gonen M, Krug L, Larson SM. Prognostic value of [18F]FDG-PET imaging in small cell lung cancer. Eur J Nucl Med Mol Imaging 2003;30:78-84.

22. Niho S, Fujii H, Murakami K, et al. Detection of unsuspected distant metastases and/or regional nodes by FDG-PET in LD-SCLC scan in apparent limited-disease small-cell lung cancer. Lung Cancer 2007; 57:328-33.

23. Mountain CF, Dresler CM. Regional lymph node classification for lung cancer staging. Chest 1997;111:1718-23.

24. Chapet O, Kong FM, Quint LE, et al. CT-based definition of thoracic lymph node stations: an atlas from the University of Michigan. Int J Radiat Oncol Biol Phys 2005;63:170-8.

25. Nestle U, Kremp S, Grosu AL. Practical integration of [18F]-FDG-PET and PET-CT in the planning of radiotherapy for non-small cell lung cancer (NSCLC): the technical basis, ICRU-target volumes, problems, perspectives. Radiother Oncol 2006;81:209-25.

26. Vansteenkiste JF, Stroobants SG, De Leyn PR, et al. Lymph node staging in non-small-cell lung cancer with FDG-PET scan: a prospective study on 690 lymph node stations from 68 patients. J Clin Oncol 1998;16:2142-9.

27. ICRU Report 50. Prescribing, recording and reporting photon beam therapy. International Commission on Radiation Units and Measurements; 1993.

28. Bradley J, Deasy JO, Bentzen S, El-Naqa I. Dosimetric correlates for acute esophagitis in patients treated with radiotherapy for lung carcinoma. Int J Radiat Oncol Biol Phys 2004;58:1106-13.

29. De Ruysscher D, Dehing C, Bremer $\mathrm{RH}$, et al. Maximal neutropenia during chemotherapy and radiotherapy is significantly associated with the development of acute radiation-induced dysphagia in lung cancer patients. Ann Oncol 2007;18:909-16.

30. Lenth RV. Java Applets for Power and Sample Size In. retrieved November, 1, 2006 ed; 2006.

31. Pijls-Johannesma M, De Ruysscher D, Vansteenkiste J, Kester A, Rutten I, Lambin P. Timing of chest radiotherapy in patients with limited stage small cell lung cancer: A systematic review and metaanalysis of randomised controlled trials. Cancer Treat Rev 2007.

32. Kamel EM, Zwahlen D, Wyss MT, Stumpe KD, von Schulthess GK, Steinert HC. Whole-body (18)F-FDG PET improves the management of patients with small cell lung cancer. J Nucl Med 2003;44:1911-7.

33. Kwa SL, Lebesque JV, Theuws JC, et al. Radiation pneumonitis as a function of mean lung dose: an analysis of pooled data of 540 patients. Int J Radiat Oncol Biol Phys 1998;42:1-9.

34. Jenkins P, Salmon C, Mannion C. Analysis of the movement of calcified lymph nodes during breathing. Int J Radiat Oncol Biol Phys 2005;61:329-34.

35. Goerres GW, Burger C, Kamel E, et al. Respiration-induced attenuation artifact at PET/CT: technical considerations. Radiology 2003;226:906-10.

36. Nagel CC, Bosmans G, Dekker AL, et al. Phased attenuation correction in respiration correlated computed tomography/positron emitted tomography. Med Phys 2006;33:1840-7.

37. Smulders SA, Gundy CM, van Lingen A, Comans EF, Smeenk FW, Hoekstra OS. Observer variation of 2-deoxy-2-[F-18]fluoro-D-glucose-positron emission tomography in mediastinal staging of non-small cell lung cancer as a function of experience, and its potential clinical impact. Mol Imaging Biol 2007;9:318-22.

38. Cascade PN, Gross BH, Kazerooni EA, et al. Variability in the detection of enlarged mediastinal lymph nodes in staging lung cancer: a comparison of contrast-enhanced and unenhanced CT. AJR Am J Roentgenol 1998;170:927-31. 


\section{CHAPTER 4 \\ Selective nodal irradiation on basis of ${ }^{18}$ FDG-PET scans in limited disease small cell lung cancer: a prospective study}

Judith van Loon

Dirk De Ruysscher

Rinus Wanders

Liesbeth Boersma

Jean Simons

Michel Öllers

Anne-Marie Dingemans

Monique Hochstenbag

Gerben Bootsma

Wiel Geraedts

Cordula Pitz

Jaap Teule

Ali Rhami

Willy Thimister

Gabriel Snoep

Cary Dehing-Oberije

Philippe Lambin

International Journal of Radiation Oncology Biology

Physics 2010; 77(2): 329-36 


\section{Abstract}

\section{Background and Purpose}

To evaluate the results of selective nodal irradiation (SNI) on basis of FDG-PET scans in patients with limited disease small cell lung cancer (LD-SCLC), on isolated nodal failures.

\section{Methods and Materials}

A prospective study was performed of 60 patients with LD-SCLC. Radiotherapy was given to a dose of $45 \mathrm{~Gy}$ in twice daily fractions of $1.5 \mathrm{~Gy}$, concurrent with carboplatin and etoposide chemotherapy. Only the primary tumour and the mediastinal lymph nodes involved on the pre-treatment PET scan were irradiated. A chest CT-scan was performed 3 months after completion of radiotherapy and every six months thereafter.

\section{Results}

A difference was seen in the involved nodal stations between the pre-treatment FDG-PET and CT scans in 30\% (95\% Cl: 20-43\%) of patients. Of the 60 patients, 39 (65\%, 95\% Cl: $52-76 \%)$ developed a recurrence. Two patients (3\%, 95\% Cl: $1-11 \%)$ experienced an isolated regional failure. The median actuarial overall survival was 19 months (95\% Cl: 17-21 months). The median actuarial progression free survival was 14 months (95\% Cl: $12-16$ months). $12 \%$ (95\% Cl: $6-22 \%)$ of patients experienced acute grade 3 (CTCAE v 3.0) esophagitis.

\section{Conclusions}

FDG-PET based selective nodal irradiation for LD-SCLC resulted in a low rate of isolated nodal failures (3\%), with a low percentage of acute esophagitis. These findings are in contrast to those from our prospective study of CT-based selective nodal irradiation, which resulted in an unexpectedly high percentage of isolated nodal failures (11\%). Because of the low rate of isolated nodal failures and toxicity, we believe that our data support the use of PET-based SNI for LD-SCLC. 


\subsection{Introduction}

The prognosis of patients with limited disease small cell lung cancer (LD-SCLC) has improved significantly with the application of accelerated radiotherapy (RT) and concurrent chemotherapy ${ }^{1}$, which have become the current standard treatment. Although long term survival rates of approximately $25 \%$ have been reached, more than $30 \%$ of patients will still develop local failure with this treatment ${ }^{1}$. Improving locoregional tumour control by simply increasing the radiation dose is not straightforward, because dose limiting toxicity occurs, consisting of severe reversible esophagitis and lung damage ${ }^{2-4}$. An attractive strategy to reduce the toxicity is to diminish the radiation fields by omitting routine elective nodal irradiation (ENI) of the mediastinum. This strategy has proved its efficacy in non-small cell lung cancer (NSCLC), in which radiation fields could be safely reduced by selective nodal irradiation (SNI), using $\mathrm{CT}$, and even further using ${ }^{18} \mathrm{~F}$-fluorodeoxyglucose (FDG) positron emission tomography (PET) scans ${ }^{5-8}$. Treating only FDG-positive mediastinal areas decreased the radiation exposure of the lungs and the esophagus sufficiently as to allow for radiation dose-escalation in $\mathrm{NSCLC}^{9,10}$. Although selective irradiation of clinically involved nodes is also regularly applied in clinical practice for SCLC, no published data are available supporting this practice. A recent report from the International Atomic Energy Agency meeting emphasized the need for prospective clinical evidence regarding SNI for SCLC ${ }^{11}$.

To date, only a few prospective data concerning selective nodal irradiation (SNI) for SCLC are available. In a previous phase II trial from our group, isolated nodal failures were observed outside of the clinical target volume (CTV) in $11 \%$ of patients undergoing SNI, using $\mathrm{CT}^{12}$. These isolated nodal failures all occurred in the ipsilateral supraclavicular fossa. Baas et al. ${ }^{10}$ and Belderbos et al. ${ }^{13}$ reported an isolated nodal recurrence in the ipsilateral supraclavicular fossa in 1 of 36 patients treated with concurrent chemotherapy and CT-based involved field irradiation. Although no definitive conclusions could be drawn because of the small sample size, those findings imply that the safety of SNI in NSCLC cannot be straightforwardly extrapolated to SCLC patients. The available data suggest that FDG-PET scans are more accurate than $\mathrm{CT}$ in the primary staging of SCLC ${ }^{14-17}$. In a planning study on FDG-PET based selective mediastinal node irradiation in 21 LD-SCLC patients to investigate the potential role of FDG-PET in RT planning ${ }^{18}$, we found a change in the treatment plan compared with the CT based plan in $24 \%$ of patients. Because of these results, we decided to prospectively evaluate SNI based on FDG-PET for LD-SCLC. Our primary end point was to evaluate the proportion of isolated nodal failures; secondary end points were the patterns of recurrence and esophageal and pulmonary toxicity. 


\subsection{Methods and Materials}

\section{Patient population}

Patients diagnosed with LD-SCLC and referred for radical RT to Maastro clinic between December 2004 and November 2006 were prospectively evaluated. The inclusion criteria were cytologically or histologically proven SCLC; limited disease, defined as International Union Against Cancer Stage I-III, with the exclusion of T4 lesions because of malignant pleural or pericardial effusion; World Health Organization (WHO) performance status 0-2; age at least 18 years; adequate pulmonary function (forced expiratory volume in 1 second $>1$ litre). Patients with severe recent cardiac disease (e.g., arrhythmia, congestive heart failure, infarction) were excluded. The minimal follow-up time after the start of RT was 18 months.

\section{Staging}

All patients underwent bronchoscopy with biopsy and standard haematological and biochemical workup. Brain imaging was performed with either MRI or a contrastenhanced CT. Pre-treatment imaging of the chest consisted of either both a whole body FDG-PET scan and a contrast-enhanced CT scan of the chest, or a combined whole body FDG-PET-CT scan with contrast.

\section{Chest imaging with FDG-PET and CT}

For PET-based RT planning, a combined PET-CT scan was performed either during the diagnostic process only or during both the diagnostic process and for RT simulation. In both cases, to ensure optimal co-registration, the PET-CT scan was obtained with the patient in the RT position with both arms above the head ${ }^{19}$. Patients had to have fasted for at least 6 hours before the examination. The injected total activity of FDG was calculated from the weight of the patient: (weight* $4+20$ ) MBq. After a rest period of 60 min (interval needed for FDG uptake), the PET and CT images were acquired. A CT scan of the whole thorax was performed with intravenous contrast during free-breathing.

Lymph nodes were judged positive and included in the CTV on basis of the report of the PET and CT scan. The CT and PET findings were interpreted and reported independently by an experienced chest radiologist and nuclear medicine specialist, respectively.

The CT-findings from the diagnostic CT scan were also interpreted by an experienced chest radiologist. Lymph nodes were considered to be pathologic on CT when their axial diameter was $>1 \mathrm{~cm}$. The lymph nodes were considered positive on the FDG-PET scan on basis of visual interpretation by an experienced PET scan specialist. 
No quantitative standardized uptake value (SUV) threshold was used, as a visual scale has been shown to be at least as accurate as the use of a SUV-threshold to distinguish benign from malignant nodes ${ }^{20,21}$. The involved lymph node stations were recorded according to the Mountain and Dresler classification scheme ${ }^{22}$.

\section{Radiotherapy}

For RT planning, contrast-enhanced CT or combined FDG-PET-CT was performed that extended from the cricoid to the second lumbar vertebra, with a maximal slice thickness of $3 \mathrm{~mm}$. Patients were scanned in the supine position with both arms above the head. The CT and PET images were automatically registered using a rigid registration technique based on mutual information and were subsequently fused using Focal software (Computerized Medical Systems (CMS), St Louis, MS). RT planning was performed with a XiO treatment planning system (CMS), using inhomogeneity corrections based on a convolution algorithm. For all patients, the gross tumour volume (GTV) and planning target volume (PTV) were defined on basis of the PET and CT data. In the case of induction chemotherapy, the post-chemotherapy volume was considered as the GTV of the primary tumour, whereas for the lymph nodes, only the pre-treatment extension was considered. For the primary tumour, the GTV was delineated using the CT findings only, using lung window settings ( $\mathrm{W}=$ $1700, L=-300$ ). We deliberately avoided contouring on the basis of ill-defined areas on the PET scan. Instead, the sharp boundaries of the CT scan images were used. For planning of the lymph nodes, the pre-treatment anatomic sites of the involved zones on the FDG-PET scan were delineated on the planning CT scan in a mediastinal window setting $(W=600, L=40)$. The whole pathologic anatomic region as described by the nuclear medicine specialist in the original diagnostic report (i.e., before the start of chemotherapy) was delineated ${ }^{23}$. If the PET scan was negative in the mediastinum and the CT scan positive, the mediastinum was not included in the GTV. The margin from the GTV to the CTV (Clinical Target Volume) was $5 \mathrm{~mm}$, and from the CTV to the PTV $5 \mathrm{~mm}$ for the nodal areas and $10 \mathrm{~mm}$ for the primary lung tumour. No elective nodal irradiation was performed.

Contouring of the lung was done automatically by the treatment planning system. The mean lung dose (MLD) was analyzed as a possible predictor for radiation pneumonitis. For the calculation of the MLD, the volume of both lungs minus the GTV was considered $^{24}$. The dose constraint to the lungs was set at a MLD of 19 Gy. The esophagus was delineated from just below the larynx to the gastro-esophageal junction. Neither the GTV nor the PTV was subtracted from this volume. The mean esophageal dose (MED) and the maximal esophageal dose (Dmax) were analyzed as possible predictors of early and late esophageal toxicity ${ }^{24,25}$. The spinal cord was drawn throughout the whole CT scan and was considered to be at the inner margin 
of the bony spinal canal. The maximum allowed dose to the spinal cord was $54 \mathrm{~Gy}$, and this dose constraint was not reached in the present study.

All patients were treated with a three-dimensional conformal treatment plan using 6-10 MV photons. The prescribed dose to the PTV was $45 \mathrm{~Gy}$ in 30 fractions within 3 weeks (1.5 Gy twice daily, with a minimal interval between two fractions of 8 hours) according to the ICRU report 50 guidelines ${ }^{26}$. During RT, patients were seen weekly by the radiation oncologist, for the evaluation of acute side effects.

Chest RT was planned to start as early as possible after the beginning of chemotherapy. After thoracic irradiation and 5 cycles of chemotherapy, re-staging was performed including a chest X-ray and contrast-enhanced CT scan or MRI of the brain. If no progression was found on the chest $X$-ray and no brain metastases were seen, patients were offered prophylactic cranial irradiation (PCl) to a dose of $25 \mathrm{~Gy}$ in 10 fractions.

\section{Chemotherapy}

Patients underwent chemotherapy according to the standard protocol in the Comprehensive Cancer Centre Limburg (the Netherlands). The standard protocol was carboplatin on day 1 and etoposide $\left(120 \mathrm{mg} / \mathrm{m}^{2}\right)$ on day $1-3$. The carboplatin dose was based on the target area under the curve $(5 \mathrm{mg} / \mathrm{ml} / \mathrm{h}) *$ (glomerular filtration rate +25$)$, with the glomerular filtration rate calculated according to the CockroftGault formula. The chemotherapy cycles were repeated every 21 days for a total of 5 cycles.

\section{Post-treatment follow-up}

The follow-up consisted of a visit 3 weeks after the end of RT for the evaluation of acute side effects. Thereafter, visits every 3 months, including history taking and physical examination, were performed, for the first 2 years. After this period, 6month visits were performed until 5 years after treatment. CT of the thorax was performed 3 months after RT completion and every 6 months thereafter. When a patient presented with a recurrence outside of the follow-up visits, chest imaging was performed with chest X-ray and CT. After the detection of a recurrence, the follow-up visits were continued at 3 month intervals, with the type of imaging being guided by the site of progression and the presence of symptoms.

Local tumour control was evaluated according to the criteria of Green et al. ${ }^{27}$. An isolated nodal recurrence was defined as a recurrence in the regional nodes outside the CTV, in the absence of in-field failure or distant metastases.

The pulmonary and esophageal toxicity were scored according to the Common Terminology Criteria for Adverse Events (CTCAE), version 3.0 (Table 4.1$)^{28}$. Toxicity 
was scored before the start of RT, at the weekly visits during RT, and at the follow up visits.

\begin{tabular}{|c|c|c|c|c|c|}
\hline \multirow[b]{2}{*}{ Adverse event } & \multicolumn{5}{|c|}{ Grade } \\
\hline & 1 & 2 & 3 & 4 & 5 \\
\hline Esophagitis & $\begin{array}{l}\text { Asymptomatic, } \\
\text { pathologic, } \\
\text { radiologic or } \\
\text { endoscopic } \\
\text { findings only }\end{array}$ & $\begin{array}{l}\text { Symptomatic; } \\
\text { altered eat- } \\
\text { ing/swallowing } \\
\text { (e.g. altered } \\
\text { dietary habits, } \\
\text { oral supple- } \\
\text { ments); IV } \\
\text { fluids indicated } \\
<24 \text { hrs }\end{array}$ & $\begin{array}{l}\text { Symptomatic and } \\
\text { severely altered } \\
\text { eating/swallowing } \\
\text { (e.g. inadequate } \\
\text { oral caloric or } \\
\text { fluid intake); IV } \\
\text { fluids, tube } \\
\text { feedings, or TPN } \\
\text { indicated } \geq 24 \text { hrs }\end{array}$ & $\begin{array}{l}\text { Life threaten- } \\
\text { ing conse- } \\
\text { quences }\end{array}$ & Death \\
\hline Cough & $\begin{array}{l}\text { Symptomatic, } \\
\text { non-narcotic } \\
\text { medication } \\
\text { only indicated }\end{array}$ & $\begin{array}{l}\text { Symptomatic, } \\
\text { narcotic medi- } \\
\text { cation indi- } \\
\text { cated }\end{array}$ & $\begin{array}{l}\text { Symptomatic, } \\
\text { significantly } \\
\text { interfering with } \\
\text { sleep or ADL }\end{array}$ & - & - \\
\hline Dyspnea & $\begin{array}{l}\text { Dyspnea on } \\
\text { exertion, but } \\
\text { can walk } 1 \\
\text { flight of stairs } \\
\text { without stop- } \\
\text { ping }\end{array}$ & $\begin{array}{l}\text { Dyspnea on } \\
\text { exertion, } \\
\text { unable to walk } \\
1 \text { flight of } \\
\text { stairs or } 1 \text { city } \\
\text { block ( } 0.1 \mathrm{~km} \text { ) } \\
\text { without stop- } \\
\text { ping }\end{array}$ & Dyspnea with ADL & $\begin{array}{l}\text { Dyspnea at } \\
\text { rest; intuba- } \\
\text { tion/ } \\
\text { ventilator } \\
\text { indicated }\end{array}$ & Death \\
\hline
\end{tabular}

\section{Ethics}

The trial was performed in accordance with the Dutch laws and regulations. The study protocol was registered at the National Institute of Health (NIH) clinical trial database, under NCT00572923.

\section{Statistical analysis}

On basis of the planning study we had previously performed ${ }^{18}$, we hypothesized that introducing PET into the RT planning would change the treatment fields in $25 \%$ of the patients compared with CT-based planning ${ }^{29}$. From the results of PET based SNI for NSCLC, we expected the percentage of isolated nodal failures to not exceed $5 \%$. As the upper bound of the $95 \%$ confidence interval $(\mathrm{Cl})$, we used the observed $11 \%$ of isolated nodal failures with CT-based SNI ${ }^{12}$. To detect this rate of failures, at least 50 patients were needed for the present study ${ }^{30}$ 
The results are expressed as the mean \pm standard deviation (SD) or as a proportion, with the $95 \% \mathrm{Cl}$ 's. The estimates of overall survival (OS) and progression free survival (PFS) rates were calculated with the Kaplan Meier method, on an intent to treat basis, starting from the first day of RT. Correlations between the dose volume parameters and toxicity were calculated using a two-sided Spearman's test or a chisquare test in the case of nominal variables.

\subsection{Results}

\section{Patient and treatment characteristics}

A total of 60 patients with LD-SCLC, referred to our institution between December 2004 and November 2006 were included. The baseline patient characteristics are summarized in Table 4.2. Most patients were male (67\%). All patients received chemotherapy, which in $97 \%$ consisted of carboplatin-etoposide. One patient received carboplatin-paclitaxel because she was diagnosed with ovarian cancer during the diagnostic workup. A total of 59 patients (98\%) received a dose of 45 Gy. Five patients were treated with sequential chemoradiotherapy instead of concurrent chemoradiotherapy. The reasons for this protocol violation were either a too high MLD owing to the size of the primary tumour, or a delay in patient referral. One patient was not considered fit enough to undergo accelerated RT with concomitant chemotherapy and was therefore treated with 5 cycles of induction chemotherapy, followed by RT to a dose of $54 \mathrm{~Gy}$ in 30 once-daily fractions.

The median interval between the first day of chemotherapy and the start of chest RT for patients treated with concurrent chemo-radiotherapy was $18.0 \pm 11.1$ days (range: -13 to 49 days). The overall treatment time of RT was $21 \pm 3.7$ days (range 17-41). The median interval between the start of chemotherapy and the end of RT (SER) was $39 \pm 34.0$ days (range: $7-176$ ). The median SER for patients treated with concurrent chemoradiotherapy was $38 \pm 11.6$ days (range: 7-71 days). Of the 60 patients, 50 (83\%, 95\% $\mathrm{Cl}$ : 72-91\%) received $\mathrm{PCl}$.

A difference in mediastinal staging according to CT and PET was observed in $30 \%$ (95\% Cl: $20-43 \%$ ) of the patients (Figure 4.1). In 15\% (95\% Cl: 8-26\%), more nodal stations were involved on PET than on CT, and in $13 \%$ of patients (95\% Cl: $7-24 \%$ ) fewer nodal stations were involved on PET than on CT. In 1 patient, nodal stations were involved on PET that were not involved on CT and vice versa. In 3 patients ( $5 \%$, $95 \% \mathrm{Cl} 2-14 \%$ ) supraclavicular nodal stations were found to be involved on PET, but the CT scan was negative for these stations. 


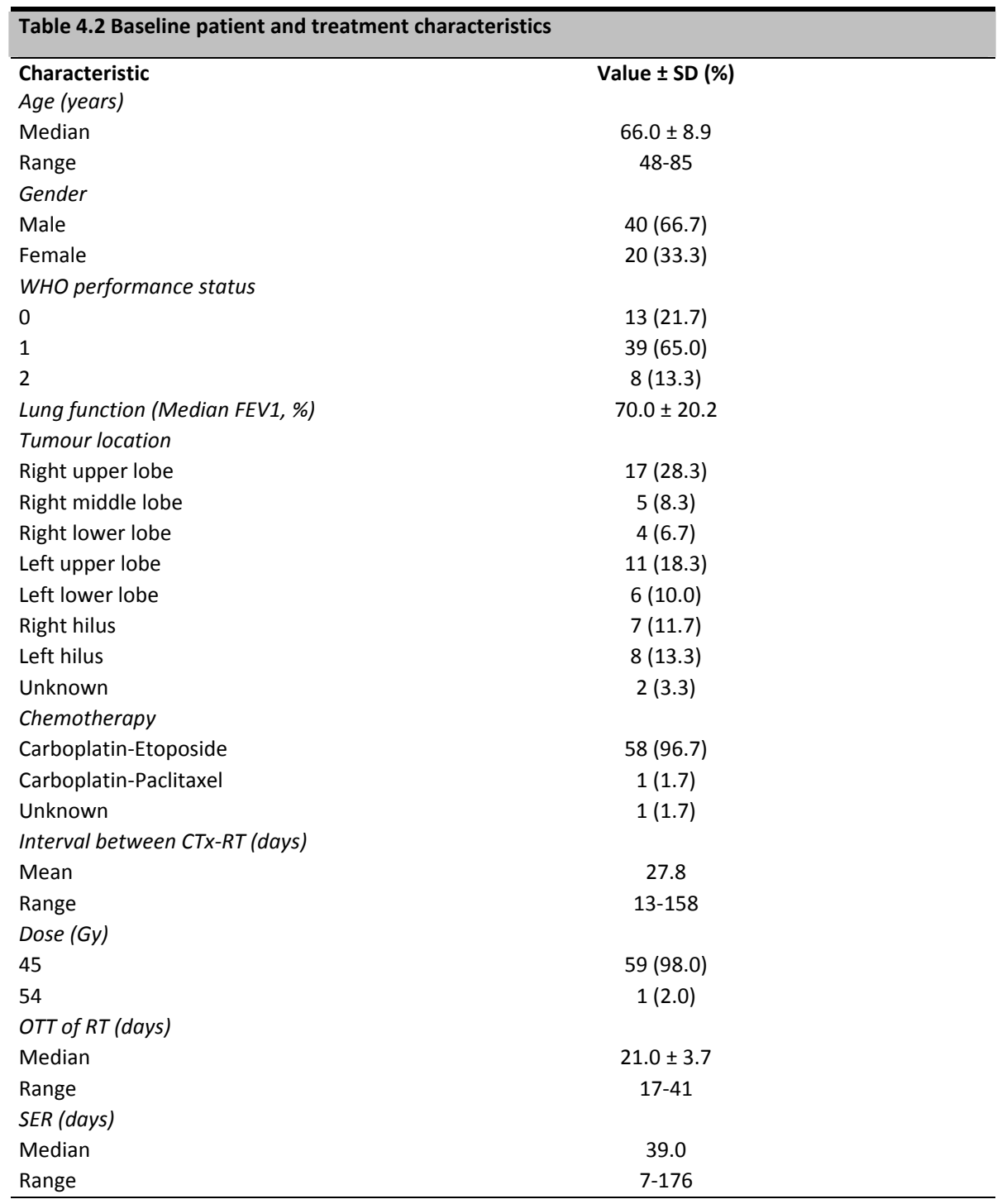

WHO: world health organization; FEV1: forced expiratory volume in 1 second; CTx: Chemotherapy; RT: radiotherapy; OTT: overall treatment time; SER: interval between the start of CTx and the end of RT 


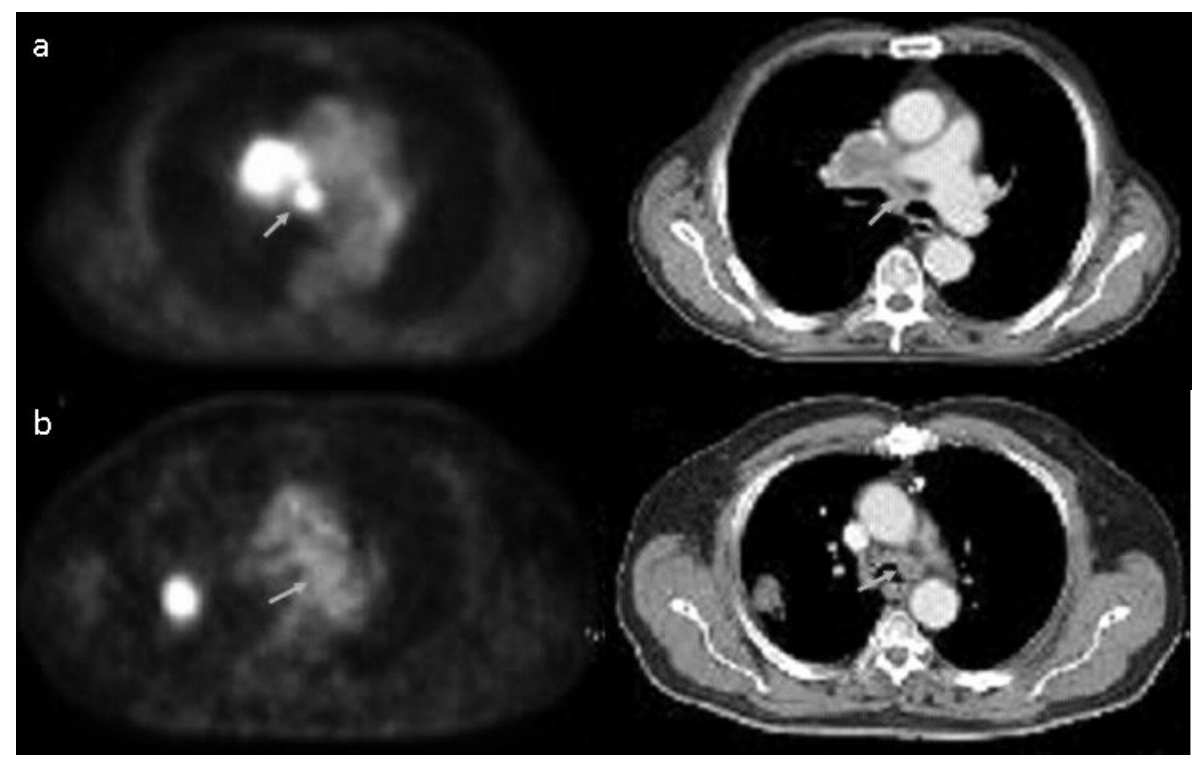

Figure 4.1 Difference in involved nodal stations between PET and CT

a) Representative image of a patient with a positive nodal station 7 on PET, while CT is negative

b) Representative image of a patient with a positive nodal station $4 \mathrm{~L}$ on $\mathrm{CT}$, while PET is negative

\section{Patterns of failure}

An overview of the frequency and site of relapses is listed in Table 4.3.

\begin{tabular}{lc}
\hline Table 4.3 Frequency and location of recurrences as assessed by CT \\
\hline Recurrence & Number of patients (\%) \\
None & $21(35)$ \\
Local & $9(15)$ \\
In field & $3(5.0)$ \\
Out of field & $4(6.7)$ \\
Both in field and out of field & $2(3.3)$ \\
Isolated local & $2(3.3)$ \\
Local and distant/nodal & $7(11.7)$ \\
Nodal & $20(33.3)$ \\
In field & $8(13.3)$ \\
Out of field & $7(11.7)$ \\
Both in field and out of field & $5(8.0)$ \\
Isolated nodal & $2(3.3)$ \\
Nodal and distant/local & $18(30.0)$ \\
Distant & $34(56.7)$ \\
Isolated distant & $19(31.7)$ \\
Distant and local/nodal & $15(25.0)$ \\
Isolated brain & $9(15.0)$ \\
\hline
\end{tabular}


The minimal follow up of all surviving patients was 18 months. The median followup for all patients was $18.5 \pm 10.3$ months (range: $3-52$ months). Of the 60 patients, 39 (65\%, 95\% Cl: 52-76\%) developed a recurrence. Two patients (3\%, 95\% Cl: $1-11 \%)$ experienced an isolated nodal recurrence. Both recurrences were treated with concurrent chemoradiotherapy. The first patient, whose primary tumour was located in the left lower lobe, developed a nodal recurrence in station 4R at 15 months after treatment. Different nodal stations had been involved before treatment on PET (stations 5 and 10L) and CT (station 10L), but station 4R was not involved before treatment on PET or CT. The second patient, with the primary tumour located in the lingula of the left lung, developed nodal recurrence in station $2 \mathrm{~L}$ and the left supraclavicular region, also 15 months after treatment. Those stations were not involved before treatment on the basis of PET or CT (only station 6 involved).

In $87 \%$ (95\% Cl: $73-94 \%)$, distant metastases (either isolated or combined with local or nodal recurrence) were present at recurrence. Nine patients $(15 \%, 95 \% \mathrm{Cl}$ : 8 $26 \%)$ were diagnosed with isolated brain metastases, of whom 6 had previously received $\mathrm{PCl}$. A nodal recurrence outside the treatment field combined with recurrence inside the treatment field occurred in $5(8 \%, 95 \% \mathrm{Cl}: 4-18 \%)$ patients. In one of them, the nodal recurrence occurred in a nodal station that was positive on $\mathrm{CT}$, but negative on PET, and hence had not been included in the treatment field.

\section{Survival}

The median actuarial overall survival (OS) time for all patients was 19 months (95\% $\mathrm{Cl}$ : $17-21$ months) (Figure 4.2 ), with a 2 year OS rate of $35 \%$. The median OS for patients treated with concurrent chemoradiotherapy was also 19 months $(95 \% \mathrm{Cl}$ : 16-22 months). The median actuarial progression free survival (PFS) was 14 months (95\% Cl: $12-16$ months) (Figure 4.3 ), the 2 year PFS rate was $26 \%$. 


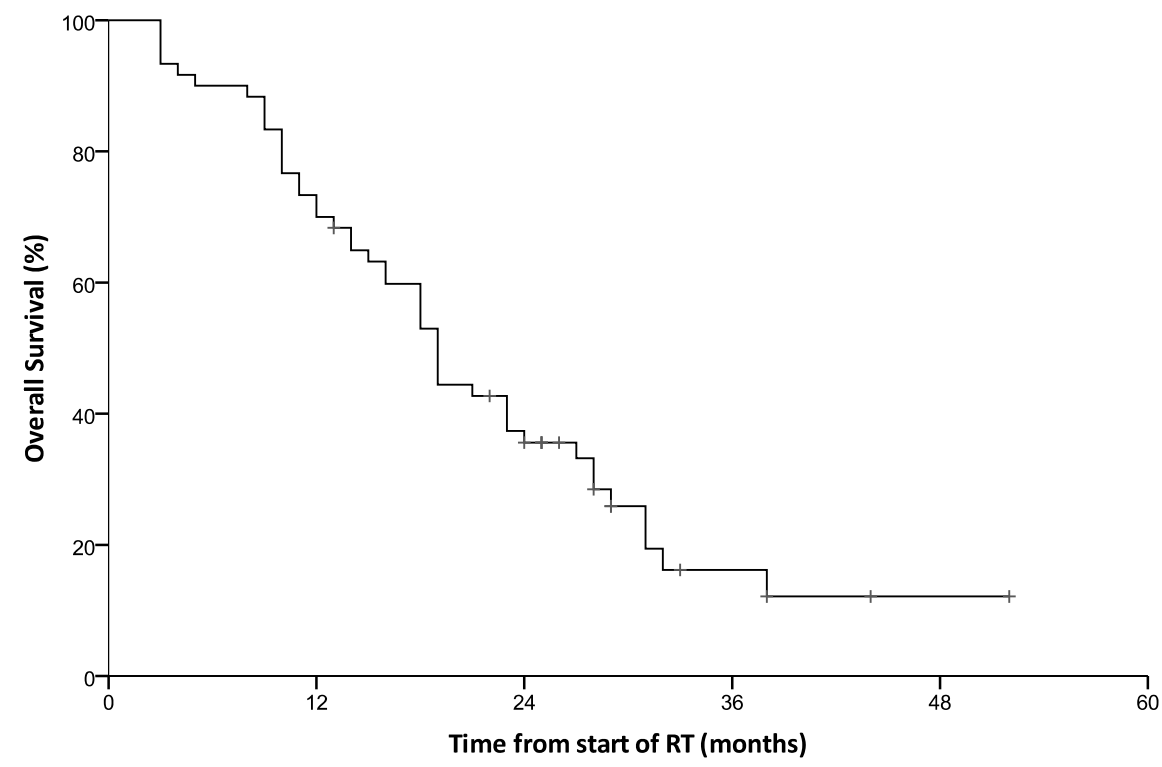

Figure 4.2 Actuarial overall survival

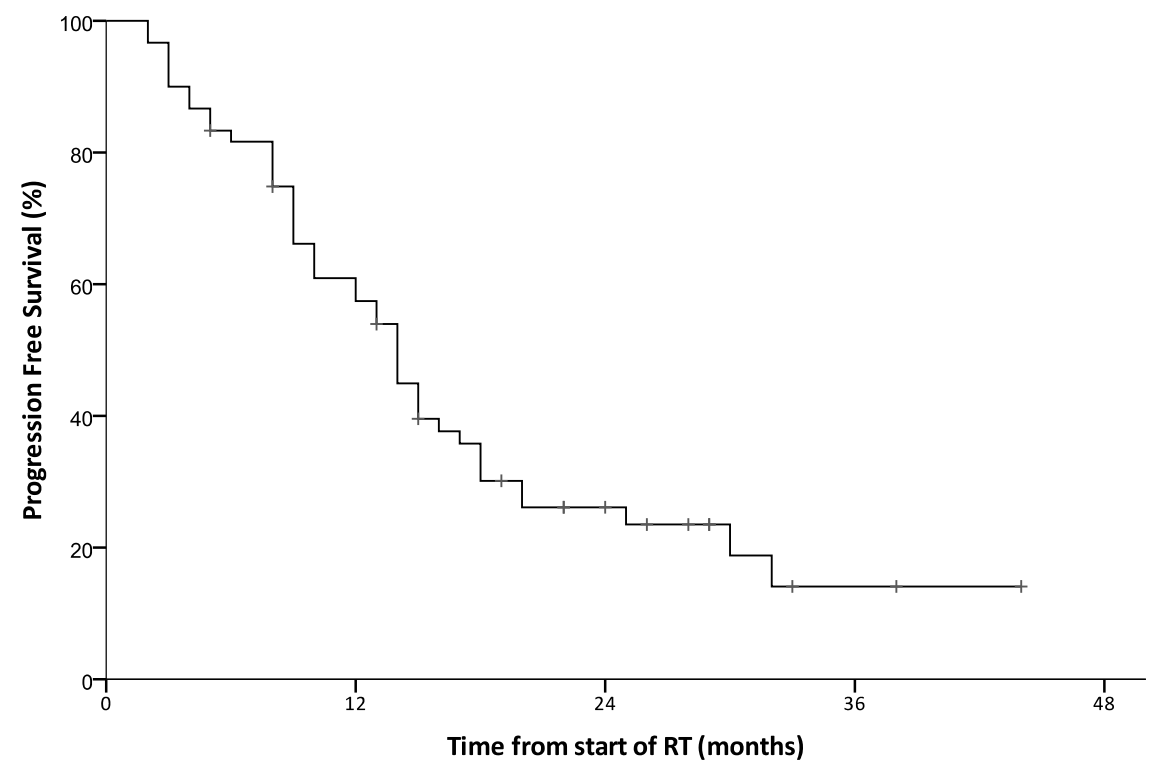

Figure 4.3 Actuarial progression free survival 


\section{Toxicity}

An overview of the dose-volume-histogram (DVH) parameters according to the toxicity grade is presented in Table 4.4. The mean DVH parameters were as follows: mean MLD $12.9 \pm 4.2$ Gy; mean MED: $22.1 \pm 8.6$ Gy; mean Dmax: $44.5 \pm 8.6$ Gy. Treatment related toxicity to the lungs was relatively mild, with grade 3 cough in 1 patient and grade 3 dyspnea in 2 patients. However, $62 \%$ of patients experienced acute esophagitis of grade 2 or more, with $12 \%$ (95\% Cl: $6-22 \%)$ experiencing grade 3 esophagitis. The frequency of grade 3 esophagitis in patients treated with concurrent chemoradiotherapy was $13 \%$ (95\% Cl: $7-25 \%)$. No grade 4 or 5 toxicity was observed. The esophagitis resolved within 4 weeks after RT in all patients. No significant correlation was found between the toxicity grade and the radiation parameters, neither for lung, nor for esophageal toxicity.

\begin{tabular}{|c|c|c|c|}
\hline Toxicity & $\mathrm{N}$ of patients (\%) & \multicolumn{2}{|c|}{ Parameter } \\
\hline Cough & \multicolumn{3}{|c|}{$\mathrm{MLD} \pm \mathrm{SD}(\mathrm{Gy})$} \\
\hline G0 & $11(18.3)$ & \multicolumn{2}{|l|}{$12.0 \pm 4.1$} \\
\hline G1 & $34(56.7)$ & \multicolumn{2}{|l|}{$13.8 \pm 4)}$. \\
\hline $\mathrm{G} 2$ & $14(23.3)$ & \multicolumn{2}{|l|}{$13.5 \pm 3.3$} \\
\hline G3 & $1(1.7)$ & \multicolumn{2}{|l|}{$6.9 \pm 0.0$} \\
\hline Dyspnea & \multicolumn{3}{|c|}{$M L D \pm S D(G y)$} \\
\hline G0 & $22(36.7)$ & \multicolumn{2}{|l|}{$11.8 \pm 3.7$} \\
\hline G1 & $27(45.0)$ & \multicolumn{2}{|l|}{$13.5 \pm 3.9$} \\
\hline $\mathrm{G} 2$ & $9(15.0)$ & \multicolumn{2}{|l|}{$15.2 \pm 4.1$} \\
\hline G3 & $2(3.3)$ & \multicolumn{2}{|l|}{$16.5 \pm 3.4$} \\
\hline \multicolumn{4}{|c|}{ Esophageal toxicity } \\
\hline Esophagitis & & $\mathrm{MED} \pm \mathrm{SD}(\mathrm{Gy})$ & Dmax $\pm S D(G y)$ \\
\hline G0 & $9(15.0)$ & $14.6 \pm 9.7$ & $41.0 \pm 10.2$ \\
\hline G1 & $14(23.3)$ & $23.4 \pm 9.3$ & $44.1 \pm 9.7$ \\
\hline $\mathrm{G} 2$ & $30(50.0)$ & $22.9 \pm 7.8$ & $44.9 \pm 3.4$ \\
\hline G3 & 7 (11.7) & $24.0 \pm 6.8$ & $47.0 \pm 0.9$ \\
\hline
\end{tabular}

G: Grade; MLD: Mean Lung dose; MED: Mean esophageal dose; Dmax: maximal esophageal dose * Common Terminology Criteria for Adverse Events, version 3.0

\subsection{Discussion}

This is the first prospective study evaluating selective nodal irradiation based on FDG-PET scans in LD-SCLC patients.

In the absence of clinical evidence regarding the safety of SNI, radiation oncologists are confronted with the choice between a possible reduction in treatment related toxicity and the possibility of increasing the risk of locoregional failure ${ }^{11}$. A phase II trial by our group evaluating the safety of CT-based SNI resulted in an unacceptably 
high percentage of isolated regional failures (11\%, 95\% Cl: $2-29 \%)$. In contrast, in the present study with SNI based on PET, isolated nodal recurrences occurred in $3 \%$ of patients (95\% Cl: $1-11 \%)$. This proportion is comparable to that found with $\mathrm{SNI}$ in NSCLC, in which about $2 \%$ experienced an isolated nodal recurrence with SNI on basis of FDG-PET scans ${ }^{5,6}$.

The remarkable difference between the value of SNI based on CT vs. PET in LD-SCLC, may be explained by the discrepancy in the involved nodal stations on the PET and CT scans. Indeed, we observed different lymph node stations involved on PET compared with those on CT in 30\% of our LD-SCLC patients. The proportion of patients in whom more nodal stations were involved on PET than on CT was similar to the percentage in whom fewer nodal stations were involved on PET than on CT. These data correspond to those found in the planning study we performed, in which a difference in involved nodal stations in $24 \%$ of patients was observed. In our prospective study concerning CT-based SNI for SCLC, all isolated nodal failures occurred in the ipsilateral supraclavicular area ${ }^{12}$. The present study showed involvement of the ipsilateral supraclavicular nodes on PET in $5 \%$ of patients whose CT scan was negative for this region. This confirms that PET scanning can result in the upfront detection of supraclavicular lymph node metastases, thereby reducing the risk of an isolated nodal recurrence in this area.

Patients with an isolated nodal failure could theoretically have been cured if elective nodal irradiation had been performed instead of SNI. However, aside from the nodal recurrences, both local and distant recurrences still occurred in most patients, emphasizing the need for better treatment strategies for this disease.

The median OS in our study of 19 months ( 2 year OS rate: $35 \%$ ) was lower than that reported in the trial by Turrisi et al. ${ }^{1}$, in which LD-SCLC patients were treated with concurrent chemoradiotherapy with elective nodal irradiation (median OS of 23 months and 2 year OS rate of 47\%). A possible explanation for this difference in survival is the relatively long SER in our study (39 days, range: 20-176). Moreover, the standard chemotherapy regimen in our region consisted of carboplatinetoposide, not cisplatin-etoposide chemotherapy as in the trial by Turrisi et al. ${ }^{1}$. Although one randomized prospective trial showed equal efficacy for both treatment regimens in the treatment of $\mathrm{SCLC}^{31}$, no definitive conclusions could be drawn regarding the outcomes with concurrent chemoradiotherapy for LD-SCLC. Finally, in the trial by Turrisi et al. ${ }^{1}$, patients with contralateral hilar or supraclavicular involvement were excluded, whereas they were included in our study.

Lung toxicity was generally mild and rare, with only $5 \%$ of patients experiencing grade 3 toxicity (cough or dyspnea according to the CTCAE 3.0 criteria). A remarkably low percentage of severe acute esophagitis was found, with only $12 \%$ (95\% Cl: 6- 
$22 \%$ ) of patients experiencing grade 3 esophagitis. In patients who have undergone elective nodal irradiation, or CT based SNI, grade 3 esophagitis usually occurs in about $30 \%$ of patients ${ }^{1,6}$. This cannot be straightforwardly explained by a reduction of radiation fields, because both our previous planning study and the present trial showed an equal percentage of increases and decreases in radiation fields when using PET instead of CT. Possible hypotheses include the relatively long SER in the present study ${ }^{32}$, a lower than average neutropenia level ${ }^{33}$, which was not investigated in the present study, or simply an observation due to chance. If the current finding of lower esophageal toxicity holds true, PET based SNI could provide opportunities for dose escalation and hence, improvement of locoregional tumour control. Therefore, more studies are warranted to investigate this finding.

The use of FDG-PET-CT is likely to be the most accurate non-invasive staging method for the mediastinum in SCLC ${ }^{15,29,34}$. However, the most reliable method to detect mediastinal nodal involvement remains pathological verification. The available studies have indicated that CT underestimates mediastinal nodal involvement ${ }^{35-37}$. No prospective data exist concerning correlation of the pathologic findings with PET findings in SCLC. Because of the low rate of isolated nodal failures found in the present study and the morbidity associated with invasive staging, we believe that our data support the use of PET-based SNI for LD-SCLC.

\subsection{Conclusion}

This prospective study shows that PET-based SNI in LD-SCLC is safe and is associated with low toxicity. 


\subsection{References}

1. Turrisi AT, 3rd, Kim K, Blum R, et al. Twice-daily compared with once-daily thoracic radiotherapy in limited small-cell lung cancer treated concurrently with cisplatin and etoposide. N Engl J Med 1999;340:265-71.

2. Choi NC, Herndon JE, 2nd, Rosenman J, et al. Phase I study to determine the maximum-tolerated dose of radiation in standard daily and hyperfractionated-accelerated twice-daily radiation schedules with concurrent chemotherapy for limited-stage small-cell lung cancer. J Clin Oncol 1998;16:352836.

3. De Ruysscher D, Pijls-Johannesma M, Vansteenkiste J, Kester A, Rutten I, Lambin P. Systematic review and meta-analysis of randomised, controlled trials of the timing of chest radiotherapy in patients with limited-stage, small-cell lung cancer. Ann Oncol 2006;17:543-52.

4. Pijls-Johannesma MC, De Ruysscher D, Lambin P, Rutten I, Vansteenkiste JF. Early versus late chest radiotherapy for limited stage small cell lung cancer. Cochrane Database Syst Rev 2005:CD004700.

5. Belderbos JS, Heemsbergen WD, De Jaeger K, Baas $P$, Lebesque JV. Final results of a Phase I/II dose escalation trial in non-small-cell lung cancer using three-dimensional conformal radiotherapy. Int J Radiat Oncol Biol Phys 2006;66:126-34.

6. De Ruysscher D, Wanders S, van Haren E, et al. Selective mediastinal node irradiation based on FDGPET scan data in patients with non-small-cell lung cancer: a prospective clinical study. Int J Radiat Oncol Biol Phys 2005;62:988-94.

7. Senan S, Burgers S, Samson MJ, et al. Can elective nodal irradiation be omitted in stage III non-smallcell lung cancer? Analysis of recurrences in a phase II study of induction chemotherapy and involvedfield radiotherapy. Int J Radiat Oncol Biol Phys 2002;54:999-1006.

8. Vanuytsel LJ, Vansteenkiste JF, Stroobants SG, et al. The impact of (18)F-fluoro-2-deoxy-D-glucose positron emission tomography (FDG-PET) lymph node staging on the radiation treatment volumes in patients with non-small cell lung cancer. Radiother Oncol 2000;55:317-24.

9. De Ruysscher D, Wanders S, Minken A, et al. Effects of radiotherapy planning with a dedicated combined PET-CT-simulator of patients with non-small cell lung cancer on dose limiting normal tissues and radiation dose-escalation: a planning study. Radiother Oncol 2005;77:5-10.

10. Baas P, Belderbos JS, Senan S, et al. Concurrent chemotherapy (carboplatin, paclitaxel, etoposide) and involved-field radiotherapy in limited stage small cell lung cancer: a Dutch multicenter phase II study. Br J Cancer 2006;94:625-30.

11. Videtic GM, Belderbos JS, Spring Kong FM, Kepka L, Martel MK, Jeremic B. Report from the International Atomic Energy Agency (IAEA) consultants' meeting on elective nodal irradiation in lung cancer: small-cell lung cancer (SCLC). Int J Radiat Oncol Biol Phys 2008;72:327-34.

12. De Ruysscher D, Bremer RH, Koppe F, et al. Omission of elective node irradiation on basis of CT-scans in patients with limited disease small cell lung cancer: a phase II trial. Radiother Oncol 2006;80:30712.

13. Belderbos JS, Baas P, Senan S. Reply: Patterns of nodal recurrence after omission of elective nodal irradiation for limited-stage small cell lung cancer. In: British Journal of Cancer; 2007:276.

14. Fischer BM, Mortensen J, Langer SW, et al. A prospective study of PET/CT in initial staging of smallcell lung cancer: comparison with $\mathrm{CT}$, bone scintigraphy and bone marrow analysis. Ann Oncol 2007; 18:338-45.

15. Niho S, Fujii H, Murakami K, et al. Detection of unsuspected distant metastases and/or regional nodes by FDG-PET in LD-SCLC scan in apparent limited-disease small-cell lung cancer. Lung Cancer 2007; 57:328-33.

16. Shen YY, Shiau YC, Wang JJ, Ho ST, Kao CH. Whole-body 18F-2-deoxyglucose positron emission tomography in primary staging small cell lung cancer. Anticancer Res 2002;22:1257-64.

17. Kamel EM, Zwahlen D, Wyss MT, Stumpe KD, von Schulthess GK, Steinert HC. Whole-body (18)F-FDG PET improves the management of patients with small cell lung cancer. J Nucl Med 2003;44:1911-7. 
18. van Loon J, Offermann C, Bosmans G, et al. 18FDG-PET based radiation planning of mediastinal lymph nodes in limited disease small cell lung cancer changes radiotherapy fields: a planning study. Radiother Oncol 2008;87:49-54.

19. Grgic A, Nestle U, Schaefer-Schuler A, Kremp S, Kirsch CM, Hellwig D. FDG-PET-based radiotherapy planning in lung cancer: optimum breathing protocol and patient positioning--an intraindividual comparison. Int J Radiat Oncol Biol Phys 2009;73:103-11.

20. Nestle U, Kremp S, Grosu AL. Practical integration of [18F]-FDG-PET and PET-CT in the planning of radiotherapy for non-small cell lung cancer (NSCLC): the technical basis, ICRU-target volumes, problems, perspectives. Radiother Oncol 2006;81:209-25.

21. Vansteenkiste JF, Stroobants SG, De Leyn PR, et al. Lymph node staging in non-small-cell lung cancer with FDG-PET scan: a prospective study on 690 lymph node stations from 68 patients. J Clin Oncol 1998;16:2142-9.

22. Mountain CF, Dresler CM. Regional lymph node classification for lung cancer staging. Chest 1997;111:1718-23.

23. Chapet $\mathrm{O}$, Kong FM, Quint LE, et al. CT-based definition of thoracic lymph node stations: an atlas from the University of Michigan. Int J Radiat Oncol Biol Phys 2005;63:170-8.

24. Senan S, De Ruysscher D, Giraud P, Mirimanoff R, Budach V. Literature-based recommendations for treatment planning and execution in high-dose radiotherapy for lung cancer. Radiother Oncol 2004;71:139-46.

25. Bradley J, Deasy JO, Bentzen S, El-Naqa I. Dosimetric correlates for acute esophagitis in patients treated with radiotherapy for lung carcinoma. Int J Radiat Oncol Biol Phys 2004;58:1106-13.

26. ICRU Report 50. Prescribing, recording and reporting photon beam therapy. International Commission on Radiation Units and Measurements; 1993.

27. Green MR, Cox JD, Ardizzoni A, et al. Endpoints for multimodal clinical trials in stage III non-small cell lung cancer (NSCLC): a consensus report. Lung Cancer 1994;11 Suppl 3:S11-3.

28. Trotti A, Colevas AD, Setser A, et al. CTCAE v3.0: development of a comprehensive grading system for the adverse effects of cancer treatment. Semin Radiat Oncol 2003;13:176-81.

29. Bradley JD, Dehdashti F, Mintun MA, Govindan R, Trinkaus K, Siegel BA. Positron emission tomography in limited-stage small-cell lung cancer: a prospective study. J Clin Oncol 2004;22:3248-54.

30. Lenth RV. Java Applets for Power and Sample Size In. retrieved November, 1, 2006 ed; 2006.

31. Skarlos DV, Samantas E, Kosmidis P, et al. Randomized comparison of etoposide-cisplatin vs. etoposide-carboplatin and irradiation in small-cell lung cancer. A Hellenic Co-operative Oncology Group study. Ann Oncol 1994;5:601-7.

32. De Ruysscher D, Pijls-Johannesma M, Bentzen SM, et al. Time between the first day of chemotherapy and the last day of chest radiation is the most important predictor of survival in limited-disease small-cell lung cancer. J Clin Oncol 2006;24:1057-63.

33. De Ruysscher D, Dehing C, Bremer RH, et al. Maximal neutropenia during chemotherapy and radiotherapy is significantly associated with the development of acute radiation-induced dysphagia in lung cancer patients. Ann Oncol 2007;18:909-16.

34. Pandit N, Gonen M, Krug L, Larson SM. Prognostic value of [18F]FDG-PET imaging in small cell lung cancer. Eur J Nucl Med Mol Imaging 2003;30:78-84.

35. Inoue M, Nakagawa K, Fujiwara K, Fukuhara K, Yasumitsu T. Results of preoperative mediastinoscopy for small cell lung cancer. Ann Thorac Surg 2000;70:1620-3.

36. Sakai M, Ishikawa S, Yamamoto T, et al. Preoperative TNM evaluation of peripheral clinical stage I small cell lung cancer treated by initial lobectomy with adjuvant chemotherapy. Interact Cardiovasc Thorac Surg 2005;4:118-22.

37. Shepherd FA, Ginsberg RJ, Feld R, Evans WK, Johansen E. Surgical treatment for limited small-cell lung cancer. The University of Toronto Lung Oncology Group experience. J Thorac Cardiovasc Surg 1991;101:385-93. 



\section{Part}

II

The value of FDG-PET-CT in the follow-up of locally advanced NSCLC patients 



\title{
CHAPTER 5
}

Follow-up with ${ }^{18}$ FDG-PET-CT after radical radiotherapy with or without chemotherapy allows the detection of potentially curable progressive disease in non-small cell lung cancer patients: a prospective study

\author{
Judith van Loon \\ Janneke Grutters \\ Rinus Wanders \\ Liesbeth Boersma \\ Michel Öllers \\ Anne-Marie Dingemans \\ Gerben Bootsma \\ Wiel Geraedts \\ Cordula Pitz \\ Jean Simons \\ Sakar Abdul Fatah \\ Gabriel Snoep \\ Monique Hochstenbag \\ Philippe Lambin \\ Dirk De Ruysscher
}

European Journal of Cancer 2009;45:588-95 


\section{Abstract}

\section{Background and purpose}

Follow-up of patients treated with curative intent for non-small cell lung cancer (NSCLC) with X-ray or CT-scans is of unproven value. Furthermore, most patients with progressive disease present with symptoms outside of follow-up visits. Because the accuracy of ${ }^{18}$ FDG-PET-CT is superior to CT, we hypothesized that FDG-PET-CT scans 3 months post-treatment could lead to early detection of progressive disease (PD) amenable for radical treatment.

\section{Methods and Materials}

Hundred patients with NSCLC, treated with curative intent with (chemo) radiation, were prospectively evaluated. All patients underwent a planned FDG-PET-CT scan three months after the start of radiotherapy.

\section{Results}

Twenty-four patients had PD 3 months post-treatment. 16/24 patients were symptomatic. No curative treatment could be offered to any of these patients. In $3 / 8$ asymptomatic patients progression, potentially amenable for radical therapy was found, which were all detected with PET, not with CT only.

\section{Conclusions}

PET scanning after curative treatment for NSCLC led to the detection of progression potentially amenable for radical treatment in a small proportion (3\%) of patients. Selectively offering a PET-CT scan to the patient group without symptoms could possibly lead to an effective follow-up method. 


\subsection{Introduction}

Lung cancer is the leading cause of cancer death, with an estimated 161.000 patients dying of this disease in the United States in $2008^{1}$. The survival of nonmetastatic non small cell lung cancer (NSCLC) patients remains poor, with 5-year survival rates of about $50 \%$ in stages I-II and $20 \%$ in stage III disease ${ }^{2,3}$. This poor survival is due to a high amount of both locoregional and distant progression ${ }^{4}$. Theoretically, early detection of progressive disease (PD) at a time when radical therapy is an option, could improve the survival. In NSCLC however, there are at present no convincing data supporting that early detection of progression improves survival ${ }^{5-8}$. Moreover, most patients who have PD present with symptoms outside of planned follow-up visits ${ }^{5,9}$. A recent study showed no significant improvement of survival with intensive follow-up by repeated CT-imaging compared to less intensive radiologic follow-up ${ }^{5}$. A major restriction of both conventional chest X-ray and CT after curative treatment for NSCLC is the poor discriminating capacity between residual or recurrent tumour and post-treatment changes ${ }^{7,10}$. Therefore, repeated imaging is often needed to confirm PD. This delay could lead to missing the chance for salvage treatment.

${ }^{18}$ F-fluorodeoxyglucose positron emission tomography $\left({ }^{18} \mathrm{FDG}-\mathrm{PET}\right)$ scanning, which allows imaging of glucose uptake of tissues, has shown to be superior to CT in the evaluation of lung lesions and mediastinal lymph nodes ${ }^{11-13}$, as well as in the detection of distant metastases in the primary staging of NSCLC ${ }^{14}$. Furthermore, FDGuptake of the primary tumour before and during therapy, as well as 3 months after treatment is prognostic for outcome ${ }^{15-22}$. Finally, PET is more accurate than CT in the distinction of tumour from post-radiotherapy (RT) effects ${ }^{18,23,24}$. Based on these data, we hypothesized that the use of PET-CT in the follow-up of patients with NSCLC treated with curative intent would be superior to CT alone. The aim of our study was to evaluate the detection rate of PD amenable for salvage treatment using routine PET-CT in the follow-up of NSCLC patients treated with curative intent with (chemo) radiation. Therefore, we prospectively investigated the impact of follow-up with PET-CT 3 months after therapy on the outcome in 100 consecutive patients with NSCLC, who were treated with curative intent.

\subsection{Methods and Materials}

\section{Patient population and study design}

Patients with stages I-III NSCLC, who were treated with curative intent with (chemo) radiotherapy at our institute from February 2005 until August 2007, consenting to 
an additional PET-CT in the follow-up, were prospectively evaluated. Patients with stage IV disease on the basis of a solitary brain metastasis, treated with curative intent, were also included. As part of the primary staging, all patients underwent an FDG-PET-CT and imaging of the brain (either MRI or CT) before the start of treatment. The follow-up consisted of a visit 3 weeks after the end of treatment for the evaluation of acute side effects. Thereafter, 3-monthly visits, comprising history taking and physical examination, were performed alternately by the pulmonologist and radiation oncologist, for the first 2 years. Thereafter, 6-monthly visits were performed until 5 years post-treatment. AN FDG-PET-CT scan was planned irrespective of the presence of symptoms at 3 months after the start of radiotherapy, with a minimum interval of 2 months (60 days) to account for persistent increased FDGuptake immediately after therapy. Within 1 week following the PET-CT scan, a follow-up visit was planned. Request of other diagnostic imaging procedures was left at the decision of the physician, as indicated by the presence of symptoms.

\section{Treatment characteristics}

Patients were treated with radical radiotherapy (RT), either alone (medically inoperable stage I-II disease) or in combination with concurrent or sequential chemotherapy in stage III disease. For stages I and II NSCLC, radical RT was given in fractions of $1.8 \mathrm{~Gy}$, twice daily, to a mean lung dose (MLD) of $19 \mathrm{~Gy}$ (maximal total tumour dose: $79.2 \mathrm{~Gy}$ ) ${ }^{25}$. Patients with stage III disease received induction chemotherapy with one cycle of carboplatin-gemcitabine (carboplatin (total dose: target AUC*(GFR+25) on day 1 - gemcitabine $1250 \mathrm{mg} / \mathrm{m} 2$ on days 1 and 8 ). This was followed by concurrent chemoradiotherapy. RT was given to a dose of $45 \mathrm{~Gy}$ in twice daily fractions of $1.5 \mathrm{~Gy}$, followed by 2 Gy daily fractions to a MLD of $19 \mathrm{~Gy}$ (maximal total tumour dose: $69 \mathrm{~Gy}$ ), concurrent with cisplatin $50 \mathrm{mg} / \mathrm{m} 2$ and vinorelbine 20 $\mathrm{mg} / \mathrm{m} 2$ on days 1 and 8 . Patients with stage III disease who were considered unable to undergo concurrent chemo-radiotherapy were treated either with radical RT alone, or with sequential chemo-radiotherapy, consisting of three cycles of induction chemotherapy (carboplatin-gemcitabine) followed by RT as described for stages I/II.

\section{PET-CT imaging}

A combined whole-body PET-CT scan was performed about 3 months (but at least 2 months) after the start of radiotherapy. Patients had to be fasting for at least 6 hours before the examination. The injected total activity of FDG was calculated based on the weight of the patient: (weight *4) $+20 \mathrm{MBq}$. After a rest period of 60 minutes (time needed for uptake of FDG), PET and CT images were acquired. A whole-body CT-scan was performed with intravenous contrast. The CT- and FDG- 
PET findings were first interpreted and reported independently by an experienced chest radiologist and nuclear medicine specialist, respectively. Tumour progression was defined according to the EORTC criteria for PET ${ }^{26}$ and to the RECIST criteria for $\mathrm{CT}^{27}$. Thereafter, both specialists jointly evaluated the combined PET-CT images, from which a distinct report was written.

\section{Data acquisition}

For each patient, the following data were collected: patient demographics; initial tumour characteristics (stage according to the TNM-classification (UICC, $6^{\text {th }}$ edition), location and histology); and treatment characteristics (dose, overall treatment time (OTT) of radiotherapy and treatment modality).

Results of the PET-CT scan were recorded as described in the diagnostic report of the radiologist and nuclear medicine specialist. Progressive disease was defined as locoregional when situated at or around the original tumour site or regional lymph nodes and further specified as within or outside the RT field. Progression was defined as distant when situated either in a different lobe as the primary tumour, or outside of the thorax. The site of distant relapse was recorded as well. If both locoregional and distant progression was detected, both were recorded. PD was judged as either diagnosed on basis of CT alone when it was described in the distinct report of the CT (PD according to the RECIST criteria), or as diagnosed with PET when it was only described in the distinct report of the PET (PD according to the EORTC criteria) and/or the report of the combined PET-CT, with the report of the CT being either negative or inconclusive.

PD was defined as amenable for salvage treatment when it was either locoregional, or in case of oligometastasis, defined as 1 or 2 metastases, amenable for radical local treatment by either radiotherapy or surgery ${ }^{28}$. The distinction between locoregional progression and post-RT changes was recorded on the basis of the diagnostic report and was made on visual interpretation by the nuclear medicine physician. Because these radiation-induced changes can normally be readily distinguished from persistent or recurrent tumour by their FDG-uptake distribution, no quantitative threshold was used ${ }^{24,29}$.

The absence or presence of symptoms at time of the PET-CT was noted. Furthermore, it was judged whether at least one of the symptoms was corresponding to the site (or one of the sites) of progression found on PET-CT. This was based on the following assumptions: pain was defined as corresponding to the site of progression when it was localized at the dermatome corresponding to the site. Pulmonary symptoms (cough, dyspnoea) were defined as corresponding when progression was either locoregional or metastases in the lung, and symptoms had increased over time after RT. Neurological symptoms were judged corresponding when either brain 
metastases were diagnosed, or symptoms were consistent with the site of metastasis in the central or peripheral nervous system.

No distinction was made between the detection of a second primary or PD. Because of the short interval between the primary treatment and the PET-CT scan 3 months after therapy, a second tumour in the same lobe was considered as PD, while a second tumour in another lobe was considered a distant relapse rather than a second primary. Survival data were obtained by consultation of the Dutch Communal Data (GBA) register. Follow-up time was defined as the time from the end of radiotherapy until death or the last time of follow-up. At the time of analysis, 51 patients had died. For three patients, survival data could not be retrieved.

\section{Statistical analysis}

We estimated that $25 \%$ of the patients would have detectable PD at the time of the post-treatment FDG-PET-CT scan ${ }^{30,31}$, with an estimated $25 \%$ of them being eligible for salvage treatment. In order to detect this proportion (6\%) with a $95 \%$ confidence interval $(\mathrm{Cl})$ of $1-11 \%$, at least 85 patients evaluable 3 months post-treatment would be needed. To account for possible dropouts, 100 patients were included.

Statistical calculations were performed using SPSS (Version 15.0 for Windows). Results were described as either median or mean \pm one standard deviation (SD) when the results were normally distributed. When there was no normal distribution, results were described as either median or mean with the range. For the calculation of 95\% confidence intervals $(95 \% \mathrm{Cl})$ for proportions, the Wilson score interval was used $^{32}$. P-values were calculated with the Chi-square test for proportions.

\section{Ethics}

The trial was performed according to the required Dutch laws and regulations. All patients gave informed consent for the study, which was part of two study protocols, NCT00573040 and NCT00572325.

\subsection{Results}

\section{Patient and treatment characteristics}

From February 2005 until August 2007, 100 NSCLC patients, stages I-III, treated with curative intent, were included. Patient, tumour and treatment characteristics are listed in Table 5.1. The mean follow-up of all patients was $55.9 \pm 29.2$ weeks, ranging from 13 to 182 weeks. Seventy males and 30 females were included, with a mean age of $66.0 \pm 9.7$ years (range: $44-86$ ). 


\begin{tabular}{|c|c|}
\hline & $\mathrm{N} \pm \mathrm{SD}(\%)$ \\
\hline \multicolumn{2}{|l|}{ Age } \\
\hline Mean (years)) & $66.0 \pm 9.7$ \\
\hline Range & $44-86$ \\
\hline \multicolumn{2}{|l|}{ Gender } \\
\hline Male & $70(70)$ \\
\hline Female & $30(30)$ \\
\hline \multicolumn{2}{|l|}{ Stage } \\
\hline IA & $4(4)$ \\
\hline IB & $6(6)$ \\
\hline IIA & $0(0)$ \\
\hline IIB & $3(3)$ \\
\hline IIIA & $25(25)$ \\
\hline IIIB & $61(61)$ \\
\hline IV & $1(1)$ \\
\hline \multicolumn{2}{|l|}{ Histology } \\
\hline Adenocarcinoma & $15(15)$ \\
\hline Large cell carcinoma & $30(30)$ \\
\hline Squamous cell carcinoma & $18(18)$ \\
\hline Bronchioloalveolar cell carcinoma & $1(1)$ \\
\hline NSCLC, NOS & $36(36)$ \\
\hline \multicolumn{2}{|l|}{ Treatment } \\
\hline Radical RT only & $16(16)$ \\
\hline Sequential Chemo-RT & $65(65)$ \\
\hline Concurrent Chemo-RT & 19 (19) \\
\hline \multicolumn{2}{|l|}{ Dose (Gy) } \\
\hline Median & 63.5 \\
\hline Range & $50.4-79.2$ \\
\hline \multicolumn{2}{|l|}{ Time interval ${ }^{*}$} \\
\hline Median & $16 \pm 3.1$ \\
\hline Range & $9-27$ \\
\hline \multicolumn{2}{|l|}{ Follow-up ${ }^{* *}$} \\
\hline Mean & $55.9 \pm 29.2$ \\
\hline Range & 13-182 \\
\hline
\end{tabular}

$\mathrm{N}=$ number of patients; $\mathrm{SD}=$ standard deviation; NOS: not otherwise specified

*Weeks from the start of radiotherapy to the date of PET-CT

**Weeks from the end of radiotherapy until death or lost to follow-up

The median radiation dose delivered was $63.5 \mathrm{~Gy}$, ranging from 50.4 to $79.2 \mathrm{~Gy}$. Most (86/100) patients had stage III disease at time of presentation. $84 \%$ of patients received chemotherapy, either sequential to or concurrent with radiotherapy. One patient had stage IV disease. This patient had a solitary brain metastasis, which was treated with stereotactic radiotherapy before radical treatment of the lung tumour. 


\section{Results of PET-CT scanning 3 months after treatment}

The mean time interval from start of RT until planned surveillance PET-CT scan was $16 \pm 3.1$ weeks (range: 9-27 weeks). All patients underwent the scan more than 2 months after the start of RT, and 75\% underwent the scan within 4 months after start of RT. Twenty-four patients had PD, of which 7 had locoregional progression only, 7 distant only and 10 had both locoregional and distant progression. The primary stage and treatment of the patients with progression are described in Table 5.2. Of the 24 patients with progression, 17 (71\%, 95\% Cl: 51-85\%) were detected with CT only, while for 7 patients, the PET scan was necessary for the detection of the progression, with CT being either negative or inconclusive (Figure 5.1). Of the 8 patients who were symptomatic at the time of progression, PET was required for the detection in $4 / 8$ patients $(50 \%, 95 \% \mathrm{Cl}: 22-78 \%)$, while for the symptomatic patients, PET was required in $3 / 16$ patients $(19 \%, 95 \% \mathrm{Cl}: 6-43 \%)$.

In 36 patients ( $36 \%, 95 \% \mathrm{Cl}: 27-46 \%)$, the PET-scan showed findings that were defined in the diagnostic report as post-RT effects. In all patients, these findings could easily be distinguished from PD on the basis of the combined PET-CT images.

\begin{tabular}{lc}
\hline Table 5.2 Characteristics of progressive disease & N (\%) \\
\hline & \\
Primary stage & $2(8)$ \\
I & $0(0)$ \\
III & $21(88)$ \\
IV & $1(4)$ \\
Primary treatment & \\
Radical RT & $2(8)$ \\
Sequential Chemo-RT & $16(67)$ \\
Concurrent Chemo-RT & $6(25)$ \\
Site of progression & \\
Locoregional & 17 \\
Inside RT-field & $10(59)$ \\
Outside RT-field & $6(35)$ \\
Both Inside and Outside & $1(6)$ \\
Distant & 17 \\
Bone & $9(38)$ \\
Brain & $4(17)$ \\
Liver & $2(8)$ \\
Muscle & $1(4)$ \\
Adrenal gland & $4(17)$ \\
Lung & $4(17)$ \\
Axilla & $1(4)$ \\
\hline N: number of patients & \\
\hline & \\
\hline
\end{tabular}




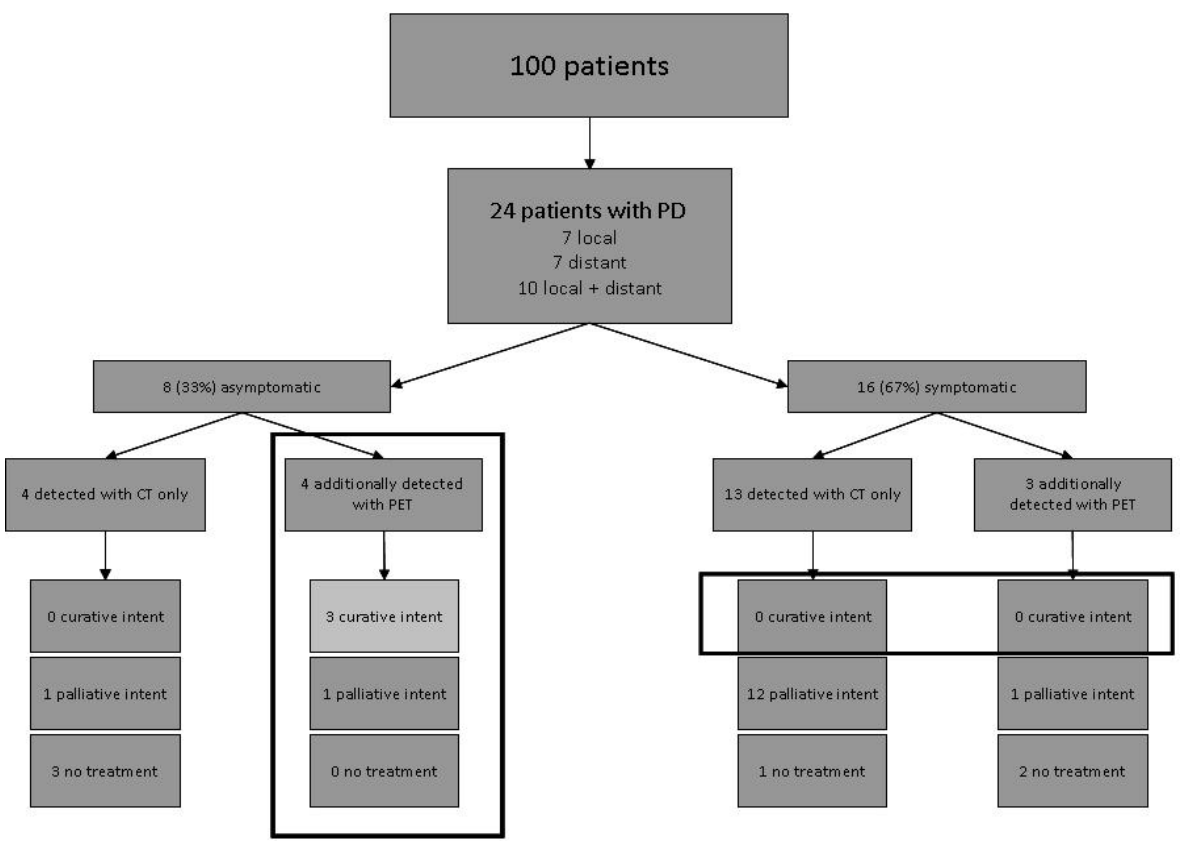

Figure 5.1 Disease progression: detection modality and treatment intent according to presence of symptoms

\section{Sites of progression}

An overview of the sites of progression at the time of the PET-CT scan is shown in Table 5.2. Seventeen patients had locoregional PD. In 10 patients, the progression was located inside the RT-field, in 6 patients outside the RT-field and in one patient both inside and outside the RT field. Six of 17 patients with distant metastases had metastases at more than one site.

\section{Correlation of PET-CT findings with symptoms}

The presence and distribution of symptoms are described in Table 5.3. Forty five patients (45\%, 95\% Cl: 36-55\%) had symptoms at the time of the PET-CT scan. Sixteen of them (36\%, 95\% Cl: $23-50 \%)$ had PD on PET-CT. The sensitivity and specificity of symptoms for the presence of progression was $67 \%$ (95\% Cl: $47-82 \%)$ and $62 \%$ (95\% Cl: 51-72\%), respectively. In 13/16 (81\%, 95\% Cl: 57-93\%) patients, the symptoms were in agreement with the site of progression. In the whole group, cough was the most common symptom, followed by pain. In the subgroup of patients with progression, pain was by far the most common symptom. 


\begin{tabular}{lcccc}
\hline \multicolumn{5}{l}{ Table 5.3 Type and frequency of symptoms according to the presence or absence of progression } \\
\hline Symptoms & All patients & Pts without progression & Pts with progression & p-value \\
& $(\%)$ & $(\%)$ & $(\%)$ & 0.42 \\
Cough & 18 & 20 & 13 & $<0.001$ \\
Pain & 15 & 5 & 46 & 0.81 \\
Dyspnea & 14 & 15 & 13 & 0.01 \\
Neurological & 6 & 3 & 17 & 0.70 \\
Dysphagia & 3 & 3 & 4 & 0.38 \\
Malaise & 2 & 1 & 4 & 0.07 \\
Palpable mass & 1 & 0 & 4 & 0.57 \\
Fatigue & 1 & 1 & 0 & \\
\hline
\end{tabular}

\section{Treatment at the time of progression}

The type of treatment of the patients after detection of PD is described in Figure 5.1. Of the 24 patients, 18 (75\%, $95 \mathrm{Cl}: 55-88 \%)$ underwent treatment directly after the detection of PD.

PD amenable for salvage treatment was detected in 3/100 (3\%, 95\% Cl: $1-8 \%$ ) patients (Table 5.4), of which two eventually received a radical treatment.

\begin{tabular}{|c|c|c|c|c|c|c|c|}
\hline Case & $\begin{array}{l}\text { Primary } \\
\text { stage }\end{array}$ & $\begin{array}{c}\text { Follow } \\
\text { up }^{*}\end{array}$ & Interval $^{*}$ & Results PET & Results CT & Therapy & Outcome $^{* *}$ \\
\hline 1 & T4NOMO & 22 & 12 & $\begin{array}{l}\text { Partial remis- } \\
\text { sion of } \\
\text { primary } \\
\text { tumour } \\
\text { Hotspot left- } \\
\text { adrenal } \\
\text { gland }\end{array}$ & $\begin{array}{l}\text { Volume } \\
\text { reduction } \\
\text { of primary } \\
\text { tumour } \\
\text { Nodus } 1.8 \\
\text { cm left } \\
\text { adrenal } \\
\text { gland }\end{array}$ & $\begin{array}{l}\text { Proposed for } \\
\text { pneumonectomy } \\
\text { and resection of } \\
\text { adrenal metasta- } \\
\text { sis } \\
\text { No candidate for } \\
\text { pneumonectomy } \\
\rightarrow \text { second line CTx }\end{array}$ & $\begin{array}{l}10 \text { wks: } \\
\text { alive }\end{array}$ \\
\hline 2 & T1NOM0 & 70 & 18 & $\begin{array}{l}\text { Hotspot left } \\
\text { hilar node }\end{array}$ & Negative & Radical RT & $\begin{array}{l}52 \text { wks: } \\
\text { alive; NED }\end{array}$ \\
\hline 3 & T2N3M0 & 89 & 13 & $\begin{array}{l}\text { Pathological } \\
\text { uptake in } \\
\text { both adrenal } \\
\text { glands }\end{array}$ & $\begin{array}{l}\text { Slight } \\
\text { increase in } \\
\text { volume of } \\
\text { both } \\
\text { adrenal } \\
\text { glands }\end{array}$ & $\begin{array}{l}\text { Bilateral extirpa- } \\
\text { tion of adrenal } \\
\text { glands }\end{array}$ & $\begin{array}{l}76 \text { wks: } \\
\text { alive; NED }\end{array}$ \\
\hline
\end{tabular}

CTx: chemotherapy; RT: Radiotherapy; NED: no evidence of disease.

*Weeks from start of radiotherapy

$* *$ Weeks from diagnosis of progressive disease

All 3 were detected by PET, and none of the 3 patients had symptoms at the time of detection of PD. The first patient finally underwent palliative chemotherapy because her lung function did not allow a pneumonectomy. The second patient had 
regional progression in the left hilus, which was treated with radical $\mathrm{RT}$, and was alive without evidence of disease 1 year after the diagnosis of PD. The third patient was diagnosed with bilateral adrenal metastases (Figure 5.2), for which he underwent a bilateral extirpation of the adrenal glands. Pathological examination confirmed the presence of adrenal metastases. He was alive without evidence of disease 1.5 years after diagnosis of the distant metastases.

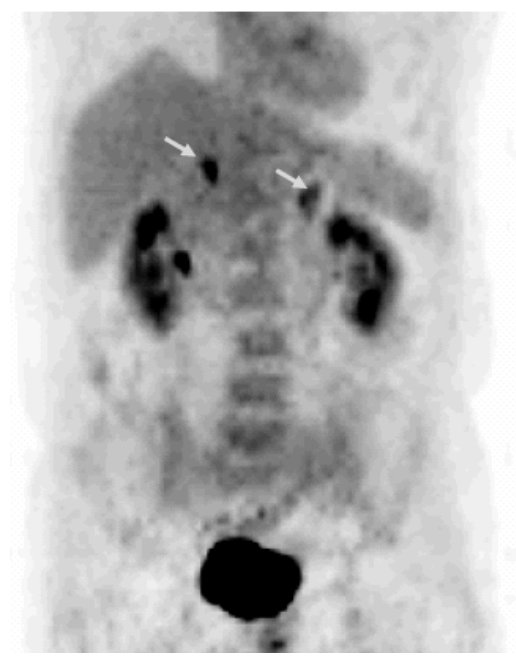

Figure 5.2 Case 3. Bilateral adrenal metastases

\subsection{Discussion}

At present, no data from randomized trials are available concerning the optimal follow-up in NSCLC, while other available data show inconsistent results ${ }^{33}$. Guidelines from different cancer associations differ widely in their recommendations concerning chest imaging, from either no routine imaging to surveillance chest CTscanning. No evidence exists that extensive follow-up with surveillance chest CTimaging is superior to routine follow-up with physical examination and a chest $X$ ray. A major disadvantage of CT- scanning is the poor sensitivity and specificity for distinguishing post treatment changes from progressive disease, which is reflected in a high negative predictive value (99\%) and a low positive predictive value $(53 \%)^{7}$, ${ }^{10}$. The accuracy of PET after treatment is assumed to be lower than that initial staging because of inflammatory and perfusion changes due to therapy ${ }^{12}$. Nevertheless, PET has still shown to have a high accuracy in detecting recurrent lung cancer, with a sensitivity up to $98 \%$ and a specificity of $62-92 \%{ }^{9,12,34}$. In this study, by using combined PET-CT scans, post-RT changes could be distinguished from PD in all patients. 
Early detection of isolated locoregional progression or oligometastasis could allow a radical treatment, with long term survival rates up to $30 \%$ and $22 \%$, respectively ${ }^{28}$, 35-37. In the present trial, PET-CT scanning 3 months after curative treatment for NSCLC led to the detection of PD potentially amenable for radical treatment in $3 / 100$ (3\%, $95 \% \mathrm{Cl} 1-8 \%)$ patients. These 3 patients were all asymptomatic and progression was only detected with PET, not with CT alone. The most important question is whether an earlier detection of progression results in a longer overall survival. The improved overall survival reported in some retrospective studies, could be attributable to lead time bias ${ }^{5,8,38}$. In the present study, we showed that none of the symptomatic patients with PD were amenable for radical treatment. Furthermore, none of the patients in whom progression was detected with CT only were amenable for radical treatment, while 3 out of 8 patients with progression (all detected with PET) in asymptomatic patients were potentially amenable for radical treatment. The detection of PD with PET-CT in the 2 patients who finally received a radical treatment, being alive without evidence of disease 52 and 76 weeks after salvage therapy, has almost certainly led to a longer overall survival compared to a policy in which diagnostics were only performed at the time when symptoms developed. Of the 3 patients with PD potentially amenable for radical treatment, two had (either uni- or bilateral) adrenal metastases. Because radical treatment by adrenalectomy may result in long term survival rates of $25 \%{ }^{39}$, we believe that there are good arguments to treat this patient group with radical intent.

No pathological confirmation was obtained in the patient with regional progression in the left hilus and in one of the patients with adrenal metastases on PET. As reported earlier, the accuracy of FDG-PET-scanning for the detection of a recurrence is high, with a specificity of $84 \%{ }^{9}$. The accuracy of FDG-PET for the diagnosis of adrenal metastasis is reported to be $92-100 \%{ }^{40-42}$.

Another important aspect is the timing of the PET-CT. It is recommended to perform a PET-CT scan not earlier than 3 to 6 months after treatment to avoid false positive results due to post-radiotherapy changes ${ }^{12,43}$. Hicks and colleagues found no confounding of the evaluation of tumour response by the presence of post radiotherapy inflammatory changes in 73 patients who underwent a PET-CT scan 70 days after radical radiotherapy ${ }^{44}$. Our data support those findings, as post-radiotherapy changes, being present in $36 \%$ of patients, did not influence the response evaluation. Furthermore, uptake associated with post radiotherapy pneumonitis can last for 15 months after the end of radiotherapy ${ }^{45}$. Theoretically, performing a PET-CT scan earlier after therapy could result in the detection of more cases with potentially curable disease.

A potential drawback of PET-CT is that it is rather costly. An important topic for further research is therefore whether the effects of PET-CT are worth the extra 
costs and for which patient groups routine PET-CT would be deemed cost-effective. As PD amenable for salvage treatment was only detected in asymptomatic patients, the added value of routine PET-CT imaging seems to be confined to this group (55\% of the patients). In patients with symptoms three months after treatment, the type of symptoms could guide the choice for an additional investigation, and routine PETCT imaging could possibly be reserved for the selection of patients without symptoms. Hereby, a potentially cost-effective follow-up method could be developed. The cost-effectiveness of PET-CT imaging in the follow-up will be examined in a separate study.

\subsection{Conclusion}

For all patients, PET-CT scanning after curative treatment for NSCLC led to the detection of progression amenable for salvage treatment in a small proportion, which is of questionable clinical value. The possible advantage seems to be confined to the patient group without symptoms. Selectively offering a PET-CT scan to this patient group could lead to an effective follow-up method. Further research is needed in this field. 


\subsection{References}

1. Jemal A, Siegel R, Ward E, et al. Cancer Statistics, 2008. CA Cancer J Clin 2008.

2. Mountain CF. Revisions in the International System for Staging Lung Cancer. Chest 1997;111:1710-7.

3. Auperin A, Le Pechoux C, Pignon JP, et al. Concomitant radio-chemotherapy based on platin compounds in patients with locally advanced non-small cell lung cancer (NSCLC): a meta-analysis of individual data from 1764 patients. Ann Oncol 2006;17:473-83.

4. Patterns of failure in patients with resected stage I and II non-small-cell carcinoma of the lung. The Ludwig Lung Cancer Study Group. Ann Surg 1987;205:67-71.

5. Benamore R, Shepherd FA, Leighl N, et al. Does intensive follow-up alter outcome in patients with advanced lung cancer? J Thorac Oncol 2007;2:273-81.

6. Edelman MJ, Schuetz J. Follow-up of local (stage I and stage II) non-small-cell lung cancer after surgical resection. Curr Treat Options Oncol 2002;3:67-73.

7. Korst RJ, Gold HT, Kent MS, Port JL, Lee PC, Altorki NK. Surveillance computed tomography after complete resection for non-small cell lung cancer: results and costs. J Thorac Cardiovasc Surg 2005;129:652-60.

8. Walsh GL, O'Connor M, Willis KM, et al. Is follow-up of lung cancer patients after resection medically indicated and cost-effective? Ann Thorac Surg 1995;60:1563-70; discussion 70-2.

9. Rubins J, Unger M, Colice GL. Follow-up and surveillance of the lung cancer patient following curative intent therapy: ACCP evidence-based clinical practice guideline (2nd edition). Chest 2007;132:355S675.

10. Korst RJ, Kansler AL, Port JL, Lee PC, Altorki NK. Accuracy of surveillance computed tomography in detecting recurrent or new primary lung cancer in patients with completely resected lung cancer. Ann Thorac Surg 2006;82:1009-15; discussion 15.

11. Toloza EM, Harpole L, McCrory DC. Noninvasive staging of non-small cell lung cancer: a review of the current evidence. Chest 2003;123:137S-46S.

12. Bruzzi JF, Munden RF. PET/CT imaging of lung cancer. J Thorac Imaging 2006;21:123-36.

13. van Baardwijk A, Baumert BG, Bosmans $G$, et al. The current status of FDG-PET in tumour volume definition in radiotherapy treatment planning. Cancer Treat Rev 2006;32:245-60.

14. Baum RP, Hellwig D, Mezzetti M. Position of nuclear medicine modalities in the diagnostic workup of cancer patients: lung cancer. Q J Nucl Med Mol Imaging 2004;48:119-42.

15. Ahuja V, Coleman RE, Herndon J, Patz EF, Jr. The prognostic significance of fluorodeoxyglucose positron emission tomography imaging for patients with nonsmall cell lung carcinoma. Cancer 1998;83:918-24.

16. Downey RJ, Akhurst T, Gonen M, et al. Preoperative F-18 fluorodeoxyglucose-positron emission tomography maximal standardized uptake value predicts survival after lung cancer resection. J Clin Oncol 2004;22:3255-60.

17. Jeong HJ, Min JJ, Park JM, et al. Determination of the prognostic value of [(18)F]fluorodeoxyglucose uptake by using positron emission tomography in patients with non-small cell lung cancer. Nucl Med Commun 2002;23:865-70.

18. Mac Manus MP, Hicks RJ, Matthews JP, et al. Positron emission tomography is superior to computed tomography scanning for response-assessment after radical radiotherapy or chemoradiotherapy in patients with non-small-cell lung cancer. J Clin Oncol 2003;21:1285-92.

19. Patz EF, Jr., Connolly J, Herndon J. Prognostic value of thoracic FDG PET imaging after treatment for non-small cell lung cancer. AJR Am J Roentgenol 2000;174:769-74.

20. van Baardwijk A, Dooms C, van Suylen RJ, et al. The maximum uptake of (18)F-deoxyglucose on positron emission tomography scan correlates with survival, hypoxia inducible factor-1alpha and GLUT-1 in non-small cell lung cancer. Eur J Cancer 2007;43:1392-8. 
21. Berghmans $T$, Dusart M, Paesmans $M$, et al. Primary tumor standardized uptake value (SUVmax) measured on fluorodeoxyglucose positron emission tomography (FDG-PET) is of prognostic value for survival in non-small cell lung cancer (NSCLC): a systematic review and meta-analysis (MA) by the European Lung Cancer Working Party for the IASLC Lung Cancer Staging Project. J Thorac Oncol 2008;3:6-12.

22. Kased N, Erasmus JJ, Komaki R, Cox JD. Prognostic value of posttreatment [18F] fluorodeoxyglucose uptake of primary non-small cell lung carcinoma treated with radiation therapy with or without chemotherapy: a brief review. J Thorac Oncol 2008;3:534-8.

23. Duhaylongsod FG, Lowe VJ, Patz EF, Jr., Vaughn AL, Coleman RE, Wolfe WG. Detection of primary and recurrent lung cancer by means of F-18 fluorodeoxyglucose positron emission tomography (FDG PET). J Thorac Cardiovasc Surg 1995;110:130-9; discussion 9-40.

24. Patz EF, Jr., Lowe VJ, Hoffman JM, Paine SS, Harris LK, Goodman PC. Persistent or recurrent bronchogenic carcinoma: detection with PET and 2-[F-18]-2-deoxy-D-glucose. Radiology 1994;191:379-82.

25. van Baardwijk A, Bosmans G, Boersma L, et al. Individualized Radical Radiotherapy of Non-Small-Cell Lung Cancer Based on Normal Tissue Dose Constraints: A Feasibility Study. Int J Radiat Oncol Biol Phys 2008.

26. Young $\mathrm{H}$, Baum R, Cremerius $\mathrm{U}$, et al. Measurement of clinical and subclinical tumour response using [18F]-fluorodeoxyglucose and positron emission tomography: review and 1999 EORTC recommendations. European Organization for Research and Treatment of Cancer (EORTC) PET Study Group. Eur J Cancer 1999;35:1773-82.

27. Therasse $P$, Arbuck SG, Eisenhauer EA, et al. New guidelines to evaluate the response to treatment in solid tumors. European Organization for Research and Treatment of Cancer, National Cancer Institute of the United States, National Cancer Institute of Canada. J Natl Cancer Inst 2000;92:205-16.

28. Khan AJ, Mehta PS, Zusag TW, et al. Long term disease-free survival resulting from combined modality management of patients presenting with oligometastatic, non-small cell lung carcinoma (NSCLC). Radiother Oncol 2006;81:163-7.

29. Hellwig D, Groschel A, Graeter TP, et al. Diagnostic performance and prognostic impact of FDG-PET in suspected recurrence of surgically treated non-small cell lung cancer. Eur J Nucl Med Mol Imaging 2006;33:13-21.

30. van Baardwijk A, Bosmans G, Dekker A, et al. Time trends in the maximal uptake of FDG on PET scan during thoracic radiotherapy. A prospective study in locally advanced non-small cell lung cancer (NSCLC) patients. Radiother Oncol 2007;82:145-52.

31. Mac Manus MP, Hicks RJ, Matthews JP, Wirth A, Rischin D, Ball DL. Metabolic (FDG-PET) response after radical radiotherapy/chemoradiotherapy for non-small cell lung cancer correlates with patterns of failure. Lung Cancer 2005;49:95-108.

32. Wilson. Probable inference, the law of succession, and statistical inference. I Am Stat Assoc 1927;22:209-12.

33. Smith TJ. Evidence-based follow-up of lung cancer patients. Semin Oncol 2003;30:361-8.

34. Hicks RJ, Kalff V, MacManus MP, et al. The utility of (18)F-FDG PET for suspected recurrent non-small cell lung cancer after potentially curative therapy: impact on management and prognostic stratification. J Nucl Med 2001;42:1605-13.

35. Curran WJ, Jr., Herbert SH, Stafford PM, et al. Should patients with post-resection locoregional recurrence of lung cancer receive aggressive therapy? Int J Radiat Oncol Biol Phys 1992;24:25-30.

36. Okamoto $\mathrm{Y}$, Murakami M, Yoden E, et al. Reirradiation for locally recurrent lung cancer previously treated with radiation therapy. Int J Radiat Oncol Biol Phys 2002;52:390-6.

37. Zimmermann FB, Molls M, Jeremic B. Treatment of recurrent disease in lung cancer. Semin Surg Oncol 2003;21:122-7.

38. Westeel V, Choma D, Clement F, et al. Relevance of an intensive postoperative follow-up after surgery for non-small cell lung cancer. Ann Thorac Surg 2000;70:1185-90. 
39. Tanvetyanon T, Robinson LA, Schell MJ, et al. Outcomes of adrenalectomy for isolated synchronous versus metachronous adrenal metastases in non-small-cell lung cancer: a systematic review and pooled analysis. J Clin Oncol 2008;26:1142-7.

40. Boland GW, Goldberg MA, Lee MJ, et al. Indeterminate adrenal mass in patients with cancer: evaluation at PET with 2-[F-18]-fluoro-2-deoxy-D-glucose. Radiology 1995;194:131-4.

41. Erasmus JJ, Patz EF, Jr., McAdams HP, et al. Evaluation of adrenal masses in patients with bronchogenic carcinoma using 18F-fluorodeoxyglucose positron emission tomography. AJR Am J Roentgenol 1997; 168:1357-60.

42. Yun M, Kim W, Alnafisi N, Lacorte L, Jang S, Alavi A. 18F-FDG PET in characterizing adrenal lesions detected on CT or MRI. J Nucl Med 2001;42:1795-9.

43. Keidar Z, Haim N, Guralnik L, et al. PET/CT using 18F-FDG in suspected lung cancer recurrence: diagnostic value and impact on patient management. J Nucl Med 2004;45:1640-6.

44. Hicks RJ, Mac Manus MP, Matthews JP, et al. Early FDG-PET imaging after radical radiotherapy for non-small-cell lung cancer: inflammatory changes in normal tissues correlate with tumor response and do not confound therapeutic response evaluation. Int J Radiat Oncol Biol Phys 2004;60:412-8.

45. Bury T, Corhay JL, Duysinx B, et al. Value of FDG-PET in detecting residual or recurrent nonsmall cell lung cancer. Eur Respir J 1999;14:1376-80. 


\title{
CHAPTER 6
}

\section{${ }^{18}$ FDG-PET-CT in the follow-up of} non-small cell lung cancer patients after radical radiotherapy with or without chemotherapy: an economic evaluation

\author{
Judith van Loon \\ Janneke Grutters \\ Rinus Wanders \\ Liesbeth Boersma \\ Anne-Marie Dingemans \\ Gerben Bootsma \\ Wiel Geraedts \\ Cordula Pitz \\ Jean Simons \\ Boudewijn Brans \\ Gabriel Snoep \\ Monique Hochstenbag \\ Philippe Lambin \\ Dirk De Ruysscher
}

European Journal of Cancer 2010;46:110-9 


\section{Abstract}

\section{Background and purpose}

The optimal follow-up strategy of non-small cell lung cancer (NSCLC) patients after curative intent therapy is still not established. In a recent prospective study with 100 patients, we showed that an FDG-PET-CT 3 months after radiotherapy could identify progression amenable for curative treatment in $2 \%(95 \% \mathrm{Cl}: 1-7 \%)$ of patients, who were all asymptomatic. Here, we report on the economic evaluation of this study.

\section{Methods and Materials}

A decision-analytic Markov model was developed in which the long-term costeffectiveness of 3 follow-up strategies was modelled with different imaging methods 3 months after therapy: a PET-CT scan; a chest CT scan; and conventional follow-up with a chest X-ray. A probabilistic sensitivity analysis was performed to account for uncertainty. Because the results of the prospective study indicated that the advantage seems to be confined to asymptomatic patients, we additionally examined a strategy where a PET-CT was applied only in the subgroup of asymptomatic patients. Cost-effectiveness of the different follow-up strategies was expressed in incremental cost-effectiveness ratios (ICERs), calculating the incremental costs per quality adjusted life year (QALY) gained.

\section{Results}

Both PET-CT and CT based follow-up were more costly but also more effective than conventional follow-up. CT-based follow-up was only slightly more effective than conventional follow-up, resulting in an incremental cost-effectiveness ratio (ICER) of $€ 264.033$ per QALY gained. For PET-CT based follow-up, the ICER was $€ 69.086$ per QALY gained compared to conventional follow-up. The strategy in which a PET-CT was only performed in the asymptomatic subgroup resulted in an ICER of $€ 42.265$ per QALY gained as opposed to conventional follow-up. With this strategy, given a ceiling ratio of $€ 80.000$, PET-CT based follow-up had the highest probability of being cost-effective (73\%).

\section{Conclusions}

This economic evaluation shows that a PET-CT scan 3 months after (chemo)radiotherapy with curative intent is a potentially cost-effective follow-up method, and is more cost-effective than CT alone. Applying a PET-CT scan only in asymptomatic patients is probably as effective and more cost-effective. It is worthwhile to perform additional research to reduce uncertainty regarding the decision concerning imaging in the follow-up of NSCLC. 


\subsection{Introduction}

The most effective follow-up strategy for non-small cell lung cancer (NSCLC) patients treated with curative intent with radiotherapy (RT) with or without chemotherapy is still not established. This uncertainty is reflected in the large heterogeneity in recommendations from the different cancer societies, diverging from no imaging at all to repeated imaging with chest $\mathrm{CT}$ scans ${ }^{1}$. The added value of chest $\mathrm{X}$-rays and/or chest CT has not been confirmed in any prospective study. A major reason for this lack of efficacy is the poor discriminating capacity of both imaging modalities. Here, ${ }^{18}$ FDG-PET-CT could have additional benefit, which has shown to be more accurate than $\mathrm{CT}$ in the evaluation of response to treatment as well as in outcome prediction ${ }^{2-4}$. We recently reported the results of a prospective study in 100 patients treated with chemo-radiotherapy or RT alone with curative intent, which showed that indeed, an FDG-PET-CT 3 months after therapy can detect progression amenable for treatment with curative intent, and hereby, possibly lead to an increase in survival ${ }^{5}$. Progressive disease (PD) amenable for curative treatment, however, was only found in $2 \%$ (95\% confidence interval $(\mathrm{Cl}): 1-7 \%$ ) of patients. The study showed that the advantage seemed to be confined to the patient group that did not have symptoms at the time that the PET-CT scan was performed. In this patient group, $5 \%$ (95\% Cl: $2-15 \%$ ) had progression, potentially amenable for curative therapy, which were all detected with FDG-PET, not with CT alone. In contrast, none of the symptomatic patients were diagnosed with progression with curative treatment options.

While a PET-CT scan 3 months post-treatment thus seems to be potentially beneficial, at least in a subset of patients, it is also more costly. This raises the question regarding the cost-effectiveness of a PET-CT-based follow-up method compared to usual follow-up with either repeated chest X-rays or CT scans, or imaging on the basis of symptoms. In order to make an evidence-based decision regarding which follow-up strategy to prefer, the costs of each strategy are essential to take into account. Information regarding cost-effectiveness can be obtained through an economic evaluation, in which a comparative analysis is performed of alternative courses of action in terms of both their costs and consequences ${ }^{6}$, on the basis of the currently available evidence.

To be able to add this information to the decision making process, we performed the current economic evaluation to evaluate the cost-effectiveness of PET-CT based follow-up as opposed to conventional follow-up in NSCLC patients treated with curative (chemo)RT. 


\subsection{Methods and Materials}

Three follow-up strategies were compared with different imaging methods 3 months after therapy: the "usual" or conventional follow-up (anamnesis, physical examination and a chest X-ray), the PET-CT based follow-up (anamnesis, physical examination and a PET-CT scan) and the CT based follow-up (anamnesis, physical examination and a chest CT scan). After the 3 months post-treatment time-point, the follow-up was the same for the different strategies. Details regarding these follow-up policies are provided in Table 6.1. Because the results of the prospective study implied that the advantage of the PET-CT seems to be confined to the patient group without symptoms at the time of the PET-CT scan (55\% of patients) ${ }^{5}$, we additionally examined a strategy where a PET-CT was applied only in the asymptomatic subgroup. Within this strategy, symptomatic patients did not receive a standard PET-CT scan, but underwent imaging on the basis of the location of symptoms (conform Table 6.1).

\begin{tabular}{|c|c|c|c|c|}
\hline \multirow[t]{2}{*}{ Follow-up strategy } & \multirow{2}{*}{$\begin{array}{l}\text { Imaging } 3 \text { months } \\
\text { after RT }\end{array}$} & \multicolumn{3}{|c|}{ Imaging at follow-up visits after $\mathbf{3}$ months } \\
\hline & & No recurrence & $P D$, treated & $P D$, not treated \\
\hline Usual & $\begin{array}{l}\text { CXR + on basis of } \\
\text { symptoms* }\end{array}$ & CXR & Chest CT & none \\
\hline CT based & $\begin{array}{l}\text { Chest } \mathrm{CT}+\text { on basis of } \\
\text { symptoms* }\end{array}$ & CXR & Chest CT & none \\
\hline PET-CT based & РET-CT & CXR & Chest CT & none \\
\hline \multicolumn{5}{|c|}{ *Imaging on basis of symptoms } \\
\hline $\begin{array}{l}\text { Symptoms } \\
\text { Pain }\end{array}$ & \multicolumn{4}{|c|}{ Pain } \\
\hline Localized & \multicolumn{4}{|c|}{ Conventional radiography of involved region } \\
\hline Diffuse & \multicolumn{4}{|l|}{ Bone scintigraphy } \\
\hline Dyspnea & \multicolumn{4}{|l|}{ CXR } \\
\hline Cough & \multicolumn{4}{|l|}{ CXR } \\
\hline Dysphagia & \multicolumn{4}{|l|}{ Chest CT } \\
\hline Malaise & \multicolumn{4}{|c|}{ CXR + screening blood sample } \\
\hline Neurological & \multicolumn{4}{|l|}{ CT brain } \\
\hline Palpable mass & \multicolumn{4}{|l|}{$\mathrm{CT}$ of involved region } \\
\hline Fatigue & \multicolumn{4}{|l|}{ Screening blood sample } \\
\hline
\end{tabular}

\section{Model structure}

A Markov transition model was constructed with mutually exclusive health states to compare long-term costs and effects of the different follow-up strategies (Figure 6.1) ${ }^{7}$. The model simulated the course of events in a hypothetical cohort of NSCLC 
patients treated with curative RT with or without chemotherapy. Health states in the model were based on the absence or presence of progression and on the treatment of progression. Patients without progression were in the health state "no evidence of disease". Patients with progression were subdivided according to their treatment: progression without treatment, progression with palliative treatment or progression with curative treatment. Patients in the CT based or usual follow up strategy, who had progression 3 months after treatment that was only detected with PET-CT and not with CT alone, were assigned the health state "progression not detected". The final health state was "death".

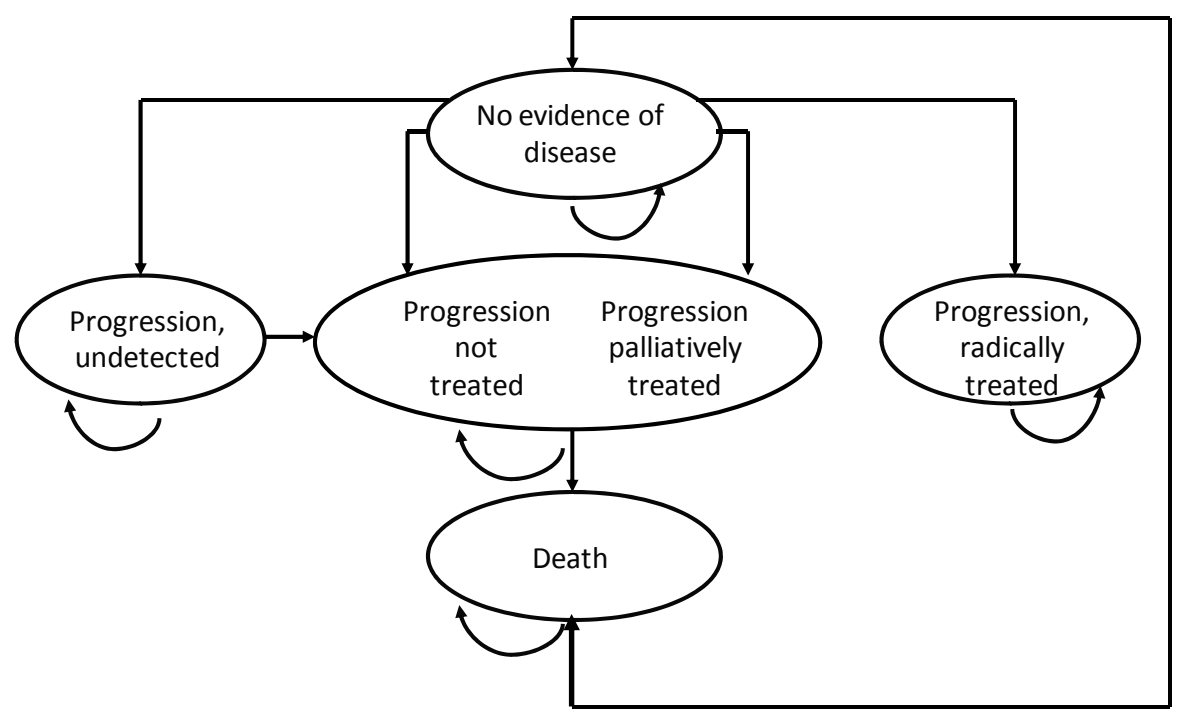

Figure 6.1 Markov Model

A hypothetical cohort of patients enters the model after the follow-up visit 3 months after radical (chemo-)RT. Patients are divided over the different health states according to the results of the prospective study

The start of the model was set after the first follow-up visit 3 months after radical therapy. At this time point, patients were divided between the different health states on the basis of the results of our prospective study ${ }^{5}$. In the model, patients moved between health states according to a set of transition probabilities. The cycle length of the model was 6 months, with a time horizon of 5 years.

\section{Data sources}

Input parameters were derived from the prospective study performed at our institute, published literature, the Dutch Health Insurance Board, and, if no other source was available, expert opinion. Details of the prospective study are published else- 
where ${ }^{5}$. In short, 100 patients with NSCLC, treated with curative intent with (chemo)radiation, were prospectively evaluated. All patients underwent a planned FDG-PET-CT scan 3 months after the start of radiotherapy, regardless of the presence of symptoms. Patients were judged symptomatic when any symptom was either new or had increased over time from the end of RT. Twenty-four percent (95\% Cl: $17-33 \%)$ of patients had progression 3 months post-treatment. No curative treatment could be offered to any of the patients who were symptomatic at the time of progression. In 2 of the 55 asymptomatic patients (4\%, 95\% Cl: $1-12 \%)$, tumour progression, amenable for curative therapy, was found, which was detected with PET, not with CT only. The first patient was treated with re-irradiation for a locoregional recurrence, the $2^{\text {nd }}$ patient was treated with adrenal resection for bilateral adrenal metastases.

\section{Probabilities}

All probabilities are listed in Table 6.2. As the cycle length was 6 months, probabilities of moving from one health state to another were calculated as 6 monthly transition probabilities. The median age of patients assumed to enter the model was 62 years, based on the patient characteristics of the prospective study ${ }^{5}$. The extra mortality risk for surviving lung cancer patients as opposed to the general population was $1.4^{8,9}$. Age-specific mortality rates were used for 5 year age groups (Central Bureau for Statistics, 2007). The probability of progression after 3 months was calculated on basis of a prospective study of Mac Manus and colleagues (1-, 2-, 3and 4 year progression free survival rates of $62 \%, 44 \%, 26 \%$ and $20 \%$ respectively) ${ }^{3}$. Patients with progression that was not treated were assumed to have a 1-year overall survival (OS) for an OS of $19 \%{ }^{8}$; patients who were palliatively treated for progression were assumed to have a 1 year OS of $30 \%{ }^{9}$. The 1 year OS for patients who were treated with curative intent was assumed to be $45 \%$, based on published results with re-irradiation and adrenal resection ${ }^{10,11}$. Percentages of patients receiving $2^{\text {nd }}$ and $3^{\text {rd }}$ line chemotherapy were based on a retrospective chart review of 417 patients with advanced NSCLC ${ }^{12}$.

\section{Costs}

An overview of the costs associated with the follow-up procedures, treatment, and terminal care is outlined in Table 6.2. All costs are reported in Euros and converted to the year 2008. Future costs and effects were discounted to their present value by a rate of $4 \%$ and $1.5 \%$, respectively ${ }^{13}$. Costs of diagnostic procedures and treatment were derived from the Dutch Health Insurance Board, adjusted to the 2007 price level (Central Bureau for Statistics 2007). The costs for first line chemotherapy were based on 4 cycles of docetaxel $75 \mathrm{mg} / \mathrm{m}^{2}$. Costs of second line chemotherapy were 
based on treatment with erlotinib during 125 days. Costs associated with side effects were based on calculations from the National Institute for Clinical Excellence ${ }^{14}$. The costs associated with dying were based on a report of Kommer and Polder ${ }^{15}$, in which costs associated with cancer death are described separately from costs associated with dying from other causes.

\section{Effects}

Global health-related quality of life (QOL) data were expressed in utility scores, varying from zero (death) to one (perfect health). The use of utility scores allows the calculation of Quality Adjusted Life Years (QALYS) and cost per QALY ratios. Utility scores were derived from a cross-sectional study performed by Trippoli and colleagues ${ }^{16}$. Based on this study, patients with progression had a utility score of 0.53 , while patients without progression had a utility score of 0.68 . Patients with progression that was curatively treated were assumed to have the same utility score as patients without progression, based on expert opinion (DDR). Furthermore, patients that were treated with palliative intent for PD were assumed to have the same utility as patients who received no treatment, on the basis of literature showing no significant difference in QOL with the administration of docetaxel $75 \mathrm{mg} / \mathrm{m}^{2}$ as second line chemotherapy ${ }^{17}$. All utility scores are listed in Table 6.2. 
Table 6.2 Inputs

Estimated value

SE

Distribution Source

\section{Transition probabilities}

\section{First 3 months}

Strategy independent probabilities

PD

Symptoms with PD

Symptoms without PD

Strategy dependent probabilities

PET-CT

Detection of symptomatic PD

Detection of asymptomatic PD

Treatment of asymptomatic PD

Treatment of symptomatic PD

Radical treatment of asymptomatic PD

Radical treatment of symptomatic PD

CT

Detection of symptomatic PD

Detection of asymptomatic PD

Treatment of asymptomatic PD

Treatment of symptomatic PD

Radical treatment of asymptomatic PD

Radical treatment of symptomatic PD

Usual

Detection of symptomatic PD

Detection of asymptomatic PD

Treatment of asymptomatic PD

Treatment of symptomatic PD

Radical treatment of asymptomatic PD

Radical treatment of symptomatic PD
0.24

0.68

0.38

0.04

0.09

0.06

beta

beta

beta

[1]

[1]

[1]

\section{1}

1

0.63

0.81

0.4

0

1

0.5

0.63

0.81

0

0

1

0

0

0.81

0

0 fixed

fixed

0.16

0.095

0.2

fixed

fixed

0.17

0.16

0.095

fixed

fixed

fixed

fixed

fixed

0.095

fixed

fixed
EO

EO

beta

beta

beta

beta [1]

beta [1]

beta [1]

[1]

[1]

EO

EO

[1]

beta [1]

[1]

\section{After 3 months}

Progression

Detection of undetected PD

$P D, 2^{\text {nd }}$ year

0.036

beta

$P D, 3^{\text {rd }}$ year

0.23

beta

[2]

$P D, 4^{\text {th }}$ year

0.12

0.036

beta

[2]

[2] 


\begin{tabular}{lcccc}
\hline Table 6.2 Inputs & & & & \\
\hline & Estimated value & SE & Distribution & Source \\
Treatment & & & & \\
Radical & 0.01 & 0.02 & dirichlet & EO \\
Palliative & 0.56 & 0.02 & dirichlet & {$[3]$} \\
No treatment & 0.43 & 0.02 & dirichlet & {$[3]$} \\
& & & & \\
Death & & & & \\
Death with PD, no treatment & 0.56 & 0.025 & beta & {$[4]$} \\
Death with PD, palliative treatment & 0.46 & 0.025 & beta & {$[5]$} \\
Death with PD, radical treatment & & & & \\
$1^{\text {st }}$ year & 0.33 & 0.019 & beta & {$[6,7]$} \\
$2^{\text {nd }}$ year & 0.18 & 0.019 & beta & \\
$3^{\text {rd }}$ year & 0.02 & 0.019 & beta & \\
Death with undetected PD & 0.54 & 0.025 & beta & EO ${ }^{1}$
\end{tabular}

\section{Utility scores}

No PD

$\mathrm{PD}$, not treated

$\mathrm{PD}$, palliatively treated

$P D$, radically treated

PD, undetected

\section{Costs}

\section{Diagnostics}

\section{First 3 months}

PET-CT whole body

Chest-CT

CXR

Follow-up visit

After 3 months ${ }^{2}$

Follow-up, No $P D^{3}$

$1^{\text {st }}$ year

$2^{\text {nd }}$ year

$3^{\text {rd+ }}$ year

Follow-up, PD

Treated $^{4}$

Untreated $^{5}$

\section{Treatment}

Probability of $2^{\text {nd }}$ line chemotherapy Probability of palliative RT
0.68

0.53

0.53

0.68

0.53
49

$\begin{array}{ll}0.1 & \text { beta } \\ 0.1 & \text { beta } \\ 0.1 & \text { beta } \\ 0.1 & \text { beta } \\ 0.1 & \text { beta }\end{array}$

[8]

[8]

EO

EO

[8]

$\begin{array}{ccc}1364 & \text { fixed } & {[9]} \\ 206 & \text { fixed } & {[9]} \\ 39 & \text { fixed } & {[9]} \\ 59 & \text { fixed } & {[9]}\end{array}$

[9]

fixed [9]

$0.18 \quad 0.018$ beta [10]




\begin{tabular}{|c|c|c|c|c|}
\hline Table 6.2 Inputs & & & & \\
\hline & \multicolumn{3}{|c|}{ Unit costs } & Source \\
\hline Radical $^{6}$ & 5746 & fixed & & {$[1,9]$} \\
\hline \multicolumn{5}{|l|}{ Palliative chemotherapy } \\
\hline \multicolumn{5}{|l|}{$1^{\text {st }} /$ line ${ }^{7}$} \\
\hline No of cycles & 4 & & & [5] \\
\hline Costs/cycle & 1302 & & & [9] \\
\hline Side effects & 349 & & & {$[11]$} \\
\hline Total costs & 5557 & fixed & & \\
\hline \multicolumn{5}{|l|}{$2^{\text {nd }} l i n e^{8}$} \\
\hline Mean treatment time (days) & 125 & & & [9] \\
\hline Costs/treatment & 9100 & & & [9] \\
\hline Side effects & 120 & & & {$[11]$} \\
\hline Total costs & 9220 & fixed & & \\
\hline Palliative $R T$ & 1017 & fixed & & {$[9]$} \\
\hline \multicolumn{5}{|l|}{ Dying } \\
\hline Dying of cancer, terminal care ${ }^{9}$ & 11602 & 800 & gamma & {$[12]$} \\
\hline Dying of other causes & 15448 & 800 & gamma & {$[12]$} \\
\hline
\end{tabular}

EO: expert opinion; CXR: Chest X-ray; RT: radiotherapy; DHIB: Dutch Health Insurance Board

${ }^{1}$ Calculated from the probability of dying with a recurrence without treatment and with palliative treatment

${ }^{2}$ Costs per 6 monthly cycle

${ }^{3}$ Based on follow-up visit with CXR, 4 times in $1^{\text {st }}$ year, twice in $2^{\text {nd }}$ year and once a year thereafter

${ }^{4}$ Based on follow-up visit with chest-CT, 4 times/year

${ }^{5}$ Based on follow-up visit without imaging, 4 times/year

${ }^{6}$ Based on type of radical treatment in prospective study, being adrenal resection and radical radiotherapy

${ }^{7}$ Docetaxel, 3-weekly cycles

${ }^{8}$ Erlotinib

${ }^{9}$ The costs of dying from cancer described in Kommer et al. were discounted by the costs of palliative treatment calculated in the current study

\section{Sources:}

1. van Loon, J., et al., Follow-up with 18FDG-PET-CT after radical radiotherapy with or without chemotherapy allows the detection of potentially curable progressive disease in non-small cell lung cancer patients: a prospective study. Eur J Cancer, 2009. 45(4): p. 588-95.

2. Mac Manus, M.P., et al., Metabolic (FDG-PET) response after radical radiotherapy/chemoradiotherapy for non-small cell lung cancer correlates with patterns of failure. Lung Cancer, 2005. 49(1): p. 95-108.

3. Murillo, J.R., Jr. and J. Koeller, Chemotherapy given near the end of life by community oncologists for advanced non-small cell lung cancer. Oncologist, 2006. 11(10): p. 1095-9.

4. Shepherd, F.A., et al., Prospective randomized trial of docetaxel versus best supportive care in patients with non-small-cell lung cancer previously treated with platinum-based chemotherapy. J Clin Oncol, 2000. 18(10): p. 2095-103.

5. Hanna, N., et al., Randomized phase III trial of pemetrexed versus docetaxel in patients with nonsmall-cell lung cancer previously treated with chemotherapy. J Clin Oncol, 2004. 22(9): p. 1589-97.

6. Khan, A.J., et al., Long term disease-free survival resulting from combined modality management of patients presenting with oligometastatic, non-small cell lung carcinoma (NSCLC). Radiother Oncol, 2006. 81(2): p. 163-7. 
7. Tanvetyanon, T., et al., Outcomes of adrenalectomy for isolated synchronous versus metachronous adrenal metastases in non-small-cell lung cancer: a systematic review and pooled analysis. J Clin Oncol, 2008. 26(7): p. 1142-7.

8. Trippoli, S., et al., Quality of life and utility in patients with non-small cell lung cancer. Quality-of-life Study Group of the Master 2 Project in Pharmacoeconomics. Pharmacoeconomics, 2001. 19(8): p. 855-63.

9. Oostenbrink J, B.C., Koopmanschap M, Rutten F, Handleiding voor kostenonderzoek, methoden en standaard kostprijzen voor economische evaluaties in de gezondheidszorg, C.v. Zorgverzekeringen, Editor. 2004.

10. Tyldesley, S., et al., Estimating the need for radiotherapy for lung cancer: an evidence-based, epidemiologic approach. Int J Radiat Oncol Biol Phys, 2001. 49(4): p. 973-85.

11. NHS, Nice guideline costing statement: Erlotinib for the treatment of NSCLC. 2008, National Institute for Clinical Excellence

12. Kommer G, S.L., Polder J., Risicosolidariteit en Zorgkosten, Quantes, Editor. 2005, Raad voor de Volksgezondheid en Zorg: Zoetermeer

\section{Cost-effectiveness analysis}

The analysis was performed from a health care perspective. The cost-effectiveness of the different follow-up strategies was compared using incremental costeffectiveness ratios (ICERs), calculating the incremental costs per QALY gained. Whether a follow-up strategy is deemed cost-effective depends on how much the society is willing to pay for a gain in effect, which is referred to as the ceiling ratio. The Dutch Health Council advises an informal ceiling ratio of $€ 80.000{ }^{18}$.

The input parameters of the model are inevitably associated with uncertainty. Probabilistic modelling is used to reflect this uncertainty in the parameters and to describe the effects on uncertainty over the outputs of interest ${ }^{19}$. Distributions to the model parameters, based on their mean value and standard error, were assigned to reflect the uncertainty in the estimation of that parameter (Table 6.2) ${ }^{20}$. A probabilistic sensitivity analysis was performed using Monte Carlo simulation with 5,000 random iterations from the assigned distributions. To illustrate the results of the simulation, cost-effectiveness acceptability curves (CEACs) were calculated to characterize the likelihood that a certain follow-up strategy would be deemed costeffective at different ceiling ratios ${ }^{19}, 21$, representing the uncertainty surrounding the cost-effectiveness for this range of thresholds.

\section{Expected Value of Perfect Information}

As uncertainty exists, there is always a chance that the "wrong" decision will be made ${ }^{19,22}$. In this case, society would suffer a loss as a consequence. The decision to reduce the chance of a wrong decision by performing additional research involves balancing between the costs of acquiring more information with the value associated with it. The EVPI (expected value of perfect information) is the expected value of obtaining perfect knowledge of the "true" values of all parameters. We calculated the total EVPI by subtracting the net monetary benefit of the follow-up 
strategy we would choose under conditions of uncertainty, from the net monetary benefit of the optimal decision we would make if we knew the "true" parameter values. The population EVPI was then calculated by multiplying the EVPI per patient by the number of patients that could potentially benefit from additional research. In the present study, this is the total number of patients with inoperable NSCLC treated with curative intent with (chemo)RT. We estimated that of the 1.35 million lung cancer patients per year, of whom $80 \%$ have NSCLC, $30 \%$ are amenable for curative (chemo)RT, being a total of 1,5 million patients worldwide in the next 5 years.

\subsection{Results}

\section{Cost effectiveness of different follow-up strategies}

Results of the analysis regarding the cost-effectiveness of the different follow-up strategies are presented in Table 6.3A. With regard to PET-CT based follow-up, the additional costs per extra curatively treated patient were $€ 64.096$ compared to conventional follow-up. The ICER (incremental cost-effectiveness ratio) for PET-CT based follow-up was $€ 69.086$ per QALY gained compared to conventional followup. Although CT-based follow-up was less costly, it was also less effective than PETCT based follow-up, resulting in an ICER of $€ 264.033$ per QALY gained.

Figure 6.2 shows cost-effectiveness acceptability curves for the 3 follow-up strategies. The figure shows that there is considerable uncertainty regarding which followup strategy is deemed cost-effective around the informal threshold of the Dutch Health Council. Given this ceiling ratio of $€ 80.000{ }^{18}$, PET-CT based follow-up and conventional follow-up had a similar probability of being cost-effective $(48 \%$ and $47 \%$, respectively), while the probability of CT-based follow-up being cost-effective was only $5 \%$ (Figure 6.2).

\section{Cost-effectiveness of a follow-up strategy with a PET-CT in the asymptomatic subgroup}

The same analysis was performed, but a PET-CT scan was now only performed in patients who were asymptomatic 3 months after treatment ( $55 \%$ of patients) (Table 6.3B). Symptomatic patients received imaging on the basis of the location of symptoms. The usual follow-up strategy and CT-based follow-up strategy remained the same. Performing PET-CT based follow-up only in the asymptomatic subgroup had no influence on the effects, but reduced the costs per patient from $€ 15.265$ to $€ 14.767$. Hence, this strategy resulted in a lower ICER of $€ 42.265$ per QALY gained as opposed to conventional follow-up. With this strategy, PET-CT based follow-up had the highest probability of being cost-effective (73\%) compared to conventional follow-up (27\%) at a ceiling ratio of $€ 80.000$ Figure 6.3 ). 
Table 6.3 Cost-effectiveness of different follow-up strategies

\section{Follow-up strategy}

$\begin{array}{cc}\text { Expected survival } & \text { Expected } \\ \text { in months } & \text { QALYs } \\ (95 \% \mathrm{Cl}) & (95 \% \mathrm{Cl})\end{array}$

ICER $^{* *}$

QALYS
$(95 \% \mathrm{Cl})$

A) Whole group

Conventional

13.983

$24(22-27)$

$1.28(0.98-1.58)$

(12.783-15.156)

CT-based follow-up

14.269

$24(22-27)$

$1.28(0.99-1.59)$

264.033

(13.076-15.441)

PET-CT-based follow-up

15.266

$25(22-28)$

$1.30(1.00-1.61)$

69.086

(14.072-16.440)

B) Asymptomatic patients only

Conventional

13.983

$24(22-27)$

$1.28(0.98-1.58)$

(12.805-15.162)

CT-based follow-up

14.269

$24(22-27)$

$1.28(0.99-1.59)$

264.033

(13.101-15.444)

PET-CT-based follow-up

$25(22-28)$

$1.30(1.00-1.61)$

42.265

(13.584-15.952)

QALY: Quality Adjusted Life Year; ICER: Incremental Cost Effectiveness Ratio * $95 \%$ Confidence Intervals (CI) based on probabilistic analysis

**Expressed in $€ / Q A L Y$ gained compared to conventional follow-up

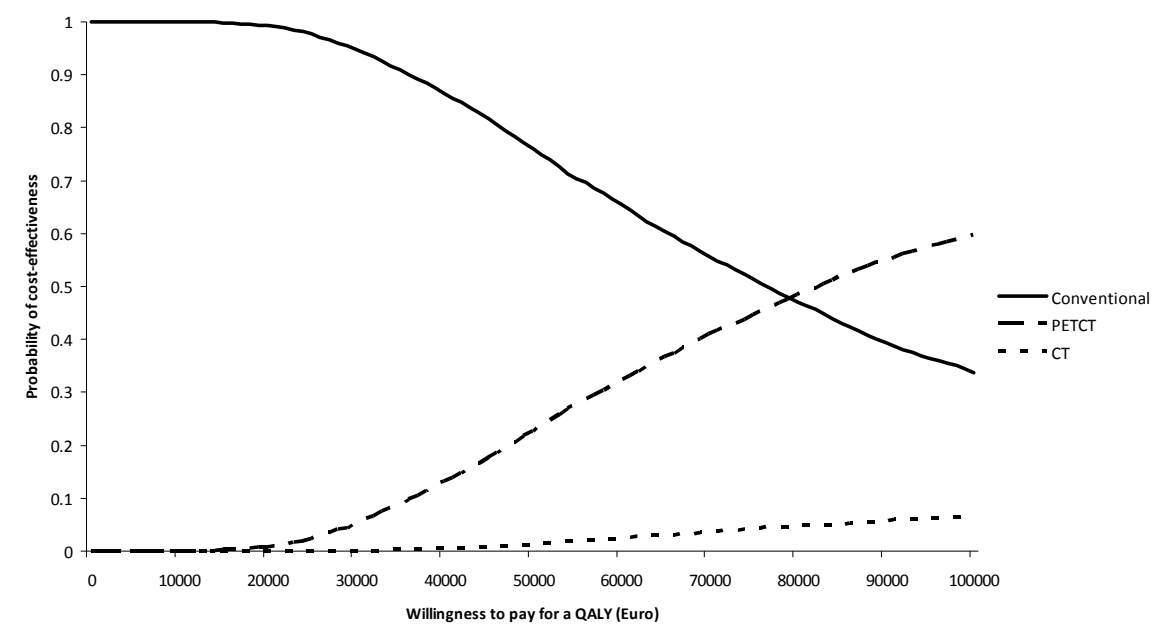

Figure 6.2 Cost-effectiveness acceptability curve (CEAC) for the strategy in which a PET-CT is performed in all patients

The probability of cost-effectiveness of a certain follow-up strategy is plotted against the willingness to pay per quality adjusted life year (QALY) gained 


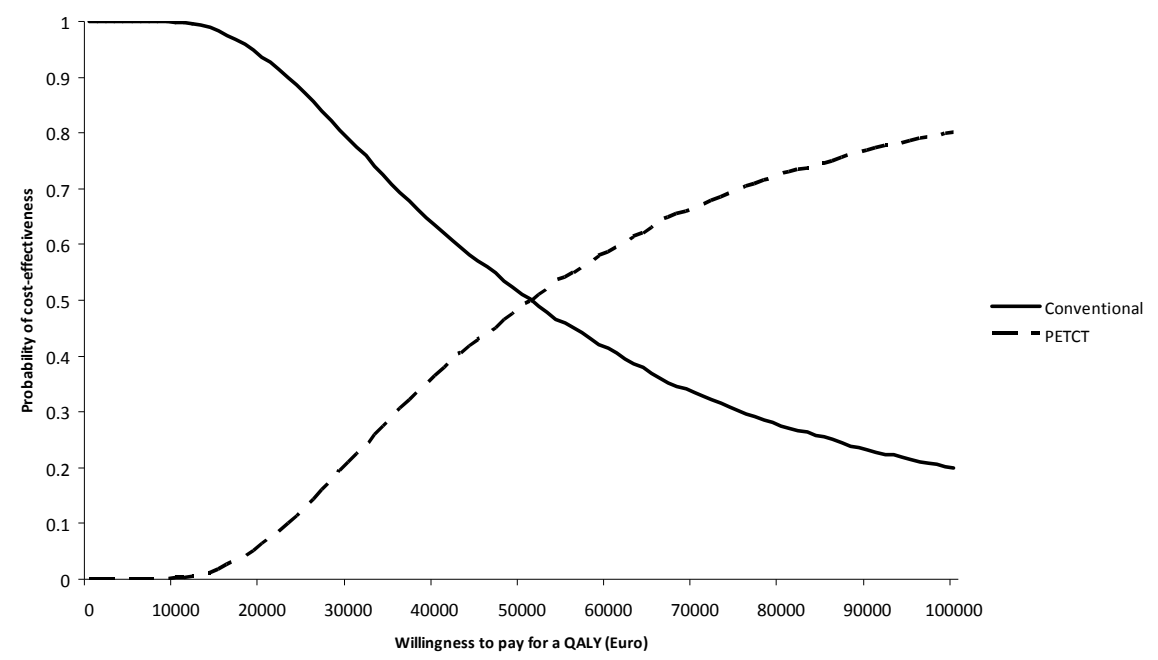

Figure 6.3 Cost-effectiveness acceptability curve (CEAC) for the strategy in which a PET-CT is performed in asymptomatic patients only

The probability of cost-effectiveness of a certain follow-up strategy is plotted against the willingness to pay per quality adjusted life year (QALY) gained

\section{Expected value of perfect information}

In the current analysis, the uncertainty surrounding the decision whether or not to implement PET-CT based follow-up resulted in an EVPI of $€ 282$ per person, given a ceiling ratio of $€ 80.000$. Implementing PET-CT based follow-up affects all patients with locally advanced NSCLC, treated with curative (chemo)RT, involving a total of 1,5 million patients worldwide in the next 5 years. This makes the population EVPI $\left(1.5 * 10^{6}\right) * 290=€ 423$ million, meaning that perfect information on this topic is worth $€ 423$ million.

The EVPI for the implementation of PET-CT based follow-up only in the subgroup of asymptomatic patients was $€ 83$ per person, given a ceiling ratio of $€ 80.000$. The population EVPI for this strategy was $€ 125$ million. The population EVPI for different ceiling ratios, both for the total group and for the asymptomatic subgroup, is presented in Figure 6.4. 


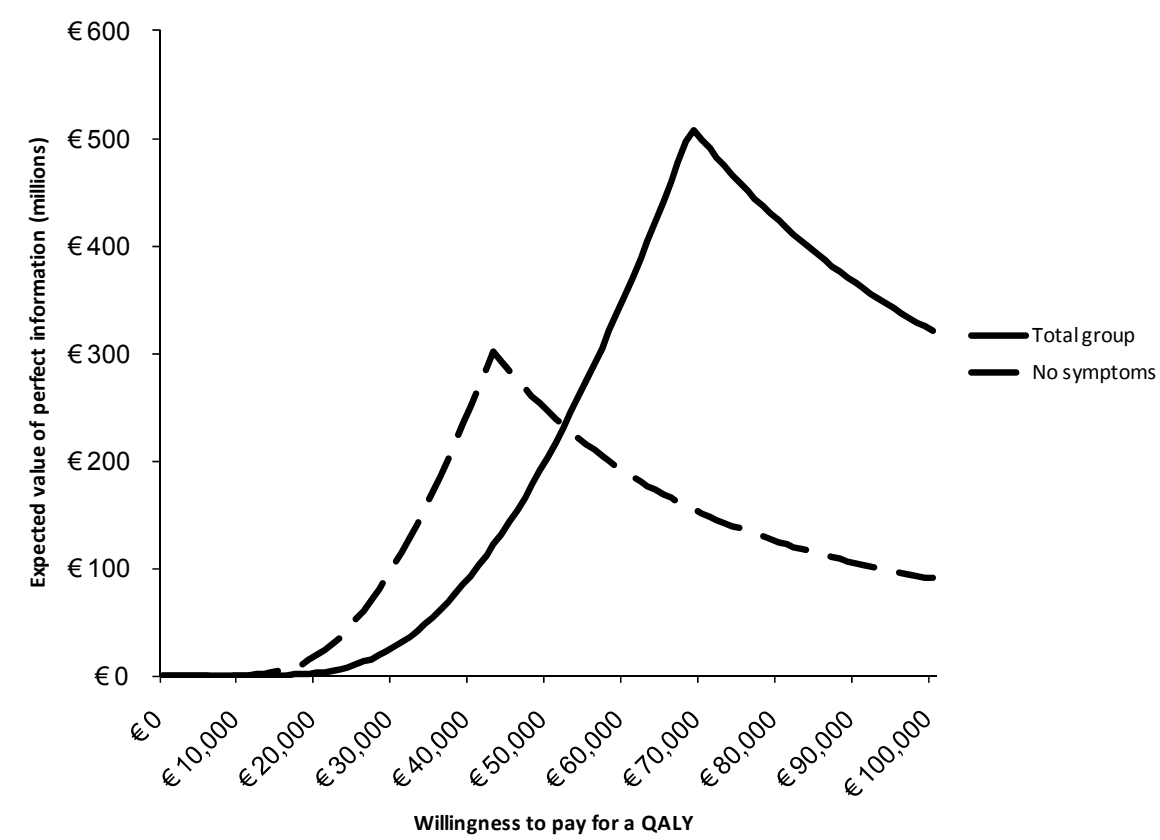

Figure 6.4 Expected Value of Perfect Information (EVPI)

The expected value of perfect information at different ceiling ratios.

Total group: EVPI for the strategy in which a PET-CT is performed in all patients.

No symptoms: EVPI for the strategy in which a PET-CT is performed in asymptomatic patients only

\subsection{Discussion}

Until now, no imaging procedure has become standard in the follow-up of NSCLC, mainly because of the fact that progression or recurrence is mostly detected at a stage that no curative treatment is possible, and hence, no survival benefit can be expected ${ }^{23}$. Our recent prospective study on a single ${ }^{18}$ FDG-PETscan 3 months posttherapy confirmed the hypothesis that this imaging modality, in contrast to CT alone, is able to detect progression amenable for curative treatment in a small percentage of patients. The question remained, however, whether this potential benefit for the individual patient outweighs the increased costs ${ }^{24}$.

The current economic evaluation shows that performing a PET-CT scan 3 months after curative (chemo-)RT is a potentially cost-effective follow-up method, and is more cost-effective than CT alone. Performing a PET-CT scan only in the subgroup of asymptomatic patients is probably as effective and more cost-effective. 
Inherently to the design of the study, there are some limitations that need to be addressed. Firstly, the current results are surrounded by considerable uncertainty, caused by uncertainty in the input parameters of the model. One important cause is the relatively small patient population $(\mathrm{N}=100)$ in the prospective study, from which the extent of the potential benefit of PET-CT was derived ${ }^{5}$. This economic evaluation aimed however, to base the decision regarding which follow-up strategy is to be preferred on the currently available evidence. Decisions will have to be made anyway, so it is better to support the decision with the available evidence including its uncertainties than doing something without any evidence at all ${ }^{25}$. Using decision-analytic modelling we were able to incorporate this uncertainty in the model by assigning distributions to the model parameters. The incorporation of uncertainty also makes results easier to interpret by decision makers, as one can calculate which strategy has the highest probability of being cost-effective at different ceiling ratios (Figure 6.2 and Figure 6.3). The EVPI analysis shows us to what extent reduction of uncertainty by performing additional research is worthwhile. The value of totally eliminating uncertainty of the input parameters of the model was $€ 435$ million, for a ceiling ratio of $€ 80.000$, implying that additional research on this subject is of great value and outweighs the associated costs.

Secondly, the threshold (also referred to as the ceiling ratio) below which a certain strategy is considered cost-effective is arbitrary and differs between countries. In the current analysis, a threshold of $€ 80.000$ (informal ceiling ratio of the Dutch Health Council) was used. Thresholds reported in literature range from $€ 35.000$ (\$ 50.000 ) to $€ 210.000$ ( $\$ 300.000)^{24,26,27}$. With a higher ceiling ratio, the probability that the PET-CT based follow-up strategy is cost-effective becomes higher, while the usual follow-up strategy has the highest probability of being cost-effective at lower ceiling ratios. Hence, whether a strategy is deemed cost-effective depends on how much the society is willing and able to pay for a gain in effect.

Thirdly, the use of a model to estimate costs and effects is always associated with a simplification of reality ${ }^{25}$. In the current analysis, we have chosen to compare the PET-CT based follow-up method with two follow-up strategies most commonly used according to the guidelines of the different institutions ${ }^{1}$. Furthermore, in the model, the difference between the 3 strategies was based upon different imaging only at one time point during follow-up, i.e. 3 months after curative treatment. This time point was chosen based on the prospective study which showed a possible advantage of PET over CT in detecting potentially curable progression at 3 months after treatment and because a PET scan performed at this interval has shown to be prognostic of outcome ${ }^{2,4}$. In none of the patients in the prospective study, additional investigations were requested to confirm the findings of the PET-CT scan. Hence, in the current economic evaluation, no costs were calculated to take into account false positive findings in the PET-CT strategy. No costs were calculated for false positive findings in the usual and CT-based follow-up strategy either, minimiz- 
ing the chance of overestimating the cost-effectiveness of PET-CT. Another drawback of the limitation to one time-point is that the potential gain of repeated imaging with e.g. chest CT scans cannot be derived from this study. The available literature however, does not confirm a benefit of repeated CT-scanning in the follow-up ${ }^{28}$. A definitive answer regarding the value of CT based follow-up can be expected from a multicentre phase III trial which is currently ongoing in France, in which conventional follow-up with chest $\mathrm{X}$-rays is compared with an intensive follow-up strategy with repeated chest CT scans in NSCLC patients after curative resection ${ }^{29}$.

The performed economic evaluation is aimed to guide decision making regarding which strategy to choose, and is not intended to reveal scientific truth ${ }^{20}$. On the basis of the currently available evidence, however, the following conclusions can be drawn: Firstly, performing a chest CT scan in the follow-up is less cost-effective than performing a PET-CT scan 3 months after treatment. Hence, if any imaging is wished to be performed for treatment evaluation, one would prefer to perform a PET-CT scan 3 months after therapy above CT alone. Secondly, irrespective of the question whether certain imaging is cost-effective, the final decision to perform the test depends on what the society can afford ${ }^{24}$. Finally, the results show that it is worthwhile to perform additional research to reduce the uncertainty surrounding the decision whether to implement PET-CT in the follow-up, including questions regarding the time-point and frequency and what the additional financial burden is. 


\subsection{References}

1. Rubins J, Unger M, Colice GL. Follow-up and surveillance of the lung cancer patient following curative intent therapy: ACCP evidence-based clinical practice guideline (2nd edition). Chest 2007;132:355S675 .

2. Mac Manus MP, Hicks RJ, Matthews JP, et al. Positron emission tomography is superior to computed tomography scanning for response-assessment after radical radiotherapy or chemoradiotherapy in patients with non-small-cell lung cancer. J Clin Oncol 2003;21:1285-92.

3. Mac Manus MP, Hicks RJ, Matthews JP, Wirth A, Rischin D, Ball DL. Metabolic (FDG-PET) response after radical radiotherapy/chemoradiotherapy for non-small cell lung cancer correlates with patterns of failure. Lung Cancer 2005;49:95-108.

4. Patz EF, Jr., Connolly J, Herndon J. Prognostic value of thoracic FDG PET imaging after treatment for non-small cell lung cancer. AJR Am J Roentgenol 2000;174:769-74.

5. van Loon J, Grutters J, Wanders R, et al. Follow-up with 18FDG-PET-CT after radical radiotherapy with or without chemotherapy allows the detection of potentially curable progressive disease in nonsmall cell lung cancer patients: a prospective study. Eur J Cancer 2009;45:588-95.

6. Drummond MF, Sculpher M.J., Torrance G.W., O'brien B., Stoddart G.L. Methods for economic evaluation of health care programmes. Oxford: Oxford University Press; 2005.

7. Sonnenberg FA, Beck JR. Markov models in medical decision making: a practical guide. Med Decis Making 1993;13:322-38.

8. Shepherd FA, Dancey J, Ramlau R, et al. Prospective randomized trial of docetaxel versus best supportive care in patients with non-small-cell lung cancer previously treated with platinum-based chemotherapy. J Clin Oncol 2000;18:2095-103.

9. Hanna N, Shepherd FA, Fossella FV, et al. Randomized phase III trial of pemetrexed versus docetaxel in patients with non-small-cell lung cancer previously treated with chemotherapy. J Clin Oncol 2004;22:1589-97.

10. Okamoto $\mathrm{Y}$, Murakami $\mathrm{M}$, Yoden $\mathrm{E}$, et al. Reirradiation for locally recurrent lung cancer previously treated with radiation therapy. Int J Radiat Oncol Biol Phys 2002;52:390-6.

11. Tanvetyanon T, Robinson LA, Schell MJ, et al. Outcomes of adrenalectomy for isolated synchronous versus metachronous adrenal metastases in non-small-cell lung cancer: a systematic review and pooled analysis. J Clin Oncol 2008;26:1142-7.

12. Murillo JR, Jr., Koeller J. Chemotherapy given near the end of life by community oncologists for advanced non-small cell lung cancer. Oncologist 2006;11:1095-9.

13. Guidelines for pharmaco-economic research. Diemen: Health Care Insurance Board; 2006.

14. NHS. Nice guideline costing statement: Erlotinib for the treatment of NSCLC: National Institute for Clinical Excellence 2008.

15. Kommer G SL, Polder J. Risicosolidariteit en Zorgkosten. Zoetermeer: Raad voor de Volksgezondheid en Zorg; 2005.

16. Trippoli S, Vaiani M, Lucioni C, Messori A. Quality of life and utility in patients with non-small cell lung cancer. Quality-of-life Study Group of the Master 2 Project in Pharmacoeconomics. Pharmacoeconomics 2001;19:855-63.

17. Dancey J, Shepherd FA, Gralla RJ, Kim YS. Quality of life assessment of second-line docetaxel versus best supportive care in patients with non-small-cell lung cancer previously treated with platinumbased chemotherapy: results of a prospective, randomized phase III trial. Lung Cancer 2004;43:18394.

18. Sensible and sustainable Care (in Dutch). Zoetermeer; 2006.

19. Briggs A CK, Sculpher M. Decision Modelling for Health Economic Evaluation Oxford University Press; 2006.

20. Weinstein MC. Recent developments in decision-analytic modelling for economic evaluation. Pharmacoeconomics 2006;24:1043-53. 
21. Fenwick E, Claxton K, Sculpher M. Representing uncertainty: the role of cost-effectiveness acceptability curves. Health Econ 2001;10:779-87.

22. Claxton K, Sculpher M, Drummond M. A rational framework for decision making by the National Institute For Clinical Excellence (NICE). Lancet 2002;360:711-5.

23. Edelman MJ, Meyers FJ, Siegel D. The utility of follow-up testing after curative cancer therapy. A critical review and economic analysis. J Gen Intern Med 1997;12:318-31.

24. Shih YC, Halpern MT. Economic evaluations of medical care interventions for cancer patients: how, why, and what does it mean? CA Cancer J Clin 2008;58:231-44.

25. Grutters JP, Joore MA, van der Horst F, Stokroos RJ, Anteunis L. Decision-Analytic Modeling to Assist Decision Making in Organizational Innovation: The Case of Shared Care in Hearing Aid Provision. Health Serv Res 2008.

26. Ubel PA, Hirth RA, Chernew ME, Fendrick AM. What is the price of life and why doesn't it increase at the rate of inflation? Arch Intern Med 2003;163:1637-41.

27. Buxton MJ. Economic evaluation and decision making in the UK. Pharmacoeconomics 2006;24:113342.

28. Benamore $\mathrm{R}$, Shepherd FA, Leighl $\mathrm{N}$, et al. Does intensive follow-up alter outcome in patients with advanced lung cancer? J Thorac Oncol 2007;2:273-81.

29. Westeel V, Lebitasy MP, Mercier M, et al. [IFCT-0302 trial: randomised study comparing two followup schedules in completely resected non-small cell lung cancer]. Rev Mal Respir 2007;24:645-52. 



\section{Part}

III

Development of novel PET tracers for the non invasive imaging of specific tumour characteristics 



\title{
CHAPTER 7 \\ PET imaging of hypoxia using $\left[{ }^{18} \mathrm{~F}\right] \mathrm{HX}$ : A phase I trial
}

\author{
Judith van Loon \\ Marco Janssen \\ Michel Öllers \\ Hugo Aerts \\ Ludwig Dubois \\ Monique Hochstenbag \\ Anne-Marie Dingemans \\ Roy Lalisang \\ Boudewijn Brans \\ Bert Windhorst \\ Guus van Dongen \\ Hartmuth Kolb \\ James Zhang \\ Dirk De Ruysscher \\ Philippe Lambin
}

European Journal of Nuclear Medicine and Molecular Imaging 2010; In press 


\section{Abstract}

\section{Background and purpose}

Non-invasive PET imaging of tumour hypoxia could help in the selection of patients who could benefit from chemotherapy or radiation with specific anti-hypoxic treatments such as bioreductive drugs or hypoxic radio-sensitizers. In this phase I trial, we aimed to determine the toxicity of $\left[{ }^{18} \mathrm{~F}\right] \mathrm{HX} 4$, a member of the 2-nitroimidazole family, at different dose levels. The secondary aim was to analyze image quality related to the $\mathrm{HX} 4$ dose and the timing of imaging.

\section{Methods and Materials}

Patients with a histologically proven solid cancer without curative treatment options were eligible for this study. A study design with two dose-steps was used in which a single dose of a maximum of $222 \mathrm{MBq}$ (step 1) or $444 \mathrm{MBq}$ (step 2) [ $\left.{ }^{18} \mathrm{~F}\right] \mathrm{HX} 4$ was injected. Toxicity was scored on day 0 and on days 3 and 7 after injection, according to the CTCAE 3.0 scoring system. PET-CT images of the largest tumour site were acquired 30, 60 and 120 minutes after injection.

\section{Results}

Six patients with stage IV carcinomas were included: four with non-small cell lung carcinoma, one with thymus carcinoma and one with colon carcinoma. No toxicity was observed in any of the patients at either dose level. The median tumour to muscle ratio 120 minutes after injection was 1.40 (range: 0.63-1.98).

\section{Conclusions}

The findings of this study show that $\left[{ }^{18} \mathrm{~F}\right] \mathrm{HX} 4$ PET imaging for the detection of hypoxia is not associated with any toxicity. Imaging was successful; however, future trials are needed to determine the optimal image parameters. 


\subsection{Introduction}

Tumour hypoxia is an important marker of cancer prognosis, being associated with aggressive growth, metastasis, and resistance to anticancer therapy ${ }^{1}$. Non-invasive PET imaging with hypoxia-specific 2-nitro-imidazoles has the ability to quantify tumour hypoxia and could help in the selection of those patients who could benefit from chemotherapy or radiation with specific anti-hypoxic treatments such as bioreductive drugs or hypoxic radio-sensitizers ${ }^{2}$. Furthermore, in contrast to invasive electrode measurements, PET imaging provides the opportunity to display the spatial distribution of hypoxia, which is essential for its integration with radiation dose distribution. $\left[{ }^{18} \mathrm{~F}\right]$ Fluoromisonidazole $\left(\left[{ }^{18} \mathrm{~F}\right] \mathrm{FMISO}\right)$ is the first radiolabelled 2nitroimidazole derivative proposed for hypoxia imaging with $\mathrm{PET}^{3,4}$. The relatively low uptake of $\left[{ }^{18} \mathrm{~F}\right] \mathrm{FMISO}$ observed in hypoxic lesions coupled with its slow clearance from normoxic tissue however, limits the clinical potential of this agent ${ }^{5}$. A number of other ${ }^{18} \mathrm{~F}$-labelled nitroimidazole derivatives have been identified, investigated and reported to overcome these problems ${ }^{6,7}$.

The 2-nitroimidazole nucleoside analogue, 3-[ $\left.{ }^{18} \mathrm{~F}\right]$ fluoro-2-(4-((2-nitro-1H-imidazol1-yl)methyl)-1H-1,2,3-triazol-1-yl)propan-1-ol ([ $\left.\left.{ }^{18} \mathrm{~F}\right] \mathrm{HX} 4\right)$, was developed as a potential marker and radio-sensitizer for hypoxic tumour cells. Because of better water solubility and faster clearance, we expect that $\left[{ }^{18} \mathrm{~F}\right] \mathrm{HX} 4$ has better pharmacokinetic properties than currently used nitroimidazole hypoxia markers such as $\left[{ }^{18} \mathrm{~F}\right] \mathrm{FMISO}$.

In this phase I trial, we aimed to determine the toxicity of $\left[{ }^{18} \mathrm{~F}\right] \mathrm{HX} 4$ at different dose levels, with the secondary aim of analyzing image quality in relation to the HX4dose and timing of imaging.

\subsection{Methods and Materials}

\section{Patient inclusion}

Patients with a histologically or cytologically confirmed stage IV solid cancer at any site, primary or secondary, without curative treatment options, were eligible. Patients were required to have a WHO performance status of 0 to 1 , normal white blood cell count and differential, normal platelet count and no anaemia requiring blood transfusion or erythropoietin. Additional eligibility criteria were adequate hepatic function; adequate renal function (calculated creatinine clearance at least $60 \mathrm{ml} / \mathrm{min}$ ); no administration of ${ }^{18} \mathrm{~F}$ in the previous 24 hours; and a minimum age of 18 years. Patients with a recent ( $<3$ months) myocardial infarction, uncontrolled infectious disease, pregnancy, or concurrent treatment with anti-cancer agents or radiotherapy were excluded. 
Approval for the study protocol (NCT00690053) was obtained from the medical ethics committee and the radiation safety committee. All patients gave written informed consent.

\section{Study design}

A study design with two dose steps was used (Figure 7.1). In step 1, a single dose of up to $222 \mathrm{MBq}\left[{ }^{18} \mathrm{~F}\right] \mathrm{HX} 4$ was injected, and in step 2 a single dose of up to $444 \mathrm{MBq}$ was injected. Six patients were included, three in each dose step. If in any patient a toxicity of grade 2 or more was observed, three more patients were included in this dose step. If another toxicity of grade 2 or more occurred in one or more of these three patients, the study would be stopped. If no more than one of six patients experienced grade 2 toxicity, the step was considered safe.

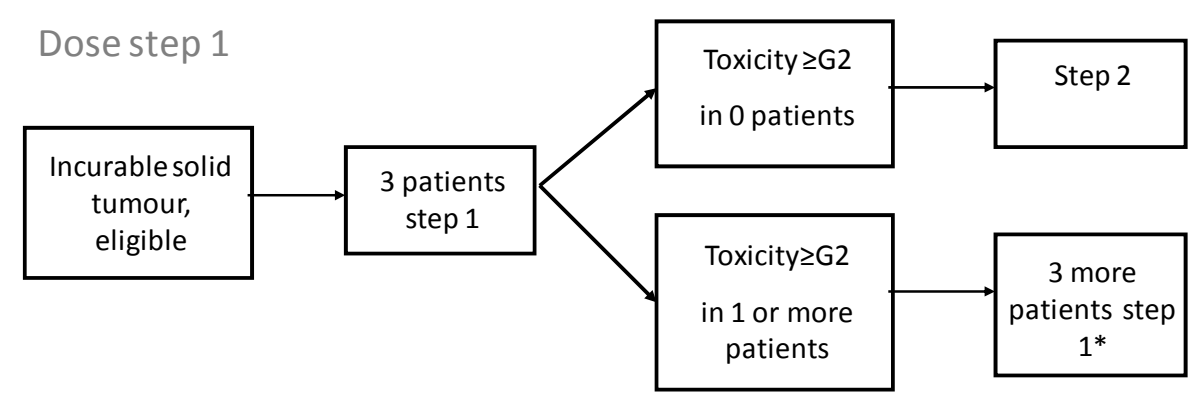

Dose step 2

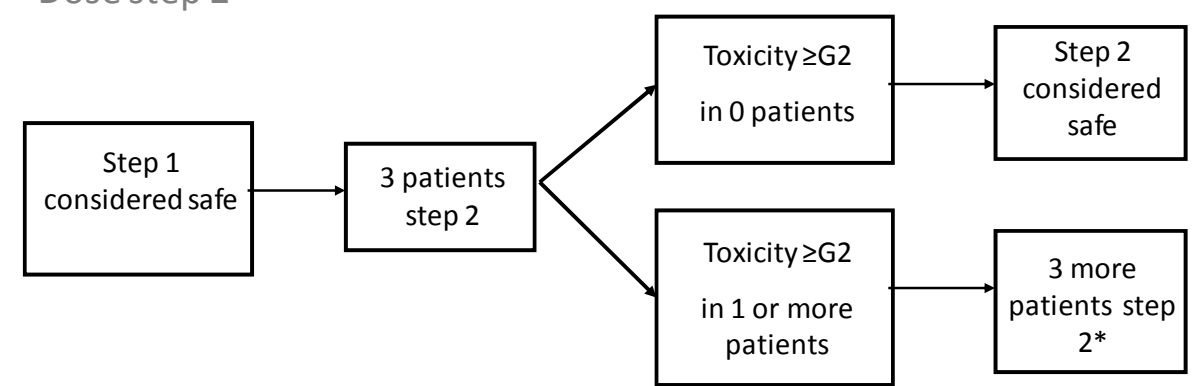

Figure 7.1 Flowchart of the study

* If toxicity of grade 2 or more was observed in none of these patients, the step was considered safe. If toxicity of grade 2 or more was observed in one or more patients, the study was stopped

\section{Synthesis of $\left[{ }^{18} \mathrm{~F}\right] \mathrm{HX} 4$}

$\left[{ }^{18} \mathrm{~F}\right] \mathrm{HX} 4$ was synthesized from the HX4 precursor in a two-step process (Figure 7.2). The product obtained was purified and formulated into a sterile and pyrogen-free solution, suitable for use in humans. The radiochemical purity was required to be 
higher than $95 \%$ in every batch. The specific radioactivity of $\left[{ }^{18} \mathrm{~F}\right] \mathrm{HX} 4$ exceeded 14.8 $\mathrm{MBq} / \mu \mathrm{mol}$. The radiopharmaceutical was produced at the government-licensed GMP-compliant (EMEA Eudralex 4) radiopharmaceutical production facility of the Department of Nuclear Medicine and PET Research of the VU University Medical Centre (license number 108897F).

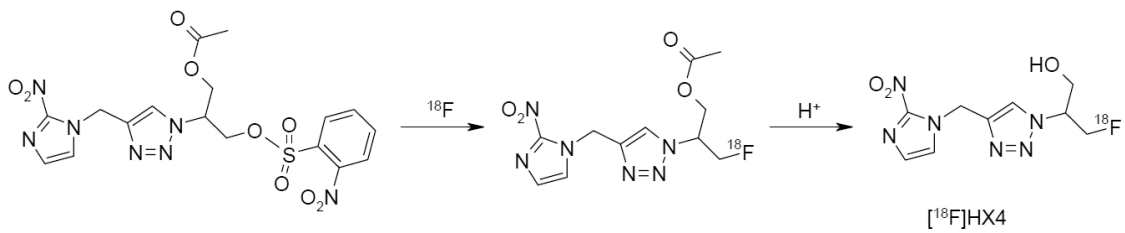

\section{Figure 7.2. Synthesis of $\left[{ }^{18} \mathrm{~F}\right] \mathrm{HX} 4$}

The precursor was supplied by Siemens Molecular Imaging (Erlangen, Germany). The first step incorporates a nucleophilic substitution of radioactive fluorine (in the form of ${ }^{18} \mathrm{~F}$ ) onto the precursor material, yielding the fluorinated intermediate which is then hydrolyzed to obtain the active drug product

\section{PET-CT imaging}

PET-CT images of the largest tumour site were acquired 30, 60 and 120 minutes after injection. Imaging at later time-points after injection was deliberately avoided to minimize the burden of the study in these patients with advanced stage disease. Images were acquired with the patient in the supine position. CT and PET images were automatically registered based on mutual information and were subsequently fused using dedicated software (TrueD, version VC50; Siemens Medical, Erlangen, Germany).

The tumour was delineated on the CT scan by the same observer (JvL). The location of the $\left[{ }^{18} \mathrm{~F}\right] \mathrm{HX} 4$ uptake and the SUV ${ }_{\max }$ (maximal standardized uptake value) were determined within the delineated tumour using a gradient-based method which was implemented in the software. Tumour to muscle ratios (TMR) for $\left[{ }^{18} \mathrm{~F}\right] \mathrm{HX} 4$ uptake were calculated at all time-points by dividing the tumour SUV $\mathrm{max}_{\max }$ by the skeletal muscle SUV $V_{\max }$. The skeletal muscle SUV $V_{\max }$ was determined by calculating the average $S_{U V} V_{\text {max }}$ in two circular regions of interest drawn in the paraspinal muscles.

In patients in whom an $\left[{ }^{18} \mathrm{~F}\right]$ FDG-PET scan was performed for diagnostic purposes during the week before or after the $\left[{ }^{18} \mathrm{~F}\right] \mathrm{HX} 4$ scan, uptake of $\left[{ }^{18} \mathrm{~F}\right] \mathrm{FDG}$ and $\left[{ }^{18} \mathrm{~F}\right] \mathrm{HX} 4$ was compared. The location of the $\left[{ }^{18}\right.$ F]FDG uptake was determined using automated SUV-thresholding with the threshold depending on the tumour-tobackground signal ratio (SBR-method) ${ }^{8}$. 


\section{Toxicity scoring}

Toxicity was scored on day 0 and days 3 and 7 after injection, according to the CTCAE (Common Terminology Criteria for Adverse Events) version 3.0 scoring system. Blood was sampled before injection and at each control point, and tests included haematology and kidney and liver function. Due to the relatively short physical half-life of ${ }^{18} \mathrm{~F}$ (110 $\mathrm{min}$ ) and biological half-life of HX4 (less than 3 hours), after 1 day the radio-activity of both the drug and its metabolites have disappeared and no additional toxicity from the radiation is expected.

The timeline for each patient entering the study is illustrated in Figure 7.3.

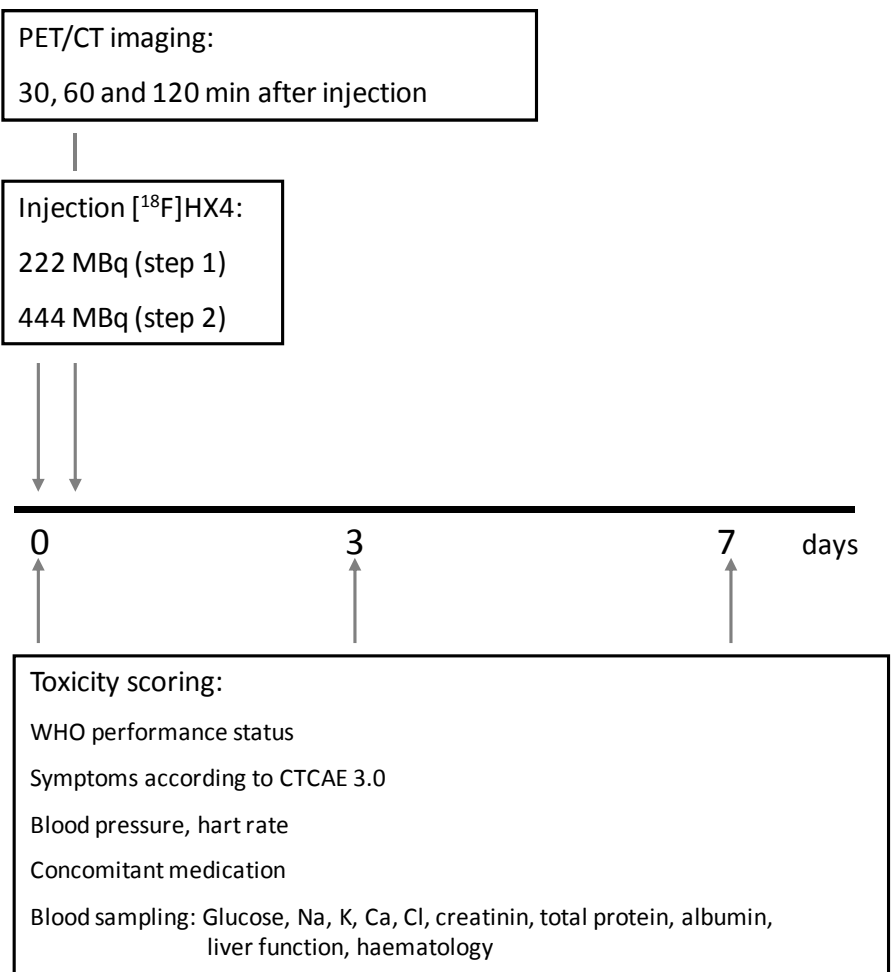

Figure 7.3 Time line of the study

CTCAE 3.0: Common Terminology Criteria for Adverse Events, version 3.0 


\subsection{Results}

\section{Patient characteristics}

Six patients, with a median age of 63 years (range: 54-68), were included. The patient characteristics are shown in Table 7.1.

\begin{tabular}{|c|c|c|c|c|c|c|c|c|}
\hline \multicolumn{9}{|c|}{ Table 7.1 Patient characteristics } \\
\hline & \multirow[t]{2}{*}{ Age } & \multirow[t]{2}{*}{ Sex } & \multirow[t]{2}{*}{ Length } & \multirow[t]{2}{*}{ Weight } & \multirow[t]{2}{*}{$\mathrm{WHO}^{*}$} & \multicolumn{2}{|c|}{ Primary tumour } & \multirow[t]{2}{*}{ Prior therapy } \\
\hline & & & & & & Site & Histology & \\
\hline 1 & 67 & $f$ & 1.58 & 58 & 1 & Lung & Adenocarcinoma & $\begin{array}{l}\text { Chemotherapy, } \\
\text { radiotherapy } \\
\text { brain }\end{array}$ \\
\hline 2 & 54 & $f$ & 1.76 & 64 & 0 & Lung & Adenocarcinoma & Chemotherapy \\
\hline 3 & 58 & $\mathrm{~m}$ & 1.79 & 82 & 0 & Thymus & Carcinoid & $\begin{array}{l}\text { Surgery, radio- } \\
\text { therapy }\end{array}$ \\
\hline 4 & 62 & $\mathrm{~m}$ & 1.90 & 80 & 1 & Lung & Adenocarcinoma & $\begin{array}{l}\text { Surgery, chemo- } \\
\text { therapy, radio- } \\
\text { therapy }\end{array}$ \\
\hline 5 & 63 & $f$ & 1.70 & 70 & 1 & Lung & $\begin{array}{l}\text { Squamous cell } \\
\text { carcinoma }\end{array}$ & $\begin{array}{l}\text { Surgery, chemo- } \\
\text { therapy }\end{array}$ \\
\hline 6 & 68 & $\mathrm{~m}$ & 1.68 & 80 & 0 & Colon & Adenocarcinoma & $\begin{array}{l}\text { Surgery, chemo- } \\
\text { therapy }\end{array}$ \\
\hline
\end{tabular}

*World Health Organisation performance status

All patients had a stage IV carcinoma: four had a non-small cell lung carcinoma, one had a thymus carcinoma and one patient a colon carcinoma. Three patients had stage IV disease at primary diagnosis, while the other had developed metastases after therapy with curative intent. All patients had previously undergone anti-cancer therapy. Two patients were unable to undergo the last scan at 120 minutes after injection due to pain (not drug-related).

\section{Toxicity}

Results of the toxicity scoring are shown in Table 7.2. No toxicity according to the CTCAE 3.0 criteria was observed at any time-point in the first three patients included in dose step 1 . Hence, it was considered safe to continue with dose step 2. Again, no toxicity was observed in any of the three patients. One patient reported mild transient headache (grade 1 ) the day after the $\left[{ }^{18} \mathrm{~F}\right] \mathrm{HX} 4$ injection, which was considered unlikely to be related to the injection. 


\begin{tabular}{|c|c|c|c|c|c|c|c|}
\hline \multicolumn{8}{|c|}{ Table 7.2 Toxicity scoring } \\
\hline \multirow[t]{2}{*}{$\mathrm{Pt}$} & \multirow{2}{*}{$\begin{array}{c}\text { Injected } \\
\text { activity (MBq) }\end{array}$} & \multirow{2}{*}{$\begin{array}{l}\text { Vital } \\
\text { signs }\end{array}$} & \multicolumn{4}{|c|}{ Toxicity scoring } & \multirow[t]{2}{*}{ Medication } \\
\hline & & & Haematology & $\begin{array}{c}\text { Liver } \\
\text { function }\end{array}$ & $\begin{array}{c}\text { Renal } \\
\text { function }\end{array}$ & Symptoms & \\
\hline 1 & 222 & 0 & 0 & 0 & 0 & 0 & 0 \\
\hline 2 & 222 & 0 & 0 & 0 & 0 & 0 & 0 \\
\hline 3 & 222 & 0 & 0 & 0 & 0 & 0 & 0 \\
\hline 4 & 444 & 0 & 0 & 0 & 0 & $1^{* * *}$ & 0 \\
\hline 5 & 444 & 0 & 0 & 0 & 0 & 0 & 0 \\
\hline 6 & 444 & 0 & 0 & 0 & 0 & 0 & 0 \\
\hline
\end{tabular}

Toxicity was scored before study entry (baseline) and on days 0,3 , and 7 of the study. The blood test results were compared with those at baseline and evaluated by the physician

*Every change in vital signs or medication compared to the baseline values was scored, with " 0 " indicating no change

** Grade according to the CTCAE version 3.0

*** Mild headache, not related to the ${ }^{18} \mathrm{~F}[\mathrm{HX} 4]$ administration

\section{Image analysis}

Images of two patients at 120 minutes after injection are presented in Figure 7.4. They show a heterogeneous uptake of $\left[{ }^{18} \mathrm{~F}\right] \mathrm{HX} 4$ throughout the tumour. The median TMR at 30, 60 and 120 minutes after injection was 1.17 (range: 0.20-1.83), 1.25 (range: $0.25-1.67$ ) and 1.40 (range: 0.63-1.98). In two of four patients in whom images were available at 120 minutes after injection a considerable increase was seen in the TMR compared to 60 minutes after injection.

In three patients an $\left[{ }^{18} \mathrm{~F}\right]$ FDG-PET scan performed during the week before or after the $\left[{ }^{18} \mathrm{~F}\right] \mathrm{HX} 4-\mathrm{PET}$ scan was available. In these three patients, there was a good correlation between the uptake of FDG and $\left[{ }^{18} \mathrm{~F}\right] \mathrm{HX} 4$, as shown in Figure 7.5. 

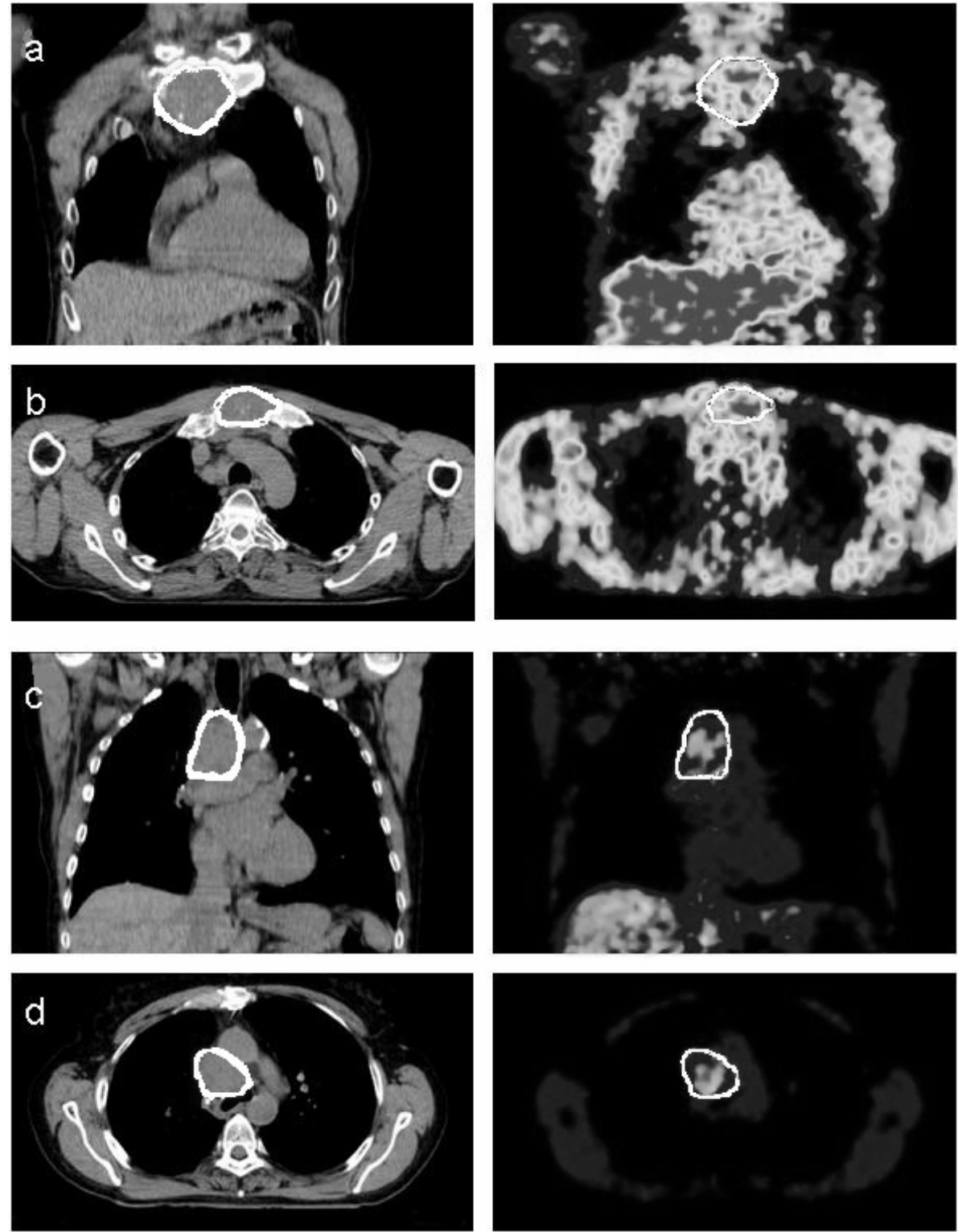

Figure 7.4 $\left[{ }^{18} \mathrm{~F}\right] \mathrm{HX} 4$ images of 2 patients

a), b) Patient 4, TMR=1.35; a) coronal, b) transversal images

c), d) Patient 5, TMR=1.98; c) coronal, d) transversal images 

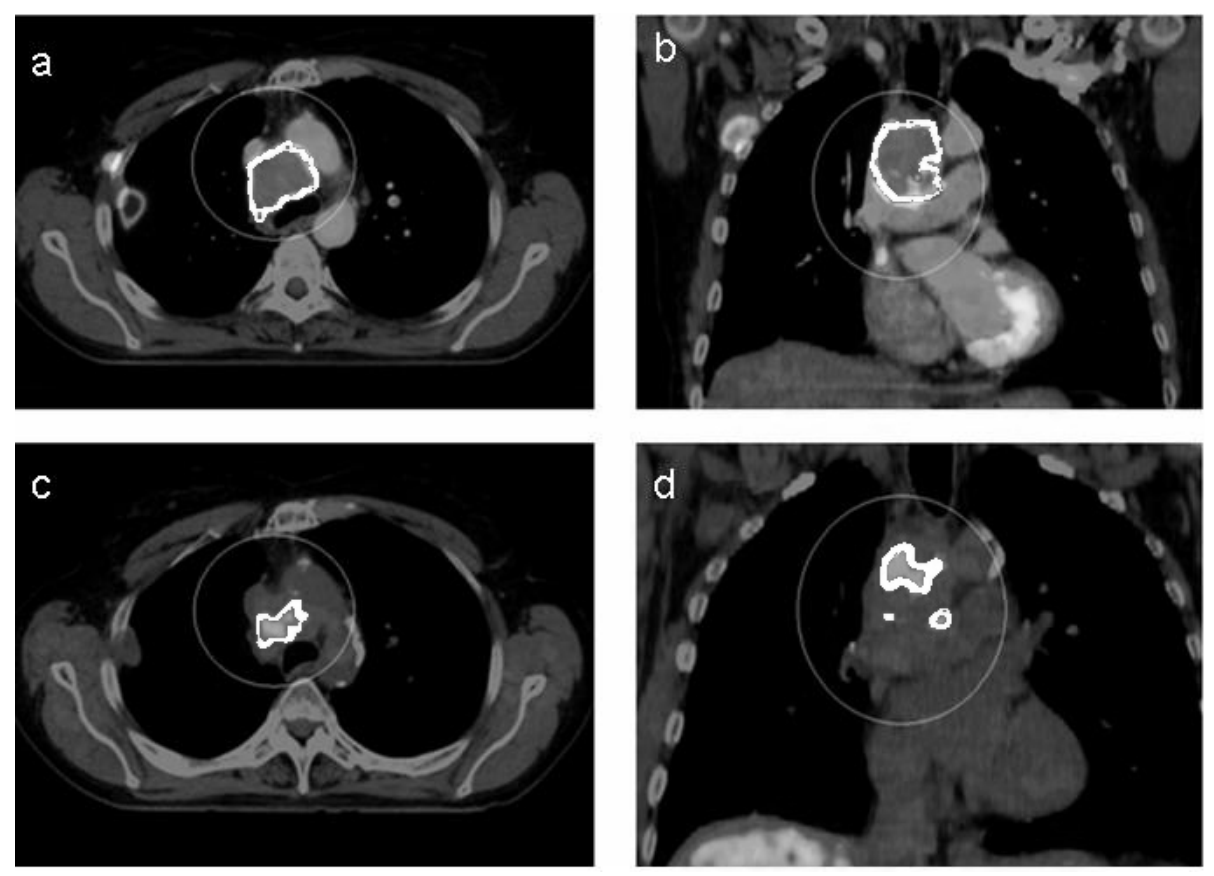

Figure 7.5 Correlation between the uptake of $\left[{ }^{18} \mathrm{~F}\right] \mathrm{HX} 4$ and ${ }^{18} \mathrm{FDG}$ (patient 5)

FDG-uptake in the tumour was delineated using automated SUV-thresholding depending on the tumourto-background signal ratio. The HX4 positive regions in the tumour were delineated using gradient-based image analysis

a) ${ }^{18}$ FDG -PET-CT images, axial view; b) ${ }^{18}$ FDG -PET-CT images, coronal view

c) $\left[{ }^{18} \mathrm{~F}\right] \mathrm{HX} 4-\mathrm{PET}-\mathrm{CT}$ images, axial view; d) $\left[{ }^{18} \mathrm{~F}\right] \mathrm{HX} 4-\mathrm{PET}-\mathrm{CT}$ images, coronal view

\subsection{Discussion}

Preclinical experience gained with $\left[{ }^{18} \mathrm{~F}\right] \mathrm{HX} 4$ and unlabelled $\mathrm{HX} 4$ did not indicate any adverse events at the dose levels used in these exploratory trials. The current phase I trial confirmed these preclinical data, with no toxicity according to the CTCAE 3.0 criteria observed in any of the patients. The time curves of the TMR showed a large divergence between the patients. In two patients, a substantial increase in the TMR was seen in the second hour after injection, indicating that the optimal TMR for imaging may be at later time points. In the three patients in whom an ${ }^{18}$ FDG-PET scan was available, a good correlation was found between the hypoxic areas imaged with HX4 and the areas of high FDG uptake. This is consistent with the often observed relationship between tumour hypoxia and FDG uptake ${ }^{9,10}$.

From the imaging perspective, there were some limitations inherent in the study design. Firstly, the imaging was limited to 120 minutes after injection. This time horizon was chosen to limit the burden on the patients, who were all suffering from 
end-stage disease. Future studies, with the final aim of adapting treatment according to hypoxia, will be performed in patients with earlier stage disease, in whom imaging at later time points would be acceptable. Secondly, only static PET imaging was performed. Hence, no correction could be made for heterogeneity in tumour perfusion. With kinetic imaging, tumour perfusion can be measured, thereby offering the opportunity to differentiate between differences in delivery of $\left[{ }^{18} \mathrm{~F}\right] \mathrm{HX} 4$ and differences in $\mathrm{pO}_{2}$ within the same tumour ${ }^{4}$. Finally, in order to allow radiotherapy dose distribution within the tumour on the basis of hypoxia, the stability of hypoxic regions within the tumour before and at different time-points during chemo- and radiotherapy should be assessed.

\subsection{Conclusion}

The results presented show that $\left[{ }^{18} \mathrm{~F}\right] \mathrm{HX} 4$ PET imaging is not associated with any toxicity. Future trials are needed to determine optimal imaging conditions, with the final aim of developing adaptive treatment strategies based on $\left[{ }^{18} \mathrm{~F}\right] \mathrm{HX} 4$-imaged hypoxia.

\section{Acknowledgements}

The unlabelled HX-4 and its precursor were kindly provided by Siemens Molecular Imaging.

The authors acknowledge financial support from the Dutch Cancer Society (KWFfellowship granted to H.J.W.L.A.). 


\subsection{References}

1. Ruan K, Song G, Ouyang G. Role of hypoxia in the hallmarks of human cancer. J Cell Biochem 2009.

2. Wouters BG, Weppler SA, Koritzinsky M, et al. Hypoxia as a target for combined modality treatments. Eur J Cancer 2002;38:240-57.

3. Rasey JS, Grunbaum Z, Magee S, et al. Characterization of radiolabeled fluoromisonidazole as a probe for hypoxic cells. Radiat Res 1987;111:292-304.

4. Thorwarth D, Eschmann SM, Paulsen F, Alber M. A kinetic model for dynamic [18F]-Fmiso PET data to analyse tumour hypoxia. Phys Med Biol 2005;50:2209-24.

5. Nunn A, Linder K, Strauss HW. Nitroimidazoles and imaging hypoxia. Eur J Nucl Med 1995;22:265-80.

6. Krohn KA, Link JM, Mason RP. Molecular imaging of hypoxia. J Nucl Med 2008;49 Suppl 2:129S-48S.

7. Piert M, Machulla HJ, Picchio $\mathrm{M}$, et al. Hypoxia-specific tumor imaging with $18 \mathrm{~F}$-fluoroazomycin arabinoside. J Nucl Med 2005;46:106-13.

8. Ollers $M$, Bosmans $G$, van Baardwijk $A$, et al. The integration of PET-CT scans from different hospitals into radiotherapy treatment planning. Radiother Oncol 2008;87:142-6.

9. Dierckx RA, Van de Wiele C. FDG uptake, a surrogate of tumour hypoxia? Eur J Nucl Med Mol Imaging 2008;35:1544-9.

10. van Baardwijk A, Dooms C, van Suylen RJ, et al. The maximum uptake of (18)F-deoxyglucose on positron emission tomography scan correlates with survival, hypoxia inducible factor-1alpha and GLUT-1 in non-small cell lung cancer. Eur J Cancer 2007;43:1392-8. 


\title{
CHAPTER 8 PET imaging of Cetuximab-Zirconium-89 uptake: a phase I trial
}

\author{
Judith van Loon \\ Hugo Aerts \\ Marco Janssen \\ Michel Öllers \\ Ludwig Dubois \\ Anne-Marie Dingemans \\ Arne van Belle \\ Monique Hochstenbag \\ Roy Lalisang \\ Erik Vegt \\ Boudewijn Brans \\ Pascal Kempers \\ Ronald Boellaard \\ Danielle Vugts \\ Guus van Dongen \\ Dirk De Ruysscher \\ Philippe Lambin
}

Manuscript in preparation 


\section{Abstract}

\section{Background and Purpose}

Non invasive PET imaging of cetuximab uptake could help to select patients with the highest chance of benefit from this treatment. Cetuximab labelled with Zirconium89 is a promising new conjugate to determine tumour uptake of cetuximab, which has been tested in pre-clinical animal models with excellent results (Aerts et al, J Nucl Med 2009).

In this trial (NCT00691548), we aimed to determine the toxicity of ${ }^{89} \mathrm{Zr}$-cetuximab in incurable cancer patients, with tumour visualization as a secondary aim.

\section{Methods and Materials}

The safety of two different dose schedules was tested. In step 1, the toxicity of two consecutive low radioactivity doses of ${ }^{89} \mathrm{Zr}$-cetuximab (60 MBq) was investigated. In step 2 , the toxicity of a single larger dose (120 MBq) was investigated. Labelled cetuximab administration was preceded by a standard loading dose of unlabelled cetuximab. Toxicity was scored twice weekly up to 14 days after injection, according to the CTCAE 3.0 scoring system and with blood tests for haematological and liver/kidney function. Total body PET-CT scans were acquired on day 4, 5 and 6 (step 1) and 5, 6, 7 (step 2) post injection. Images were analyzed using dedicated software.

\section{Results}

Seven patients with a histologically proven solid tumour without curative treatment options were included. One patient was excluded before administration of the studied drug because of hypertension during the administration of unlabelled cetuximab. Six patients had NSCLC, whereas 1 patient had a tonsillar carcinoma. Five of six patients who completed the study experienced skin toxicity. No additional toxicity was associated with the administration of ${ }^{89} \mathrm{Zr}$-cetuximab. The maximal tumour to blood ratio (TBR) observed was 1.6. In general, the most optimal TBR was found at later imaging time points (day 6 and day 7 ).

\section{Conclusions}

No additional toxicity was observed for ${ }^{89} \mathrm{Zr}$-cetuximab administration. ${ }^{89} \mathrm{Zr}$ cetuximab is thus safe to be implemented in immuno-PET studies guiding cetuximab therapy. 


\subsection{Introduction}

Monoclonal antibodies are increasingly used in oncology as a mean to specifically target receptors at the surface of tumour cells that are associated with tumour aggressiveness, such as proliferation, hypoxia and angiogenesis. Cetuximab is a monoclonal antibody that blocks the Epidermal Growth Factor Receptor (EGFR). The EGFR is a transmembrane glycoprotein which is commonly expressed in many normal human tissues. It is a member of the tyrosine kinase family of growth factor receptors and is overexpressed in many human malignancies ${ }^{1,2}$. EGFR is activated upon ligand binding to the extracellular domain, which results in the induction of a signal transduction pathway that cascades many cellular operations concerning cell growth and division. EGFR activation and overexpression appear to be important tumour cell mechanisms in the development of resistance to radiation and chemotherapy in epithelial cancers, with decreased rates of local tumour control and survival $^{3-7}$.

Cetuximab specifically binds to the EGFR with high affinity, internalising the receptor and thus effectively blocking ligand-induced EGFR phosphorylation. It is a very promising drug to combine with radiotherapy alone or with concurrent chemoradiation, as it has shown to improve local tumour control without enhancing the toxicity of radiotherapy or chemotherapy ${ }^{8,9}$. It plays currently a role as part of the standard treatment for a variety of cancers, including colorectal cancer and squamous cell carcinoma of the head and neck. The selection of patients with the highest chance of benefit from cetuximab treatment is of obvious relevance, also in view of its high costs. As no direct relationship has been observed between EGFR expression determined with immunohistochemistry and response to cetuximab treatment, EGFR status of the primary tumour cannot be used as a selection criterion. As the expression of EGFR can be induced by radiation and chemotherapy, it is possible that an initially EGFR-negative tumour may become positive early during therapy, thereby still benefiting from cetuximab treatment ${ }^{10-12}$. On the other hand, EGFR expressing tumours will not respond to cetuximab when cetuximab does not reach therapeutic concentrations in the tumour because of e.g. interstitial pressure and vascular perfusion changes in the micro-environment of the tumour or the surrounding tissues. In this regard, non-invasive visualization and quantification of tumour uptake of cetuximab with positron emission tomography (PET) before and during therapy could contribute significantly to patient selection and determination of the needed dosage ${ }^{13}$.

As the biologic half-life of cetuximab in the blood is 70-100 hours, a positron emitter with a long half-life is needed to visualize its uptake. Zirconium-89 $\left({ }^{89} \mathrm{Zr}\right)$, a positron emitter with a half life of approximately 78 hours, can successfully be coupled to 
cetuximab and has shown excellent results in preclinical animal models ${ }^{14}$. In the preclinical study, tumour cell lines with varying EGFR expression levels were used for in vivo imaging experiments. PET with ${ }^{89} \mathrm{Zr}$-labeled cetuximab was performed on tumour-bearing NMRI-nu mice at several time points after injection and uptake was quantified within regions of interest on selected tissues. Uptake of ${ }^{89} \mathrm{Zr}$-labeled cetuximab was demonstrated in the EGFR-positive tumours. Furthermore, it was shown that indeed, levels of EGFR expression did not correlate with ${ }^{89} \mathrm{Zr}$-cetuximab uptake, implying that pharmacokinetic and -dynamic factors influence the cetuximab distribution in the tumour ${ }^{14}$.

Here, we report the results of a phase I study to determine toxicity of Zirconium-89 labelled cetuximab in incurable cancer patients, with tumour visualisation as a secondary end point.

\subsection{Methods and Materials}

\section{Patient selection}

Patients with a histologically or cytologically confirmed solid cancer at any site without curative treatment options were eligible. Inclusion criteria were as follows: WHO performance status 0 to 2; adequate bone marrow, hepatic and renal function (calculated creatinine clearance at least $60 \mathrm{ml} / \mathrm{min}$ ); life expectancy $>3$ months and written informed consent to the study. Patients with a recent ( $<3$ months) myocardial infarction, uncontrolled infectious disease, pregnancy, previous administration of cetuximab or concurrent treatment with anti-cancer agents or radiotherapy were excluded. EGFR expression and mutation status as well as k-ras mutation were assessed for the primary tumour.

The study protocol (NCT00691548) was approved by the medical ethical committee and the radiation safety committee (MECazM 083039.7 and 2008-8, respectively).

\section{Study design}

A two dose-step study design was used, graphically represented in Figure 8.1. The study design anticipated on the future aim, which is to determine the tumour uptake of ${ }^{89} \mathrm{Zr}$-cetuximab before and during therapy. Therefore, in step 1 , the toxicity of two consecutive low doses of ${ }^{89} \mathrm{Zr}$-cetuximab was investigated. A standard loading dose of $400 \mathrm{mg} / \mathrm{m}^{2}$ of cetuximab was administered, followed by administration of the cetuximab labelled with ${ }^{89} \mathrm{Zr}(60 \mathrm{MBq})$ on day 0 . The second injection on day 14 consisted of a dose of $250 \mathrm{mg} / \mathrm{m}^{2}$ of cetuximab, followed by cetuximab labelled with $60 \mathrm{MBq}{ }^{89} \mathrm{Zr}$. 
As a larger radioactivity dose of ${ }^{89} \mathrm{Zr}$ is possibly needed to obtain the best image quality, the toxicity of a single larger dose of ${ }^{89} \mathrm{Zr}$-cetuximab was investigated in step 2. A loading dose of $400 \mathrm{mg} / \mathrm{m}^{2}$ of cetuximab was administered in 3 patients, followed by administration of the cetuximab labelled with $120 \mathrm{MBq}{ }^{89} \mathrm{Zr}$.
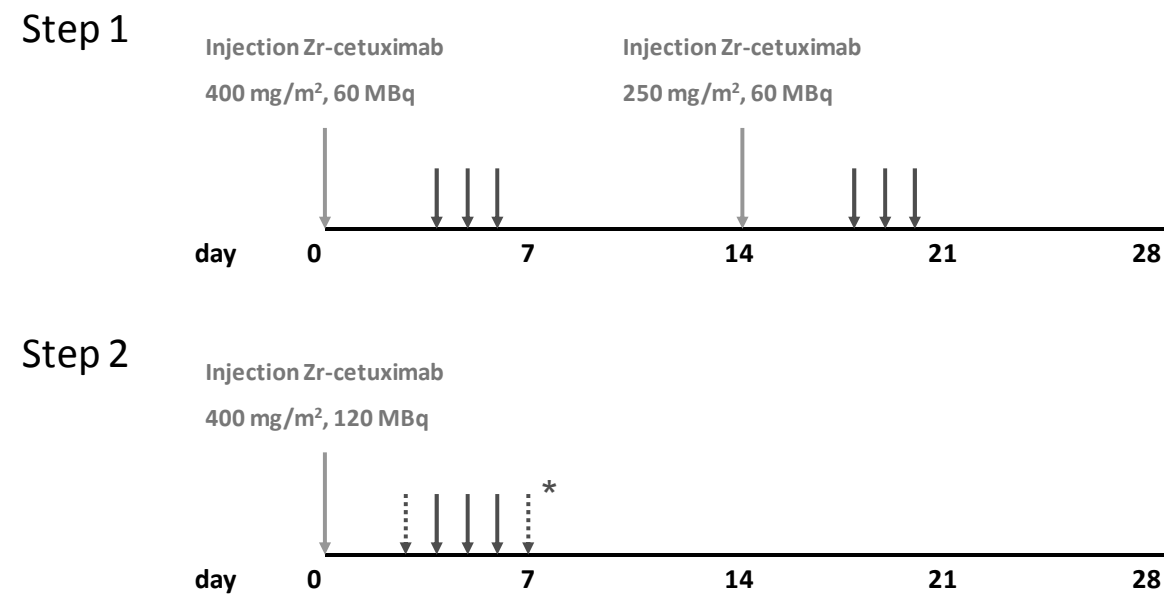

* days of scanning in step 2 depend on imaging results in step 1

\section{Figure 8.1 Timeline of the study}

A two dose-step study design was used. In step 1 , the toxicity of two low doses of ${ }^{89} \mathrm{Zr}$-cetuximab was investigated. In step 2, the toxicity of a single larger dose of cetuximab was tested. PET-CT imaging was performed at three consecutive days after administration, starting at day 4 in dose step 1

* In step 2, PET-CT scans on day 3 and 7 after injection were optional and depended on the imaging results in step 1: If in step 1 two or more patients had a higher tumour to blood ratio (TBR) on day 4 then on day 5 , an additional scan on day 3 would be performed. If in step 1 two or more patients had a higher TBR on day 6 then on day 5 , an additional scan on day 7 would be performed

In both steps, the ${ }^{89} \mathrm{Zr}$-labelled cetuximab was administered within one hour after the administration of the loading dose. Six patients were included, three in each dose step. If grade 2 or higher toxicity was observed related to the administration of the studied drug $\left({ }^{89} \mathrm{Zr}\right.$-labelled cetuximab) in any patient, 3 more patients had to be included in this dose step. When at maximum 1/6 patients experienced grade 2 toxicity, the step was considered safe.

\section{Toxicity scoring}

Toxicity was assessed during treatment, and twice weekly thereafter until 14 days after the last injection, according to the CTCAE 3.0 scoring system. At baseline and on days 7 and 14 after injection, blood testing was performed for haematology (haemoglobin, hematocrite, mean cell volume, reticulocytes, white blood cell count and differentiation, platelets), kidney function (creatinine) and liver function (aspar- 
tate aminotransferase, alanine aminotransferase, alkalic phosphatase, $\quad$-GT, bilirubin).

The most common side effect of cetuximab administration that was anticipated for was skin toxicity (acne-form rash). The classification of the degree of skin toxicity according to the CTCAE is provided in Table $8.1^{15}$.

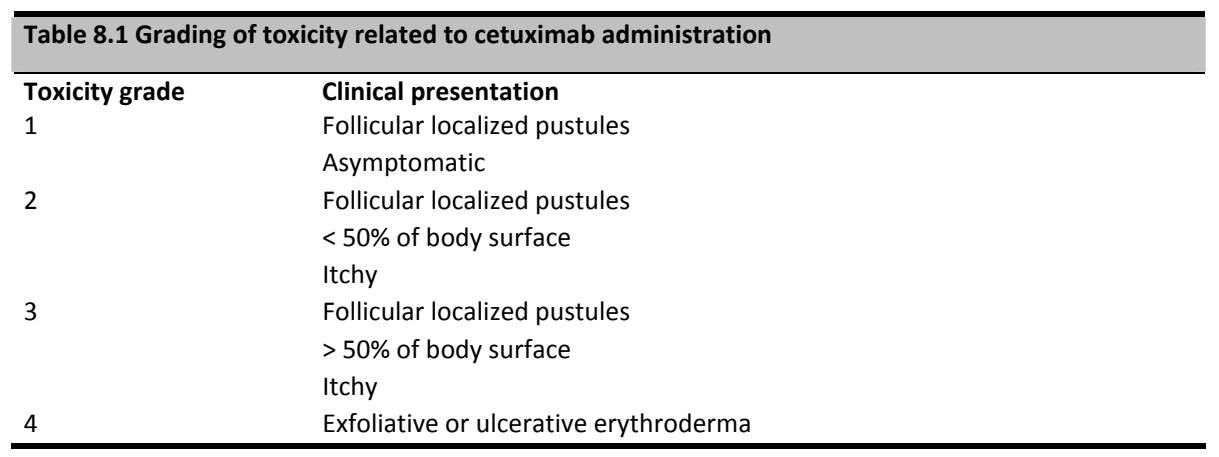

\section{Synthesis of ${ }^{89} \mathrm{Zr}$ labelled cetuximab}

${ }^{89} \mathrm{Zr}$ was produced by a $(p, n)$ reaction on natural ${ }^{89} \mathrm{Y}$ as described by Verel et al. ${ }^{16}$. Subsequently, labelling of ${ }^{89} \mathrm{Zr}$ to the mAb cetuximab was performed as previously reported ${ }^{17}$. In short, desferrioxamine $B$ was succinylated (N-sucDf), temporarily filled with iron $\left(\mathrm{Fe}^{3+}\right)$, and coupled to cetuximab using a tetrafluorophenol-N-sucDf ester. The premodified mAb was purified on a PD10 column after removal of $\mathrm{Fe}^{3+}$ by transchelation to ethylenediaminetetraacetic acid (EDTA). Approximately $1 \mathrm{~N}$-sucDf moiety was coupled per cetuximab molecule, assessed by using ${ }^{59} \mathrm{Fe}$. Next, N-sucDfcetuximab was labelled with ${ }^{89} \mathrm{Zr}$ in $0.5 \mathrm{M} \mathrm{N}$-(2-hydroxyethyl)piperazine-N9-(2ethanesulfonic acid) (HEPES) buffer at $\mathrm{pH} 7.0$ and again purified on a PD10 column to remove unbound ${ }^{89} \mathrm{Zr}$. ${ }^{89} \mathrm{Zr}$-cetuximab preparations contained $10 \mathrm{mg}{ }^{89} \mathrm{Zr}$ cetuximab in $5 \mathrm{mg} / \mathrm{ml}$ gentisic acid in $0.9 \% \mathrm{NaCl}$, containing 60 or $120 \mathrm{MBq}{ }^{89} \mathrm{Zr}$. ${ }^{89} \mathrm{Zr}$-cetuximab release criteria were: radiochemical purity $>90 \%$; immunoreactivity $>70 \%$; $\mathrm{pH}=4.7-5.3$; sterile and free of endotoxins (European Pharmacopeia).

\section{PET-CT imaging}

Whole body immuno-PET-CT imaging was performed at day 4, 5 and 6 after injection in dose step 1. Imaging time points in step 2 were adapted based on the tumour to blood ratios at subsequent days in step 1 . A list mode acquisition of the largest tumour site was carried out in addition to the whole body PET-CT. Furthermore, an optional ${ }^{18} \mathrm{~F}$-fluorodeoxyglucose (FDG-)PET scan was performed within the study period, at least 24 hours before or 10 days after the ${ }^{89} \mathrm{Zr}$-cetuximab administration. 
Images were acquired with the patient in supine position. CT and PET images were automatically registered based on mutual information and fused using dedicated software (TrueD, version VC50, Siemens Medical, Erlangen, Germany).

The tumour was delineated on the CT scan by the same observer (JvL). If available, FDG-PET information was used in addition to the CT. The maximum standardized uptake value $\left(\mathrm{SUV}_{\max }\right)$ and the location of the ${ }^{89} \mathrm{Zr}$-cetuximab uptake within the delineated tumour were determined using dedicated software (TrueD VC50, Siemens Medical, Erlangen, Germany). Maximal tumour to blood ratios (TBRs) for ${ }^{89} \mathrm{Zr}$ cetuximab uptake were calculated at all time points by dividing the tumour SUV $\mathrm{max}_{\max }$ by the SUV $V_{\text {max }}$ in the aortic arch.

For patients in whom an ${ }^{18} \mathrm{~F}$-FDG-PET scan was performed within one week before or after the ${ }^{89} \mathrm{Zr}$-cetuximab scan, the ${ }^{18} \mathrm{FDG}$ and ${ }^{89} \mathrm{Zr}$-cetuximab uptake was visually compared. The location of the 18FDG uptake was determined using automated SUV-thresholding with the threshold depending on the tumour-to-background signal ratio (SBR-method) ${ }^{18,19}$.

\subsection{Results}

\section{Patient characteristics}

Seven patients, with a median age of 63 years (range: 53-75), were included. The third patient was excluded from the study before injection of the ${ }^{89} \mathrm{Zr}$-labelled cetuximab, because of malignant hypertension during the administration of the unlabelled cetuximab. The tension normalized within two hours of observation without further sequelae. Patient and tumour characteristics are shown in Table 8.2.

Six patients had a non-small cell lung carcinoma (NSCLC) and 1 had a tonsillar carcinoma. All patients had previously undergone anti-cancer therapy. In one patient, EGFR expression and mutation and k-ras mutation status of the primary tumour could not be assessed due to insufficient quantity of histological material. In the other patients, none of the primary tumours showed overexpression of EGFR or a mutation in exons 18-21 of the EGFR gene. In one patient, the primary tumour showed a mutation in the k-ras gene.

Each patient received ${ }^{89} \mathrm{Zr}$-labelled cetuximab administration as planned. In two patients (patient 2 and 4) enrolled in the first dose step, however, the second series of PET-CT scans could not be completed due to pain and dyspnea attributable to disease progression. 


\begin{tabular}{|c|c|c|c|c|c|c|c|c|c|c|}
\hline \multicolumn{11}{|c|}{ Table 8.2 Patient characteristics } \\
\hline & \multirow[t]{2}{*}{ Age } & \multirow[t]{2}{*}{ Sex } & \multirow[t]{2}{*}{ Length } & \multirow[t]{2}{*}{ Weight } & \multirow{2}{*}{$\begin{array}{l}\text { WHO } \\
\text { PS }\end{array}$} & \multicolumn{4}{|c|}{ Primary tumour } & \multirow{2}{*}{$\begin{array}{l}\text { Prior } \\
\text { therapy }\end{array}$} \\
\hline & & & & & & Site & Histology & Mutation $^{*}$ & Overexpression & \\
\hline 1 & 72 & $\mathrm{~m}$ & 1.85 & 75 & 0 & Lung & SCC & NA & NA & CTx \\
\hline 2 & 61 & $\mathrm{~m}$ & 1.76 & 82 & 1 & Lung & LCC & $\begin{array}{l}\text { k-ras: + } \\
\text { EGFR: - }\end{array}$ & No & CTx, RT \\
\hline $3^{* *}$ & 55 & $f$ & 1.56 & 61 & 0 & Lung & $\mathrm{LCC}$ & - & - & CTx \\
\hline 4 & 75 & $\mathrm{~m}$ & 1.79 & 74 & 2 & Lung & $A C$ & $\begin{array}{l}\text { k-ras: - } \\
\text { EGFR: - }\end{array}$ & No & CTx \\
\hline 5 & 53 & $\mathrm{~m}$ & 1.80 & 91 & 1 & Lung & $\mathrm{SCC}$ & $\begin{array}{l}\text { k-ras: - } \\
\text { EGFR: - }\end{array}$ & No & CTx \\
\hline 6 & 63 & $\mathrm{~m}$ & 1.78 & 86 & 0 & Lung & $A C$ & $\begin{array}{l}\text { k-ras: - } \\
\text { EGFR: - }\end{array}$ & No & CTx \\
\hline 7 & 63 & $\mathrm{~m}$ & 1.86 & 95 & 1 & Tonsil & SCC & $\begin{array}{l}\text { k-ras: - } \\
\text { EGFR: - }\end{array}$ & No & $\mathrm{RT}, \mathrm{CT} \mathrm{x}$ \\
\hline
\end{tabular}

*k-ras: codons 12 and 13; EGFR: exons 18-21

**Excluded patient: 55 year old female, NSCLC

WHO PS: World Health Organisation performance status; m: male; f: female; SCC: squamous cell carcinoma; LCC: large cell carcinoma; AC: adenocarcinoma; NA: not assessable due to insufficient quantity of histological material; CTx: Chemotherapy; RT: Radiotherapy

\section{Toxicity}

An overview of the toxicity per patient is presented in Table 8.3.

\begin{tabular}{|c|c|c|c|c|c|c|c|c|}
\hline \multirow[t]{2}{*}{$\mathrm{Pt}$} & \multirow{2}{*}{$\begin{array}{c}\text { Injected } \\
\text { activity } \\
\text { (MBq) }\end{array}$} & \multirow{2}{*}{$\begin{array}{c}\text { Vital } \\
\text { signs }\end{array}$} & \multicolumn{5}{|c|}{ Toxicity scoring ${ }^{*}$} & \multirow[t]{2}{*}{ Medication } \\
\hline & & & Haematology & $\begin{array}{c}\text { Liver } \\
\text { function }\end{array}$ & $\begin{array}{c}\text { Renal } \\
\text { function }\end{array}$ & Skin & Symptoms & \\
\hline 1 & $2 \times 60$ & 0 & 0 & 0 & 0 & 2 & 0 & $1^{* *}$ \\
\hline 2 & $2 \times 60$ & 0 & 0 & 0 & 0 & 1 & 0 & 0 \\
\hline 3 & none & NA & NA & NA & NA & NA & NA & NA \\
\hline 4 & $2 \times 60$ & 0 & 0 & 0 & 0 & 0 & 0 & 0 \\
\hline 5 & 120 & 0 & 0 & 0 & 0 & 2 & 0 & $1^{* *}$ \\
\hline 6 & 120 & 0 & 0 & 0 & 0 & 2 & 0 & $1^{* *}$ \\
\hline 7 & 120 & 0 & 0 & 0 & 0 & 1 & 0 & 0 \\
\hline
\end{tabular}

Toxicity was scored before study entry (baseline) and at days 7 and 14 after cetuximab administration NA: not assessed because of premature exclusion from the study

*Every change in vital signs or medication compared to the baseline values was scored, with " 0 " indicating no change.

**Doxycycline $100 \mathrm{mg}$, Hydroxyzine $25 \mathrm{mg}$, Metronidazolcream $10 \mathrm{mg} / \mathrm{g}$ 


\section{Image analysis}

Images of ${ }^{89} \mathrm{Zr}$-cetuximab uptake in the tumour of 2 patients are presented in Figure 8.2. For these patients, an ${ }^{18} \mathrm{~F}$-FDG-PET scan was performed 1 week after the ${ }^{89} \mathrm{Zr}$ cetuximab scan. A heterogeneous uptake of ${ }^{89} \mathrm{Zr}$-cetuximab was observed throughout the tumour and the rest of the body. In patient 1 , a remarkable mismatch was observed between FDG- and ${ }^{89} \mathrm{Zr}$-cetuximab uptake (Figure 8.3).

For the patients in dose step 1, the average maximum TBR at day 4, 5 and 6 after injection was 0.89 (range: 0.83-0.94), 0.98 (range: 0.88-1.05) and 1.09 (range: 0.761.60), respectively. As the most optimal TBR was found at day 6 after injection, imaging in dose step 2 was performed at days 5, 6 and 7. For patients in dose step 2, the average maximum TBR at day 5, 6 and 7 after injection was 0.88 (range: 0.571.05), 0.86 (range: $0.54-1.02$ ) and 0.91 (range: 0.42-1.20). Three patients had a maximum TBR of $\geq 1$ at any of the imaging time points: patient 4 had a maximum TBR of 1.60, patient 6 had a maximum TBR of 1.20 and the maximum TBR of patient 7 was 1.11 .
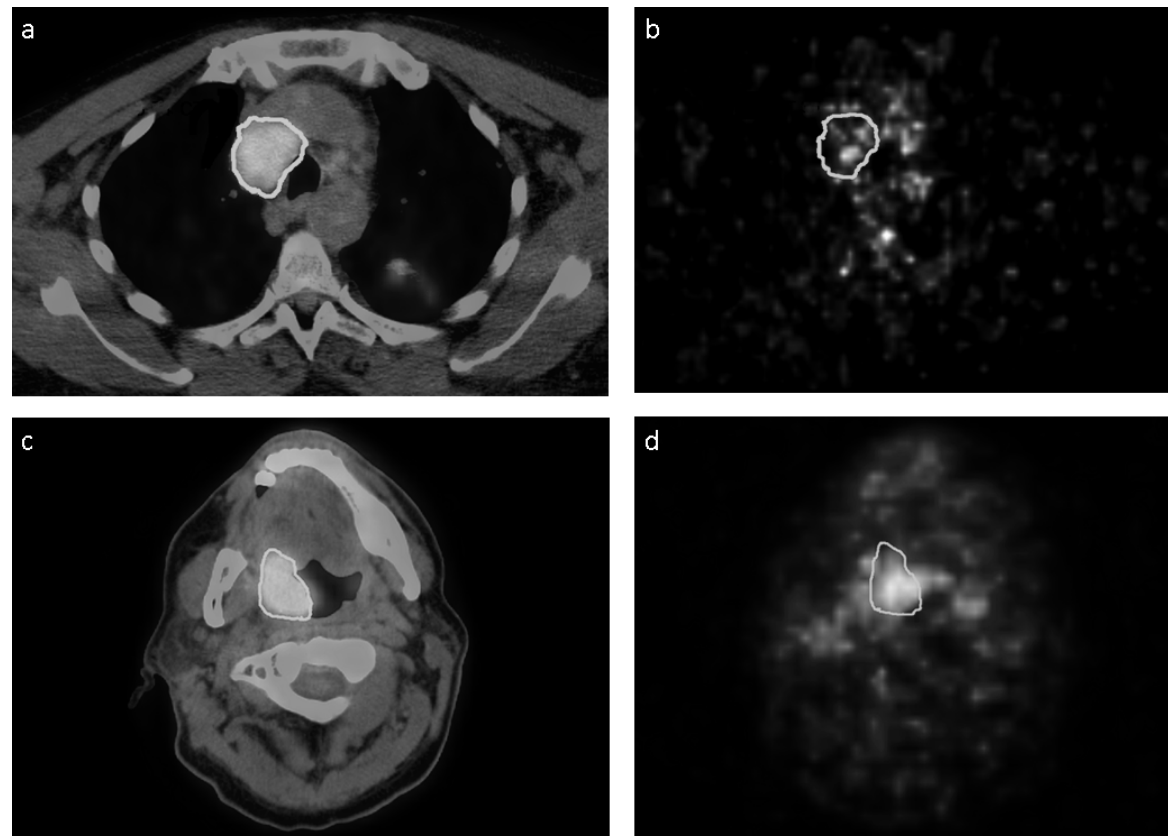

Figure 8.2. ${ }^{89} \mathrm{Zr}$-cetuximab and ${ }^{18} \mathrm{FDG}$ images of 2 patients

${ }^{89} \mathrm{Zr}$-cetuximab images at day 7 after injection are shown. ${ }^{18} \mathrm{FDG}$ images were acquired at day 14 after ${ }^{89} \mathrm{Zr}$-cetuximab administration.

a), b) Patient 6, $\max$ TBR=1.20; a) FDG-PET-CT, b) ${ }^{89} \mathrm{Zr}$-cetuximab-PET

c), d) Patient 7, $\max$ TBR=1.11; c) FDG-PET-CT, d) ${ }^{89} \mathrm{Zr}$-cetuximab-PET 

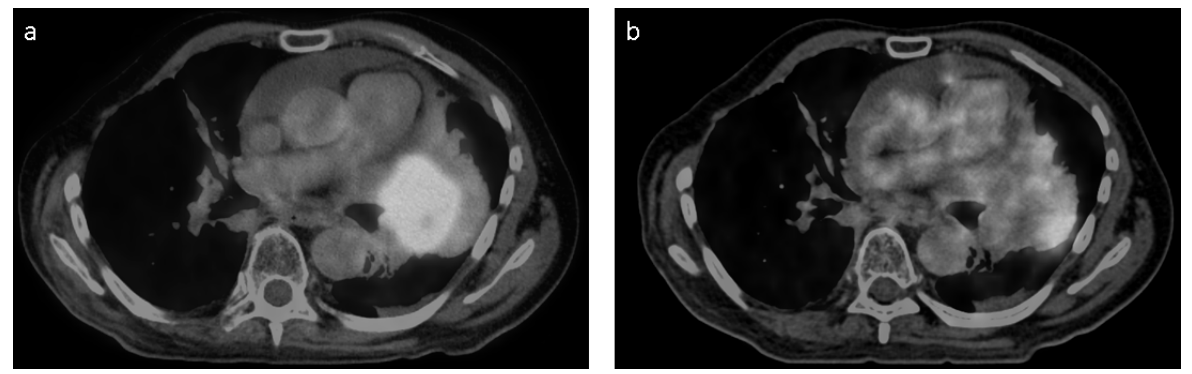

Figure 8.3. Correlation between ${ }^{89} \mathrm{Zr}$-cetuximab and ${ }^{18} \mathrm{FDG}$ uptake in patient 1

a) FDG-PET-CT (day 12 after ${ }^{89} \mathrm{Zr}$-cetuximab administration)

b) ${ }^{89} \mathrm{Zr}$-cetuximab-PET-CT (day 6 after injection)

\subsection{Discussion}

Although zirconium-89 labelled with other monoclonal antibodies has been evaluated in patients before without additional toxicity ${ }^{20}$, the current phase I trial is the first study in humans evaluating ${ }^{89} \mathrm{Zr}$ labelled with cetuximab. No additional toxicity was associated with the ${ }^{89} \mathrm{Zr}$ administration. Acne-form eruption was observed in $83 \%$ of patients, a rate comparable to that found with the therapeutic administration of cetuximab ${ }^{8,15,21}$. One patient developed malignant hypertension during the administration of unlabelled cetuximab. Although rare, this side-effect has been described previously ${ }^{22}$.

Many preclinical data show additive anti-tumour effects for cetuximab with radiotherapy and chemo-radiotherapy in experimental models ${ }^{9,23,24}$. The mechanisms underlying clinical response or resistance to treatment against EGFR with cetuximab are unknown. Until now, the only factors found to be associated with tumourresponse to cetuximab are wild-type K-RAS and an increased EGFR gene copy number. EGFR status was not associated with significant differences in response rates or survival. Also, time-frames of EGFR-expression during the course of (chemo)radiation are largely unknown. EGFR tyrosine kinase activity can be initiated by a single dose of radiation in experimental tumour models ${ }^{25}$. Repeated doses of daily radiation, similar to standard clinical therapy, stimulate increased EGFR expression in experimental models ${ }^{26}$. Visualization and quantification of cetuximab uptake in the tumour with PET before and during (chemo-)radiotherapy would have major benefit in the appropriate selection of patients for cetuximab treatment ${ }^{13}$.

The maximal TBR of ${ }^{89} \mathrm{Zr}$-cetuximab uptake in the patients included in this phase I study was 1.6. Correlation of the ${ }^{89} \mathrm{Zr}$-cetuximab and FDG uptake showed a remarkable mismatch between the two tracers in one patient. Although a large divergence was observed between patients in the time curves of the TBR, overall, the most optimal TBR was observed at the latest time point of imaging, being day 6 for dose 
step 1 and day 7 for dose step 2. Therefore, we would suggest the time point of 6 to 7 days after administration to perform $\mathrm{Zr}$-cetuximab imaging.

Several possibilities may explain the low TBRs observed in this study. First, the results may represent true negative findings in this selected patient group. Biopsies taken prior to any treatment of the primary tumours of the patients enrolled in this study did not show overexpression of EGFR or a mutation in the EGFR gene. All patients, however, had undergone extensive treatment with chemotherapy or radiotherapy, of which the long term effect on EGFR expression is largely unknown. Five of the 6 included patients had NSCLC. Although $40-80 \%$ of NSCLC tumours show EGFR expression ${ }^{1}$, response rates to cetuximab monotherapy in pre-treated patients with EGFR expressing primary tumours of only $5 \%$ are reported ${ }^{21}$. Second, the loading dose administered in this study $\left(400 \mathrm{mg} / \mathrm{m}^{2}\right)$, which is the standard in therapeutic regimens might be either too low or too high to enable adequate tumour visualization. The rationale of the loading dose of cetuximab is that cetuximab first binds irreversibly to EGFR expressing liver cells, and that tumour cells are only targeted after the liver has been saturated ${ }^{27}$. This rationale is supported by animal studies as well as by the positive relation between skin toxicity and tumour response to cetuximab, implying that skin saturation only occurs after the liver has been saturated ${ }^{28-30}$. On the other hand, it cannot be excluded that the unlabelled cetuximab is already sufficient to saturate the EGF receptors on the tumour cells. Future studies should address these critical questions. Finally, it is possible that cetuximab might not reach its target receptor at tumour cells due to limited blood supply and interstitial pressure of the tumour ${ }^{31}$. Hereby, a disparity could result between the in vivo EGFR expression and the uptake of cetuximab, a finding that has been confirmed in our preclinical study with ${ }^{89} \mathrm{Zr}$-cetuximab ${ }^{14}$.

Future studies are planned addressing the role of each of these contributing factors. Patients will be studied at primary diagnosis before the start of any antitumour therapy, to allow correlation of EGFR expression at histology with imaging results. As radiotherapy induces upregulation of EGFR expression, visualization of ${ }^{89} \mathrm{Zr}$ cetuximab uptake before and after a single fraction of RT will be evaluated. ${ }^{89} \mathrm{Zr}$ cetuximab administration with different loading doses of unlabelled cetuximab will be evaluated to address its influence on tumour visualization. Finally, kinetic imaging enables the measurement of tumour perfusion, and this should thus be incorporated in future clinical trials. 


\subsection{Conclusion}

The administration of ${ }^{89} \mathrm{Zr}$ labelled cetuximab to image EGFR expression in vivo is not associated with any additional toxicity. Based on the tumour to background ratios, a time delay of 6-7 days after injection is advised for further research.

\section{Acknowledgements}

The authors would like to thank the Dutch Cancer Society (KWF-fellowship granted to H.J.W.L.A.) and the Centre for Translational Molecular Medicine (CTMM) for their financial support. 


\subsection{References}

1. Rowinsky EK. The erbB family: targets for therapeutic development against cancer and therapeutic strategies using monoclonal antibodies and tyrosine kinase inhibitors. Annu Rev Med 2004;55:43357.

2. Herbst RS. Review of epidermal growth factor receptor biology. Int J Radiat Oncol Biol Phys 2004;59:21-6.

3. Akimoto T, Hunter NR, Buchmiller L, Mason K, Ang KK, Milas L. Inverse relationship between epidermal growth factor receptor expression and radiocurability of murine carcinomas. Clin Cancer Res 1999;5:2884-90.

4. Ang KK, Berkey BA, Tu X, et al. Impact of epidermal growth factor receptor expression on survival and pattern of relapse in patients with advanced head and neck carcinoma. Cancer Res 2002;62:7350-6.

5. Baumann M, Krause M, Zips D, et al. Selective inhibition of the epidermal growth factor receptor tyrosine kinase by BIBX1382BS and the improvement of growth delay, but not local control, after fractionated irradiation in human FaDu squamous cell carcinoma in the nude mouse. Int J Radiat Biol 2003;79:547-59.

6. Gibson MK, Abraham SC, Wu TT, et al. Epidermal growth factor receptor, p53 mutation, and pathological response predict survival in patients with locally advanced esophageal cancer treated with preoperative chemoradiotherapy. Clin Cancer Res 2003;9:6461-8.

7. Giralt J, de las Heras M, Cerezo L, et al. The expression of epidermal growth factor receptor results in a worse prognosis for patients with rectal cancer treated with preoperative radiotherapy: a multicenter, retrospective analysis. Radiother Oncol 2005;74:101-8.

8. Bonner JA, Harari PM, Giralt J, et al. Radiotherapy plus cetuximab for squamous-cell carcinoma of the head and neck. N Engl J Med 2006;354:567-78.

9. Raben D, Helfrich B, Chan DC, et al. The effects of cetuximab alone and in combination with radiation and/or chemotherapy in lung cancer. Clin Cancer Res 2005;11:795-805.

10. Rasbridge SA, Gillett CE, Seymour AM, et al. The effects of chemotherapy on morphology, cellular proliferation, apoptosis and oncoprotein expression in primary breast carcinoma. $\mathrm{Br} \mathrm{J}$ Cancer 1994; 70:335-41.

11. Contessa JN, Reardon DB, Todd D, et al. The inducible expression of dominant-negative epidermal growth factor receptor-CD533 results in radiosensitization of human mammary carcinoma cells. Clin Cancer Res 1999;5:405-11.

12. Schmidt-Ullrich RK, Contessa JN, Dent $P$, et al. Molecular mechanisms of radiation-induced accelerated repopulation. Radiat Oncol Investig 1999;7:321-30.

13. van Dongen GA, Visser GW, Lub-de Hooge MN, de Vries EG, Perk LR. Immuno-PET: a navigator in monoclonal antibody development and applications. Oncologist 2007;12:1379-89.

14. Aerts HJ, Dubois L, Perk L, et al. Disparity between in vivo EGFR expression and $89 \mathrm{Zr}$-labeled cetuximab uptake assessed with PET. J Nucl Med 2009;50:123-31.

15. Galimont-Collen AF, Vos LE, Lavrijsen AP, Ouwerkerk J, Gelderblom H. Classification and management of skin, hair, nail and mucosal side-effects of epidermal growth factor receptor (EGFR) inhibitors. Eur J Cancer 2007;43:845-51.

16. Verel I, Visser GW, Boellaard R, Stigter-van Walsum M, Snow GB, van Dongen GA. 89Zr immuno-PET: comprehensive procedures for the production of $89 \mathrm{Zr}$-labeled monoclonal antibodies. J Nucl Med 2003;44:1271-81.

17. Perk LR, Visser GW, Vosjan MJ, et al. (89)Zr as a PET surrogate radioisotope for scouting biodistribution of the therapeutic radiometals (90)Y and (177)Lu in tumor-bearing nude mice after coupling to the internalizing antibody cetuximab. J Nucl Med 2005;46:1898-906.

18. Daisne JF, Sibomana M, Bol A, Doumont T, Lonneux M, Gregoire V. Tri-dimensional automatic segmentation of PET volumes based on measured source-to-background ratios: influence of reconstruction algorithms. Radiother Oncol 2003;69:247-50. 
19. Ollers $M$, Bosmans $G$, van Baardwijk $A$, et al. The integration of PET-CT scans from different hospitals into radiotherapy treatment planning. Radiother Oncol 2008;87:142-6.

20. Borjesson PK, Jauw YW, Boellaard R, et al. Performance of immuno-positron emission tomography with zirconium-89-labeled chimeric monoclonal antibody U36 in the detection of lymph node metastases in head and neck cancer patients. Clin Cancer Res 2006;12:2133-40.

21. Hanna N, Lilenbaum R, Ansari R, et al. Phase II trial of cetuximab in patients with previously treated non-small-cell lung cancer. J Clin Oncol 2006;24:5253-8.

22. http://www.ema.europa.eu/humandocs/PDFs/EPAR/erbitux/H-558-PI-en.pdf. European Medicines Agency.

23. Huang SM, Bock JM, Harari PM. Epidermal growth factor receptor blockade with C225 modulates proliferation, apoptosis, and radiosensitivity in squamous cell carcinomas of the head and neck. Cancer Res 1999;59:1935-40.

24. Milas L, Mason K, Hunter N, et al. In vivo enhancement of tumor radioresponse by C225 antiepidermal growth factor receptor antibody. Clin Cancer Res 2000;6:701-8.

25. Schmidt-Ullrich RK, Valerie K, Fogleman PB, Walters J. Radiation-induced autophosphorylation of epidermal growth factor receptor in human malignant mammary and squamous epithelial cells. Radiat Res 1996;145:81-5.

26. Schmidt-Ullrich RK, Valerie KC, Chan W, McWilliams D. Altered expression of epidermal growth factor receptor and estrogen receptor in MCF-7 cells after single and repeated radiation exposures. Int J Radiat Oncol Biol Phys 1994;29:813-9.

27. Divgi $C R$, Welt $S$, Kris $M$, et al. Phase I and imaging trial of indium 111-labeled anti-epidermal growth factor receptor monoclonal antibody 225 in patients with squamous cell lung carcinoma. J Natl Cancer Inst 1991;83:97-104.

28. Burtness B, Goldwasser MA, Flood W, Mattar B, Forastiere AA. Phase III randomized trial of cisplatin plus placebo compared with cisplatin plus cetuximab in metastatic/recurrent head and neck cancer: an Eastern Cooperative Oncology Group study. J Clin Oncol 2005;23:8646-54.

29. Cunningham D, Humblet $Y$, Siena $S$, et al. Cetuximab monotherapy and cetuximab plus irinotecan in irinotecan-refractory metastatic colorectal cancer. N Engl J Med 2004;351:337-45.

30. Tolmachev $\mathrm{V}$, Rosik D, Wallberg $\mathrm{H}$, et al. Imaging of EGFR expression in murine xenografts using sitespecifically labelled anti-EGFR 111In-DOTA-Z EGFR:2377 Affibody molecule: aspect of the injected tracer amount. Eur J Nucl Med Mol Imaging;37:613-22.

31. de Bree R, Kuik DJ, Quak JJ, et al. The impact of tumour volume and other characteristics on uptake of radiolabelled monoclonal antibodies in tumour tissue of head and neck cancer patients. Eur J Nucl Med1998;25:1562-5. 
Part

IV

Discussion 



\title{
CHAPTER 9
}

\section{Therapeutic implications of molecular imaging with PET in the combined modality treatment of lung cancer}

\author{
Judith van Loon \\ Dirk De Ruysscher \\ Angela van Baardwijk \\ Liesbeth Boersma \\ Michel Öllers \\ Philippe Lambin
}

Submitted 


\section{Abstract}

With the introduction of targeted chemotherapy and radiotherapy techniques, accurate definition of the tumour volume becomes increasingly important. Molecular imaging with PET, and certainly integrated PET-CT, combining functional and anatomical imaging, has many potential advantages over anatomical imaging alone in the combined modality treatment of lung cancer. The aim of the current article is to review the available evidence regarding PET with FDG and other tracers in the combined modality treatment of locally advanced lung cancer. The following topics are addressed: tumour volume definition, outcome prediction and the added value of PET after therapy, and finally its clinical implications and future perspectives.

The additional value of FDG-PET in defining the primary tumour volume has been established, mainly in regions with atelectasis or post-treatment effects. Selective nodal irradiation (SNI) of FDG-PET positive nodal stations is the preferred treatment in NSCLC, being safe and leading to decreased normal tissue exposure, providing opportunities for dose escalation. First results in SCLC show similar results. FDGuptake on the pre-treatment PET scan is of prognostic value. Data on the value of pre-treatment FDG-uptake to predict response to combined modality treatment are conflicting, but the limited data regarding early metabolic response assessment during treatment do show predictive value. FDG response after radical treatment is of prognostic significance. An FDG-PET scan in the follow-up has potential benefit in NSCLC, while data in SCLC are lacking. Radiotherapy boosting of radioresistant areas identified with FDG-PET is subject of current research.

Tracers other than ${ }^{18}$ FDG are promising for treatment response assessment and the visualization of intra-tumour heterogeneity, but more research is needed before they can be clinically implemented. 


\subsection{Background}

Lung cancer accounts for 219,000 new cancer cases and 159,000 deaths a year in the United States, representing $15 \%$ of cancer cases and $28 \%$ of cancer death in $2009^{1}$. As patients often present with primary irresectable disease, the majority of patients with localized disease is currently treated with multimodality treatment using a combination of surgery, chemotherapy (CTx), radiotherapy (RT) and targeted agents. Although survival has significantly improved with combined modality treatment, still, about one third of locally advanced lung cancer patients experience local failure as their first site of relapse. Furthermore, these combined treatment strategies are often associated with dose limiting toxicity, prohibiting further intensification of treatment. This could potentially be overcome by targeted antitumour therapy with more conformal RT techniques and targeted agents. This provides opportunities to increase locoregional control without increasing toxicity. Furthermore, progress is made in strategies directed at an early adaptation of therapy dependent on the treatment response, which may lead to optimization of the therapeutic ratio in each individual. After completion of curative treatment, improvement of outcome could be accomplished by an early detection of local progression, increasing the possibility for those patients to be offered salvage therapy.

The introduction of these techniques makes accurate definition of the tumour volume to be treated increasingly important. This emphasizes the need for imaging techniques enabling accurate definition of the presence and extent of tumour before, during and after curative treatment in cancers of the respiratory tract. While CT and MRI are the most accurate imaging modalities with respect to anatomical information, they often lack the potential to distinguish between vital tumour and non-malignant tissue. Here, molecular imaging with positron emission tomography (PET), providing metabolic information, has additional value. Different radiopharmaceuticals have been evaluated for the imaging of malignant tumours, of which ${ }^{18}$ F-fluorodeoxyglucose $\left({ }^{18} \mathrm{FDG}\right)$ is by far most commonly used. FDG-PET scanning utilizes the difference in accumulation of FDG between normal and cancerous tissues, based on an enhanced glucose metabolism in cancer cells. Other PET tracers, visualizing specific molecular pathways in tumours such as proliferation (e.g., ${ }^{11} \mathrm{C}$ methionine, ${ }^{11} \mathrm{C}$-choline, ${ }^{18} \mathrm{~F}$-fluorothymidine) hypoxia (e.g., ${ }^{18} \mathrm{~F}$-FMISO) or expression of certain receptors (Her2Neu, EGFR) are increasingly being used in the evaluation of malignancies.

Thus, metabolic imaging with PET, and certainly integrated PET-CT, combining functional and anatomical imaging, has many potential advantages over anatomical imaging alone in the combined modality treatment of lung cancer. PET using FDG is 
at present most widely applied in the clinical practice of non-small cell lung cancer (NSCLC). Its use in small cell lung cancer (SCLC) is rapidly emerging.

The aim of the current article is to review the available evidence on the use of PET in the combined modality treatment of locally advanced lung cancer. For NSCLC and SCLC separately, the role of PET imaging will be addressed with respect to the following topics:

- Definition of the tumour volume to be treated, both with respect to the primary tumour and the locoregional lymph nodes

- Outcome prediction on basis of PET before or early after the start of treatment, and the added value of PET after therapy

With regard to both these topics, the clinical implications of the use of PET are addressed, and future perspectives are provided.

Because ${ }^{18}$ FDG is by far most commonly applied in clinical practice, the majority of evidence comes from this tracer. Therefore, where "PET" is used in this article, this refers to " ${ }^{18}$ FDG-PET", unless otherwise stated. Wherever other tracers have shown additional value, or are regarded as promising in the near future, they will be discussed.

\subsection{Search strategy}

A comprehensive literature search was conducted using the "Pubmed" database. Included search terms were: "Non small cell lung cancer", "Small cell lung cancer", "NSCLC", "SCLC", "Target volume definition", "Delineation", "Gross tumour volume (GTV)", "Clinical target volume (CTV)", "Tumour heterogeneity", "Selective nodal irradiation", "Prognostic value", "Outcome prediction", "Follow-up", "Combined modality treatment", "Chemotherapy", "Radiotherapy" or "Radiation" in combination with "PET", "Positron emission tomography" or "Molecular imaging".

Reference lists of relevant articles were searched for further studies. Only publications in the English language and published online before February 1, 2010 were included.

\subsection{Non-small cell lung cancer (NSCLC)}

NSCLC represents more than $80 \%$ of lung cancer cases ${ }^{2}$. Combined chemoradiotherapy is the standard treatment for locally advanced (stage III), inoperable NSCLC. 
NSCLC is the tumour type in which the role of ${ }^{18}$ FDG-PET imaging has been investigated most extensively.

The added value of PET to select patients for combined modality treatment has been studied extensively ${ }^{3-5}$, and it was shown that PET staging results in superior outcome due to stage migration: up to $30 \%$ of stage III patients are diagnosed with distant metastases ${ }^{6,7}$. This clearly affects patient outcome as it withholds toxic therapy in individuals who will not benefit from it.

Below, we will discuss the role of PET in the radiation treatment planning and evaluation of combined chemoradiotherapy for stage III NSCLC.

\subsubsection{Definition of the tumour volume to be treated}

\section{Primary tumour}

Although FDG-PET has a high sensitivity for the detection of the primary tumour, an important drawback is its lack of anatomic detail, which limits its ability to define the exact tumour boundaries. The spatial resolution of current PET scanners is limited to 4-6 $\mathrm{mm}^{8}$, which is far lower than that of modern CT scanners, with a resolution down to $1 \mathrm{~mm}$. There are cases, however, where anatomic imaging modalities such as CT and MRI are compromised in their ability to define the exact tumour border, such as in patients with atelectasis or tumours near the thoracic wall ${ }^{9}$. Multiple studies have shown a large interobserver variation in delineation of the tumour on $\mathrm{CT}^{9,10}$. This interobserver variation is significantly diminished by using the information of an FDG-PET scan, co-registered with $\mathrm{CT}^{11-14}$. Overall, volumes delineated using PET-CT are smaller ${ }^{12}$. Differences between PET and CT were mainly found in the regions with atelectasis ${ }^{12,15,16}$.

Various quantitative methods have been developed for automatic tumour delineation using PET instead of visual interpretation of the PET signal. The most straightforward method uses an absolute threshold of the standardized uptake value (SUV). The SUV $\mathrm{Sax}_{\max }$ threshold of 2.5 is often used for this purpose ${ }^{17}$. An absolute threshold should be used with caution, however, as the SUV is associated with considerable variety due to both technical and biological factors ${ }^{18}$. An alternative method is the use of a relative threshold, e.g. a certain percentage of the SUV $V_{\max }$. Recently, more complex methods have been developed, including the application of an individualized threshold based on the source-to-background ratio (SBR) or the watershed clustering method ${ }^{19-21}$. An example of the difference in interobserver variation between manual and autocontour based delineation is provided in Figure 9.1. Nestle et al. compared absolute (SUV $\max \geq 2.5)$, relative (40\% SUV $V_{\max }$ and individual (SBR algorithm) quantitative methods and a visual interpretation method with CTvolumes $^{22}$. There were large differences in the resulting volumes, particularly in patients with a heterogeneous pattern of FDG-uptake. 

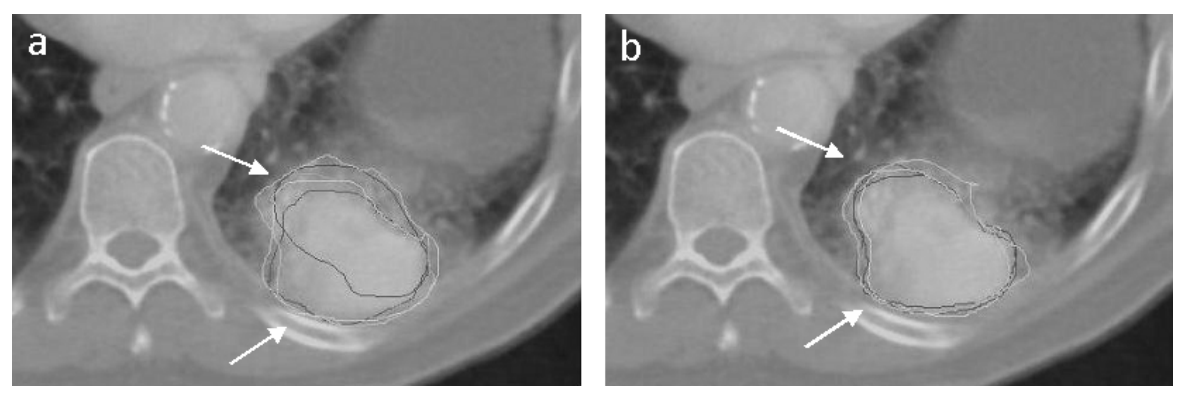

Figure 9.1 Example of a manual (a) and autocontour based (b) delineation of the primary tumour For autocontouring, the SBR based method was used

Arrows indicate changes in interobserver variation in delineation between the two methods

Ideally, validation of the delineated tumour volume should be obtained by correlating it with the tumour volume at pathologic examination, being the gold standard. The currently available data are based on two-dimensional correlations in early stage disease ${ }^{23-25}$. With the use of a relative threshold, a better correlation was found for CT than for PET (correlation coefficient 0.87 versus 0.77 ) ${ }^{23}$. Yu et al. found the best correlation with integrated PET-CT based on an absolute threshold (SU$\left.V_{\max } \geq 2,5\right)^{24}$. A correlation coefficient of 0.90 was found between the maximal tumour diameter obtained with SBR-based autodelineation and pathology ${ }^{25}$. Promising attempts are made to develop a three-dimensional model (Figure 9.2), but results in large patient cohorts are to be awaited ${ }^{26-28}$.

The methods described above are aimed at an accurate definition of the gross tumour volume (GTV) in order to ensure that this region is adequately covered by the RT treatment fields. Characteristics associated with radioresistance, such as hypoxia, cell density and proliferation, however, are known to be heterogeneous across the tumour ${ }^{29-31}$. FDG-PET scans may allow the identification of therapyresistant areas within the tumour. It would be logical to selectively boost the radioresistant areas, whilst decreasing the dose to the less resistant zones, resulting in higher tumour control with similar side effects ${ }^{32-35}$. It has been demonstrated that regions with high FDG uptake prior to radiotherapy correspond well with the location of recurrent/persistent tumour after sequential chemo-radiotherapy or RT alone (Figure 9.3) ${ }^{36,37}$. Furthermore, those regions remain stable during a course of RT (Figure 9.4) ${ }^{38}$. Thus, selective boosting of areas of assumed radioresistance identified with FDG-PET before the start of RT appears to have a good rationale. 
(A)

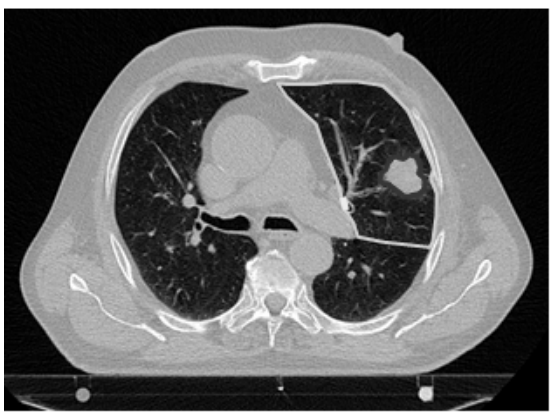

(c)

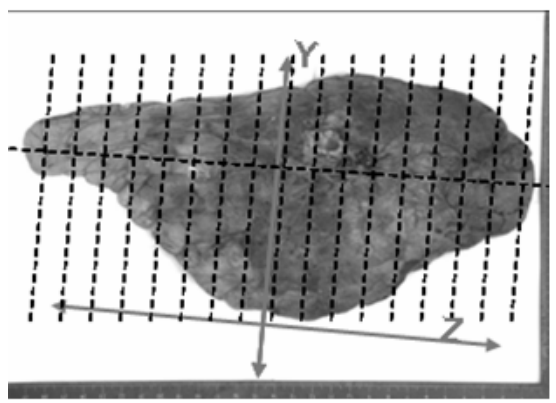

(E)

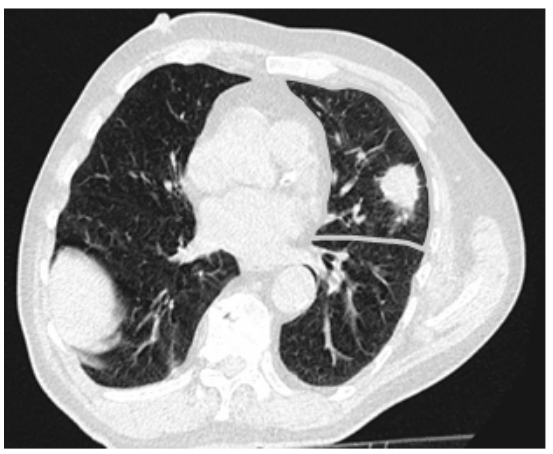

(B)

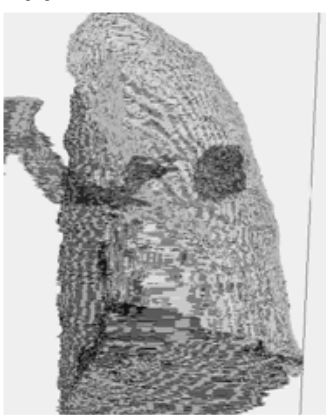

(D)
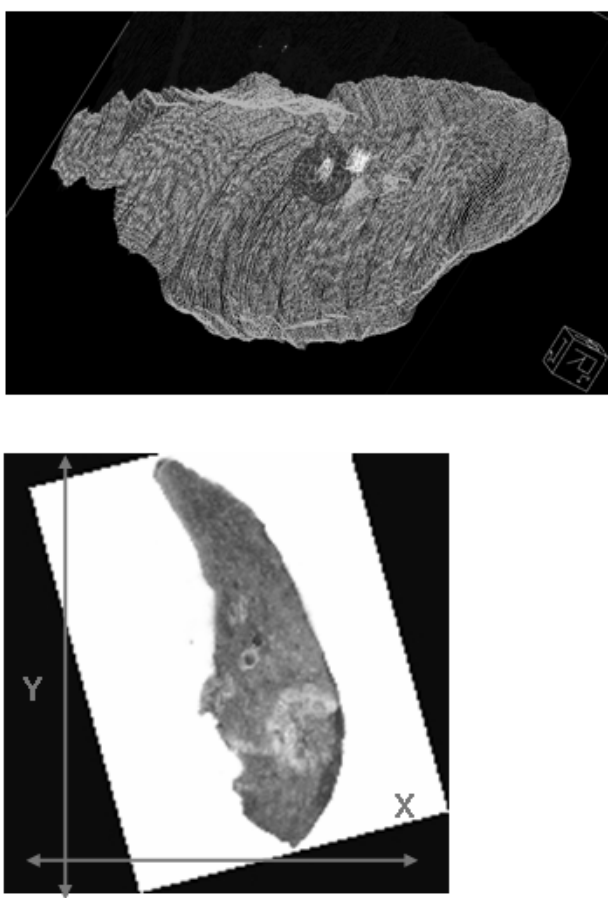

Figure 9.2 Example of the procedure to correlate imaging with pathology in three dimensions: Estimation of the orientation of the $\mathrm{CT}$ with respect to the macroscopic slices

In (A), the volumes of interest (lobe, GTV-CT, bronchus entrance) are delineated in the CT slices. In (B) a 3D representation of the CT volumes is depicted. In (C) the inflated specimen after surgery is photographed. The slice direction is indicated by the dashed lines. In (D) the 3D CT volumes are rotated in such a way that the orientation corresponds to the macroscopic specimen

In (E) the CT data are resliced accordingly and for each macroscopic slice the corresponding CT slice can be found. After this procedure, $\mathrm{X}$ corresponds approximately to the medio-lateral direction, $\mathrm{Y}$ to anteroposterior, and $Z$ to cranio-caudal 

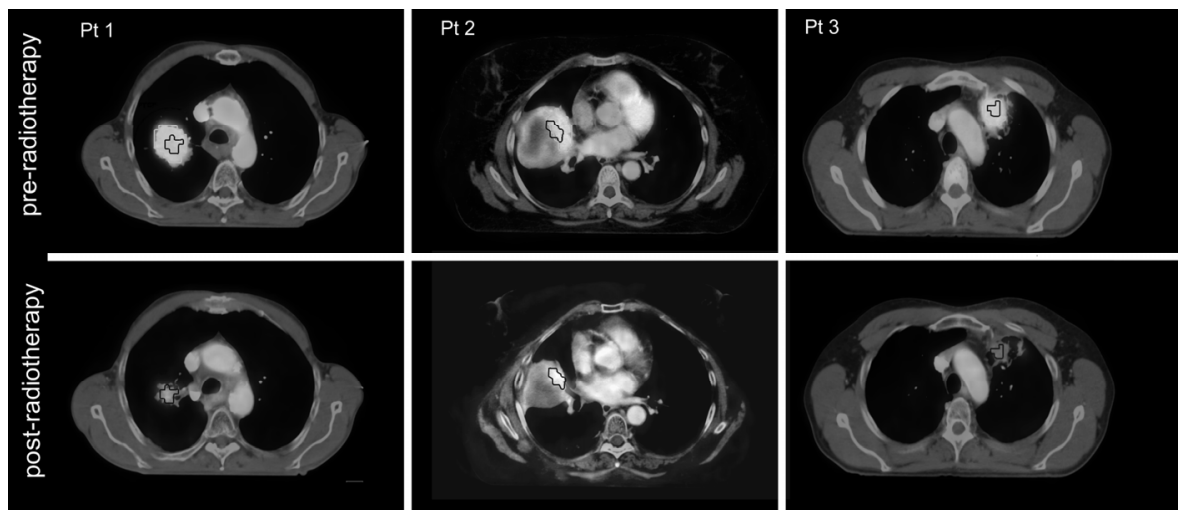

Figure 9.3 Correlation between pre-treatment high FDG-uptake areas and location of residual disease Representative FDG-PET-CT images of three patients pre- and post-radiotherapy.

The light grey lines indicate the 50\%SUVmax FDG high-uptake area pre-radiotherapy. The dark lines indicate the residual metabolic-active areas post-radiotherapy, also transposed on the pre-radiotherapy scan. Visual evaluation shows a large correspondence between the residual areas post-radiotherapy with the high FDG uptake areas pre-radiotherapy
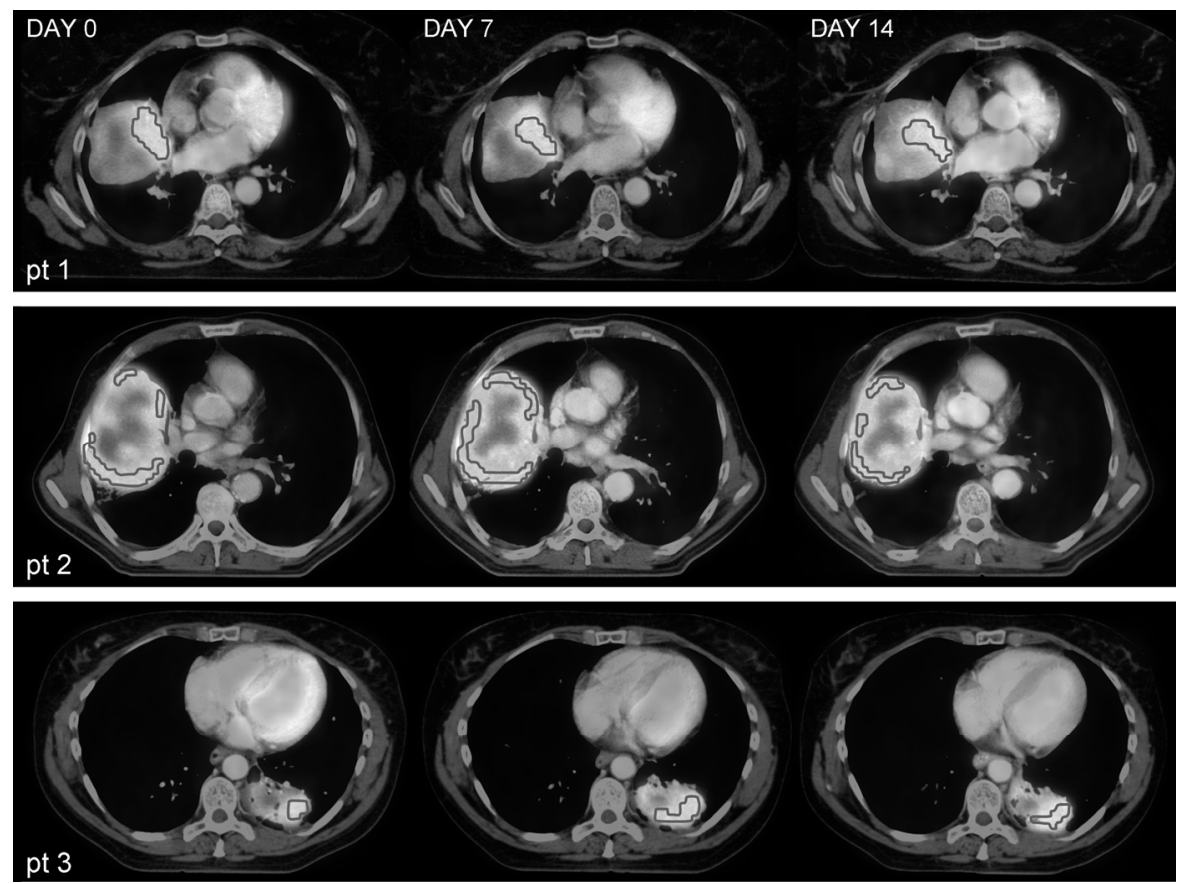

Figure 9.4 Stability of high FDG-uptake areas during a course of RT

PET-CT images of 3 patients before treatment (Day 0) and during treatment (Days 7 and 14). Lines indicate $60 \%$ of maximal standardized uptake value (SUVmax) threshold. Visual inspection showed that location of the hotspot remained at the same location during treatment; however, the volume of the hotspot changed 
The additional value of FDG-PET scanning in defining the primary tumour volume is thus beyond doubt. However, the drawbacks of FDG-PET should be kept in mind. Due to the poor resolution, blurring does occur, particularly at the tumour edges ${ }^{18}$. Those blurring effects at the tumour boundary are even more pronounced by motion artefacts. Although the long acquisition time of PET is disadvantageous with respect to defining an absolute tumour edge and quantifying metabolic activity, it may have additional value in determining the extent of tumour motion. The acquisition time of several minutes results in a tumour volume incorporating the averaged position of the tumour over multiple respiratory and cardiac cycles. In a phantom study, PET-based treatment volumes resulted in an adequate coverage of the tumour, while CT-based volumes harboured the risk of a geographical miss ${ }^{39}$. Respiratory gating or $4 \mathrm{D}$ imaging techniques allow the incorporation of the extent of tumour movement, while optimizing image quality and quantification as the blurring effect is reduced ${ }^{40}$. Those techniques are presently being evaluated in clinical studies $^{40,41}$.

\section{Microscopic disease extension}

The poor spatial resolution of PET precludes a direct evaluation of the presence and extent of microscopic disease around the macroscopic tumour border. Definition of the area of potential microscopic spread in patients treated with chemoradiotherapy is important as this region should be covered in the radiation field. The only way to quantify microscopic spread beyond the tumour border visible on imaging is by correlating imaging with the findings at pathologic examination. Until now, this correlation has only been performed between CT and pathology ${ }^{42-44}$. Furthermore, no correction was applied for deformation of the lung lobe after surgery. Methods for the correlation of both PET and CT with pathology, which do take into account deformation, are under development ${ }^{26,27}$. First results indicate an average microscopic spread in vivo of $9 \mathrm{~mm}^{27}$, suggesting that currently applied margins might be too small to cover microscopic disease.

\section{Lymph nodes}

Accurate identification of nodal metastases has become of particular importance since routine elective nodal irradiation, i.e. the prophylactic irradiation of clinically uninvolved lymph nodes, is no longer recommended in NSCLC ${ }^{45,46}$. FDG-PET has a higher sensitivity and specificity for the detection of lymph node involvement in NSCLC than CT (sensitivity: $83 \%$ vs. $62 \%$; specificity: $97 \%$ vs. $91 \%$, respectively) ${ }^{47}$. Both PET- and CT-based selective irradiation of involved lymph nodes has proven its safety in NSCLC, with the occurrence of isolated nodal failures (INF) in less than $5 \%$ of patients ${ }^{48-51}$. One study found INF in up to $15 \%$ with PET-based SNI ${ }^{52}$. However, the accuracy of the identification of lymph nodes in this study was questionable, as only visual interpretation of non-coregistered PET images was used. In general, the 
PET-based treatment volumes are smaller than CT-based volumes ${ }^{53,54}$. Selective nodal irradiation (SNI) has shown not only to be safe, but also to result in a reduction of radiation fields based on $\mathrm{CT}$, and even further based on PET ${ }^{50}$. A modelling study showed that treating only FDG-positive mediastinal areas decreases radiation exposure of the lungs and the esophagus sufficiently as to allow for radiation doseescalation ${ }^{50,54}$. An example of the difference resulting from RT planning with PETCT compared to CT alone is illustrated in Figure 9.5.

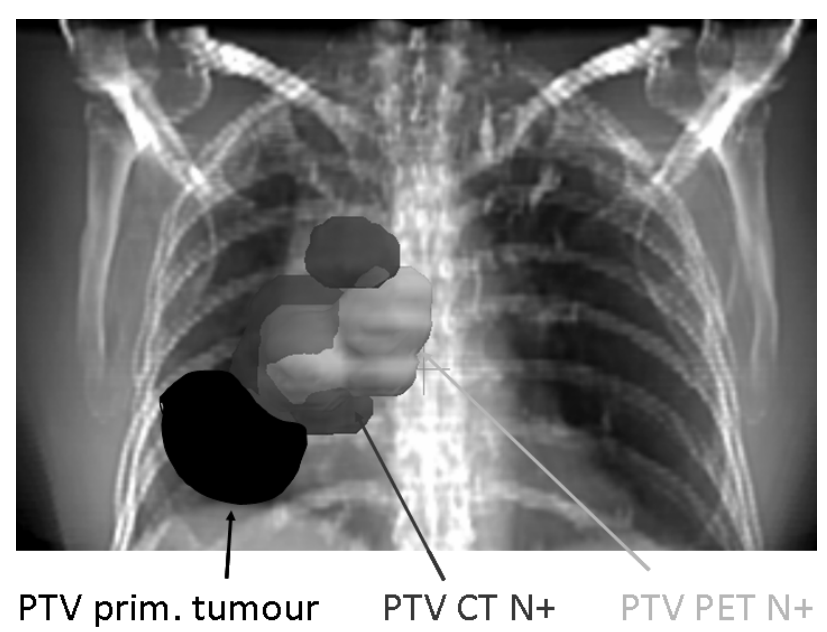

Figure 9.5 Example of the effects of RT planning with PET-CT compared to CT alone

Projection of the planning target volume (PTV) of a 66-yearold female with a large cell carcinoma of the right lower lobe with pathological lymph nodes on CT scan in areas $4 R$ and $3 R$ and on FDG-PET scan in area 7. Although the lung exposure was lower with PET-CT than with CT (V20 25 vs. 30\% and MLD 15.4 vs. $19.3 \mathrm{~Gy}$, respectively), the oesophageal exposure was higher with PET-CT because of the involvement of level 7 (MED 16.9 vs. 14.1 Gy, V55 18 vs. 4\%, Dmax 60.1 vs. 58.6 Gy, respectively, for PET-CT and CT)

Although PET-defined SNI appears to be safe, ideally, pathological confirmation of PET-positive mediastinal nodes should be obtained. Pathological validation of the CT-and PET-based nodal treatment volumes was performed in 998 lymph nodal stations from 105 patients ${ }^{55}$. The coverage of all pathologic lymph nodes was $89 \%$ with PET-based treatment volumes compared to $75 \%$ with CT $(p=0.005)$. Nevertheless, a false negative rate with PET up to $14 \%$ has been reported in operable patients ${ }^{56}$. A possible explanation for the low amount of isolated nodal failures is the incidental irradiation of clinically negative lymph node stations through coverage by the beam penumbra of conventional RT fields. The Michigan group showed that risk factors of nodal metastases, such as a large tumour size and central location, were associated with a considerable dose to the high-risk nodal regions ${ }^{57}$, indicating that incidental nodal irradiation might play an important role. Therefore, caution is warranted with the application of new RT technologies, such as stereotactic body radiotherapy (SBRT), intensity modulated radiotherapy (IMRT) and particle therapy, as 
they are associated with a more conformal dose distribution and altered penumbra characteristics.

Different methods can be used for delineation of the involved lymph nodes on PET. Nestle et al. compared the nodal volumes resulting from visual delineation and absolute $\left(\mathrm{SUV}_{\max } \geq 2.5\right)$, relative $\left(40 \% \mathrm{SUV}_{\max }\right)$ and individual (SBR-based) thresholds 58 . There were no clinically relevant differences in resulting volumes. SBR-based contouring of lymph nodes generally showed a good correlation with pathology ${ }^{25}$. Regardless of the delineation method, the question remains how to incorporate the lymph nodes in the treatment volume. There are no data available on the microscopic extension of disease outside lymph nodes. This residual uncertainty can be overcome by encompassing the whole anatomical mediastinal region in the treatment volume, as was done in the Maastricht studies described above ${ }^{50,53,54}$.

As for the primary tumour, the exact anatomical localization of the mediastinal lymph nodes may be blurred because of respiratory motion. Ideally, individually determined margins should be applied to cover the lymph nodes in all respiratory phases, as there is a large intra- and inter-individual variation in lymph node motion, not related to the motion of the primary tumour ${ }^{59-61}$.

\section{Clinical implications and future perspectives}

The incorporation of PET in RT planning has shown the potential for dose escalation through a reduction of the radiation fields, mainly because of avoidance of irradiating PET negative lymph nodes $53,54,62$. With individualized radiation dose escalation based on normal tissue constraints, patients treated with sequential chemoradiation had survival rates comparable to results with concurrent chemo-radiation schedules while less toxicity was observed ${ }^{63}$. These results imply that PET-based RT planning might ultimately lead to higher cure rates, and randomized prospective studies are warranted to investigate this further.

Further optimization of the radiotherapy treatment volume could be obtained by an accurate definition of the appropriate margin around the delineated tumour to cover microscopic disease. This information should become available from studies correlating PET-CT findings with pathology.

Recently, an increasing tendency has emerged to move away from the concept of homogeneous irradiation. Studies have been performed to investigate the feasibility of selectively boosting areas with residual FDG-uptake after 40-60 Gy, with diverging results ${ }^{64,65}$. Prospective trials are awaited to investigate whether radiation dose redistribution leads to better treatment outcome, for which preparations are currently being performed ${ }^{33,66}$. In the studies mentioned before, ${ }^{18} \mathrm{FDG}$ was used as a tracer for radioresistant areas. Other tracers, e.g. for hypoxia $\left({ }^{18} \mathrm{~F}-\mathrm{FMISO},{ }^{18} \mathrm{~F}-\mathrm{HX} 4\right)$ 
or proliferation $\left({ }^{18} \mathrm{~F}-\mathrm{FLT}\right)$ could be used complimentary to or instead of FDG ${ }^{67-71}$. These tracers deserve further investigation for this purpose.

\section{Conclusion}

FDG-PET has an important additional role to anatomic imaging in defining the primary tumour volume. Automatic delineation with adaptive techniques, such as SBRbased methods is to be preferred above absolute thresholding. Models are under development that correlate imaging findings with pathology in three dimensions. These could finally allow validation of different thresholds for SUV-based contouring and evaluation of microscopic spread and intra-tumour heterogeneity. Selective boosting of radioresistant areas identified with FDG-PET is subject of current research.

Selective irradiation of FDG-PET positive nodal stations is safe and leads to decreased normal tissue exposure, providing opportunities for dose escalation. With the increased use of more conformal radiation techniques, the safety of PET-based SNI should be re-evaluated. Disparities in treatment volumes resulting from different contouring methods are smaller than for the primary tumour.

\subsubsection{Outcome prediction on basis of PET before or early after the start of treatment, and the added value of PET after therapy}

Despite the improved outcome of inoperable stage III NSCLC achieved with combined chemoradiotherapy, the majority of patients still show disease progression after treatment, with $23-43 \%$ having an isolated local recurrence as their first site of progression ${ }^{72-76}$. As the treatment is associated with considerable toxicity, it would be of great value to be able to select patients before or early during treatment, with the highest probability to benefit from treatment.

Early response assessment with conventional chest X-ray and CT is limited by their poor discriminating capacity between residual tumour and treatment induced changes ${ }^{77,78}$. PET scanning allows for the assessment of changes in glucose consumption of the tumour during chemo- and radiotherapy. Several studies have shown a correlation between the SUV and tumour cell proliferation ${ }^{79-81}$, supporting the hypothesis that an early change in FDG uptake has predictive value.

\section{Prognostic value of pre-treatment PET}

Most evidence regarding the prognostic value of pre-treatment PET comes from studies in heterogeneous patient populations with both early and late stage disease, treated with different modalities. A meta-analysis was performed within the IASLC lung cancer staging project. $11 / 13$ eligible studies in stage I-IV NSCLC identified a high SUV as a poor prognostic factor for survival, with a combined HR for survival of 2.27 (95\% Cl: 1.43-3.04) for low versus high SUV ${ }^{82}$. The threshold was variable be- 
tween the studies, ranging from 5 to 20 . Those differences are due to both technical and patient related factors, such as different scanners, time intervals between injection and scanning and fasting times. Furthermore, the relationship between SUV and prognosis is rather gradual than fixed at a single cut-off point.

Regarding the ability of PET to predict response to combined modality treatment, the first study in patients with advanced disease treated with (chemo-)radiotherapy showed a positive correlation between the tumour to muscle ratio (TMR) and response, but no significant correlation with outcome ${ }^{83}$. Two later studies revealed SUV $_{\text {mean }}$ and SUV $V_{\text {max }}$ to be significantly associated with overall survival ${ }^{84,85}$. In the first population, both tumour grade and UICC stage showed a stronger correlation with survival than the SUV ${ }^{84}$, while in the second study, SUV $\max$ was the strongest predictor ${ }^{85}$. In contrast, the most recent study in the largest cohort of stage III and IV NSCLC patients thus far $(n=214)$, did not show a significant relationship with survival ${ }^{86}$. This study was not included in the mentioned IASLC meta-analysis.

\section{Outcome prediction on basis of early PET response during combined modality treatment}

Because FDG is preferentially accumulated in viable tumour cells ${ }^{87,88}$, FDG-PET imaging is an attractive method to visualize early treatment response, as the change in SUV should reflect the rate of tumour cell killing. In advanced NSCLC, the predictive value of an early metabolic response to palliative chemotherapy, as well as to radical treatment with (chemo)radiotherapy has been evaluated. Prospective observational studies have consistently shown that in advanced NSCLC treated with palliative chemotherapy, the metabolic response after 1-3 cycles of chemotherapy is strongly correlated with final outcome ${ }^{89-92}$.

With respect to radical treatment, metabolic response to induction chemotherapy prior to radiotherapy or surgery in locally advanced NSCLC patients has been shown to correlate with outcome in multiple studies as well ${ }^{90,93,95,96}$. One study, however, did not show predictive value ${ }^{98}$.

While the evidence regarding the predictive value of a metabolic response to induction chemotherapy is abundant, far less is known about its value early during the course of radical treatment itself. One study investigated the predictive value of response assessment during concurrent chemoradiotherapy ${ }^{99}$. A significant difference in long-term survival was found between patients with and without a metabolic response after 3 weeks of concurrent chemoradiotherapy. A study evaluating response during radical $\mathrm{RT}$ revealed a large intra-patient heterogeneity in the evolution of SUV $V_{\max }$ during and after radical RT ${ }^{100}$. Different time patterns were seen for responders and non-responders, but due to the limited patient numbers, the predictive value of the SUV $V_{\max }$ changes could not be assessed. 
To make FDG response assessment a valuable tool in routine clinical practice, a clear definition of response should be prescribed, as the intra-patient variability of repeated tumour SUV-measurements is in the range of $10-15 \%{ }^{101-103}$. Furthermore, early response should be assessed at a fixed time interval. Ideally, the interval should be short enough to switch to a potentially more successful treatment as early as possible. This should be balanced, however, with a time interval sufficient to allow for a reliable response assessment. In 1999, the EORTC published consensus guidelines on which cut-off points should be used to define response at different time intervals ${ }^{104}$, which are still widely applied in clinical practice. Weber et al. defined a metabolic response after the first cycle of chemotherapy as a decrease in FDG uptake of more than twice the standard deviation, calculated to be $20 \%$. This definition correlated with final response according to RECIST, as well as with time to progression and overall survival ${ }^{91}$. In 2009, the PET Response Criteria in Solid Tumours (PERCIST, version 1) have been proposed resulting from a review of qualitative and quantitative methods of metabolic response assessment ${ }^{97}$. PERCIST recommends to correct SUV for lean body mass (SUL) as this accounts for variations due to differences in body composition. A comparison between the EORTC criteria and PERCIST is provided in Table 9.1. Overall and most importantly, the same definition of response criteria should be used by different groups to be able to compare metabolic response studies across different centres.

Concerning the type of measurement, semiquantitative methods, such as the relative change in SUV, appear to perform equally well as more complex quantitative methods such as change in the net-influx constants (Ki) or metabolic rate of glucose (MRglu) ${ }^{90-92}$. This facilitates the use of early PET response for outcome prediction in daily clinical practice. 


\begin{tabular}{|c|c|c|}
\hline & EORTC & PERCIST \\
\hline $\begin{array}{l}\text { Progressive Metabolic } \\
\text { Disease (PMD) }\end{array}$ & $\begin{array}{l}\text { - }>25 \% \text { increase in SUV of tumour } \\
\text { defined on pretreatment scan, } \\
\text { or } \\
\text { - }>20 \% \text { increase in the longest } \\
\text { dimension of FDG-uptake, or } \\
\text { - Appearance of new FDG-uptake } \\
\text { in metastatic lesions }\end{array}$ & $\begin{array}{l}\text { - }>30 \% \text { increase in SUL peak and } \\
\text { absolute increase of SUL units } \geq \\
0.8 \text { from baseline scan in pat- } \\
\text { tern typical of tumour and not } \\
\text { of infection /treatment effect, } \\
\text { or } \\
\text { - Visible increase in extent of } \\
\text { FDG-uptake (> 75\% increase in } \\
\text { total lesion glycolysis), or } \\
\text { Appearance of new FDG-avid } \\
\text { lesions typical of cancer and not } \\
\text { related to infection /treatment } \\
\text { effect }\end{array}$ \\
\hline $\begin{array}{l}\text { Stable Metabolic Disease } \\
\text { (SMD) }\end{array}$ & $\begin{array}{l}-\quad<25 \% \text { increase or }<15 \% \text { de- } \\
\text { crease in SUV of tumour defined } \\
\text { on pretreatment scan, and } \\
-<20 \% \text { increase in the longest } \\
\text { dimension of FDG-uptake }\end{array}$ & - $\quad$ No CMR, PMR or PMD \\
\hline $\begin{array}{l}\text { Partial Metabolic Re- } \\
\text { sponse (PMR) }\end{array}$ & $\begin{array}{l}\text { - } \quad>15 \% \text { decrease in SUV of tu- } \\
\text { mour defined on pretreatment } \\
\text { scan (after } 1 \text { cycle) } \\
>25 \% \text { decrease in SUV of tu- } \\
\text { mour defined on pretreatment } \\
\text { scan (after }>1 \text { cycle) }\end{array}$ & $\begin{array}{l}\text { - }>30 \% \text { decrease in SUL peak and } \\
\text { absolute drop in SUL units } \geq 0.8 \\
\text { of the most intense lesion be- } \\
\text { fore and after treatment (not } \\
\text { necessarily the same lesion) } \\
\text { No new FDG-avid lesions typical } \\
\text { of cancer }\end{array}$ \\
\hline $\begin{array}{l}\text { Complete Metabolic } \\
\text { Response (CMR) }\end{array}$ & $\begin{array}{l}\text { - Complete resolution of FDG- } \\
\text { uptake within tumour defined } \\
\text { on pretreatment scan, not dis- } \\
\text { tinguishable from surrounding } \\
\text { normal tissue }\end{array}$ & $\begin{array}{l}\text { Complete resolution of FDG- } \\
\text { uptake within measurable tar- } \\
\text { get lesion, less than mean liver } \\
\text { activity and indistinguishable } \\
\text { from surrounding background } \\
\text { blood-pool levels } \\
\text { - Disappearance of all other } \\
\text { lesions to background blood- } \\
\text { pool levels } \\
\text { No new FDG-avid lesions typical } \\
\text { of cancer }\end{array}$ \\
\hline
\end{tabular}

SUL: Standardized uptake value corrected for lean body mass

\section{Added value of PET after combined modality treatment}

The accuracy of PET after treatment is assumed to be lower than at initial staging because of therapy induced inflammatory and perfusion changes ${ }^{105}$. Nevertheless, PET still has a high accuracy in detecting recurrent lung cancer, with a sensitivity up to $98 \%$ and a specificity of $62-92 \%{ }^{105-107}$, and is more accurate than CT in the distinction of tumour from post-RT effects ${ }^{108-110}$. Here, the added value of a post- 
treatment PET is addressed with regard to the prognostic value of a PET early after treatment as well as the role of PET in the follow-up after combined modality therapy.

We identified four studies addressing the prognostic value of PET after radical treatment in locally advanced NSCLC patients, consisting of (chemo-)RT ${ }^{74,83,100,112}$. Four studies evaluated the predictive value of PET after induction chemoRT before surgery ${ }^{94,96,111,113}$. The studies were unambiguous in their conclusion that the FDG response after chemoradiotherapy has prognostic and predictive value, respectively. Mac Manus proved the superiority of PET response above CT. Response on PET and CT were identical in only $40 \%$ of patients. In multivariate analysis, only the PET response was significantly associated with survival ${ }^{109}$.

Clear cut-offs should be prescribed to define the different prognostic subgroups. In the aforementioned studies, however, there is a large heterogeneity in the way FDG-uptake after therapy was measured. Some studies reported an absolute threshold post-treatment ${ }^{83,96,111,113}$, while others stratified patients according to the relative change in SUV ${ }^{74,94,100,109,112}$. In none of the studies a direct comparison was made between the different methods. Until more data are available we recommend the use of the EORTC criteria for PET response ${ }^{104}$ for prognostic stratification, as the results of the larger studies are mainly based on these criteria.

Another important aspect is the timing of the PET-CT. The median time interval in the studies described above was 14 to 70 days. It is recommended to perform a PET-CT scan not earlier than 3 to 6 months after treatment to avoid false positive results due to post-therapy inflammatory changes ${ }^{105,114}$. The time interval should not be excessive either, as the final aim is to select patients for further therapy. Hicks et al. observed no confounding effect through post-RT inflammatory changes for response assessment with a PET-CT scan performed 70 days after radical RT ${ }^{115}$. As different time-points have not been compared directly, we recommend the use of the time point 70 days post-treatment.

It should be noted that the results described above only apply for patients treated with conventional or hyperfractionated RT with or without chemotherapy. In hypofractionated SBRT, where 3 to 5 large fractions are applied, persistently elevated SUV $_{\text {max }}$ of $>3.5$ have been described up to one year post treatment ${ }^{116,117}$. These different findings may be explained by localized normal tissue changes induced by SBRT, such as segmental atelectasis or focal fibrosis, that are not distinguishable from persistent or recurrent tumour.

PET in the follow-up of NSCLC could improve outcome when progressive disease can be detected early enough to allow radical retreatment. There are no convincing data supporting that early detection of progression with chest X-ray or CT scan im- 
proves survival ${ }^{77,118-120}$. This might be different for FDG-PET scanning, as PET is more accurate than CT in the distinction of tumour from post-RT effects ${ }^{108,109,121}$, and is known to be prognostic for outcome ${ }^{82,88,122-124}$. A prospective study was performed to evaluate whether PET-CT 3 months after therapy can detect potentially curable progression in locally advanced NSCLC ${ }^{125}$, which was the case in a small proportion (3\%) of patients, who were all asymptomatic. An economic evaluation based on these results showed that a PET-CT scan 3 months after (chemo)radiotherapy is potentially cost-effective, and is more cost-effective than CT alone ${ }^{126}$. As the advantage was confined to the asymptomatic patients, a PET-CT scan in this group only is probably as effective and more cost-effective.

\section{Other tracers}

As response assessment early during and after therapy is complicated by the limited ability of FDG to discriminate between inflammation and tumour activity, it is worthwhile to investigate alternative tracers, corresponding more specifically with tumour proliferative activity.

The uptake of ${ }^{18} \mathrm{~F}$-fluorothymidine $\left({ }^{18} \mathrm{~F}-\mathrm{FLT}\right)$, a marker of DNA synthesis, has been correlated with tumour proliferative activity in various tumour sites including NSCLC 127-132. Recent (pre)clinical studies have demonstrated that FLT can detect changes in proliferation during and after irradiation in colorectal tumours and breast cancer cell lines ${ }^{133-135}$. One pilot study in NSCLC has shown the feasibility of FLT to image proliferation during chemo-radiotherapy ${ }^{71}$.

Amino-acid tracers theoretically have an advantage over FDG in that it more specifically accumulates in viable cancer cells ${ }^{136}$. However, data on its usefulness in evaluating treatment response are scarce. One study compared ${ }^{18}$ FDG and the aminoacid tracer ${ }^{11} \mathrm{C}$-methionine $\left({ }^{11} \mathrm{C}\right.$-Met) for evaluation of treatment response in lung cancer, but this study focussed on early stage patients treated with stereotactic RT ${ }^{117}$. In this study, FDG and Met showed an equal accumulation in inflammatory tissue, a finding that is supported by the results of other research groups ${ }^{137-139}$. Another amino-acid tracer has recently been put forward for monitoring treatment response, being ${ }^{18} \mathrm{~F}$-fluoromethyltyrosine $\left({ }^{18} \mathrm{~F}-\mathrm{FMT}\right)$. Two animal studies showed a rapid response to antitumour therapy, and less accumulation in inflammatory cells 140,141

\section{Clinical implications and future perspectives}

The clinical impact of patient selection before or early during treatment is beyond doubt, as it avoids ineffective treatment with the associated side-effects and enables alternative therapy in case of an inadequate early response. Before this principle can be implemented in clinical practice, additional research is needed to define 
clear cut-off points for FDG uptake to stratify patients into different treatment modalities. With regard to early response assessment, attention should be paid to other tracers, in particular proliferation markers, as they are less susceptible to uptake in inflammatory tissue ${ }^{71}$.

A final option for improvement in outcome is the use of PET in the follow-up. Currently available data do show a potential benefit of PET in the follow-up compared to CT. Ideally, different follow-up strategies, including PET-CT based follow-up, should be compared in a randomized controlled trial to provide a definitive insight in the added value of PET in the follow-up of NSCLC patients after combined modality therapy.

\section{Conclusion}

In the overall NSCLC patient group, pre-treatment FDG-uptake is of prognostic value. Results on its ability to predict response to combined modality therapy in advanced stage NSCLC are conflicting. The most recent study in the largest patient cohort did not show a significant correlation with survival.

The predictive value of an early metabolic (FDG) response during induction chemotherapy has been established. Less is known about the predictive value of a metabolic response during radical (chemo-)RT, but the limited available data show a correlation with survival. The FDG response after radical treatment is of proven prognostic significance. A time interval of 70 days after the end of treatment is recommended for metabolic response assessment on basis of the EORTC criteria.

An FDG-PET scan in the follow-up after combined modality therapy can detect progression amenable for radical retreatment in a limited number of patients.

Tracers other than FDG are promising for treatment response assessment, but more research is needed before they can be clinically implemented.

\subsection{Small cell lung cancer (SCLC)}

$\mathrm{SCLC}$ is a tumour with a poor prognosis, characterized by a rapid growth rate. Traditionally, staging of those patients has been limited to the distinction between limited (LD) and extensive disease (ED) ${ }^{142}$. Approximately $25 \%$ of patients present with limited-disease (LD), defined as disease confined to one hemithorax, including the mediastinum and bilateral supraclavicular fossae ${ }^{143-145}$. Even in this patient group, surgery is rarely an option because of the advanced stage of locoregional disease. Concurrent chemo-radiation is currently the first choice treatment. Literature is sparse on the role of PET in LD-SCLC. The available literature suggests that FDG-PET has additional value above standard staging procedures in SCLC ${ }^{146-153}$, with a reported sensitivity and specificity up to $100 \%$ and $95 \%{ }^{154}$. Staging with PET can positively influence the outcome of chemoradiotherapy for LD-SCLC patients by means 
of stage migration. Upstaging from LD to ED by FDG-PET scanning occurs in 6-33\% $146-148,155-158$ and downstaging in $3-40 \%{ }^{147,148,155,157}$ of patients.

\subsubsection{Definition of the tumour volume to be treated}

\section{Primary tumour}

In order to define the tumour volume, PET should be assessed for its ability to distinguish malignant from surrounding normal tissue. Studies addressing this issue are focussed on NSCLC ${ }^{11-14}$. The same holds true for correlation studies with pathology $24,26,27,43,44$. Therefore, we can only assume that similar caveats apply as described above for NSCLC. In short, a major limitation of PET is the low spatial resolution. Hence, the major gain is to be expected in regions where anatomical imaging techniques lack the capacity to discriminate malignant from normal tissue, e.g. in areas with atelectasis. Another question refers to which method should be applied for PET-based tumour delineation. Again, comparison and validation of different methods has exclusively been performed in NSCLC ${ }^{22,25}$. No conclusions can be drawn regarding which method is to be preferred, except that adaptive techniques are likely to be more accurate than the use of an absolute or relative SUV-based threshold ${ }^{20,21}$. Obviously, blurring effects due to motion do hinder exact tumour delineation. Respiration correlated imaging techniques have the potential to include individual tumour motion in the treatment volume, in conjunction with optimal image quality, as blurring effects are significantly reduced ${ }^{40,41}$.

\section{Microscopic disease extension}

As described previously, the only way to define microscopic disease extension beyond the tumour border visible on imaging is to correlate imaging with pathology. There are no data on image correlation with pathology available for SCLC.

\section{Lymph nodes}

The available data suggest that an FDG-PET scan can identify metastases to regional lymph nodes in $14-25 \%$ of patients whose mediastinal CT scan is negative ${ }^{146,150,157 .}$ With the high sensitivity and specificity of PET in SCLC, it is likely that the use of PET scans improves the coverage of mediastinal lymph node areas in LD-SCLC.

Until recently, only few prospective data concerning selective nodal irradiation (SNI) in SCLC were available. A report from the International Atomic Energy Agency (IAEA) meeting emphasized the need for prospective clinical evidence regarding SNI in SCLC ${ }^{159}$. CT-based SNI resulted in an unacceptable amount (11\%) of isolated nodal failures outside the treatment volume ${ }^{160}$. These findings imply that results on the safety of SNI in NSCLC cannot straightforwardly be extrapolated to SCLC. 
Since the publication of the IASLC report, two studies have become available evaluating FDG-PET based SNI in SCLC. In a planning study, a difference in the treatment plan resulting from PET- and CT-based SNI was found in $24 \%$ of patients ${ }^{161}$. Radiation fields increased in $10 \%$ and decreased in $14 \%$ of patients, respectively. No significant changes in the radiation exposure of the normal tissue were observed. In the subsequent prospective study, $3 \%$ of the patients experienced an isolated nodal failure after a minimal follow-up of 18 months, comparable to results in NSCLC. A remarkably low percentage (12\%) of grade III esophagitis was found, while this occurs in about $30 \%$ of patients receiving elective nodal irradiation or CT based SNI ${ }^{160}$, ${ }^{162}$. This finding deserves further investigation. The low rate of isolated nodal failures and toxicity thus supports the use of PET-based SNI in LD-SCLC.

A few points of caution should be taken into consideration. First, incidental irradiation of surrounding nodal stations might partially explain the low rates of isolated nodal failures with SNI. Therefore, results should be re-evaluated with the application of more conformal techniques (SBRT, IMRT, particle therapy). A second point of attention consists of the methods for target volume definition. In the available study, the mediastinal nodal regions involved on PET were included in the treatment field ${ }^{163}$. As our literature search did not yield any study evaluating autocontouring methods for lymph node delineation in SCLC, we recommend SNI of the whole mediastinal nodal station involved on PET.

\section{Clinical implications and future perspectives}

As in most cases, the bulk of disease in SCLC is located in the hilar and mediastinal regions, reduction of the treatment volume can mainly be reached by omitting elective nodal irradiation. As mentioned above, the first study with PET-based SNI showed a remarkably low rate of oesophageal toxicity ${ }^{163}$. If this finding holds true, PET based SNI indeed provides opportunities for treatment intensification. With regard to RT planning, another point of consideration is the concept of subboosting areas of supposed radioresistance. FDG-PET, as well as PET with other tracers, could help to identify those regions within the tumour. Although this concept is readily evolving in NSCLC, no such trend is observed until now in SCLC. Although it is reasonable to assume that characteristics associated with radioresistance are also heterogeneous in SCLC ${ }^{29-31}$, the disease load in NSCLC is different from SCLC, as most of the tumour load is accounted for by nodal stations. Studies on the evolution and stability of regions with high FDG-uptake in NSCLC are entirely focussed on the primary tumour, and no such information is available with respect to lymph nodes. These issues should be addressed when heterogeneous dose escalation is taken into consideration in SCLC. 


\section{Conclusion}

There are no data available on the role of FDG-PET in defining the borders of the primary tumour. In contrast with CT-based SNI, first results indicate that selective irradiation of FDG-PET positive nodal stations appears to be safe and results in remarkably limited toxicity. With the increased use of more conformal radiation techniques, the safety of PET-based SNI should be re-evaluated. It is recommended to encompass the whole anatomical mediastinal region containing FDG-positive nodes in the treatment volume.

\subsubsection{Outcome prediction on basis of PET before or early after the start of treatment, and the prognostic value of PET after therapy}

The majority of SCLC patients still shows disease progression short after the completion of chemoradiotherapy, with over $30 \%$ having an isolated local recurrence as their first site of progression ${ }^{162}$. Furthermore, the treatment is associated with considerable toxicity, with grade 3 esophagitis in up to $27 \%$ of patients ${ }^{111,164-166}$. Therefore, the ability to predict the benefit from treatment would be of great clinical value, hereby avoiding ineffective treatment in the patient group in which benefit is less likely. Recent data have made clear that the traditional staging system with two categories (limited and extensive disease) is on its own not an adequate predictor of survival and is not sufficient to stratify patients for the most optimal therapy ${ }^{167,}{ }^{168}$. Since recently, it is recommended to use the TNM staging for SCLC, as it has proven to result in a better stratification of patients in prognostic subgroups ${ }^{169,} 170$. FDG uptake on PET before, during or after therapy could have a role as additional prognostic and predictive marker in SCLC.

\section{Prognostic value of pre-treatment PET}

Evidence concerning the prognostic value of FDG-uptake before treatment in SCLC is scarce. One study was identified that addressed this subject ${ }^{171}$. The majority of patients had LD and were treated with concurrent chemoradiotherapy. Overall, as

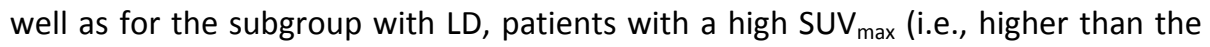
median) had a significantly worse overall survival than patients with a low SUV $V_{\max }$ (LD: 20.1 vs. 35.3 months). Three prognostic subgroups could be defined on basis of FDG-uptake and disease stage. Those results imply that different treatment strate-

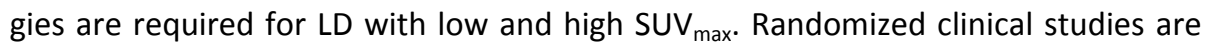
warranted to answer whether FDG-uptake in combination with anatomical staging is predictive of outcome and can be used to select the appropriate therapy for each patient group. 


\section{Outcome prediction on basis of early PET response during combined modality treatment}

The predictive ability of an FDG response early after the start of chemotherapy has been evaluated in 2 studies, both after one cycle of chemotherapy ${ }^{172,173}$. However, patients with both LD and ED were investigated. Therefore, the results reflect the predictive value of an FDG response early during palliative chemotherapy or radical chemoradiotherapy. Furthermore, both studies used CT response after completion of therapy as a reference, and not survival. Both studies concluded that the metabolic response was correlated with the response according to RECIST.

A couple of important questions need to be addressed in future studies to make early response assessment with PET during treatment a valuable clinical tool. Those questions include the type of measurement, the definition for response, and the most optimal time interval for the measurement of early response. Regarding response criteria, the use of the EORTC recommendations ${ }^{104}$, a $20 \%$ threshold, as well as the criteria for visual response assessment by MacManus are valid ${ }^{109}$ : Fischer et al. compared the visual method with the EORTC criteria in SCLC response evaluation after one cycle of chemotherapy and found no significant difference ${ }^{172}$. Regarding the type of measurement and the time interval, no separate data on SCLC are available. As long as no such data are available, the most practical alternative is to adhere to the NSCLC recommendations. Those are the use of relatively simple semiquantitative measurements such as SUV ${ }_{\max }{ }^{90-92}$, and a time interval of 1 to 3 cycles of chemotherapy ${ }^{90-92}$.

Caution is warranted, however, when projecting results obtained in NSCLC at SCLC. As mentioned before, those are two distinct types of disease with different clinical behaviour. SCLC is characterized by a rapid response to chemo- and radiotherapy. Therefore, a response to therapy could be more rapidly visible on $\mathrm{CT}$ than it is in NSCLC, which might restrict the beneficial effect of PET. This hypothesis is supported by the study of Fischer et al., who found that early response assessment after one cycle of chemotherapy with CT and PET showed a comparable correlation with the final evaluation on basis of RECIST ${ }^{172}$.

\section{Added value of PET after combined modality treatment}

Two retrospective studies evaluated the prognostic value of PET after treatment in SCLC patients ${ }^{151,174}$, with one specifically aimed at LD ${ }^{174}$. The first study included both LD and ED, and both treated and untreated patients, with treated LD patients representing $50 \%$ of the study population. It is hard to draw separate conclusions on this group, but overall, there was a significant negative correlation between PET positivity or SUV max $_{\text {and overall survival }}{ }^{151}$. 
The study evaluating exclusively LD patients has some limitations: only $73 \%$ was treated with chemoradiotherapy, the remaining patients with palliative chemotherapy ${ }^{174}$. Furthermore, the time interval between the end of treatment and PETscanning was variable (3-125 days). Finally, the definition of PET positivity was rather broad. With those limitations in mind, the study showed a significant difference in progression free survival between PET positive and -negative patients, with a trend for overall survival.

A prerequisite for PET in the follow-up to have a positive impact on the final outcome is that progression should be detected at a time that radical retreatment is still an option. The rapid growth rate and early dissemination make it less likely for progression to be detected in a "curable" stage in SCLC than in NSCLC. Although no studies have addressed the role of FDG-PET in the follow-up of SCLC, it can therefore be questioned whether PET scanning is advantageous with respect to outcome.

\section{Clinical implications and future perspectives}

It is obvious that the currently available data are insufficient to modify or adapt treatment on basis of pre-treatment FDG uptake or an early metabolic response in SCLC patients. Research in the field of early response assessment is of particular importance to define the additional benefit of PET above CT given the rapid response of SCLC to chemo- and radiotherapy.

Finally, the role of PET after combined modality therapy of LD-SCLC should be addressed. Given the early dissemination of SCLC, most benefit is to be expected with a tracer that allows response evaluation early after treatment. Given the high uptake in inflammatory regions, FDG might not be ideal for this purpose. Therefore, other tracers should be evaluated.

\section{Conclusion}

Studies evaluating the prognostic value of PET, its ability to predict response to combined modality treatment and the added value of PET after treatment in SCLC are scarce. Available results mainly come from studies in patients with both limited and extensive disease. Overall, results do show some predictive value of an FDG response before and during therapy, as well as prognostic value of FDG uptake after treatment. No studies have evaluated the impact of PET in the follow-up of SCLC.

\subsection{General conclusions}

Molecular imaging with PET, using different tracers, has the potential to distinguish between vital tumour and non-malignant tissue and to identify intra-tumour characteristics. The additional value of FDG-PET in defining the primary tumour volume has been established, mainly in regions with atelectasis or post-treatment effects. 
Three dimensional models that correlate imaging findings with pathology are being developed for NSCLC, which could allow validation of different thresholds for SUVbased contouring, evaluation of microscopic spread and intra-tumour heterogeneity. FDG-PET has the ability to identify regions within the tumour that are associated with radioresistance, and for NSCLC, it has been proved that these regions remain stable during a radiotherapy course. Therefore, boosting of radioresistant areas identified with FDG-PET appears to be feasible and is subject of current research. Selective irradiation of FDG-PET positive nodal stations in NSCLC is safe and leads to decreased normal tissue exposure, providing opportunities for dose escalation. For this reason, it is the preferred treatment in NSCLC. First results in SCLC suggest that the same holds true for SCLC. Data on the predictive value of pre-treatment FDGuptake and an early metabolic response during combined modality treatment are conflicting and limited, respectively. The FDG response after radical treatment is of prognostic significance. A time interval of 70 days between end of treatment and PET scanning is recommended for response evaluation in NSCLC. A PET scan in the follow-up of NSCLC potentially improves survival through the detection of progression with radical treatment options. Data on its value in the follow-up of SCLC are lacking.

Tracers other than ${ }^{18}$ FDG are promising for treatment response assessment and the visualization of intra-tumour heterogeneity, but more research is needed before they can be clinically implemented. 


\subsection{References}

1. Jemal A, Siegel R, Ward E, Hao Y, Xu J, Thun MJ. Cancer statistics, 2009. CA Cancer J Clin 2009;59:22549.

2. Janssen-Heijnen ML, Coebergh JW. Trends in incidence and prognosis of the histological subtypes of lung cancer in North America, Australia, New Zealand and Europe. Lung Cancer 2001;31:123-37.

3. Hoekstra CJ, Stroobants SG, Hoekstra OS, et al. The value of [18F]fluoro-2-deoxy-D-glucose positron emission tomography in the selection of patients with stage IIIA-N2 non-small cell lung cancer for combined modality treatment. Lung Cancer 2003;39:151-7.

4. Mac Manus MP, Hicks RJ, Ball DL, et al. F-18 fluorodeoxyglucose positron emission tomography staging in radical radiotherapy candidates with nonsmall cell lung carcinoma: powerful correlation with survival and high impact on treatment. Cancer 2001;92:886-95.

5. Mac Manus MP, Wong K, Hicks RJ, Matthews JP, Wirth A, Ball DL. Early mortality after radical radiotherapy for non-small-cell lung cancer: comparison of PET-staged and conventionally staged cohorts treated at a large tertiary referral center. Int J Radiat Oncol Biol Phys 2002;52:351-61.

6. Hicks RJ, Kalff V, MacManus MP, et al. (18)F-FDG PET provides high-impact and powerful prognostic stratification in staging newly diagnosed non-small cell lung cancer. J Nucl Med 2001;42:1596-604.

7. MacManus MP, Hicks RJ, Matthews JP, et al. High rate of detection of unsuspected distant metastases by pet in apparent stage III non-small-cell lung cancer: implications for radical radiation therapy. Int J Radiat Oncol Biol Phys 2001;50:287-93.

8. Nestle U, Weber W, Hentschel M, Grosu AL. Biological imaging in radiation therapy: role of positron emission tomography. Phys Med Biol 2009;54:R1-25.

9. Van de Steene J, Linthout N, de Mey J, et al. Definition of gross tumor volume in lung cancer: interobserver variability. Radiother Oncol 2002;62:37-49.

10. Steenbakkers RJ, Duppen JC, Fitton I, et al. Observer variation in target volume delineation of lung cancer related to radiation oncologist-computer interaction: a 'Big Brother' evaluation. Radiother Oncol 2005;77:182-90.

11. Mah K, Caldwell CB, Ung YC, et al. The impact of (18)FDG-PET on target and critical organs in CTbased treatment planning of patients with poorly defined non-small-cell lung carcinoma: a prospective study. Int J Radiat Oncol Biol Phys 2002;52:339-50.

12. Steenbakkers RJ, Duppen JC, Fitton I, et al. Reduction of observer variation using matched CT-PET for lung cancer delineation: a three-dimensional analysis. Int J Radiat Oncol Biol Phys 2006;64:435-48.

13. Ashamalla $\mathrm{H}$, Rafla S, Parikh K, et al. The contribution of integrated PET/CT to the evolving definition of treatment volumes in radiation treatment planning in lung cancer. Int J Radiat Oncol Biol Phys 2005;63:1016-23.

14. Fox JL, Rengan R, O'Meara W, et al. Does registration of PET and planning CT images decrease interobserver and intraobserver variation in delineating tumor volumes for non-small-cell lung cancer? Int J Radiat Oncol Biol Phys 2005;62:70-5.

15. Bradley J, Thorstad WL, Mutic S, et al. Impact of FDG-PET on radiation therapy volume delineation in non-small-cell lung cancer. Int J Radiat Oncol Biol Phys 2004;59:78-86.

16. Nestle U, Walter K, Schmidt S, et al. 18F-deoxyglucose positron emission tomography (FDG-PET) for the planning of radiotherapy in lung cancer: high impact in patients with atelectasis. Int J Radiat Oncol Biol Phys 1999;44:593-7.

17. Lowe VJ, Fletcher JW, Gobar L, et al. Prospective investigation of positron emission tomography in lung nodules. J Clin Oncol 1998;16:1075-84.

18. Nestle U, Kremp S, Grosu AL. Practical integration of [18F]-FDG-PET and PET-CT in the planning of radiotherapy for non-small cell lung cancer (NSCLC): the technical basis, ICRU-target volumes, problems, perspectives. Radiother Oncol 2006;81:209-25.

19. Geets X, Lee JA, Bol A, Lonneux M, Gregoire V. A gradient-based method for segmenting FDG-PET images: methodology and validation. Eur J Nucl Med Mol Imaging 2007;34:1427-38. 
20. Black QC, Grills IS, Kestin LL, et al. Defining a radiotherapy target with positron emission tomography. Int J Radiat Oncol Biol Phys 2004;60:1272-82.

21. Daisne JF, Sibomana M, Bol A, Doumont T, Lonneux M, Gregoire V. Tri-dimensional automatic segmentation of PET volumes based on measured source-to-background ratios: influence of reconstruction algorithms. Radiother Oncol 2003;69:247-50.

22. Nestle U, Kremp S, Schaefer-Schuler A, et al. Comparison of different methods for delineation of $18 \mathrm{~F}-$ FDG PET-positive tissue for target volume definition in radiotherapy of patients with non-Small cell lung cancer. J Nucl Med 2005;46:1342-8.

23. Wu K, Ung YC, Hornby J, et al. PET CT Thresholds for Radiotherapy Target Definition in Non-Small-Cell Lung Cancer: How Close Are We to the Pathologic Findings? Int J Radiat Oncol Biol Phys 2009.

24. Yu HM, Liu YF, Hou M, Liu J, Li XN, Yu JM. Evaluation of gross tumor size using CT, 18F-FDG PET, integrated 18F-FDG PET/CT and pathological analysis in non-small cell lung cancer. Eur J Radiol 2009;72:104-13.

25. van Baardwijk A, Bosmans G, Boersma L, et al. PET-CT-based auto-contouring in non-small-cell lung cancer correlates with pathology and reduces interobserver variability in the delineation of the primary tumor and involved nodal volumes. Int J Radiat Oncol Biol Phys 2007;68:771-8.

26. Dahele M, Hwang D, Peressotti C, et al. Developing a methodology for three-dimensional correlation of PET-CT images and whole-mount histopathology in non-small-cell lung cancer. Curr Oncol 2008;15:62-9.

27. Stroom J, Blaauwgeers $H$, van Baardwijk A, et al. Feasibility of pathology-correlated lung imaging for accurate target definition of lung tumors. Int J Radiat Oncol Biol Phys 2007;69:267-75.

28. Siedschlag C, van Loon J, van Baardwijk A, et al. Analysis of the relative deformation of lung lobes before and after surgery in patients with NSCLC. Phys Med Biol 2009;54:5483-92.

29. Cooper RA, Carrington BM, Loncaster JA, et al. Tumour oxygenation levels correlate with dynamic contrast-enhanced magnetic resonance imaging parameters in carcinoma of the cervix. Radiother Oncol 2000;57:53-9.

30. Foo SS, Abbott DF, Lawrentschuk N, Scott AM. Functional imaging of intratumoral hypoxia. Mol Imaging Biol 2004;6:291-305.

31. Zhao S, Kuge $Y$, Mochizuki T, et al. Biologic correlates of intratumoral heterogeneity in $18 F-F D G$ distribution with regional expression of glucose transporters and hexokinase-II in experimental tumor. J Nucl Med 2005;46:675-82.

32. Bentzen SM. Theragnostic imaging for radiation oncology: dose-painting by numbers. Lancet Oncol 2005;6:112-7.

33. Bentzen SM. Dose painting and theragnostic imaging: towards the prescription, planning and delivery of biologically targeted dose distributions in external beam radiation oncology. Cancer Treat Res 2008;139:41-62.

34. Galvin JM, De Neve W. Intensity modulating and other radiation therapy devices for dose painting. J Clin Oncol 2007;25:924-30.

35. Das SK, Miften MM, Zhou S, et al. Feasibility of optimizing the dose distribution in lung tumors using fluorine-18-fluorodeoxyglucose positron emission tomography and single photon emission computed tomography guided dose prescriptions. Med Phys 2004;31:1452-61.

36. Aerts $\mathrm{HJ}$, van Baardwijk AA, Petit SF, et al. Identification of residual metabolic-active areas within individual NSCLC tumours using a pre-radiotherapy (18)Fluorodeoxyglucose-PET-CT scan. Radiother Oncol 2009;91:386-92.

37. Abramyuk A, Tokalov S, Zophel K, et al. Is pre-therapeutical FDG-PET/CT capable to detect high risk tumor subvolumes responsible for local failure in non-small cell lung cancer? Radiother Oncol 2009;91:399-404.

38. Aerts HJ, Bosmans G, van Baardwijk AA, et al. Stability of 18F-deoxyglucose uptake locations within tumor during radiotherapy for NSCLC: a prospective study. Int J Radiat Oncol Biol Phys 2008;71:1402-7. 
39. Caldwell CB, Mah K, Skinner M, Danjoux CE. Can PET provide the 3D extent of tumor motion for individualized internal target volumes? A phantom study of the limitations of CT and the promise of PET. Int J Radiat Oncol Biol Phys 2003;55:1381-93.

40. Nehmeh SA, Erdi YE. Respiratory motion in positron emission tomography/computed tomography: a review. Semin Nucl Med 2008;38:167-76.

41. Grgic A, Nestle U, Schaefer-Schuler A, Kremp S, Kirsch CM, Hellwig D. FDG-PET-based radiotherapy planning in lung cancer: optimum breathing protocol and patient positioning--an intraindividual comparison. Int J Radiat Oncol Biol Phys 2009;73:103-11.

42. Chan R, He Y, Haque A, Zwischenberger J. Computed tomographic-pathologic correlation of gross tumor volume and clinical target volume in non-small cell lung cancer: a pilot experience. Arch Pathol Lab Med 2001;125:1469-72.

43. Giraud $\mathrm{P}$, Antoine M, Larrouy $A$, et al. Evaluation of microscopic tumor extension in non-small-cell lung cancer for three-dimensional conformal radiotherapy planning. Int J Radiat Oncol Biol Phys 2000;48:1015-24.

44. Grills IS, Fitch DL, Goldstein NS, et al. Clinicopathologic analysis of microscopic extension in lung adenocarcinoma: defining clinical target volume for radiotherapy. Int J Radiat Oncol Biol Phys 2007;69:334-41.

45. Belderbos JS, Kepka L, Spring Kong FM, Martel MK, Videtic GM, Jeremic B. Report from the International Atomic Energy Agency (IAEA) consultants' meeting on elective nodal irradiation in lung cancer: non-small-Cell lung cancer (NSCLC). Int J Radiat Oncol Biol Phys 2008;72:335-42.

46. Senan S, De Ruysscher D, Giraud P, Mirimanoff R, Budach V. Literature-based recommendations for treatment planning and execution in high-dose radiotherapy for lung cancer. Radiother Oncol 2004;71:139-46.

47. Gould MK, Kuschner WG, Rydzak CE, et al. Test performance of positron emission tomography and computed tomography for mediastinal staging in patients with non-small-cell lung cancer: a metaanalysis. Ann Intern Med 2003;139:879-92.

48. Senan S, Burgers S, Samson MJ, et al. Can elective nodal irradiation be omitted in stage III non-smallcell lung cancer? Analysis of recurrences in a phase II study of induction chemotherapy and involvedfield radiotherapy. Int J Radiat Oncol Biol Phys 2002;54:999-1006.

49. Belderbos JS, Heemsbergen WD, De Jaeger K, Baas P, Lebesque JV. Final results of a Phase I/II dose escalation trial in non-small-cell lung cancer using three-dimensional conformal radiotherapy. Int J Radiat Oncol Biol Phys 2006;66:126-34.

50. De Ruysscher D, Wanders S, van Haren E, et al. Selective mediastinal node irradiation based on FDGPET scan data in patients with non-small-cell lung cancer: a prospective clinical study. Int J Radiat Oncol Biol Phys 2005;62:988-94.

51. Sulman EP, Komaki R, Klopp AH, Cox JD, Chang JY. Exclusion of elective nodal irradiation is associated with minimal elective nodal failure in non-small cell lung cancer. Radiat Oncol 2009;4:5.

52. Sura S, Greco C, Gelblum D, Yorke ED, Jackson A, Rosenzweig KE. (18)F-fluorodeoxyglucose positron emission tomography-based assessment of local failure patterns in non-small-cell lung cancer treated with definitive radiotherapy. Int J Radiat Oncol Biol Phys 2008;70:1397-402.

53. De Ruysscher D, Wanders S, Minken A, et al. Effects of radiotherapy planning with a dedicated combined PET-CT-simulator of patients with non-small cell lung cancer on dose limiting normal tissues and radiation dose-escalation: a planning study. Radiother Oncol 2005;77:5-10.

54. van Der Wel A, Nijsten S, Hochstenbag M, et al. Increased therapeutic ratio by 18FDG-PET CT planning in patients with clinical CT stage N2-N3M0 non-small-cell lung cancer: a modeling study. Int J Radiat Oncol Biol Phys 2005;61:649-55.

55. Vanuytsel LJ, Vansteenkiste JF, Stroobants SG, et al. The impact of (18)F-fluoro-2-deoxy-D-glucose positron emission tomography (FDG-PET) lymph node staging on the radiation treatment volumes in patients with non-small cell lung cancer. Radiother Oncol 2000;55:317-24. 
56. Gomez-Caro A, Garcia S, Reguart N, et al. Incidence of occult mediastinal node involvement in CNO non-small-cell lung cancer patients after negative uptake of positron emission tomography/computer tomography scan. Eur J Cardiothorac Surg.

57. Zhao L, Chen M, Ten Haken R, et al. Three-dimensional conformal radiation may deliver considerable dose of incidental nodal irradiation in patients with early stage node-negative non-small cell lung cancer when the tumor is large and centrally located. Radiother Oncol 2007;82:153-9.

58. Nestle U, Schaefer-Schuler A, Kremp S, et al. Target volume definition for 18F-FDG PET-positive lymph nodes in radiotherapy of patients with non-small cell lung cancer. Eur J Nucl Med Mol Imaging 2007;34:453-62.

59. Thomas JG, Kashani R, Balter JM, Tatro D, Kong FM, Pan CC. Intra and interfraction mediastinal nodal region motion: implications for internal target volume expansions. Med Dosim 2009;34:133-9.

60. Bosmans G, van Baardwijk A, Dekker A, et al. Time trends in nodal volumes and motion during radiotherapy for patients with stage III non-small-cell lung cancer. Int J Radiat Oncol Biol Phys 2008;71:139-44.

61. Pantarotto JR, Piet AH, Vincent A, van Sornsen de Koste JR, Senan S. Motion analysis of 100 mediastinal lymph nodes: potential pitfalls in treatment planning and adaptive strategies. Int J Radiat Oncol Biol Phys 2009;74:1092-9.

62. van Baardwijk A, Bosmans G, Boersma L, et al. Individualized radical radiotherapy of non-small-cell lung cancer based on normal tissue dose constraints: a feasibility study. Int J Radiat Oncol Biol Phys 2008;71:1394-401.

63. van Baardwijk A, Wanders S, Boersma L, et al. Mature Results of an Individualized Radiation Dose Prescription Study Based on Normal Tissue Constraints in Stages I to III Non-Small-Cell Lung Cancer. J Clin Oncol.

64. Feng M, Kong FM, Gross M, Fernando S, Hayman JA, Ten Haken RK. Using fluorodeoxyglucose positron emission tomography to assess tumor volume during radiotherapy for non-small-cell lung cancer and its potential impact on adaptive dose escalation and normal tissue sparing. Int J Radiat Oncol Biol Phys 2009;73:1228-34.

65. Gillham C, Zips D, Ponisch F, et al. Additional PET/CT in week 5-6 of radiotherapy for patients with stage III non-small cell lung cancer as a means of dose escalation planning? Radiother Oncol 2008;88:335-41.

66. Petit SF, Aerts HJ, van Loon JG, et al. Metabolic control probability in tumour subvolumes or how to guide tumour dose redistribution in non-small cell lung cancer (NSCLC): an exploratory clinical study. Radiother Oncol 2009;91:393-8.

67. Rasey JS, Koh WJ, Evans ML, et al. Quantifying regional hypoxia in human tumors with positron emission tomography of [18F]fluoromisonidazole: a pretherapy study of 37 patients. Int J Radiat Oncol Biol Phys 1996;36:417-28.

68. Thorwarth D, Eschmann SM, Scheiderbauer J, Paulsen F, Alber M. Kinetic analysis of dynamic 18Ffluoromisonidazole PET correlates with radiation treatment outcome in head-and-neck cancer. BMC Cancer 2005;5:152.

69. Mees G, Dierckx R, Vangestel C, Van de Wiele C. Molecular imaging of hypoxia with radiolabelled agents. Eur J Nucl Med Mol Imaging 2009;36:1674-86.

70. Sovik A, Malinen E, Skogmo HK, Bentzen SM, Bruland OS, Olsen DR. Radiotherapy adapted to spatial and temporal variability in tumor hypoxia. Int J Radiat Oncol Biol Phys 2007;68:1496-504.

71. Everitt S, Hicks RJ, Ball D, et al. Imaging cellular proliferation during chemo-radiotherapy: a pilot study of serial 18F-FLT positron emission tomography/computed tomography imaging for non-smallcell lung cancer. Int J Radiat Oncol Biol Phys 2009;75:1098-104.

72. Ataman OU, Barrett A, Filleron T, Kramar A. Optimization of follow-up timing from study of patterns of first failure after primary treatment. An example from patients with NSCLC: a study of the REACT working group of ESTRO. Radiother Oncol 2006;78:95-100. 
73. Furuse K, Fukuoka M, Kawahara M, et al. Phase III study of concurrent versus sequential thoracic radiotherapy in combination with mitomycin, vindesine, and cisplatin in unresectable stage III nonsmall-cell lung cancer. J Clin Oncol 1999;17:2692-9.

74. Mac Manus MP, Hicks RJ, Matthews JP, Wirth A, Rischin D, Ball DL. Metabolic (FDG-PET) response after radical radiotherapy/chemoradiotherapy for non-small cell lung cancer correlates with patterns of failure. Lung Cancer 2005;49:95-108.

75. Zatloukal $\mathrm{P}$, Petruzelka L, Zemanova $\mathrm{M}$, et al. Concurrent versus sequential chemoradiotherapy with cisplatin and vinorelbine in locally advanced non-small cell lung cancer: a randomized study. Lung Cancer 2004;46:87-98.

76. Fournel $P$, Robinet $G$, Thomas $P$, et al. Randomized phase III trial of sequential chemoradiotherapy compared with concurrent chemoradiotherapy in locally advanced non-small-cell lung cancer: Groupe Lyon-Saint-Etienne d'Oncologie Thoracique-Groupe Francais de Pneumo-Cancerologie NPC 95-01 Study. J Clin Oncol 2005;23:5910-7.

77. Korst RJ, Gold HT, Kent MS, Port JL, Lee PC, Altorki NK. Surveillance computed tomography after complete resection for non-small cell lung cancer: results and costs. J Thorac Cardiovasc Surg 2005;129:652-60.

78. Korst RJ, Kansler AL, Port JL, Lee PC, Altorki NK. Accuracy of surveillance computed tomography in detecting recurrent or new primary lung cancer in patients with completely resected lung cancer. Ann Thorac Surg 2006;82:1009-15; discussion 15.

79. Higashi K, Ueda $\mathrm{Y}$, Ayabe K, et al. FDG PET in the evaluation of the aggressiveness of pulmonary adenocarcinoma: correlation with histopathological features. Nucl Med Commun 2000;21:707-14.

80. Higashi $K$, Ueda $Y$, Yagishita $M$, et al. FDG PET measurement of the proliferative potential of nonsmall cell lung cancer. J Nucl Med 2000;41:85-92.

81. Vesselle H, Schmidt RA, Pugsley JM, et al. Lung cancer proliferation correlates with [F18]fluorodeoxyglucose uptake by positron emission tomography. Clin Cancer Res 2000;6:3837-44.

82. Berghmans T, Dusart M, Paesmans M, et al. Primary tumor standardized uptake value (SUVmax) measured on fluorodeoxyglucose positron emission tomography (FDG-PET) is of prognostic value for survival in non-small cell lung cancer (NSCLC): a systematic review and meta-analysis (MA) by the European Lung Cancer Working Party for the IASLC Lung Cancer Staging Project. J Thorac Oncol 2008;3:6-12.

83. Ichiya $Y$, Kuwabara $Y$, Sasaki $M$, et al. A clinical evaluation of FDG-PET to assess the response in radiation therapy for bronchogenic carcinoma. Ann Nucl Med 1996;10:193-200.

84. Eschmann SM, Friedel G, Paulsen F, et al. Is standardised (18)F-FDG uptake value an outcome predictor in patients with stage III non-small cell lung cancer? Eur J Nucl Med Mol Imaging 2006;33:263-9.

85. Borst GR, Belderbos JS, Boellaard R, et al. Standardised FDG uptake: a prognostic factor for inoperable non-small cell lung cancer. Eur J Cancer 2005;41:1533-41.

86. Hoang JK, Hoagland LF, Coleman RE, Coan AD, Herndon JE, 2nd, Patz EF, Jr. Prognostic value of fluorine-18 fluorodeoxyglucose positron emission tomography imaging in patients with advancedstage non-small-cell lung carcinoma. J Clin Oncol 2008;26:1459-64.

87. Higashi K, Clavo AC, Wahl RL. Does FDG uptake measure proliferative activity of human cancer cells? In vitro comparison with DNA flow cytometry and tritiated thymidine uptake. J Nucl Med 1993;34:414-9.

88. van Baardwijk A, Dooms C, van Suylen RJ, et al. The maximum uptake of (18)F-deoxyglucose on positron emission tomography scan correlates with survival, hypoxia inducible factor-1alpha and GLUT-1 in non-small cell lung cancer. Eur J Cancer 2007;43:1392-8.

89. Nahmias C, Hanna WT, Wahl LM, Long MJ, Hubner KF, Townsend DW. Time course of early response to chemotherapy in non-small cell lung cancer patients with 18F-FDG PET/CT. J Nucl Med 2007;48:744-51.

90. Hoekstra CJ, Stroobants SG, Smit EF, et al. Prognostic relevance of response evaluation using [18F]-2fluoro-2-deoxy-D-glucose positron emission tomography in patients with locally advanced non-smallcell lung cancer. J Clin Oncol 2005;23:8362-70. 
91. Weber WA, Petersen V, Schmidt B, et al. Positron emission tomography in non-small-cell lung cancer: prediction of response to chemotherapy by quantitative assessment of glucose use. J Clin Oncol 2003;21:2651-7.

92. de Geus-Oei LF, van der Heijden HF, Visser EP, et al. Chemotherapy response evaluation with 18FFDG PET in patients with non-small cell lung cancer. J Nucl Med 2007;48:1592-8.

93. Decoster L, Schallier D, Everaert $\mathrm{H}$, et al. Complete metabolic tumour response, assessed by 18 fluorodeoxyglucose positron emission tomography (18FDG-PET), after induction chemotherapy predicts a favourable outcome in patients with locally advanced non-small cell lung cancer (NSCLC). Lung Cancer 2008;62:55-61.

94. Eschmann SM, Friedel G, Paulsen F, et al. 18F-FDG PET for assessment of therapy response and preoperative re-evaluation after neoadjuvant radio-chemotherapy in stage III non-small cell lung cancer. Eur J Nucl Med Mol Imaging 2007;34:463-71.

95. Hellwig D, Graeter TP, Ukena D, Georg T, Kirsch CM, Schafers HJ. Value of F-18-fluorodeoxyglucose positron emission tomography after induction therapy of locally advanced bronchogenic carcinoma. J Thorac Cardiovasc Surg 2004;128:892-9.

96. Pottgen C, Levegrun S, Theegarten D, et al. Value of 18F-fluoro-2-deoxy-D-glucose-positron emission tomography/computed tomography in non-small-cell lung cancer for prediction of pathologic response and times to relapse after neoadjuvant chemoradiotherapy. Clin Cancer Res 2006;12:97106.

97. Wahl RL, Jacene $H$, Kasamon $Y$, Lodge MA. From RECIST to PERCIST: Evolving Considerations for PET response criteria in solid tumors. J Nucl Med 2009;50 Suppl 1:122S-50S.

98. Tanvetyanon T, Eikman EA, Sommers E, Robinson L, Boulware D, Bepler G. Computed tomography response, but not positron emission tomography scan response, predicts survival after neoadjuvant chemotherapy for resectable non-small-cell lung cancer. J Clin Oncol 2008;26:4610-6.

99. Zhang HQ, Yu JM, Meng X, Yue JB, Feng R, Ma L. Prognostic value of serial [(18)F]fluorodeoxyglucose PET-CT uptake in stage III patients with non-small cell lung cancer treated by concurrent chemoradiotherapy. Eur J Radiol 2009.

100. van Baardwijk A, Bosmans G, Dekker A, et al. Time trends in the maximal uptake of FDG on PET scan during thoracic radiotherapy. A prospective study in locally advanced non-small cell lung cancer (NSCLC) patients. Radiother Oncol 2007;82:145-52.

101. Krak NC, Boellaard R, Hoekstra OS, Twisk JW, Hoekstra CJ, Lammertsma AA. Effects of ROI definition and reconstruction method on quantitative outcome and applicability in a response monitoring trial. Eur J Nucl Med Mol Imaging 2005;32:294-301.

102. Minn H, Zasadny KR, Quint LE, Wahl RL. Lung cancer: reproducibility of quantitative measurements for evaluating 2-[F-18]-fluoro-2-deoxy-D-glucose uptake at PET. Radiology 1995;196:167-73.

103. Nakamoto Y, Zasadny KR, Minn H, Wahl RL. Reproducibility of common semi-quantitative parameters for evaluating lung cancer glucose metabolism with positron emission tomography using 2deoxy-2-[18F]fluoro-D-glucose. Mol Imaging Biol 2002;4:171-8.

104. Young $H$, Baum R, Cremerius $U$, et al. Measurement of clinical and subclinical tumour response using [18F]-fluorodeoxyglucose and positron emission tomography: review and 1999 EORTC recommendations. European Organization for Research and Treatment of Cancer (EORTC) PET Study Group. Eur J Cancer 1999;35:1773-82.

105. Bruzzi JF, Munden RF. PET/CT imaging of lung cancer. J Thorac Imaging 2006;21:123-36.

106. Hicks RJ, Kalff V, MacManus MP, et al. The utility of (18)F-FDG PET for suspected recurrent nonsmall cell lung cancer after potentially curative therapy: impact on management and prognostic stratification. J Nucl Med 2001;42:1605-13.

107. Rubins J, Unger M, Colice GL. Follow-up and surveillance of the lung cancer patient following curative intent therapy: ACCP evidence-based clinical practice guideline (2nd edition). Chest 2007;132:355S-67S. 
108. Duhaylongsod FG, Lowe VJ, Patz EF, Jr., Vaughn AL, Coleman RE, Wolfe WG. Detection of primary and recurrent lung cancer by means of F-18 fluorodeoxyglucose positron emission tomography (FDG PET). J Thorac Cardiovasc Surg 1995;110:130-9; discussion 9-40.

109. Mac Manus MP, Hicks RJ, Matthews JP, et al. Positron emission tomography is superior to computed tomography scanning for response-assessment after radical radiotherapy or chemoradiotherapy in patients with non-small-cell lung cancer. J Clin Oncol 2003;21:1285-92.

110. Patz EF, Jr., Lowe VJ, Hoffman JM, Paine SS, Harris LK, Goodman PC. Persistent or recurrent bronchogenic carcinoma: detection with PET and 2-[F-18]-2-deoxy-D-glucose. Radiology 1994;191:37982.

111. Choi NC, Herndon JE, 2nd, Rosenman J, et al. Phase I study to determine the maximum-tolerated dose of radiation in standard daily and hyperfractionated-accelerated twice-daily radiation schedules with concurrent chemotherapy for limited-stage small-cell lung cancer. J Clin Oncol 1998;16:3528-36.

112. Hebert ME, Lowe VJ, Hoffman JM, Patz EF, Anscher MS. Positron emission tomography in the pretreatment evaluation and follow-up of non-small cell lung cancer patients treated with radiotherapy: preliminary findings. Am J Clin Oncol 1996;19:416-21.

113. Ryu JS, Choi NC, Fischman AJ, Lynch TJ, Mathisen DJ. FDG-PET in staging and restaging non-small cell lung cancer after neoadjuvant chemoradiotherapy: correlation with histopathology. Lung Cancer 2002;35:179-87.

114. Keidar Z, Haim N, Guralnik L, et al. PET/CT using 18F-FDG in suspected lung cancer recurrence: diagnostic value and impact on patient management. J Nucl Med 2004;45:1640-6.

115. Hicks RJ, Mac Manus MP, Matthews JP, et al. Early FDG-PET imaging after radical radiotherapy for non-small-cell lung cancer: inflammatory changes in normal tissues correlate with tumor response and do not confound therapeutic response evaluation. Int J Radiat Oncol Biol Phys 2004;60:412-8.

116. Henderson MA, Hoopes DJ, Fletcher JW, et al. A pilot trial of serial 18F-fluorodeoxyglucose positron emission tomography in patients with medically inoperable stage I non-small-cell lung cancer treated with hypofractionated stereotactic body radiotherapy. Int J Radiat Oncol Biol Phys;76:789-95.

117. Ishimori T, Saga T, Nagata Y, et al. 18F-FDG and 11C-methionine PET for evaluation of treatment response of lung cancer after stereotactic radiotherapy. Ann Nucl Med 2004;18:669-74.

118. Benamore R, Shepherd FA, Leighl N, et al. Does intensive follow-up alter outcome in patients with advanced lung cancer? J Thorac Oncol 2007;2:273-81.

119. Edelman MJ, Schuetz J. Follow-up of local (stage I and stage II) non-small-cell lung cancer after surgical resection. Curr Treat Options Oncol 2002;3:67-73.

120. Walsh GL, O'Connor M, Willis KM, et al. Is follow-up of lung cancer patients after resection medically indicated and cost-effective? Ann Thorac Surg 1995;60:1563-70; discussion 70-2.

121. Patz EF, Jr., Connolly J, Herndon J. Prognostic value of thoracic FDG PET imaging after treatment for non-small cell lung cancer. AJR Am J Roentgenol 2000;174:769-74.

122. Ahuja V, Coleman RE, Herndon J, Patz EF, Jr. The prognostic significance of fluorodeoxyglucose positron emission tomography imaging for patients with nonsmall cell lung carcinoma. Cancer 1998;83:918-24.

123. Downey RJ, Akhurst T, Gonen M, et al. Preoperative F-18 fluorodeoxyglucose-positron emission tomography maximal standardized uptake value predicts survival after lung cancer resection. J Clin Oncol 2004;22:3255-60.

124. Kased N, Erasmus JJ, Komaki R, Cox JD. Prognostic value of posttreatment [18F] fluorodeoxyglucose uptake of primary non-small cell lung carcinoma treated with radiation therapy with or without chemotherapy: a brief review. J Thorac Oncol 2008;3:534-8.

125. van Loon J, Grutters J, Wanders R, et al. Follow-up with 18FDG-PET-CT after radical radiotherapy with or without chemotherapy allows the detection of potentially curable progressive disease in non-small cell lung cancer patients: a prospective study. Eur J Cancer 2009;45:588-95. 
126. van Loon J, Grutters JP, Wanders R, et al. 18FDG-PET-CT in the follow-up of non-small cell lung cancer patients after radical radiotherapy with or without chemotherapy: an economic evaluation. Eur J Cancer;46:110-9.

127. Apisarnthanarax S, Alauddin MM, Mourtada F, et al. Early detection of chemoradioresponse in esophageal carcinoma by 3'-deoxy-3'-3H-fluorothymidine using preclinical tumor models. Clin Cancer Res 2006;12:4590-7.

128. Buck AK, Halter $\mathrm{G}$, Schirrmeister $\mathrm{H}$, et al. Imaging proliferation in lung tumors with PET: $18 \mathrm{~F}-\mathrm{FLT}$ versus 18F-FDG. J Nucl Med 2003;44:1426-31.

129. Muzi M, Vesselle H, Grierson JR, et al. Kinetic analysis of 3'-deoxy-3'-fluorothymidine PET studies: validation studies in patients with lung cancer. J Nucl Med 2005;46:274-82.

130. Wagner M, Seitz U, Buck A, et al. 3'-[18F]fluoro-3'-deoxythymidine ([18F]-FLT) as positron emission tomography tracer for imaging proliferation in a murine B-Cell lymphoma model and in the human disease. Cancer Res 2003;63:2681-7.

131. Yamamoto Y, Nishiyama Y, Ishikawa S, et al. Correlation of 18F-FLT and 18F-FDG uptake on PET with Ki-67 immunohistochemistry in non-small cell lung cancer. Eur J Nucl Med Mol Imaging 2007;34:1610-6.

132. Yap CS, Czernin J, Fishbein MC, et al. Evaluation of thoracic tumors with 18F-fluorothymidine and 18F-fluorodeoxyglucose-positron emission tomography. Chest 2006;129:393-401.

133. Pan MH, Huang SC, Liao YP, et al. FLT-PET imaging of radiation responses in murine tumors. Mol Imaging Biol 2008;10:325-34.

134. Roels S, Slagmolen $\mathrm{P}$, Nuyts J, et al. Biological image-guided radiotherapy in rectal cancer: is there a role for FMISO or FLT, next to FDG? Acta Oncol 2008;47:1237-48.

135. Wieder HA, Geinitz H, Rosenberg R, et al. PET imaging with [18F]3'-deoxy-3'-fluorothymidine for prediction of response to neoadjuvant treatment in patients with rectal cancer. Eur J Nucl Med Mol Imaging 2007;34:878-83.

136. Kubota R, Kubota K, Yamada S, et al. Methionine uptake by tumor tissue: a microautoradiographic comparison with FDG. J Nucl Med 1995;36:484-92.

137. Nettelbladt OS, Sundin AE, Valind SO, et al. Combined fluorine-18-FDG and carbon-11-methionine PET for diagnosis of tumors in lung and mediastinum. J Nucl Med 1998;39:640-7.

138. Tsuyuguchi N, Sunada I, Ohata K, et al. Evaluation of treatment effects in brain abscess with positron emission tomography: comparison of fluorine-18-fluorodeoxyglucose and carbon-11methionine. Ann Nucl Med 2003;17:47-51.

139. van Waarde A, Jager PL, Ishiwata K, Dierckx RA, Elsinga PH. Comparison of sigma-ligands and metabolic PET tracers for differentiating tumor from inflammation. J Nucl Med 2006;47:150-4.

140. Murayama C, Harada N, Kakiuchi T, et al. Evaluation of D-18F-FMT, 18F-FDG, L-11C-MET, and 18FFLT for monitoring the response of tumors to radiotherapy in mice. J Nucl Med 2009;50:290-5.

141. Yamaura G, Yoshioka T, Fukuda H, et al. O-[18F]fluoromethyl-L-tyrosine is a potential tracer for monitoring tumour response to chemotherapy using PET: an initial comparative in vivo study with deoxyglucose and thymidine. Eur J Nucl Med Mol Imaging 2006;33:1134-9.

142. Zelen M. Keynote address on biostatistics and data retrieval. Cancer Chemother Rep 3 1973;4:3142.

143. de Jong WK, Schaapveld M, Blaauwgeers JL, Groen HJ. Pulmonary tumours in the Netherlands: focus on temporal trends in histology and stage and on rare tumours. Thorax 2008;63:1096-102.

144. Bunn PA, Jr., Carney DN. Overview of chemotherapy for small cell lung cancer. Semin Oncol 1997;24:S7-69-S7-74.

145. Ihde DC. Small cell lung cancer. State-of-the-art therapy 1994. Chest 1995;107:243S-8S.

146. Bradley JD, Dehdashti F, Mintun MA, Govindan R, Trinkaus K, Siegel BA. Positron emission tomography in limited-stage small-cell lung cancer: a prospective study. J Clin Oncol 2004;22:3248-54.

147. Brink I, Schumacher T, Mix M, et al. Impact of [18F]FDG-PET on the primary staging of small-cell lung cancer. Eur J Nucl Med Mol Imaging 2004;31:1614-20. 
148. Chin R, Jr., McCain TW, Miller AA, et al. Whole body FDG-PET for the evaluation and staging of small cell lung cancer: a preliminary study. Lung Cancer 2002;37:1-6.

149. Fischer BM, Mortensen J, Langer SW, et al. A prospective study of PET/CT in initial staging of smallcell lung cancer: comparison with $\mathrm{CT}$, bone scintigraphy and bone marrow analysis. Ann Oncol 2007; 18:338-45.

150. Niho S, Fujii H, Murakami K, et al. Detection of unsuspected distant metastases and/or regional nodes by FDG-PET in LD-SCLC scan in apparent limited-disease small-cell lung cancer. Lung Cancer 2007; 57:328-33.

151. Pandit N, Gonen M, Krug L, Larson SM. Prognostic value of [18F]FDG-PET imaging in small cell lung cancer. Eur J Nucl Med Mol Imaging 2003;30:78-84.

152. Shen YY, Shiau YC, Wang JJ, Ho ST, Kao CH. Whole-body 18F-2-deoxyglucose positron emission tomography in primary staging small cell lung cancer. Anticancer Res 2002;22:1257-64.

153. Vinjamuri M, Craig M, Campbell-Fontaine A, Almubarak M, Gupta N, Rogers JS. Can positron emission tomography be used as a staging tool for small-cell lung cancer? Clin Lung Cancer 2008;9:30-4.

154. Ung YC, Maziak DE, Vanderveen JA, et al. 18Fluorodeoxyglucose positron emission tomography in the diagnosis and staging of lung cancer: a systematic review. J Natl Cancer Inst 2007;99:1753-67.

155. Azad A, Chionh F, Scott AM, et al. High Impact of (18)F-FDG-PET on Management and Prognostic Stratification of Newly Diagnosed Small Cell Lung Cancer. Mol Imaging Biol 2009.

156. Blum R, MacManus MP, Rischin D, Michael M, Ball D, Hicks RJ. Impact of positron emission tomography on the management of patients with small-cell lung cancer: preliminary experience. Am J Clin Oncol 2004;27:164-71.

157. Kamel EM, Zwahlen D, Wyss MT, Stumpe KD, von Schulthess GK, Steinert HC. Whole-body (18)FFDG PET improves the management of patients with small cell lung cancer. J Nucl Med 2003;44:1911-7.

158. Schumacher T, Brink I, Mix M, et al. FDG-PET imaging for the staging and follow-up of small cell lung cancer. Eur J Nucl Med 2001;28:483-8.

159. Videtic GM, Belderbos JS, Spring Kong FM, Kepka L, Martel MK, Jeremic B. Report from the International Atomic Energy Agency (IAEA) consultants' meeting on elective nodal irradiation in lung cancer: small-cell lung cancer (SCLC). Int J Radiat Oncol Biol Phys 2008;72:327-34.

160. De Ruysscher D, Bremer RH, Koppe F, et al. Omission of elective node irradiation on basis of CTscans in patients with limited disease small cell lung cancer: a phase II trial. Radiother Oncol 2006;80:307-12.

161. van Loon J, Offermann C, Bosmans G, et al. 18FDG-PET based radiation planning of mediastinal lymph nodes in limited disease small cell lung cancer changes radiotherapy fields: a planning study. Radiother Oncol 2008;87:49-54.

162. Turrisi AT, 3rd, Kim K, Blum R, et al. Twice-daily compared with once-daily thoracic radiotherapy in limited small-cell lung cancer treated concurrently with cisplatin and etoposide. N Engl J Med 1999;340:265-71.

163. van Loon J, De Ruysscher D, Wanders R, et al. Selective Nodal Irradiation on Basis of (18)FDG-PET Scans in Limited-Disease Small-Cell Lung Cancer: A Prospective Study. Int J Radiat Oncol Biol Phys 2009.

164. De Ruysscher D, Pijls-Johannesma M, Bentzen SM, et al. Time between the first day of chemotherapy and the last day of chest radiation is the most important predictor of survival in limited-disease small-cell lung cancer. J Clin Oncol 2006;24:1057-63.

165. De Ruysscher D, Pijls-Johannesma M, Vansteenkiste J, Kester A, Rutten I, Lambin P. Systematic review and meta-analysis of randomised, controlled trials of the timing of chest radiotherapy in patients with limited-stage, small-cell lung cancer. Ann Oncol 2006;17:543-52.

166. Pijls-Johannesma MC, De Ruysscher D, Lambin P, Rutten I, Vansteenkiste JF. Early versus late chest radiotherapy for limited stage small cell lung cancer. Cochrane Database Syst Rev 2005:CD004700. 
167. Jeremic B, Shibamoto $\mathrm{Y}$, Nikolic $\mathrm{N}$, et al. Role of radiation therapy in the combined-modality treatment of patients with extensive disease small-cell lung cancer: A randomized study. J Clin Oncol 1999;17:2092-9.

168. Shepherd FA, Ginsberg RJ, Haddad R, et al. Importance of clinical staging in limited small-cell lung cancer: a valuable system to separate prognostic subgroups. The University of Toronto Lung Oncology Group. J Clin Oncol 1993;11:1592-7.

169. Shepherd FA, Crowley J, Van Houtte P, et al. The International Association for the Study of Lung Cancer lung cancer staging project: proposals regarding the clinical staging of small cell lung cancer in the forthcoming (seventh) edition of the tumor, node, metastasis classification for lung cancer. J Thorac Oncol 2007;2:1067-77.

170. Vallieres E, Shepherd FA, Crowley J, et al. The IASLC Lung Cancer Staging Project: proposals regarding the relevance of TNM in the pathologic staging of small cell lung cancer in the forthcoming (seventh) edition of the TNM classification for lung cancer. J Thorac Oncol 2009;4:1049-59.

171. Lee YJ, Cho A, Cho BC, et al. High tumor metabolic activity as measured by fluorodeoxyglucose positron emission tomography is associated with poor prognosis in limited and extensive stage small-cell lung cancer. Clin Cancer Res 2009;15:2426-32.

172. Fischer BM, Mortensen J, Langer SW, et al. PET/CT imaging in response evaluation of patients with small cell lung cancer. Lung Cancer 2006;54:41-9.

173. Yamamoto Y, Kameyama R, Murota M, Bandoh S, Ishii T, Nishiyama Y. Early assessment of therapeutic response using FDG PET in small cell lung cancer. Mol Imaging Biol 2009;11:467-72.

174. Onitilo AA, Engel JM, Demos JM, Mukesh B. Prognostic significance of 18 F-fluorodeoxyglucose positron emission tomography after treatment in patients with limited stage small cell lung cancer. Clin Med Res 2008;6:72-7. 


\section{CHAPTER 10 \\ General Discussion and Future Perspectives}


CHAPTER 10 
Combined modality treatment with chemotherapy and radiotherapy (RT) is the treatment of choice for the approximately one third of lung cancer patients presenting with locally advanced disease. Although survival has improved significantly with combined modality therapy, the prognosis remains very poor. The objective of this thesis was to address the potential of molecular imaging with PET to optimize combined modality treatment in lung cancer. In this chapter, the main findings are summarized and discussed in view of the currently available evidence. Future perspectives to further improve outcome in locally advanced lung cancer are provided.

\subsection{FDG-PET-CT based target volume definition to optimize radiotherapy for locally advanced lung cancer}

\section{Microscopic disease extension}

In RT planning, a margin of surrounding tissue is added to the gross tumour volume (GTV) to ensure coverage of potential microscopic spread, resulting in the clinical target volume (CTV) ${ }^{1}$.

Microscopic spread beyond the tumour border visible on imaging can only be quantified by correlating imaging with the findings at pathologic examination. Population statistics in NSCLC report an average distance of microscopic spread ranging from $1.5 \mathrm{~mm}$ to $8 \mathrm{~mm}^{2-5}$. These ranges are probably underestimated as tissue deformations occur between in-vivo imaging and ex-vivo pathology. This underestimation may arise up to a factor of $2^{6,7}$, suggesting that currently applied margins, usually around $5 \mathrm{~mm}$, are probably too small to allow delivery of the full radiotherapy dose to areas with microscopic disease. The dose required to eradicate microscopic disease, however, is expected to be lower than the dose for macroscopic tumour ${ }^{8,9}$. Furthermore, not all lung tumours do show microscopic disease spread ${ }^{3,7}$. In this thesis, a prediction model for the presence of microscopic spread in NSCLC was developed on the basis of risk factors on pre-treatment PET-CT (Chapter 2). Mean tumour density on $\mathrm{CT}$ and tumour volume on $\mathrm{CT}$ were predictive for the presence of microscopic disease. After validation in an independent patient cohort, finally, these factors could allow an individual adaptation of the dose to the tissue surrounding the GTV according to subgroups of patients, thus optimizing the balance between local control and toxicity in the individual patient.

\section{FDG-PET based selective nodal irradiation}

Routine elective nodal irradiation is no longer recommended in NSCLC ${ }^{10,11}$. FDGPET scan is more accurate for the detection of lymph node involvement than $\mathrm{CT}$ in both NSCLC and SCLC ${ }^{12-16}$. In NSCLC, the sensitivity and specificity of PET compared 
to CT are $83 \%$ vs. $56 \%$ and $89 \%$ vs. $81 \%$, respectively. Although in SCLC, no clinical trials are available that directly assess the diagnostic performance for lymph node staging, the available data report a sensitivity and specificity of $89-100 \%$ and $78-95 \%$ in the overall staging of SCLC. This suggests that the diagnostic accuracy for lymph node staging of PET is higher than CT in SCLC as well ${ }^{16}$.

Both PET- and CT-based selective nodal irradiation (SNI) of involved lymph nodes has proven its safety in NSCLC, with an isolated nodal failure rate of less than $5 \%{ }^{17-}$ ${ }^{20}$. In NSCLC, SNI is not only safe, but also results in a reduction of radiation fields based on $\mathrm{CT}$, and even further based on FDG-PET ${ }^{21}$, providing opportunities for radiation dose-escalation through decreased radiation exposure of the lungs and the esophagus ${ }^{21,22}$.

In SCLC, data on the applicability of SNI are scarce ${ }^{23}$. CT-based SNI cannot be considered safe, as it resulted in an amount of $11 \%$ of isolated nodal failures ${ }^{24}$. We confirmed in a planning study that differences in the treatment plan resulting from PET- and CT-based SNI occur, which was the case in $24 \%$ of patients (Chapter 3 ). The subsequent prospective study indicated that FDG-PET-based SNI is safe, with $3 \%$ of the patients experiencing an isolated nodal failure (Chapter 4). The treatment resulted in a remarkably low percentage (12\%) of grade III esophagitis. Anticipating that further intensification of the combined modality treatment regimen results in improved outcome in SCLC patients as well ${ }^{25}$, two intensified RT schedules are currently compared to the standard treatment schedule (45 Gy twice daily) in a randomized phase III trial ${ }^{26}$. The low rate of isolated nodal failures and toxicity supports the use of PET-based SNI in future intensified treatment schedules for stage IIII SCLC.

Caution is warranted with the application of more conformal RT technologies, such as stereotactic body radiotherapy (SBRT), intensity modulated radiotherapy (IMRT) and particle therapy, as they are associated with altered penumbra characteristics.

\subsection{Value of FDG-PET-CT in the follow-up of locally advanced lung cancer}

The most effective follow-up strategy for lung cancer patients treated with curative intent therapy is still not established. This uncertainty is reflected in the large heterogeneity in recommendations from the different cancer societies, diverging from no imaging at all to repeated imaging with chest CT scans ${ }^{27}$. The added value of chest X-rays and/or chest CT has not been confirmed in any prospective study. The most recent study comparing intensive follow-up with repeated CT-imaging to less 
intensive radiologic follow-up showed no significant improvement of survival ${ }^{28}$. A main reason for this is the fact that progression or recurrence is mostly detected at a stage that no more radical treatment options exist, and hence, no survival benefit can be expected ${ }^{29}$. The poor discriminating capacity of CT and chest X-ray between residual tumour and post-treatment changes ${ }^{30,31}$ causes a delay as progression is often only confirmed after repeated imaging.

FDG-PET-CT is more accurate than CT in the evaluation of response to treatment as well as in outcome prediction ${ }^{32-40}$. This formed the rationale for the hypothesis that PET-CT may have additional benefit. We report in this thesis the results of a prospective study in 100 NSCLC patients treated with chemo-radiotherapy or RT alone with curative intent. This study confirms that an FDG-PET-CT 3 months after therapy can detect progression amenable for treatment with curative intent, and hereby, possibly lead to an increase in survival. This was, however, only the case in a small proportion of patients (2\%), and only in the subgroup that was asymptomatic at the time of scanning (Chapter 5). Based on these results, an economic evaluation was subsequently performed comparing PET-CT based follow-up with usual follow-up with either a CT scan or repeated chest X-rays. A PET-CT scan 3 months after (chemo-)radiotherapy turned out to be potentially cost-effective, and was more cost-effective than $\mathrm{CT}$ alone. As the advantage was confined to the asymptomatic patients, representing $55 \%$ of the total population, performing a PET-CT in this group only is probably as effective and more cost-effective (Chapter 6).

Hence, we suggest that on basis of the currently available evidence, if any imaging is wished to be performed for treatment evaluation in NSCLC, an FDG- PET-CT scan 3 months after therapy is to be preferred above CT alone. The uncertainty surrounding the decision whether to implement PET-CT in the follow-up makes it worthwhile to perform additional research. This uncertainty is caused for a major part by the relatively small patient population in the prospective study. In this respect, a direct comparison between conventional, CT based and PET-CT based follow-up in a randomized trial, including a prospective evaluation of the associated costs, would add significantly to the final decision regarding which strategy to implement in routine clinical practice.

A multicentre phase III trial in NSCLC patients after curative resection is currently ongoing in France which should give a definitive answer regarding the value of CT based follow-up ${ }^{41}$. Unfortunately, however, PET-CT scans are not included in this trial.

No studies have addressed the role of FDG-PET in the follow-up of SCLC. Because of the rapid growth rate and early dissemination of SCLC, it is less likely that an FDGPET scan 3 months after therapy detects progression in a stage that is still curable. 
As earlier response evaluation with FDG is limited by its uptake in inflammatory areas, other tracers, such as proliferation markers that are described below, may be better suitable for this purpose.

\subsection{Novel PET tracers for the non invasive imaging of tumour characteristics}

The supplementary role of FDG-PET in the diagnosis, staging and treatment of lung cancer is beyond doubt. The correlation between high FDG uptake and worse overall survival has been shown in multiple studies ${ }^{42-45}$, and was confirmed in a metaanalysis, with a combined HR for survival of $2.27^{36}$. Nevertheless, the inherent properties of FDG limit its value in certain areas. Furthermore, the development and introduction of new therapeutic strategies specifically targeted at tumour cell characteristics provide novel opportunities for molecular imaging to specifically visualize one of these characteristics. This makes it worthwhile to investigate whether alternative tracers can complement FDG.

The limited ability of FDG to discriminate between tumour activity and inflammatory effects due to therapy, has forced the search for more specific markers of tumour cell proliferation. Two groups of proliferation markers have been evaluated for their ability to image proliferation during (chemo-)radiotherapy. Thymidine analogues, markers of DNA synthesis, of which ${ }^{18} \mathrm{~F}$-fluorothymidine $\left({ }^{18} \mathrm{~F}-\mathrm{FLT}\right)$ is most extensively applied, has been correlated with tumour proliferative activity in lung cancer ${ }^{46-49}$ and has the feasibility to image proliferation during chemoradiotherapy ${ }^{50}$. In head and neck cancer patients, however, FLT has been shown to accumulate as well in reactive B-lymphocytes, which forms a potential drawback for is use in early response assessment ${ }^{51}$.

The second group of proliferation markers consists of amino-acid tracers, such as ${ }^{11} \mathrm{C}$-methionine $\left({ }^{11} \mathrm{C}\right.$-Met) and ${ }^{18} \mathrm{~F}$-fluoromethyltyrosine $\left({ }^{18} \mathrm{~F}\right.$-FMT). Data on their usefulness in evaluating treatment response are scarce ${ }^{52-55}$, but preclinical studies with ${ }^{18} \mathrm{~F}$-FMT did show a rapid response to antitumour therapy with little accumulation in inflammatory cells ${ }^{56,57}$.

Tumour hypoxia is an important marker of cancer prognosis, being associated with aggressive growth, metastasis, and resistance to anticancer therapy ${ }^{58}$. Non-invasive PET imaging allowing detection and quantification of hypoxia could select patients who may benefit from hypoxic radio-sensitizers or dose-escalation. Although the uptake of glucose, and thus FDG, is increased by hypoxia, many other factors including proliferation and cell density also increase cellular glucose influx ${ }^{59}$. Clinical studies in NSCLC regarding the correlation between FDG uptake and the degree of hy- 
poxia within the tumour have shown contradictory results ${ }^{39,60-63}$. Therefore, specific hypoxia targeted tracers are required to image hypoxia in lung cancer.

$\left[{ }^{18} \mathrm{~F}\right] \mathrm{HX} 4$, a recently developed hypoxia marker of the 2-nitroimidazole family, has in preclinical models proven to be a good tracer for the detection and evaluation of tumour hypoxia. $\left[{ }^{18} \mathrm{~F}\right] \mathrm{HX} 4$ was cleared faster from normal tissues and better reflected tumour heterogeneity compared to commonly used hypoxia markers such as $\left[{ }^{18} \mathrm{~F}\right] \mathrm{FMISO}$ and $\left[{ }^{18} \mathrm{~F}\right] \mathrm{FAZA}$, suggesting that $\left[{ }^{18} \mathrm{~F}\right] \mathrm{HX} 4$ may be a better alternative than these known hypoxia markers ${ }^{64}$. We demonstrated in a phase I trial that PET imaging with $\left[{ }^{18} \mathrm{~F}\right] \mathrm{HX} 4$ is safe (Chapter 7 ). The median tumour to muscle ratio (TMR) at 120 minutes post-injection was 1.40 (range: 0.63-1.98). No imaging at later time points was performed to limit the burden for the patients, all suffering from end stage disease. Future trials are needed to determine optimal imaging parameters, as preclinical data suggest 240 minutes post-injection as the most optimal time-point of scanning, with a maximum tumour to blood ratio of $7.6^{64}$.

Another area where non-invasive PET imaging could have additional clinical benefit is in the imaging of tumour expression of receptors that are targets for specific anticancer agents. One of these targets is the epidermal growth factor receptor (EGFR). Expression of this receptor has been correlated with tumour aggressiveness and treatment resistance ${ }^{65}$. EGFR inhibitors, such as the monoclonal antibody cetuximab, are increasingly used in combination with RT and/or chemotherapy to improve treatment outcome compared to RT alone ${ }^{66,67}$. The expression of EGFR, however, is heterogeneous throughout the tumour, and can alter under the influence of anticancer treatment ${ }^{68}$. Therefore, non invasive imaging of cetuximab binding to cancer cells before and during combined modality therapy could help to select the patients with the highest probability to benefit from treatment and would provide insight in intra-tumour characteristics associated with treatment resistance. Zirconium-89 $\left({ }^{89} \mathrm{Zr}\right)$ labelled cetuximab has been tested in pre-clinical animal models with excellent results (Figure 10.1) ${ }^{69}$.

Safety results of the phase I trial in this thesis form the basis for future patient studies to evaluate its potential clinical efficacy (Chapter 8 ). In this study, the maximal tumour to blood ratio for cetuximab uptake was 1.6. Future clinical studies are planned in patients before the start of any antitumour therapy, to allow correlation of EGFR expression at histology with imaging results. These studies will include kinetic imaging to enable the measurement of tumour perfusion. Optimal imaging conditions, including the appropriate loading dose of unlabelled cetuximab, are to be defined. 


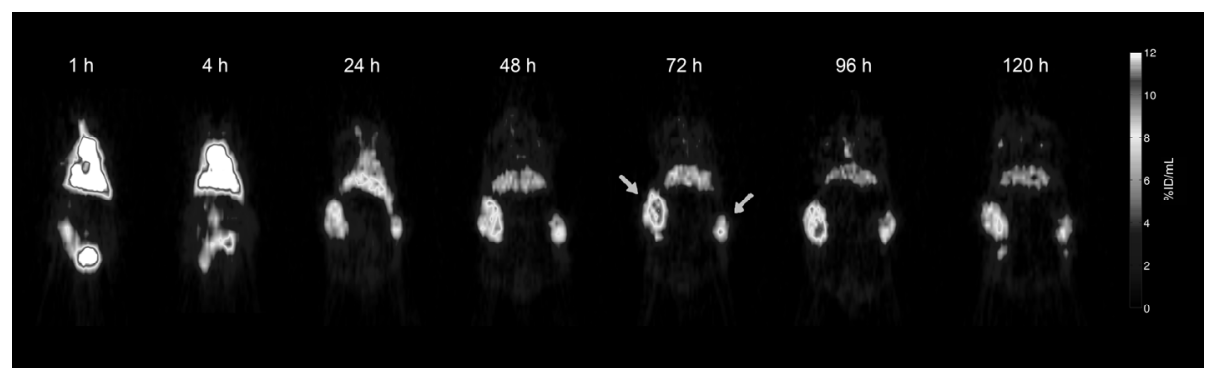

Figure 10.1 Time series of representative small-animal PET images at indicated time points after injection of ${ }^{89} \mathrm{Zr}$-cetuximab into HT-29 tumour bearing mouse

Grey arrows indicate tumours. Uptake levels plateaued from $72 \mathrm{~h}$ after injection onward. To allow comparison between different time points, images are shown at mid-plane cross-section through tumour. Images are corrected for injected dose and decay and represented as $\% \mathrm{ID} / \mathrm{mL}$

\subsection{Future perspectives}

Future developments to further improve outcome of the combined modality treatment of locally advanced lung cancer should adhere to the following principle: Improving tumour control whilst keeping normal tissue toxicity at a constant level.

Molecular imaging provides several opportunities to contribute to this goal in the future, which will be discussed below.

Accurate target volume definition is a prerequisite for the further improvement of conformal radiotherapy. PET-CT could optimize different aspects with regard to this subject: delineation of macroscopic tumour and lymph nodes encompassing the GTV, definition of the CTV margin to cover microscopic spread, and finally, the application of a PTV-margin appropriate to cover inaccuracies due to delineation uncertainty, set-up errors and tumour movement ${ }^{1}$. Ideally, validation of the delineated tumour volume on PET AND CT should be obtained by correlating it with the tumour volume at pathologic examination, being the gold standard. Data that are currently available are only based on two-dimensional correlations in early stage disease ${ }^{70-72}$. Three-dimensional models correlating PET and CT findings with pathology are under development, and results in large patient cohorts are pending ${ }^{6,7,73}$. Individually adapted CTV and PTV margins could contribute significantly to personalized optimization of therapy. This thesis proved the feasibility to predict the presence of microscopic spread on basis of the pre-treatment PET/CT scan. Validation of the model is to be awaited, with the final aim to implement the use of individually adapted CTV margins.

The limitations of PET to define the exact tumour extent should be kept in mind. Blurring of the tumour edges does occur due to the poor resolution and motion 
artefacts associated with the long acquisition time of PET ${ }^{74}$. The long acquisition time is, however, advantageous with respect to determining the extent of tumour motion. In a phantom study, PET-based treatment volumes resulted in an adequate coverage of the tumour during the whole respiratory cycle, while CT-based volumes harboured the risk of a geographical miss ${ }^{75}$. So-called four dimensional (4D) imaging techniques add respiration movements as a fourth dimension to conventional 3D CT and PET. It allows the incorporation of information on the extent of tumour motion, while optimizing image quality and quantification through reduction of the blurring effect. This provides the opportunity to apply personalized PTV margins depending on the extent of tumour motion. These techniques are presently being evaluated in clinical studies ${ }^{76,77}$.

The incorporation of PET in RT planning has already shown the potential for dose escalation through a reduction of the radiation fields ${ }^{21,22,78}$. Further optimization could be reached with the prescription of an individually determined maximal tolerable dose instead of applying the same radiation dose in all patients. The concept of individualized radiation dose escalation based on normal tissue constraints has recently been introduced in the clinic. This technique is an ultimate example of individualized treatment intensification at an acceptable toxicity rate. Survival rates of patients treated on basis of this concept with sequential chemo-radiation had survival rates comparable to results with concurrent chemo-radiation schedules, while less toxicity was observed ${ }^{79}$. These results suggest that individual dose escalation with PET-based RT planning can ultimately lead to higher cure rates, which should be the subject of future randomized prospective studies.

Recently, the concept of intratumoral radiation dose distribution has been established as a counterpart to homogeneous irradiation. The rationale behinds this concept is that characteristics associated with radioresistance, such as hypoxia, cell density and proliferation, are heterogeneous across the tumour ${ }^{80-82}$. Therefore, it is anticipated that selective boosting of these radioresistant areas, whilst decreasing the dose to the less resistant zones, would result in higher tumour control with similar side effects ${ }^{83-86}$. FDG is at present the most reasonable tracer to identify therapy-resistant areas within the tumour. Certain key issues before initiating a clinical trial on FDG-PET based dose redistribution have recently been addressed. First, it has been demonstrated that regions with high FDG uptake prior to radiotherapy correspond well with the location of recurrent or persistent tumour after sequential chemo-radiotherapy or radiotherapy alone ${ }^{69,87}$. Furthermore, it has been shown that those regions remain stable during a course of $\mathrm{RT}^{88}$. Thus, selective boosting of areas of assumed radioresistance identified with FDG-PET before the start of RT appears to be feasible. A multicentre prospective trial has recently been started to evaluate whether selective boosting leads to better treatment out- 
come. On basis of the currently available evidence and the wide availability of FDG as a tracer, FDG represents the most appropriate tracer for boosting subvolumes. Other tracers that are more specific to hypoxia $\left({ }^{18} \mathrm{~F}-\mathrm{FMISO},\left[{ }^{18} \mathrm{~F}\right] \mathrm{HX} 4\right)$ or proliferation $\left({ }^{18} \mathrm{~F}-\mathrm{FLT}\right)$, however, could be used complimentary to FDG ${ }^{50,89-92}$, and deserve further investigation for this purpose.

The ultimate method to guide tumour dose distribution would be the development of a voxel control probability map on the basis of tumour characteristics identified on CT and PET with different tracers. For this purpose, pathology correlation studies are underway to examine the relation between the pre-treatment PET/CT characteristics of a voxel and the underlying histopathology (tumour cell density, hypoxia, proliferation). The resulting probability map could be used for dose distribution with the application of a dose modifying factor to each voxel depending on the relative radioresistance, resulting in an optimal "voxel control probability".

Until now, the majority of patients still suffer from disease progression short after the completion of treatment ${ }^{33,93-96}$. In order to avoid ineffective treatment with the associated toxicity, extensive efforts have been made to select these patients before or early during treatment, enabling alternative therapy or treatment modification in cases where the expected benefit of the proposed treatment is insufficient.

Different methodologies have been developed in the search for predictive factors of treatment outcome, such as genomics, cytomics, proteomics and identification of predictive imaging features. It remains a challenge to effectively select those parameters that are of up most predictive value. So-called "Computer assisted theranostics" (CAT) provide a method to incorporate different predictive parameters to determine the expected benefit of a particular treatment for each individual patient. Obviously, data obtained with molecular imaging should be included in CAT. Although in the overall patient group with NSCLC, pre-treatment FDG-uptake has prognostic value ${ }^{36}$, results in advanced stage disease are conflicting, with the most recent study in the largest patient cohort not showing a significant correlation with survival ${ }^{42,43,97}$. Data in SCLC are scarce, but indicate that pre-treatment SUV $_{\text {max }}$ has prognostic value ${ }^{98}$. The predictive value of an early metabolic response during induction chemotherapy has been established ${ }^{99,100}$. With respect to the predictive value of a metabolic response during radical (chemo-)RT itself, the limited available data show a correlation with survival ${ }^{101,102}$. Also in this regard, other tracers are worthwhile to be investigated. Especially proliferation markers, that are less susceptible to uptake in inflammatory tissue, are supposed to have additional value above FDG in response evaluation during and after treatment ${ }^{50}$.

A potential drawback of PET is its associated costs in comparison to anatomic imaging modalities. Health care costs put an increasing burden on the overall economy. In the Netherlands, in 2008, 80 billion Euro was spent on health care, representing 
$13 \%$ of the gross domestic product ${ }^{103}$. At present, cancer care accounts for approximately $5 \%$ of the total health care costs, and this proportion is expected to increase ${ }^{104}$. Different countries increasingly request for evidence regarding the cost-effectiveness of novel therapeutic strategies in order to support its reimbursement, as only finite resources are available. In this light, the costs associated with the introduction of PET in different aspects of the combined modality treatment of lung cancer have to be weighed against its benefits. Information regarding cost-effectiveness can be obtained by an economic evaluation in which different treatment strategies including diagnostics can be compared with respect to both their costs and consequences on the basis of the currently available evidence ${ }^{105}$.

\subsection{Conclusions}

The aim of this thesis was to address the potential of molecular imaging with PET to optimize combined modality treatment in lung cancer.

FDG-PET improves target volume definition both with respect to the primary tumour and lymph nodes. The only way to accurately assess the extent of microscopic spread is by means of pathology correlation studies. This thesis proved the feasibility to predict the presence of microscopic spread on basis of the pre-treatment PET/CT scan. Finally, adapted CTV margins may be applied for low and high risk patients, resulting in an individually optimized sparing of normal tissue and improved coverage of all microscopic disease.

Selective nodal irradiation (SNI) of FDG-PET positive nodal stations has already been established as the preferred treatment in NSCLC. Results from this thesis suggest that FDG-PET based SNI is also safe in SCLC and is associated with a low toxicity rate, which may provide opportunities for dose escalation.

With regard to the role of PET scanning in the follow-up of lung cancer, it has been shown that an FDG-PET scan 3 months after combined modality therapy for NSCLC potentially improves survival through the detection of progression in a stage that radical treatment is still an option.

Tracers other than ${ }^{18}$ FDG offer potential to select patients with the highest probability to benefit from treatment with hypoxic radio-sensitizers or anticancer agents targeted at receptors on the surface of cancer cells. Furthermore, these tracers could have additional value for treatment response assessment and the visualization of intra-tumour heterogeneity, but more research is needed before they can be clinically implemented. 


\subsection{References}

1. ICoRUa. International Commission on Radiation Units and Measurements. ICRU Report 62: Prescribing, recording, and reporting photon beam therapy (Supplement to ICRU Report 50). Bethesda; 1999.

2. Chan R, He Y, Haque A, Zwischenberger J. Computed tomographic-pathologic correlation of gross tumor volume and clinical target volume in non-small cell lung cancer: a pilot experience. Arch Pathol Lab Med 2001;125:1469-72.

3. Giraud $P$, Antoine M, Larrouy A, et al. Evaluation of microscopic tumor extension in non-small-cell lung cancer for three-dimensional conformal radiotherapy planning. Int J Radiat Oncol Biol Phys 2000;48:1015-24.

4. Grills IS, Fitch DL, Goldstein NS, et al. Clinicopathologic analysis of microscopic extension in lung adenocarcinoma: defining clinical target volume for radiotherapy. Int J Radiat Oncol Biol Phys 2007;69:334-41.

5. Li WL, Yu JM, Liu GH, Zhong WX, Li WW, Zhang BJ. [A comparative study on radiology and pathology target volume in non-small-cell lung cancer]. Zhonghua Zhong Liu Za Zhi 2003;25:566-8.

6. Siedschlag C, van Loon J, van Baardwijk A, et al. Analysis of the relative deformation of lung lobes before and after surgery in patients with NSCLC. Phys Med Biol 2009;54:5483-92.

7. Stroom J, Blaauwgeers $\mathrm{H}$, van Baardwijk A, et al. Feasibility of pathology-correlated lung imaging for accurate target definition of lung tumors. Int J Radiat Oncol Biol Phys 2007;69:267-75.

8. Goitein M, Schultheiss TE. Strategies for treating possible tumor extension: some theoretical considerations. Int J Radiat Oncol Biol Phys 1985;11:1519-28.

9. Webb S, Nahum AE. A model for calculating tumour control probability in radiotherapy including the effects of inhomogeneous distributions of dose and clonogenic cell density. Phys Med Biol 1993;38:653-66.

10. Belderbos JS, Kepka L, Spring Kong FM, Martel MK, Videtic GM, Jeremic B. Report from the International Atomic Energy Agency (IAEA) consultants' meeting on elective nodal irradiation in lung cancer: non-small-Cell lung cancer (NSCLC). Int J Radiat Oncol Biol Phys 2008;72:335-42.

11. Senan S, De Ruysscher D, Giraud P, Mirimanoff R, Budach V. Literature-based recommendations for treatment planning and execution in high-dose radiotherapy for lung cancer. Radiother Oncol 2004;71:139-46.

12. Bradley JD, Dehdashti F, Mintun MA, Govindan R, Trinkaus K, Siegel BA. Positron emission tomography in limited-stage small-cell lung cancer: a prospective study. J Clin Oncol 2004;22:3248-54.

13. Gould MK, Kuschner WG, Rydzak CE, et al. Test performance of positron emission tomography and computed tomography for mediastinal staging in patients with non-small-cell lung cancer: a metaanalysis. Ann Intern Med 2003;139:879-92.

14. Kamel EM, Zwahlen D, Wyss MT, Stumpe KD, von Schulthess GK, Steinert HC. Whole-body (18)F-FDG PET improves the management of patients with small cell lung cancer. J Nucl Med 2003;44:1911-7.

15. Niho S, Fujii H, Murakami K, et al. Detection of unsuspected distant metastases and/or regional nodes by FDG-PET in LD-SCLC scan in apparent limited-disease small-cell lung cancer. Lung Cancer 2007;57:328-33.

16. Hellwig D, Baum RP, Kirsch C. FDG-PET, PET/CT and conventional nuclear medicine procedures in the evaluation of lung cancer: a systematic review. Nuklearmedizin 2009;48:59-69, quiz N8-9.

17. Belderbos JS, Heemsbergen WD, De Jaeger K, Baas P, Lebesque JV. Final results of a Phase I/II dose escalation trial in non-small-cell lung cancer using three-dimensional conformal radiotherapy. Int J Radiat Oncol Biol Phys 2006;66:126-34.

18. De Ruysscher D, Wanders S, van Haren E, et al. Selective mediastinal node irradiation based on FDGPET scan data in patients with non-small-cell lung cancer: a prospective clinical study. Int J Radiat Oncol Biol Phys 2005;62:988-94. 
19. Senan S, Burgers S, Samson MJ, et al. Can elective nodal irradiation be omitted in stage III non-smallcell lung cancer? Analysis of recurrences in a phase II study of induction chemotherapy and involvedfield radiotherapy. Int J Radiat Oncol Biol Phys 2002;54:999-1006.

20. Sulman EP, Komaki R, Klopp AH, Cox JD, Chang JY. Exclusion of elective nodal irradiation is associated with minimal elective nodal failure in non-small cell lung cancer. Radiat Oncol 2009;4:5.

21. De Ruysscher D, Wanders S, Minken A, et al. Effects of radiotherapy planning with a dedicated combined PET-CT-simulator of patients with non-small cell lung cancer on dose limiting normal tissues and radiation dose-escalation: a planning study. Radiother Oncol 2005;77:5-10.

22. van Der Wel A, Nijsten S, Hochstenbag M, et al. Increased therapeutic ratio by 18FDG-PET CT planning in patients with clinical CT stage N2-N3M0 non-small-cell lung cancer: a modeling study. Int J Radiat Oncol Biol Phys 2005;61:649-55.

23. Videtic GM, Belderbos JS, Spring Kong FM, Kepka L, Martel MK, Jeremic B. Report from the International Atomic Energy Agency (IAEA) consultants' meeting on elective nodal irradiation in lung cancer: small-cell lung cancer (SCLC). Int J Radiat Oncol Biol Phys 2008;72:327-34.

24. De Ruysscher D, Bremer RH, Koppe F, et al. Omission of elective node irradiation on basis of CT-scans in patients with limited disease small cell lung cancer: a phase II trial. Radiother Oncol 2006;80:30712.

25. Socinski MA, Bogart JA. Limited-stage small-cell lung cancer: the current status of combinedmodality therapy. J Clin Oncol 2007;25:4137-45.

26. Bogart JA. Rationale for phase III trials of thoracic radiation therapy doses in limited-stage small-cell lung cancer. Clin Lung Cancer 2008;9:202-5.

27. Rubins J, Unger M, Colice GL. Follow-up and surveillance of the lung cancer patient following curative intent therapy: ACCP evidence-based clinical practice guideline (2nd edition). Chest 2007;132:355S675 .

28. Benamore $\mathrm{R}$, Shepherd FA, Leighl N, et al. Does intensive follow-up alter outcome in patients with advanced lung cancer? J Thorac Oncol 2007;2:273-81.

29. Edelman MJ, Meyers FJ, Siegel D. The utility of follow-up testing after curative cancer therapy. A critical review and economic analysis. J Gen Intern Med 1997;12:318-31.

30. Korst RJ, Gold HT, Kent MS, Port JL, Lee PC, Altorki NK. Surveillance computed tomography after complete resection for non-small cell lung cancer: results and costs. J Thorac Cardiovasc Surg 2005;129:652-60.

31. Korst RJ, Kansler AL, Port JL, Lee PC, Altorki NK. Accuracy of surveillance computed tomography in detecting recurrent or new primary lung cancer in patients with completely resected lung cancer. Ann Thorac Surg 2006;82:1009-15; discussion 15.

32. Mac Manus MP, Hicks RJ, Matthews JP, et al. Positron emission tomography is superior to computed tomography scanning for response-assessment after radical radiotherapy or chemoradiotherapy in patients with non-small-cell lung cancer. J Clin Oncol 2003;21:1285-92.

33. Mac Manus MP, Hicks RJ, Matthews JP, Wirth A, Rischin D, Ball DL. Metabolic (FDG-PET) response after radical radiotherapy/chemoradiotherapy for non-small cell lung cancer correlates with patterns of failure. Lung Cancer 2005;49:95-108.

34. Patz EF, Jr., Connolly J, Herndon J. Prognostic value of thoracic FDG PET imaging after treatment for non-small cell lung cancer. AJR Am J Roentgenol 2000;174:769-74.

35. Ahuja V, Coleman RE, Herndon J, Patz EF, Jr. The prognostic significance of fluorodeoxyglucose positron emission tomography imaging for patients with nonsmall cell lung carcinoma. Cancer 1998;83:918-24.

36. Berghmans T, Dusart M, Paesmans M, et al. Primary tumor standardized uptake value (SUVmax) measured on fluorodeoxyglucose positron emission tomography (FDG-PET) is of prognostic value for survival in non-small cell lung cancer (NSCLC): a systematic review and meta-analysis (MA) by the European Lung Cancer Working Party for the IASLC Lung Cancer Staging Project. J Thorac Oncol 2008;3:6-12. 
37. Downey RJ, Akhurst T, Gonen M, et al. Preoperative F-18 fluorodeoxyglucose-positron emission tomography maximal standardized uptake value predicts survival after lung cancer resection. J Clin Oncol 2004;22:3255-60.

38. Kased N, Erasmus JJ, Komaki R, Cox JD. Prognostic value of posttreatment [18F] fluorodeoxyglucose uptake of primary non-small cell lung carcinoma treated with radiation therapy with or without chemotherapy: a brief review. J Thorac Oncol 2008;3:534-8.

39. van Baardwijk A, Dooms C, van Suylen RJ, et al. The maximum uptake of (18)F-deoxyglucose on positron emission tomography scan correlates with survival, hypoxia inducible factor-1alpha and GLUT-1 in non-small cell lung cancer. Eur J Cancer 2007;43:1392-8.

40. Duhaylongsod FG, Lowe VJ, Patz EF, Jr., Vaughn AL, Coleman RE, Wolfe WG. Detection of primary and recurrent lung cancer by means of F-18 fluorodeoxyglucose positron emission tomography (FDG PET). J Thorac Cardiovasc Surg 1995;110:130-9; discussion 9-40.

41. Westeel V, Lebitasy MP, Mercier M, et al. [IFCT-0302 trial: randomised study comparing two followup schedules in completely resected non-small cell lung cancer]. Rev Mal Respir 2007;24:645-52.

42. Borst GR, Belderbos JS, Boellaard R, et al. Standardised FDG uptake: a prognostic factor for inoperable non-small cell lung cancer. Eur J Cancer 2005;41:1533-41.

43. Eschmann SM, Friedel G, Paulsen F, et al. Is standardised (18)F-FDG uptake value an outcome predictor in patients with stage III non-small cell lung cancer? Eur J Nucl Med Mol Imaging 2006;33:263-9.

44. Ichiya $Y$, Kuwabara $Y$, Sasaki $M$, et al. A clinical evaluation of FDG-PET to assess the response in radiation therapy for bronchogenic carcinoma. Ann Nucl Med 1996;10:193-200.

45. Vansteenkiste JF, Stroobants SG, Dupont PJ, et al. Prognostic importance of the standardized uptake value on (18)F-fluoro-2-deoxy-glucose-positron emission tomography scan in non-small-cell lung cancer: An analysis of 125 cases. Leuven Lung Cancer Group. J Clin Oncol 1999;17:3201-6.

46. Buck AK, Halter G, Schirrmeister $\mathrm{H}$, et al. Imaging proliferation in lung tumors with PET: 18F-FLT versus 18F-FDG. J Nucl Med 2003;44:1426-31.

47. Muzi M, Vesselle H, Grierson JR, et al. Kinetic analysis of 3'-deoxy-3'-fluorothymidine PET studies: validation studies in patients with lung cancer. J Nucl Med 2005;46:274-82.

48. Yamamoto Y, Nishiyama Y, Ishikawa S, et al. Correlation of 18F-FLT and 18F-FDG uptake on PET with Ki-67 immunohistochemistry in non-small cell lung cancer. Eur J Nucl Med Mol Imaging 2007;34:1610-6.

49. Yap CS, Czernin J, Fishbein MC, et al. Evaluation of thoracic tumors with $18 \mathrm{~F}$-fluorothymidine and 18F-fluorodeoxyglucose-positron emission tomography. Chest 2006;129:393-401.

50. Everitt S, Hicks RJ, Ball D, et al. Imaging cellular proliferation during chemo-radiotherapy: a pilot study of serial 18F-FLT positron emission tomography/computed tomography imaging for non-smallcell lung cancer. Int J Radiat Oncol Biol Phys 2009;75:1098-104.

51. Troost EG, Vogel WV, Merkx MA, et al. 18F-FLT PET does not discriminate between reactive and metastatic lymph nodes in primary head and neck cancer patients. J Nucl Med 2007;48:726-35.

52. Ishimori T, Saga T, Nagata Y, et al. 18F-FDG and 11C-methionine PET for evaluation of treatment response of lung cancer after stereotactic radiotherapy. Ann Nucl Med 2004;18:669-74.

53. Nettelbladt OS, Sundin AE, Valind SO, et al. Combined fluorine-18-FDG and carbon-11-methionine PET for diagnosis of tumors in lung and mediastinum. J Nucl Med 1998;39:640-7.

54. Tsuyuguchi N, Sunada I, Ohata K, et al. Evaluation of treatment effects in brain abscess with positron emission tomography: comparison of fluorine-18-fluorodeoxyglucose and carbon-11-methionine. Ann Nucl Med 2003;17:47-51.

55. van Waarde A, Jager PL, Ishiwata K, Dierckx RA, Elsinga PH. Comparison of sigma-ligands and metabolic PET tracers for differentiating tumor from inflammation. J Nucl Med 2006;47:150-4.

56. Murayama C, Harada N, Kakiuchi T, et al. Evaluation of D-18F-FMT, 18F-FDG, L-11C-MET, and 18F-FLT for monitoring the response of tumors to radiotherapy in mice. J Nucl Med 2009;50:290-5.

57. Yamaura G, Yoshioka T, Fukuda H, et al. O-[18F]fluoromethyl-L-tyrosine is a potential tracer for monitoring tumour response to chemotherapy using PET: an initial comparative in vivo study with deoxyglucose and thymidine. Eur J Nucl Med Mol Imaging 2006;33:1134-9. 
58. Vaupel P. Hypoxia and aggressive tumor phenotype: implications for therapy and prognosis. Oncologist 2008;13 Suppl 3:21-6.

59. Busk M, Horsman MR, Jakobsen S, Bussink J, van der Kogel A, Overgaard J. Cellular uptake of PET tracers of glucose metabolism and hypoxia and their linkage. Eur J Nucl Med Mol Imaging 2008;35:2294-303.

60. Dehdashti F, Mintun MA, Lewis JS, et al. In vivo assessment of tumor hypoxia in lung cancer with 60Cu-ATSM. Eur J Nucl Med Mol Imaging 2003;30:844-50.

61. Buck AK, Glatting G, Reske SN. Quantification of 18F-FDG uptake in non-small cell lung cancer: a feasible prognostic marker? J Nucl Med 2004;45:1274-6.

62. Cherk MH, Foo SS, Poon AM, et al. Lack of correlation of hypoxic cell fraction and angiogenesis with glucose metabolic rate in non-small cell lung cancer assessed by $18 \mathrm{~F}-\mathrm{Fluoromisonidazole} \mathrm{and} 18 \mathrm{~F}-$ FDG PET. J Nucl Med 2006;47:1921-6.

63. Dierckx RA, Van de Wiele C. FDG uptake, a surrogate of tumour hypoxia? Eur J Nucl Med Mol Imaging 2008;35:1544-9.

64. Dubois L LN, Janssen MHM, Secrest J, Windhorst AD, van Dongen GAMS, Kolb H, Oellers MC, Zhang J, Lambin P. Preclinical evaluation of [18F]-HX4, a novel promising hypoxia marker for PET imaging. Submitted 2010.

65. Eriksen JG, Steiniche T, Overgaard J. The influence of epidermal growth factor receptor and tumor differentiation on the response to accelerated radiotherapy of squamous cell carcinomas of the head and neck in the randomized DAHANCA 6 and 7 study. Radiother Oncol 2005;74:93-100.

66. Baumann M, Krause M. Targeting the epidermal growth factor receptor in radiotherapy: radiobiological mechanisms, preclinical and clinical results. Radiother Oncol 2004;72:257-66.

67. Bonner JA, Harari PM, Giralt J, et al. Radiotherapy plus cetuximab for squamous-cell carcinoma of the head and neck. N Engl J Med 2006;354:567-78.

68. Van Schaeybroeck S, Kyula J, Kelly DM, et al. Chemotherapy-induced epidermal growth factor receptor activation determines response to combined gefitinib/chemotherapy treatment in non-small cell lung cancer cells. Mol Cancer Ther 2006;5:1154-65.

69. Aerts HJ, Dubois L, Perk L, et al. Disparity between in vivo EGFR expression and 89Zr-labeled cetuximab uptake assessed with PET. J Nucl Med 2009;50:123-31.

70. van Baardwijk A, Bosmans G, Boersma L, et al. PET-CT-based auto-contouring in non-small-cell lung cancer correlates with pathology and reduces interobserver variability in the delineation of the primary tumor and involved nodal volumes. Int J Radiat Oncol Biol Phys 2007;68:771-8.

71. Wu K, Ung YC, Hornby J, et al. PET CT Thresholds for Radiotherapy Target Definition in Non-Small-Cell Lung Cancer: How Close Are We to the Pathologic Findings? Int J Radiat Oncol Biol Phys 2009.

72. Yu HM, Liu YF, Hou M, Liu J, Li XN, Yu JM. Evaluation of gross tumor size using CT, 18F-FDG PET, integrated 18F-FDG PET/CT and pathological analysis in non-small cell lung cancer. Eur J Radiol 2009;72:104-13.

73. Dahele M, Hwang D, Peressotti C, et al. Developing a methodology for three-dimensional correlation of PET-CT images and whole-mount histopathology in non-small-cell lung cancer. Curr Oncol 2008;15:62-9.

74. Nestle U, Kremp S, Grosu AL. Practical integration of [18F]-FDG-PET and PET-CT in the planning of radiotherapy for non-small cell lung cancer (NSCLC): the technical basis, ICRU-target volumes, problems, perspectives. Radiother Oncol 2006;81:209-25.

75. Caldwell CB, Mah K, Skinner M, Danjoux CE. Can PET provide the 3D extent of tumor motion for individualized internal target volumes? A phantom study of the limitations of CT and the promise of PET. Int J Radiat Oncol Biol Phys 2003;55:1381-93.

76. Grgic A, Nestle U, Schaefer-Schuler A, Kremp S, Kirsch CM, Hellwig D. FDG-PET-based radiotherapy planning in lung cancer: optimum breathing protocol and patient positioning--an intraindividual comparison. Int J Radiat Oncol Biol Phys 2009;73:103-11.

77. Nehmeh SA, Erdi YE. Respiratory motion in positron emission tomography/computed tomography: a review. Semin Nucl Med 2008;38:167-76. 
78. van Baardwijk A, Bosmans G, Boersma L, et al. Individualized radical radiotherapy of non-small-cell lung cancer based on normal tissue dose constraints: a feasibility study. Int J Radiat Oncol Biol Phys 2008;71:1394-401.

79. van Baardwijk A, Wanders S, Boersma L, et al. Mature Results of an Individualized Radiation Dose Prescription Study Based on Normal Tissue Constraints in Stages I to III Non-Small-Cell Lung Cancer. J Clin Oncol. 2010, in press

80. Cooper RA, Carrington BM, Loncaster JA, et al. Tumour oxygenation levels correlate with dynamic contrast-enhanced magnetic resonance imaging parameters in carcinoma of the cervix. Radiother Oncol 2000;57:53-9.

81. Foo SS, Abbott DF, Lawrentschuk N, Scott AM. Functional imaging of intratumoral hypoxia. Mol Imaging Biol 2004;6:291-305.

82. Zhao S, Kuge $\mathrm{Y}$, Mochizuki T, et al. Biologic correlates of intratumoral heterogeneity in $18 \mathrm{~F}-\mathrm{FDG}$ distribution with regional expression of glucose transporters and hexokinase-II in experimental tumor. J Nucl Med 2005;46:675-82.

83. Bentzen SM. Theragnostic imaging for radiation oncology: dose-painting by numbers. Lancet Oncol 2005;6:112-7.

84. Bentzen SM. Dose painting and theragnostic imaging: towards the prescription, planning and delivery of biologically targeted dose distributions in external beam radiation oncology. Cancer Treat Res 2008;139:41-62.

85. Das SK, Miften MM, Zhou S, et al. Feasibility of optimizing the dose distribution in lung tumors using fluorine-18-fluorodeoxyglucose positron emission tomography and single photon emission computed tomography guided dose prescriptions. Med Phys 2004;31:1452-61.

86. Galvin JM, De Neve W. Intensity modulating and other radiation therapy devices for dose painting. J Clin Oncol 2007;25:924-30.

87. Abramyuk A, Tokalov S, Zophel K, et al. Is pre-therapeutical FDG-PET/CT capable to detect high risk tumor subvolumes responsible for local failure in non-small cell lung cancer? Radiother Oncol 2009;91:399-404.

88. Aerts HJ, Bosmans G, van Baardwijk AA, et al. Stability of 18F-deoxyglucose uptake locations within tumor during radiotherapy for NSCLC: a prospective study. Int J Radiat Oncol Biol Phys 2008;71:1402-7.

89. Mees G, Dierckx R, Vangestel C, Van de Wiele C. Molecular imaging of hypoxia with radiolabelled agents. Eur J Nucl Med Mol Imaging 2009;36:1674-86.

90. Rasey JS, Koh WJ, Evans ML, et al. Quantifying regional hypoxia in human tumors with positron emission tomography of [18F]fluoromisonidazole: a pretherapy study of 37 patients. Int J Radiat Oncol Biol Phys 1996;36:417-28.

91. Sovik A, Malinen E, Skogmo HK, Bentzen SM, Bruland OS, Olsen DR. Radiotherapy adapted to spatial and temporal variability in tumor hypoxia. Int J Radiat Oncol Biol Phys 2007;68:1496-504.

92. Thorwarth D, Eschmann SM, Scheiderbauer J, Paulsen F, Alber M. Kinetic analysis of dynamic 18Ffluoromisonidazole PET correlates with radiation treatment outcome in head-and-neck cancer. BMC Cancer 2005;5:152.

93. Ataman OU, Barrett A, Filleron T, Kramar A. Optimization of follow-up timing from study of patterns of first failure after primary treatment. An example from patients with NSCLC: a study of the REACT working group of ESTRO. Radiother Oncol 2006;78:95-100.

94. Fournel P, Robinet G, Thomas P, et al. Randomized phase III trial of sequential chemoradiotherapy compared with concurrent chemoradiotherapy in locally advanced non-small-cell lung cancer: Groupe Lyon-Saint-Etienne d'Oncologie Thoracique-Groupe Francais de Pneumo-Cancerologie NPC 95-01 Study. J Clin Oncol 2005;23:5910-7.

95. Furuse K, Fukuoka M, Kawahara M, et al. Phase III study of concurrent versus sequential thoracic radiotherapy in combination with mitomycin, vindesine, and cisplatin in unresectable stage III nonsmall-cell lung cancer. J Clin Oncol 1999;17:2692-9. 
96. Zatloukal P, Petruzelka L, Zemanova $M$, et al. Concurrent versus sequential chemoradiotherapy with cisplatin and vinorelbine in locally advanced non-small cell lung cancer: a randomized study. Lung Cancer 2004;46:87-98.

97. Hoang JK, Hoagland LF, Coleman RE, Coan AD, Herndon JE, 2nd, Patz EF, Jr. Prognostic value of fluorine-18 fluorodeoxyglucose positron emission tomography imaging in patients with advancedstage non-small-cell lung carcinoma. J Clin Oncol 2008;26:1459-64.

98. Lee YJ, Cho A, Cho BC, et al. High tumor metabolic activity as measured by fluorodeoxyglucose positron emission tomography is associated with poor prognosis in limited and extensive stage small-cell lung cancer. Clin Cancer Res 2009;15:2426-32.

99. Fischer BM, Mortensen J, Langer SW, et al. PET/CT imaging in response evaluation of patients with small cell lung cancer. Lung Cancer 2006;54:41-9.

100. Yamamoto Y, Kameyama R, Murota M, Bandoh S, Ishii T, Nishiyama Y. Early assessment of therapeutic response using FDG PET in small cell lung cancer. Mol Imaging Biol 2009;11:467-72.

101. Onitilo AA, Engel JM, Demos JM, Mukesh B. Prognostic significance of 18 F-fluorodeoxyglucose positron emission tomography after treatment in patients with limited stage small cell lung cancer. Clin Med Res 2008;6:72-7.

102. Pandit N, Gonen M, Krug L, Larson SM. Prognostic value of [18F]FDG-PET imaging in small cell lung cancer. Eur J Nucl Med Mol Imaging 2003;30:78-84.

103. Statistics Netherlands. Gezondheid en zorg in cijfers 2009. Den Haag; 2009.

104. Meropol NJ, Schrag D, Smith TJ, et al. American Society of Clinical Oncology guidance statement: the cost of cancer care. J Clin Oncol 2009;27:3868-74.

105. Drummond MF, Sculpher M.J., Torrance G.W., O'brien B., Stoddart G.L. Methods for economic evaluation of health care programmes. Oxford: Oxford University Press; 2005. 

CHAPTER 11

Summary 
CHAPTER 11 
English summary 
CHAPTER 11 
Lung carcinoma is the third common malignancy in Europe and forms the major cause of cancer death. On basis of its histology, it is broadly divided in two main categories: non-small cell lung cancer (NSCLC) and small cell lung cancer (SCLC). Combined modality treatment with radiotherapy (RT) and chemotherapy is the treatment of choice for locally advanced NSCLC patients and for SCLC patients without distant metastases. Traditionally, anatomical imaging modalities are applied for the diagnosis and staging, as well as in the follow-up of lung cancer patients. Anatomical imaging with computed tomography (CT) is very accurate with respect to anatomical information in lung cancer, but it has limitations in certain other areas, such as the distinction between vital tumour and non-malignant tissue. Recently, molecular imaging techniques have been developed, which allow the visualization of molecular processes inside tumour and normal tissues in a non-invasive manner. In this thesis, different aspects of the potential of molecular imaging with positron emission tomography (PET) to optimize the combined modality treatment of lung cancer are assessed. Chapter 1 provides a general introduction to the epidemiology and treatment of lung cancer, and the imaging modalities that are used. Furthermore, the outline of the thesis is described. The thesis consists of 3 main parts, which are summarized below.

\section{Part I: FDG-PET-CT based target volume definition to optimize radiotherapy for locally advanced lung cancer}

In RT planning, a margin of tissue surrounding the macroscopic tumour is added in all patients to ensure that the area with potential microscopic tumour spread is covered by the radiation field. Microscopic disease spread, however, does not occur in all patients with NSCLC. In chapter 2, risk factors for the presence of microscopic disease spread were identified on pre-treatment PET-CT. The pathological specimens of 34 NSCLC patients who underwent lobectomy were examined microscopically for microscopic disease extension outside the macroscopic tumour. Image based risk factors for microscopic disease were identified and a prediction model was developed based on these factors. Mean tumour density on CT and tumour volume on CT were predictive for the presence of microscopic disease. Finally, these risk factors could allow tumour tailored adaptation of the dose to the tissue surrounding the macroscopic tumour. In this way, the balance between local tumour control and sparing of normal tissue in individual patients can be optimised.

In chapter 3 and 4 , selective irradiation of FDG-PET positive mediastinal lymph nodes in SCLC was evaluated. Traditionally, all mediastinal nodal areas are irradiated prophylactically, resulting in large treatment volumes. Selective nodal irradiation (SNI) on basis of CT has previously shown to result in an unacceptable amount (11\%) 
of isolated nodal failures in SCLC. On basis of the hypothesis that fluorodeoxyglucose (FDG)-PET based SNI would improve the coverage of involved lymph nodes, a planning study (chapter 3) was performed. Two conformal treatment plans were made with selective irradiation of involved lymph nodes, based on CT and on PET, respectively. A difference in the treatment plan resulting from PET- and CT-based SNI was seen in $24 \%$ of patients. Results of the subsequent prospective study are reported in chapter 4 , in which the safety of PET-based SNI in SCLC was evaluated in 60 patients. Two patients (3\%) experienced an isolated nodal failure. The median actuarial overall survival was 19 months. The treatment resulted in a remarkably low percentage (12\%) of grade III or worse oesophageal toxicity.

It was concluded that this low rate of isolated nodal failures and toxicity supports the use of PET-based SNI in stage I-III SCLC. Results should be re-evaluated, however, with the application of more conformal RT techniques because these are associated with altered penumbra characteristics.

\section{Part II: Value of FDG-PET-CT in the follow-up of locally advanced lung cancer}

In the second part of this thesis, the added value of FDG-PET-CT after curative intent therapy for locally advanced NSCLC was evaluated. In chapter 5, we prospectively evaluated whether a PET-CT 3 months after therapy can detect potentially curable progression in 100 NSCLC patients treated with (chemo-)radiation. Progression amenable for retreatment with curative intent was detected in a small proportion of patients (2\%), and only in the subgroup that did not have symptoms at the time of scanning. This progression was only detected with PET, not with CT alone.

The results of this study formed the basis for the economic evaluation described in chapter 6. The long-term cost-effectiveness of a PET-CT based follow-up was compared with the "usual" follow-up with either a CT scan or repeated chest X-rays. Cost-effectiveness of the different follow-up strategies was expressed in incremental cost-effectiveness ratios (ICERs), calculating the incremental costs per quality adjusted life year (QALY) gained. A PET-CT scan 3 months after treatment turned out to be potentially cost-effective, costing $€ 69.086$ per QALY gained compared to conventional follow-up. As the advantage was confined to the asymptomatic patients, performing a PET-CT in this group only is probably as effective and more costeffective ( $€ 42.265$ per QALY gained). CT-based follow-up was only slightly more effective than conventional follow-up, resulting in an ICER of $€ 264.033$ per QALY gained.

This part of the thesis thus indicates that a PET-CT scan 3 months after (chemo)radiotherapy with curative intent is a potentially cost-effective follow-up method, and is more cost-effective than CT alone. On basis of the currently avail- 
able evidence, it is therefore suggested that an FDG-PET-CT scan 3 months after therapy is to be preferred above CT alone. It is worthwhile to perform additional research to reduce the uncertainty regarding the decision which imaging to perform in the follow-up of NSCLC.

\section{Part III: Novel PET tracers for the non invasive imaging of tumour characteristics}

Part III of this thesis consists of two trials evaluating the safety of new PET-tracers directed at two different biological characteristics of cancer cells. Chapter 7 reports the results of a phase I trial in incurable cancer patients evaluating $\left[{ }^{18} \mathrm{~F}\right] \mathrm{HX} 4$, a recently developed hypoxia marker of the 2-nitroimidazole family. A two-dose step study design was used, with 3 patients included in each dose step. PET-CT images of the largest tumour site were acquired at 30,60 and 120 minutes after injection. No toxicity was observed in any of the patients at either dose level. The median tumour to muscle ratio (TMR) at 120 minutes post-injection was 1.40 (range: 0.63-1.98). In conclusion, $\left[{ }^{18} \mathrm{~F}\right] \mathrm{HX} 4$ PET imaging is not associated with any toxicity. Trials are planned to determine the optimal time point of imaging, as in preclinical studies tumour to blood ratios up to 7.6 can be reached when imaging is performed at later time points post-injection.

In chapter 8 , the safety of Zirconium-89 $\left({ }^{89} \mathrm{Zr}\right)$ labelled cetuximab, an antibody against the epidermal growth factor receptor, was evaluated in 7 patients with incurable cancer. The safety of two different dose schedules was tested. Labelled cetuximab administration was preceded by a standard loading dose of unlabelled cetuximab. PET-CT scans were acquired on day 4, 5 and 6 (step 1) and 5, 6, 7 (step 2) post injection. Five of six patients who completed the study experienced skin toxicity, a known side-effect from cetuximab administration. No additional toxicity was reported. The maximal tumour to blood ratio (TBR) was 1.6 (range: 0.42-1.60). Future trials are needed to define optimal imaging conditions, including the appropriate loading dose of unlabelled cetuximab. In the end, visualization and quantification of tumour uptake of cetuximab with PET before and during (chemoJradiotherapy would have major benefit in the appropriate selection of patients for cetuximab treatment.

Finally, part IV of this thesis provides a discussion on the role of PET in the combined modality therapy of lung cancer. In chapter $\mathbf{9}$, the available literature regarding this subject is reviewed, while chapter $\mathbf{1 0}$ describes the major results of this thesis in the context of the currently existing evidence. Furthermore, perspectives for future research to further improve outcome in locally advanced lung cancer are highlighted. 
In conclusion, FDG-PET provides several opportunities to improve the combined modality treatment of locally advanced lung cancer, both in the field of defining the volume to be treated with RT, and in the follow-up after treatment. Prospective randomized trials are encouraged in this field. Tracers other than ${ }^{18} \mathrm{FDG}$ offer potential to select patients with the highest probability to benefit from treatment with hypoxic radio-sensitizers or anticancer agents targeted at receptors on the surface of cancer cells, but additional research is needed before these tracers can be implemented in clinical practice. 
Nederlandse samenvatting 
CHAPTER 11 
Longkanker is de derde meest voorkomende maligniteit in Europa en is de belangrijkste oorzaak van kankersterfte. Op basis van de celkenmerken wordt longkanker ruwweg ingedeeld in 2 hoofdcategorieën: het niet-kleincellig longcarcinoom (nonsmall cell lung carcinoma, NSCLC) en het kleincellig longcarcinoom (small cell lung carcinoma, SCLC).

Gecombineerde behandeling met bestraling (radiotherapie, RT) en chemotherapie is de behandeling van keuze voor patiënten met lokaal gevorderd NSCLC of SCLC zonder uitzaaiingen op afstand. Van oudsher worden anatomische beeldvormingstechnieken gebruikt, zowel voor de diagnostiek en stadiëring van longkanker als voor de evaluatie na de behandeling. Anatomische beeldvorming met "computed tomography", ofwel CT scans, is accuraat wat betreft anatomische informatie, maar kent beperkingen op andere gebieden, zoals het onderscheid tussen vitaal tumorweefsel en niet-kwaadaardig weefsel. Meer recent zijn moleculaire beeldvormingstechnieken ontwikkeld die het mogelijk maken moleculaire processen binnen de tumor en normale weefsels te visualiseren op een niet-invasieve manier. Positron emissie tomografie (PET) is een bekende moleculaire beeldvormingstechniek. PET maakt het mogelijk de verdeling van een radioactieve stof in het lichaam driedimensionaal in beeld te brengen. Voor de beeldvorming van kanker wordt verreweg het meest gebruik gemaakt van radioactief gelabelde suiker $\left({ }^{18} \mathrm{~F}\right.$-fluorodeoxyglucose, FDG). Kankercellen gebruiken meer suiker dan de meeste niet-kwaadaardige cellen, en dit verschil in suikermetabolisme resulteert in een verhoogde opname van FDG ter plaatse van de tumor. Ook andere moleculen kunnen radioactief worden gemaakt door ze te binden aan een radioactieve tracer. Dit maakt het mogelijk om bepaalde eigenschappen van een tumor te visualiseren die geassocieerd zijn met de agressiviteit van de tumor en de te verwachten respons op antikankerbehandeling. In dit proefschrift werden verschillende mogelijkheden onderzocht om de gecombineerde modaliteitsbehandeling van longkanker te optimaliseren door middel van moleculaire beeldvorming met PET. Hoofdstuk 1 geeft een algemene introductie in de epidemiologie en de behandeling van longkanker en de beeldvormingstechnieken die worden gebruikt. Ook wordt een overzicht gegeven van de opbouw van het proefschrift. De drie hoofdonderdelen van het proefschrift worden hieronder samengevat.

\section{Deel 1: Definitie van het doelvolume op basis van FDG-PET-CT ter optimalisatie van de radiotherapie voor locaal uitgebreide longkanker}

Bij het plannen van de bestralingsbehandeling wordt altijd een marge weefsel rondom de macroscopisch zichtbare tumor meegenomen om te verzekeren dat het 
gebied met mogelijk microscopische tumoruitbreiding wordt meebestraald. Microscopische ziekte-uitbreiding is echter slechts in een deel van de patiënten met NSCLC aanwezig. In hoofdstuk 2 werden risicofactoren voor de aanwezigheid van microscopische tumoruitbreiding vastgesteld aan de hand van een PET-CT die voor de behandeling werd verricht bij 34 NSCLC patiënten die een lobectomie ondergingen. De pathologische preparaten van deze patiënten werden microscopisch onderzocht op ziekte-uitbreiding buiten de macroscopische tumor. Risicofactoren op PET en/of CT werden geïdentificeerd en op basis van deze factoren werd een predictiemodel ontwikkeld. De gemiddelde tumordichtheid op CT en het tumorvolume op CT waren predictief voor de aanwezigheid van microscopische ziekte. Uiteindelijk zouden deze risicofactoren kunnen worden gebruikt om de bestralingsdosis op het weefsel rondom de macroscopische tumor per individu aan te passen. Op deze manier kan het evenwicht tussen lokale tumorcontrole en het sparen van het normale weefsel in elke individuele patiënt worden geoptimaliseerd.

In hoofdstuk 3 en 4 werden de resultaten geëvalueerd van selectieve klierbestraling van FDG-PET positieve mediastinale klieren in SCLC. Bij een conventionele bestraling worden alle mediastinale klierstations profylactisch bestraald, resulterend in grote bestralingsvolumes. In NSCLC is inmiddels aangetoond dat selectieve bestraling van klieren die positief zijn op CT of PET veilig is. Selectieve bestraling van CT-positieve klieren leidde in SCLC echter tot een onacceptabele hoeveelheid (11\%) geïsoleerde klierrecidieven. Op basis van de hypothese dat FDG-PET betrouwbaarder is dan CT voor de detectie van positieve klieren in SCLC, werd in hoofdstuk 3 een planning studie uitgevoerd. Er werden twee conformele bestralingsplannen ontwikkeld, één voor selectieve bestraling van CT-positieve klieren, de andere voor PET-gebaseerde selectieve klierbestraling. In $24 \%$ van de patiënten werd een verschil gevonden tussen de bestralingsplannen voor PET- en CT gebaseerde klierbestraling. Vervolgens werd een prospectieve studie uitgevoerd welke beschreven wordt in hoofdstuk 4. In deze prospectieve studie werd de veiligheid van PET-gebaseerde selectieve klierbestraling geëvalueerd in 60 SCLC patiënten. Twee van hen (3\%) ontwikkelden een geïsoleerd klierrecidief. De mediane overleving bedroeg 19 maanden. De behandeling resulteerde in een opvallend laag percentage patiënten met een graad 3 of hogere slokdarmtoxiciteit.

Het lage aantal geïsoleerde klierrecidieven samen met een lage toxiciteit ondersteunt de toepassing van PET-gebaseerde selectieve klierbestraling in stadium I-III SCLC. Indien in de toekomst meer conformele bestralingstechnieken worden toegepast zullen resultaten opnieuw moeten worden geëvalueerd aangezien deze nieuwe technieken gepaard gaan met een andere dosisverdeling rondom het doelvolume van de radiotherapie. 


\section{Deel II: Waarde van FDG-PET in de evaluatie na behandeling van het lokaal uitgebreide longcarcinoom}

In het tweede deel van het proefschrift werd de toegevoegde waarde onderzocht van een FDG-PET-CT na curatieve behandeling van het lokaal uitgebreide longcarcinoom. In hoofdstuk 5 werd bij 100 NSCLC patiënten prospectief beoordeeld of een PET-CT 3 maanden na de behandeling progressie kan detecteren die in aanmerking komt voor herbehandeling met curatieve opzet. In een klein aandeel (2\%) van de patiënten werd progressie vastgesteld die in opzet curatief kon worden behandeld. Dit was alleen het geval bij de patiënten die asymptomatisch waren op het moment van de PET-CT scan. Progressie werd bij deze patiënten alleen gedetecteerd met PET, niet met uitsluitend de CT-scan.

De resultaten van deze studie vormden de basis van de economische evaluatie die wordt beschreven in hoofdstuk 6. In deze studie werd de kosteneffectiviteit op de lange termijn vergeleken van verschillende follow-up strategieën: de PET-CT gebaseerde follow-up, een follow-up met CT-scan, of een conventionele follow-up waarbij alleen een $\mathrm{X}$-thorax wordt vervaardigd. De kosteneffectiviteit van de verschillende strategieën werd uitgedrukt in zogenaamde incrementele kosteneffectiveitsratio's (ICER's). Deze ratio geeft de additionele kosten aan per gewonnen levensjaar gecorrigeerd voor de kwaliteit van leven gedurende dit jaar (quality adjusted lifeyear, QALY). Uit deze analyse kon worden afgeleid dat een PET-CT scan 3 maanden na behandeling een potentieel kosteneffectieve methode is vergeleken met conventionele follow-up, resulterend in een ICER van $€ 69.086$ per gewonnen QALY. Aangezien het voordeel beperkt was tot de groep asymptomatische patiënten, is het waarschijnlijk even effectief en meer kosteneffectief om alleen een PET-CT te verrichten in deze patiëntengroep ( $€ 42.265$ per QALY). CT-gebaseerde follow-up was in geringe mate effectiever dan conventionele follow-up, resulterend in een ICER van € 264.033 per QALY.

Concluderend geeft deel II van dit proefschrift aan dat een PET-CT 3 maanden na curatieve (chemo)radiotherapie een potentieel kosteneffectieve methode is voor de evaluatie na behandeling, en meer kosteneffectief is dan alleen een CT-scan. Op basis van het beschikbare bewijs is daarom een FDG-PET-CT te prefereren boven alleen een CT-scan 3 maanden na behandeling. Aanvullend onderzoek is zinvol ter reductie van de onzekerheid in de besluitvorming rond beeldvorming in de followup. 


\section{Deel III: Nieuwe PET-tracers voor de niet-invasieve beeldvorming van tumoreigenschappen}

Deel III van dit proefschrift bestaat uit 2 studies die de veiligheid van nieuwe PETtracers evalueren, beide gericht op specifieke biologische eigenschappen van kankercellen. Hoofdstuk 7 beschrijft de resultaten van een fase I studie met ${ }^{18} \mathrm{~F}-\mathrm{HX} 4$ in incurabele kankerpatiënten. ${ }^{18} \mathrm{~F}-\mathrm{HX} 4$ is een recent ontwikkelde radioactieve merkstof voor cellen met zuurstoftekort (hypoxie), behorend tot de familie van 2nitroimidazolen. Er werd een studieopzet met 2 dosisstappen gebruikt. In elke stap werden 3 patiënten geïncludeerd. PET-CT beelden van de grootste tumorlokalisatie werden verkregen op 30, 60 en 120 minuten na injectie van ${ }^{18} \mathrm{~F}-\mathrm{HX} 4$. In geen van de geïncludeerde patiënten werd toxiciteit geobserveerd. De mediane tumor-spier ratio 120 minuten na injectie was 1.40 (range: 0.63-1.98). Uit deze studie kan worden geconcludeerd dat PET met ${ }^{18} \mathrm{~F}-\mathrm{HX} 4$ niet gepaard gaat met toxiciteit. Momenteel worden studies opgezet met als doel het optimale tijdstip voor de PET scan te bepalen. In preklinische studies met proefdieren zijn tumor-bloed ratio's tot een waarde van 7.6 gedetecteerd indien op latere tijdstippen na injectie werd gescand. In hoofdstuk 8 wordt de veiligheid geëvalueerd van cetuximab gelabeld met de radioactieve tracer Zirconium-89 $\left({ }^{89} \mathrm{Zr}\right)$. Cetuximab is een antilichaam gericht tegen de epidermale groeifactor receptor (EGFR). Activatie en overexpressie van EGFR in kankercellen is geassocieerd met de ontwikkeling van resistentie voor radiotherapie en chemotherapie. De toxiciteit van twee verschillende doseringsschema's van ${ }^{89} \mathrm{Zr}$ cetuximab werd onderzocht. In beide schema's werd de dosering van het gelabelde cetuximab voorafgegaan door een standaard "laaddosis" ongelabeld cetuximab. Op dag 4, 5 en 6 (stap 1), of dag 5, 6 en 7 (stap 2) na injectie werden PET-CT beelden verkregen. Vijf van de zes patiënten ontwikkelden huidtoxiciteit, een bekende bijwerking van cetuximab. Additionele toxiciteit ten gevolge van de toediening van het gelabelde cetuximab werd niet geobserveerd. De maximale tumor-bloedratio was 1.6 (range: 0.42-1.60). Toekomstige studies zijn nodig om de optimale beeldvormingsomstandigheden te definiëren, waaronder de optimale laaddosis ongelabeld cetuximab. Uiteindelijk kan de visualisatie en de kwantificatie van cetuximabopname door de tumor met PET voor en tijdens (chemo)radiotherapie een belangrijke invloed hebben op een juiste selectie van patiënten voor behandeling met cetuximab.

Tenslotte wordt in deel IV van dit proefschrift de rol van PET in de gecombineerde modaliteitsbehandeling van longkanker bediscussieerd. Hoofdstuk 9 bestaat uit een review van de beschikbare literatuur over dit onderwerp. Hoofdstuk $\mathbf{1 0}$ beschrijft de belangrijkste resultaten van het proefschrift in het licht van het momenteel beschikbare bewijs. Hiernaast worden toekomstperspectieven beschreven ten aanzien van verder wetenschappelijk onderzoek. 
Concluderend biedt FDG-PET verschillende mogelijkheden om de gecombineerde modaliteitsbehandeling van het lokaal gevorderde longcarcinoom te verbeteren. Dit geldt zowel op het gebied van het definiëren van het doelgebied voor radiotherapie, als voor de evaluatie na de behandeling. Prospectieve gerandomiseerde studies op dit gebied worden aanbevolen. Andere tracers dan ${ }^{18}$ FDG bieden de mogelijkheid om patiënten te selecteren met de hoogste kans op baat van behandeling met radiosensitizers gericht op hypoxie of middelen gericht tegen receptoren op het oppervlak van kankercellen. Aanvullend wetenschappelijk onderzoek is echter noodzakelijk voordat deze tracers in de klinische praktijk kunnen worden geïntroduceerd. 

Appendices 
APPENDICES 
Dankwoord 
APPENDICES 
Terugkijkend op 3 jaar onderzoek moet ik toch echt concluderen dat de tijd is omgevlogen. Dit wil natuurlijk niet zeggen dat alle onderzoeksresultaten zonder slag of stoot tot stand zijn gekomen. Ik wil dan ook iedereen bedanken die direct of indirect hieraan heeft bijgedragen.

In de eerste plaats de patiënten, in het bijzonder zij die hebben deelgenomen aan de studies uit het derde deel van het proefschrift. In hun verlangen een bijdrage te leveren aan de strijd tegen longkanker bezochten ze ondanks hun slechte prognose herhaaldelijk het ziekenhuis voor injecties, scans of bloedafnames in het kader van wetenschappelijk onderzoek.

De leden van de beoordelingscommissie, prof. dr. E. Wouters, dr. B. Brans, prof. dr. Y. Lievens en prof. dr. J. van Meerbeeck, wil ik hartelijk danken voor het beoordelen van dit proefschrift en de bereidheid plaats te nemen in de promotiecommissie.

Dan de 3 teamleden die me de afgelopen jaren heel wat kneepjes van het wetenschapsvak hebben bijgebracht: promotoren prof dr. De Ruysscher en prof. dr. Lambin, en copromotor dr. Boersma. Dirk, er zijn tig redenen te noemen waarom ik me gelukkig mag prijzen je eerste "promovenda" te zijn. De belangrijkste is natuurlijk je ongebreidelde enthousiasme voor onderzoek, gepaard gaande met een voor het oor en oog onuitputtelijke literatuurkennis ("de winst in die studie was ergens in de orde van $8.63 \% .$. ") en ideeën. Daarnaast heb ik veel baat gehad bij onze synchroon afgestemde biologische klok, waardoor ik je ook in de latere "kantoor"uren nog wel te pakken kreeg om de meer of minder ingewikkelde vraagstelling te bespreken.

Philippe, een kort treffen in de wandelgang binnen Maastro, op een congres of tijdens een personeelsuitje was meestal al voldoende om weer vooruit te kunnen met een vervolgonderzoek of compleet nieuw studieonderwerp. Dank voor de geboden mogelijkheid mijn specialisatie te onderbreken voor het verrichten van promotieonderzoek.

Liesbeth, superbedankt dat je me hebt gestrikt voor de KWF-studie! Niet alleen omdat het me een ontzettend interessant project heeft opgeleverd, maar temeer omdat ik jou als leermeester erbij kreeg. Ondanks je volle agenda wist je bij vragen altijd wel ergens een plekje te creëren. Je "down to earth" benadering van elk probleem leidde er altijd toe dat ik met een concreet stappenplan en vol goede moed de deur uitliep. Je constructieve commentaar op menig manuscript, vaak uitgedrukt in een prikkelende vraag, was bijna zonder uitzondering terecht.

De radiotherapeut-oncologen wil ik bedanken voor hun interesse en bemoedigende woorden bij de koffieautomaat. Angela, bedankt voor je vertouwen in mij als jouw "opvolger". Ik heb veel gehad aan je praktische tips in elke fase van het promotietraject, van het schrijven van $\mathrm{m}^{\prime} \mathrm{n}$ eerste abstract tot advies over de hapjes bij de 
receptie! Jos de Jong: "Het belangrijkste wat je leert tijdens een promotietraject is nee zeggen." Ik heb me destijds niet gerealiseerd dat deze opmerking zo waar zou blijken. Rinus, jouw vrolijke noot was erg welkom tijdens de eenzame dagen achter de computer. Jos Jager, de herhaaldelijke vraag over wanneer ik weer terugkwam in de kliniek stelde je uit gemis, niet vanuit opleidingstechnisch oogpunt toch?

Datamanagement: ik daag jullie uit één overeenkomst te vinden tussen jullie georganiseerde bureaus en het mijne. Chantal, dank voor je toewijding bij het ontwikkelen, verzamelen en bewaken van de CRF's! Madelon, mijn statussen mogen nu echt terug naar het archief! Cary, dank voor het delen van je knoppenkennis in SPSS. Ruud, bewonderenswaardig hoe je elk "statistiekvraagje" weer op een doorzichtige wijze weet te doorgronden.

(Research)Laboranten, Marije, Daisy, dank voor jullie hulp bij het intekenen. Claudia, je spoorzoektocht naar verdwenen PET-CT's in de wirwar van digitale archieven was geweldig. "Groep CT-PET", jullie zagen me liever gaan dan komen het afgelopen jaar! Bedankt voor jullie flexibiliteit en de goede zorgen voor mijn studiepatiënten!

Het is een (niet overbodige) luxe een rij klinisch fysici op kruipafstand van je werkkamer te hebben. Geert en Lars, jullie onderwijscapaciteiten maken het erg verleidelijk even binnen te lopen voor een lesje fysica voor dummies. Geert, je mapje "promotie_info" is inmiddels een wijd verbreid begrip. Michel, ook jouw deur had een lage drempel met betrekking tot 4D-scans en zirconium, maar ook voor luchtigere onderwerpen. Ik zie uit naar het volgende hooikoortsseizoen!

De vruchtbare meetings van de researchgroep thorax waren een welkome afleiding op de dinsdagmiddag. Steven en Hugo, ik denk dat de kruisbestuiving kliniek-fysica haar vruchten wel heeft afgeworpen. Volgens mij kunnen jullie die longtumor nu ook zonder mijn hulp vinden! Wouter, kom gerust wat vaker langswandelen als het saai wordt op de derde verdieping. Marco TrueD, hoe vind je de plaatjes?? Nooit geweten dat een man zoveel kennis kan hebben van kleurencombinaties, in het bijzonder magenta en rainbowscale! Ludwig, bedankt voor je snelle en bruikbare bijdrage vanuit het Maastro-lab. Bart, de spaarzame minuten freetime op Flims waren erg gezellig! Bedankt dat je me hebt betrokken bij de PET-cursus.

Janneke, HTA, KEA, QALY, ICER, CEAC, EVPI (ik prefereer nog altijd de uitspraak efpi) waren tot 2 jaar geleden zo goed als abracadabra voor me. Bedankt voor de manier waarop je me in afzienbare tijd wegwijs heb gemaakt in de wereld die health economics heet. Je enthousiasme heeft me aangestoken, kom gerust een keertje langs straks in Londen! 
Brigitte, Tineke en Hannie, verbeeldde ik het me of trokken jullie echt wit weg als ik binnenkwam? Laten we zeggen dat het niet alleen mijn schuld was dat het inplannen van die afspraken zo lang duurde (hoe heette dat systeem ook alweer?). DA's, in het bijzonder Félice en Lizette, dank dat jullie met gevaar voor eigen leven alle bloedbuisjes veilig hebben verzameld en afgeleverd. Rianne, bedankt voor de ondersteuning bij het verzamelen en verzenden van alle benodigde correspondentie!

Verschillende afdelingen van het $\mathrm{MUMC}^{+}$hebben een belangrijke rol gespeeld in het realiseren van de verschillende studies. Ten eerste de afdeling longziekten: AnneMarie Dingemans, Monique Hochstenbag, Arne van Belle en de onco-verpleegkundigen, dank dat jullie tussen de bedrijven door er toch aan dachten patiënten te selecteren voor mijn onderzoek. Anne-Marie, ook dank voor je bijdrage aan vrijwel alle manuscripten in dit proefschrift. Longchirurgen, dankzij het accuraat plakken van dé gele sticker kwam elk preparaat veilig aan op de pathologie.

Erik Vegt, Boudewijn Brans en Pascal Kempers van nucleaire geneeskunde, dank voor jullie inzet bij de opzet, uitvoering en beoordeling van de verschillende studies, en de hulp bij het verzamelen van "mooie plaatjes".

Robert-Jan van Suylen, ik denk dat het niet ondanks, maar dankzij de bedwelmende gaslucht en sterke verhalen is geweest dat we zo'n onbeschrijflijke berg werk hebben verzet. Die longpathologie is zowaar bijna net zo interessant als je wijnkelder! Roy Lalisang, dank voor je inclusie van patiënten voor deel III van dit proefschrift!

Longartsen van de IKL-regio, dank voor de prettige samenwerking en de interesse in de onderzoeksresultaten. Nucleaire geneeskunde van het Atrium, bedankt voor jullie inzet bij het doorsturen van alle scans.

Co-investigators van "de KWF-studie": Christian Siedschlag, Kenneth Gilhuijs, Joep Stroom, Maddalena Rossi van het NKI-AvL en Hans Blaauwgeers van het OLVG, er is wat creativiteit voor nodig om duizenden coupes tussen randstad en Maastricht te vervoeren, maar we mogen trots zijn op het eindresultaat!

Dank aan de collega's in het VU medisch centrum, Guus van Dongen, Danielle Vugts, Bert Windhorst en Ronald Boellaard, voor hun onmisbare bijdrage aan de fase-I studies. Guus, bedankt voor je kritische en snelle beoordeling van de manuscripten.

Mijn kamergenoten, AIOS! Er was geen betere plek te bedenken om me elke ochtend (geen grappen aub) achter m'n compu te nestelen dan tussen jullie gekakel. De positieve correlatie tussen het aantal geproduceerde decibellen en mijn productiviteit staat onomstotelijk vast. Jeroen, Angela en Véronique, dank voor het delen van jullie ervaring als doorgewinterde assistent. Myrte, ik zal je woonplaats hier niet uitspellen, maar de afstand tot Mestreech vormt gelukkig geen barrière voor onze 
vriendschap. Bart en Torsten, testosteron en Duitse humor hebben me regelmatig tot tranen toe laten lachen. Gelukkig is jullie wijnleverancier in het zuiden blijven plakken! Inge, David (onze enige haan), Kitty, Maaike, Patricia en Ada, thanks voor het delen van alledaagse beslommeringen uit de kliniek. Succes met het veroveren van mijn privilegeplekje aan het raam. Ik zie uit naar februari!

$H \& H$, Haike en Hiske, er zijn evenveel overeenkomsten als verschillen in onze karakters, maar toch staan onze neuzen altijd dezelfde kant op, net zoals vandaag! Haike, je bent in alles net zo fanatiek als op het hockeyveld, en dat maakt je zowel een topcollega als -vriendin! His, jouw neus werkt bovengemiddeld voor de detectie van geur, maar ook voor mijn humeur! Thanks voor je relativerende woorden.

De boog kan niet altijd gespannen zijn, en gelukkig zijn er veel mensen buiten het werk die me daaraan herinneren. Nyneve, ik stond na mijn bestuursjaar al met één been in het ziekenhuis toen jullie me vroegen mede-oprichter te worden van ons genootschap. Ik heb nooit spijt gehad dat ik hier volmondig ja op heb gezegd. Thanks voor jullie blijvende interesse in de nyneve-oma. Nu alle afstudeerborrels achter de rug zijn wordt het tijd voor andere redenen tot feest. Gelukkig zijn we goed op weg! Tine, mede dankzij jou ben ik ook lichamelijk in conditie gebleven.

De geneeskundeclan, Geertje, Lilian, Leonie en Milou, de spinazie-met-spekjes (hoeveel gram?)-pasta heeft plaatsgemaakt voor hoogculinaire gerechten danwel pogingen ertoe, en ook de $\mathrm{AH}$-huiswijn is omgeruild voor iets beters, denken we tenminste. Gelukkig blijven de gespreksonderwerpen opvallend dezelfde en nemen we geen blad voor onze mond!

Anna, het letterlijk midden in de nacht elkaars studentenkamer binnenvallen is omgezet in een figuurlijk dag en nacht er voor elkaar zijn. Super!

Pap en mam, "words cannot express...". Wat ik wel kan zeggen is dat ik dolblij ben jullie dochter te zijn! Jullie vertrouwen en de geboden veiligheid en vrijheid maken dat ik de stappen kan zetten die ik zet. Tijs en Marjolein, jullie rust is als een oase voor me! Hanne, je bent nu al m'n superheldin. PimMel (!), je bent en blijft m'n kleine broertje, maar wel een van wie ik heel veel kan leren!

Cilia, bedankt voor je interesse en de gezellige bezoekjes aan Eijsden! Theo en Ine, een weekendje bij jullie voelt als een weekendje thuis!

Andor..., jouw levensvreugde straalt uit je hele doen en laten. Just what I need! Ik ben er supertrots op dat ik met de enige professionele Bourgondiër mag samenleven. Je weet het, ik vergeet het vaak te zeggen maar de liefste ben jij (GM 2009). Thanks voor dat je bent wie je bent! 
Curriculum vitae 
APPENDICES 
Judith van Loon was born on the $29^{\text {th }}$ of February, 1980, in Venray, the Netherlands and grew up in Overloon. In 1998, she graduated cum laude from the Raayland College in Venray. In the same year, she started her medical training at the Maastricht University. She was member of the administrative board of the Medical Interfacultary Conference ("MIC") in 2001. In the academic year 2002-2003, she was treasurer of the Student Rowing Club "M.S.R.V. Saurus". Her final internship was performed at the radiation oncology department of the Netherlands Cancer Institute - Antoni van Leeuwenhoek Hospital, Amsterdam. After obtaining her medical degree in November 2005, she started her specialty training in radiation oncology at the Maastro Clinic (dr. J. Jager and prof.dr. Ph. Lambin). During her residency, she got the opportunity to perform the PhD project described in this thesis, for which she suspended her training position for the period of three years. From August 2010, she continued her residency which she will finish at the end of 2013. She will perform an elective at the National Institute for Health and Clinical Excellence (NICE) in London for the period of November 2010 until January 2011 on clinical effectiveness and costs of innovations in radiation oncology.

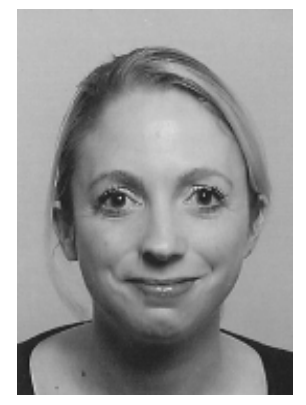


APPENDICES 
Publications and grants 
APPENDICES 


\section{Publications}

J. van Loon, M. Janssen, M. Öllers, H. Aerts, L. Dubois, M. Hochstenbag, A.C. Dingemans, R. Lalisang, B. Brans, B. Windhorst, G. van Dongen, H. Kolb, J. Zhang, D. De Ruysscher, P. Lambin;

PET imaging of hypoxia using $\left[{ }^{18} \mathrm{~F}\right] \mathrm{HX} 4$ : a phase I trial. Eur J Nucl Med Mol Imaging. 2010 Apr 6.

J. van Loon, J. Grutters, R. Wanders, L. Boersma, A.C. Dingemans, G. Bootsma, W. Geraedts, C. Pitz, J. Simons, B. Brans, G. Snoep, M. Hochstenbag, P. Lambin and D. De Ruysscher;

${ }^{18}$ FDG-PET-CT in the follow-up of non-small cell lung cancer patients after radical radiotherapy with or without chemotherapy: An economic evaluation. Eur J Cancer. 2010 Jan;46(1):110-9.

J. van Loon, D. De Ruysscher, R. Wanders, L. Boersma, J. Simons, M. Öllers, A.C. Dingemans, M. Hochstenbag, G. Bootsma, W. Geraedts, C. Pitz, J. Teule, A. Rhami, W. Thimister, G. Snoep, C. Dehing-Oberije, P. Lambin;

Selective nodal irradiation on basis of ${ }^{18}$ FDG-PET scans in limited disease small cell lung cancer: A prospective study. Int J Radiat Oncol Biol Phys. 2010 Jun; 77(2): 329336

C. Siedschlag, J. van Loon, A. van Baardwijk, M. Rossi, R. van Pel, J. Blaauwgeers, R. van Suylen, L. Boersma, J. Stroom, K. Gilhuijs;

Analysis of the relative deformation of lung lobes before and after surgery in patients with NSCLC. Phys Med Biol. 2009 Sep 21;54(18):5483-92.

S. Petit, H. Aerts, J. van Loon, C. Offermann, R. Houben, B. Winkens, M. Öllers, P. Lambin, D. De Ruysscher, A. Dekker;

Metabolic control probability in tumour subvolumes or how to guide tumour dose redistribution in non-small cell lung cancer (NSCLC): an exploratory clinical study. Radiother Oncol. 2009 Jun;91(3):393-8.

H. Aerts, A. van Baardwijk, S. Petit, C. Offermann, J. van Loon, R. Houben, A. Dingemans, R. Wanders, L. Boersma, J. Borger, G. Bootsma, W. Geraedts, C. Pitz, J. Simons, B. Wouters, M. Öllers, P. Lambin, G. Bosmans, A. Dekker, D. De Ruysscher; Identification of residual metabolic-active areas within individual NSCLC tumours using a pre-radiotherapy ${ }^{18}$ Fluorodeoxyglucose-PET-CT scan. Radiother Oncol. 2009 Jun;91(3):386-92. 
J. van Loon, J. Grutters, R. Wanders, L. Boersma, M. Öllers, A. Dingemans, G. Bootsma, W. Geraedts, C. Pitz, J. Simons, S. Abdul Fatah, G. Snoep, M. Hochstenbag, P. Lambin, D. De Ruysscher;

Follow-up with ${ }^{18}$ FDG-PET-CT after radical radiotherapy with or without chemotherapy allows the detection of potentially curable progressive disease in non small cell lung cancer patients: A prospective study. Eur J Cancer. 2009 Mar;45(4):588-95.

J. van Loon, C. Offermann, G. Bosmans, R. Wanders, A. Dekker, J. Borger, M. Öllers, A. Dingemans, A. van Baardwijk, J. Teule, G. Snoep, M. Hochstenbag, R. Houben, P. Lambin, D. De Ruysscher;

${ }^{18}$ FDG-PET based radiation planning of limited disease small cell lung cancer changes radiotherapy fields: A planning study. Radiother Oncol. 2008 Apr;87(1):49-54.

\section{Grants and awards}

Fellowship of the Dutch Cancer Society to attend the ECCO-AACR-EORTC-ESMO Workshop "Methods in clinical cancer research"; Flims, Switzerland. 2010

Young Investigator Award

13th World Conference on Lung Cancer; San Francisco, California. 2009

Young investigator travel award to attend the European Multidisciplinary Conference in Thoracic Oncology; Lugano, Switzerland. 2009

Profileringsfonds, Maastricht University Medical Centre

"Molecular imaging in the optimization of concurrent chemo-radiation of non-small cell lung cancer". €129,000. 2009 

